School of Design and the Built Environment

\title{
Managing Critical Factors Causing Delays in Public Construction Projects in the Kingdom of Saudi Arabia
}

\author{
Nasser Obaid M Alotaibi
}

This thesis is presented for the Degree of

Doctor of Philosophy

of

Curtin University

April 2018 


\section{DECLARATION}

To the best of my knowledge and belief, this thesis contains no material previously published by any other person, except where due acknowledgement has been made. This thesis includes no material which has been accepted for the award of any different degree or diploma in any university.

In accordance with the Australian National Health and Medical Research Council's guidelines for research involving humans, ethics approval for this research was obtained in 2015 . The proposed research study received human research ethics approval from the Curtin University Human Research Ethics Committee (EC00262), Approval Number \#RDHU-172-15.

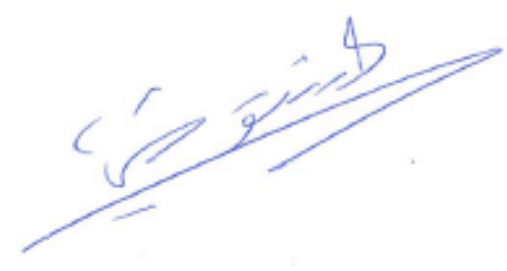

Signature: Nasser Obaid Alotaibi

Date $\quad$ : 29 March 2018 


\section{DEDICATED TO:}

My Mum, my beloved wife and my kids (Joud, Naif and Thaar) for their patience and understanding during the long journey to achieve this project. Thank you for your support through the difficult time spent on my studies.

I would also like to dedicate my work to my brother, Abdullah, and my other siblings who have always been supporting and encouraging me to complete this journey. Thank you all for your understanding during the time that I was committed to my academic work. 


\section{ACKNOWLEDGEMENTS}

I would like to take this opportunity to thank everyone who has made my journey to produce this thesis possible. First, I would like to express my sincere gratitude to my supervisor, Associate Professor Monty Sutrisna, for mentoring and guiding me through my $\mathrm{PhD}$ dissertation program and for providing his precious support to help me achieve this work. He has shown great wisdom in his guidance to me.

I would like to express my heartfelt thanks to my co-supervisor, Dr Heap-Yih Chong (John), and Associate Supervisor, Dr. Oluwole Olatunji, for their encouragement, guidance, immense assistance and support from the initial to final stages of this study.

I would like to thank all the people at Curtin University who have made it possible for me to conduct my research work. I am also grateful to the Kingdom of Saudi Arabia government for their scholarship to undertake my high-degree studies.

Many others have helped and inspired me during my studies outside of the university setting. Most importantly, I want to thank my wife, my kids and my family, who have given me their unfailing love and support throughout my life; this thesis would have been impossible without them. Special thanks go out to all the participants in this study, notably, the individuals that I interviewed. I appreciate the valuable knowledge that you have shared with me. Thank you for making it possible for me to make significant contributions to the field.

Lastly, for those that I forget to mention, I offer my regards and blessings to all of you for showing your support to me, in one way or another, during my $\mathrm{PhD}$ studies. 


\begin{abstract}
Construction projects have remained as essential drivers of economic and social development globally. The importance of construction projects is further demonstrated as the other segments of the economy depend on them to attain their objectives. The growing demands for buildings, roads, commercial and residential homes, and hospitals, amongst others, to fast-track the developmental goals of several nations have led to rapid increases in the number of construction projects. However, this situation has also brought many challenges to the implementation of these construction projects. In Saudi Arabia, there has been widespread cases of construction delays reported over the last four decades. The prevalence of delays within public construction projects in the Kingdom of Saudi Arabia (KSA) is now a source of concern for governments in the KSA, especially as the nation has recently lost significant income due to the falling prices of petroleum resources in the recent years (the mainstay of the country's economy). Consequently, the governments are becoming more interested in the implementation of construction projects that deliver on their cost, schedule, environmental, and quality objectives. This research study was conceived with the primary aim of minimising delay and improving the performance of public construction projects in the KSA, so that maximum benefits can be derived from them.
\end{abstract}

In order to develop an understanding that could be employed to address the problem of delays plaguing public construction projects in the KSA, four objectives were designed for this study. These objectives are to: identify the critical factors causing the delay in construction projects in the KSA and their relative importance; study the current use of project management knowledge, tools and techniques in managing delays in public construction projects in the KSA; evaluate the association between the application of project time management tools and incidence of project delays in the KSA's public construction industry; and to develop a framework that could be used to minimise the likelihood of delays and support the effective time management of delays in public construction projects in the KSA. To satisfy the objectives mentioned above, the following: a triangulation of three research methods, a literature review, quantitative and qualitative studies, were undertaken. Thus, this research was conducted in three phases.

In the first phase, an in-depth study of the existing literature was performed to identify the issues concerning: construction projects; delays; the magnitude of construction delays; types of construction delays; construction delay factors; sources of construction delays in the KSA; and 
gaps in the study of construction delays. Further in this stage, updated project management knowledge, tools, and techniques that could be potentially employed to address the problem of construction delays were re-examined.

Following the conceptual understanding of the problem area from the review of the relevant literature, a quantitative study was designed and carried out in phase two to address this research's objectives. A questionnaire acted as a research instrument for this phase and was developed based on the information gathered from the literature review. The data collected from the quantitative study were statistically analysed using Structural Equation Modelling and Mean Ranking. To assure the reliability and validity, a few tests such as Cronbach Alpha and Average Variance Extracted were undertaken. The results of the analyses revealed that the factors contributing to delays in KSA's public construction projects to be: slowness in decision-making; lack of qualifications; lowest bidding system; design issues; financial difficulties; ineffective project planning and scheduling; change orders; and workers' inexperience. Also, the current knowledge and application of project management tools and techniques in the management of delays were found to be inadequate and ineffective. Moreover, this study revealed that an effective implementation of project management knowledge, tools and techniques could lead to a reduction in the likelihood of the occurrence of delays in public construction projects in the KSA.

In phase three of this study, the research objectives were again addressed using four rigorously selected cases of tertiary institution buildings that were currently being constructed in the KSA. In addition to analysing documentary evidence on the cases studied, interviews were conducted for 16 professionals (four for each case project) involved in their implementation. The results obtained in the analysis of these qualitative data were found to validate those reported in the quantitative study, thereby reinforcing the need to address the problem of public construction delays in the KSA. Also, the delay factors identified in the case studies were the same as those found in the quantitative research.

Various project management tactics were identified as essential for minimising the delay factors. Essentially, this study established that an application of project management tools and techniques such as Work Breakdown Structure (WBS), Critical Path Management (CPM), Bottom-up Estimation, Gantt charts, and Earned Value Management (EVM) is crucial for minimising delay issues in the KSA's construction sector. Minimising strategies for specific delay factors were also 
identified. For the issue of slow decision-making, the minimising approaches included prioritising decision requests, decentralising the decision-making process, as well as assigning deadlines to the finalisation of decisions. Moreover, assessing the financial capacity of contractors and a periodic revisit of contractual agreements were identified as important strategies for addressing delays induced by the lowest bidding system. Tactics that can be used to reduce financial difficulties were found to include ensuring reliable financing options, alternative sources of funds such as publicprivate partnership, and stakeholder engagement. The approach identified to be useful for addressing delay issues arising from a lack of qualifications was pre-determination of the needed requirements for the contractor and consultants at the pre-project phase. Furthermore, for delays induced by workers' inexperience, they can be reduced by identifying and clarifying roles and responsibilities, establishing an active line of reporting and staff development plans, and facilitating knowledge sharing and mutual learning across the teams. This study also identified strategies for tackling design issues, ineffective planning and scheduling and change order to include the recruitment of competent design engineers, use of project scheduling software, effective communication and collaboration, changing the management plan, having a dedicated team to manage the change process, and timely documentation and prioritisation of change requests.

Based on the perspectives of the professionals in phase three, as well as the unified delay factors identified in both quantitative and qualitative studies, a framework for minimising the delays in public construction projects in the KSA was developed. It is believed that the framework may provide the required support to improve management decisions towards reducing the likelihood of delays occurring in public construction projects in the KSA, as well as mitigate against their negative consequences. Additionally, recommendations for further research on this problem area are also presented within the concluding chapter. As this study has utilised 'real-world' projects, the findings of this project provide parties involved in public construction projects with robust strategies to better manage issues that may contribute to delays in their future projects. 


\section{Table of Contents}

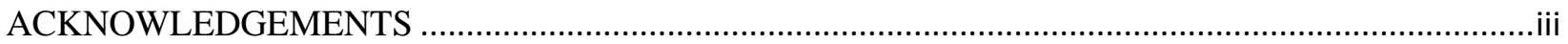

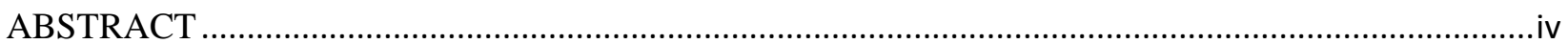

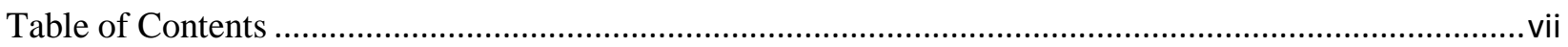

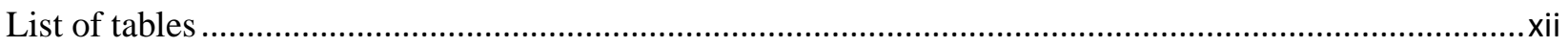

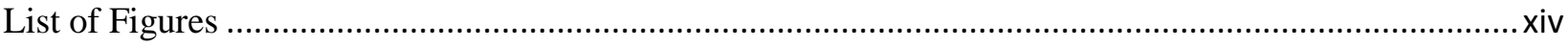

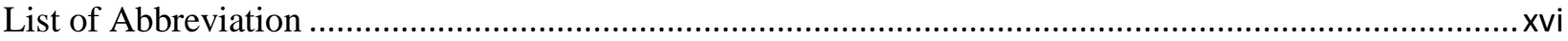

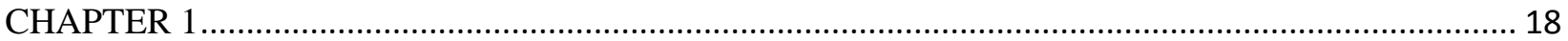

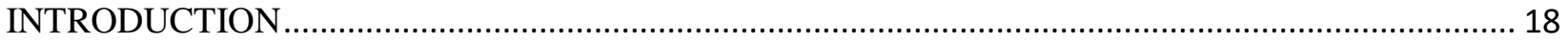

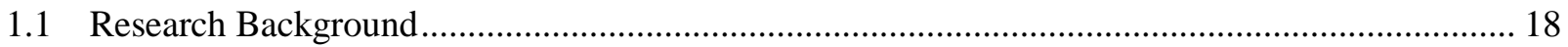

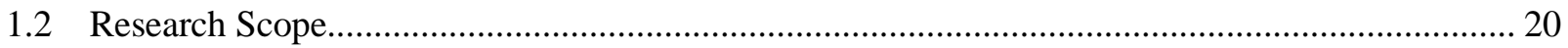

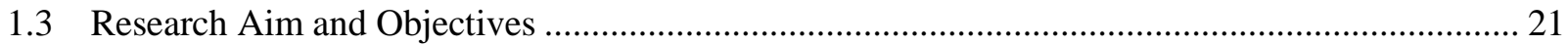

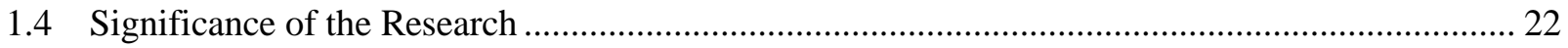

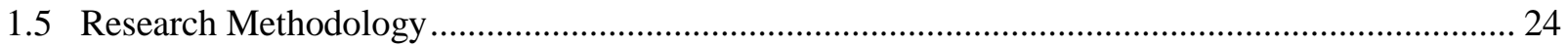

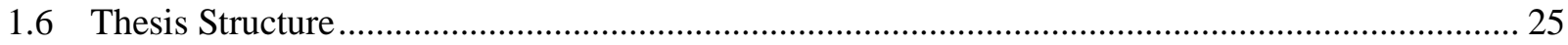

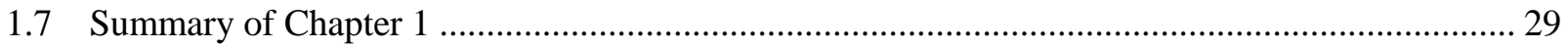

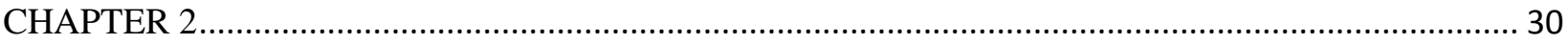

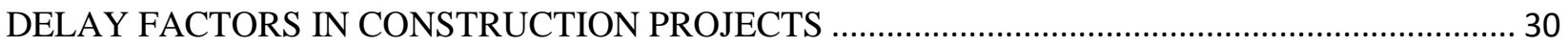

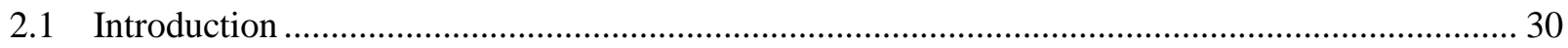

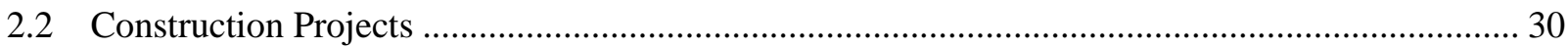

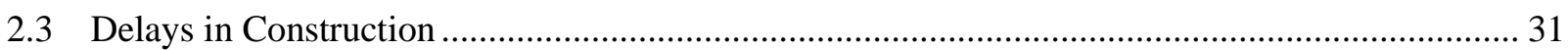

2.3.1 Magnitude of Construction Delays ............................................................................... 32

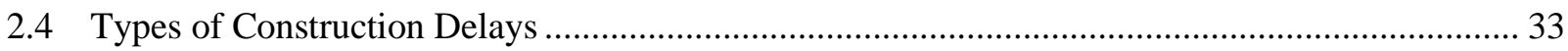

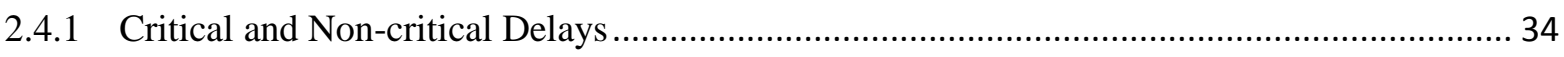

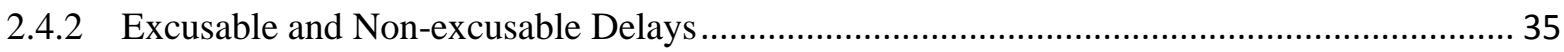

2.4.3 Compensable and Non-compensable Delays ....................................................................... 36

2.4.4 Concurrent and Non-concurrent Delays .......................................................................... 37

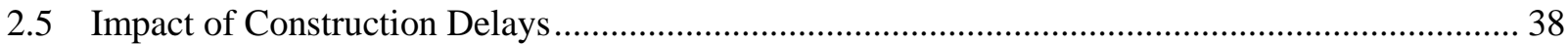

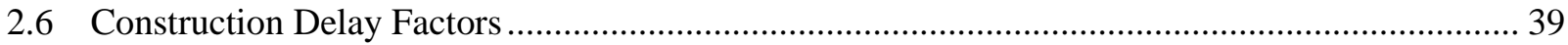

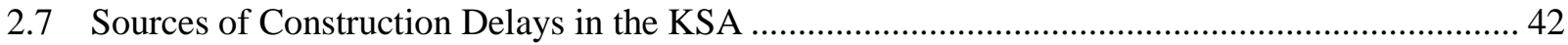

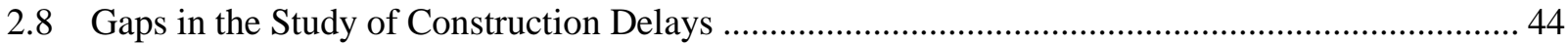

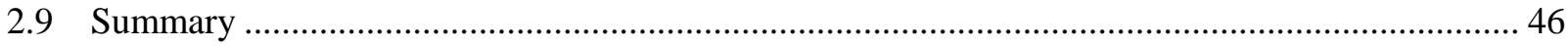

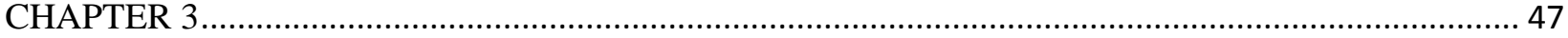




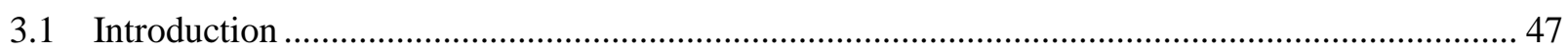

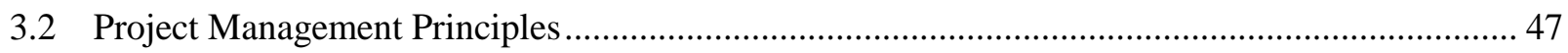

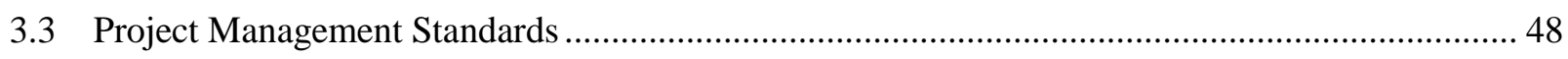

3.3.1 Project Management Standards in Initiation/Pre-Project Phase ......................................... 52

3.3.2 Project Management Standards in Planning Phase ............................................................... 53

3.3.3 Project Management Standards in Execution Phase .......................................................... 53

3.3.4 Project Management Standards in Monitoring and Controlling Phase .................................. 54

3.3.5 Project Management Standards in Closing-out Phase ........................................................ 55

3.4 Techniques and Tools for Managing Construction Delays ..................................................... 55

3.4.1 Work Breakdown Structure (WBS) ..................................................................................... 56

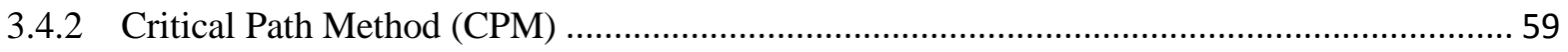

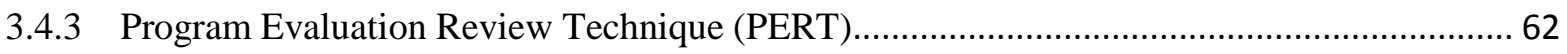

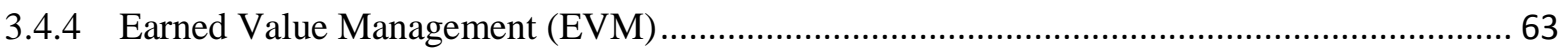

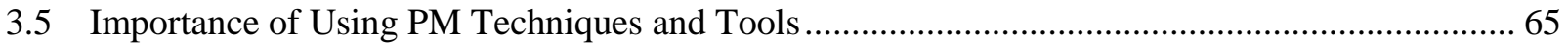

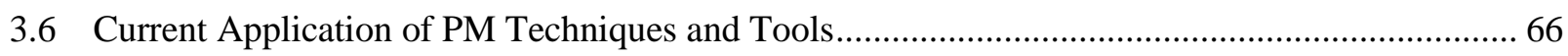

3.7 Managing Delay Factors Using PM Techniques and Tools .................................................... 67

3.8 Managing Delay Factors in KSA Using PM Techniques and Tools ........................................... 68

3.8.1 Managing Contractor-related Delay Factors .................................................................. 71

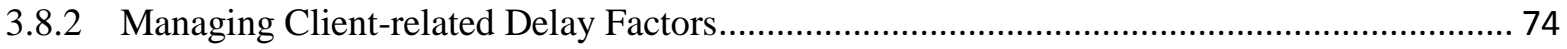

3.8.3 Managing Consultant-related Delay Factors ........................................................................ 77

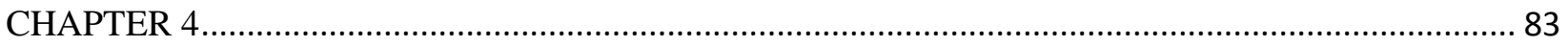

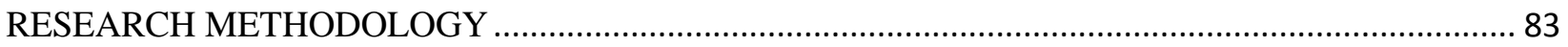

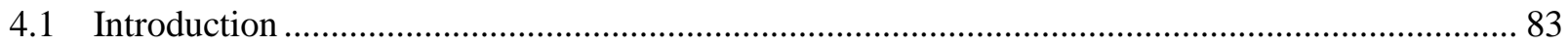

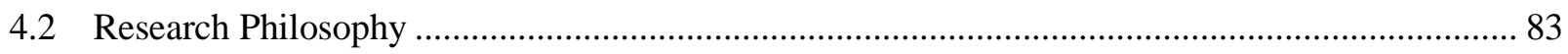

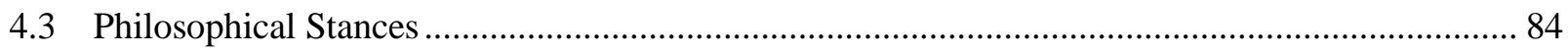

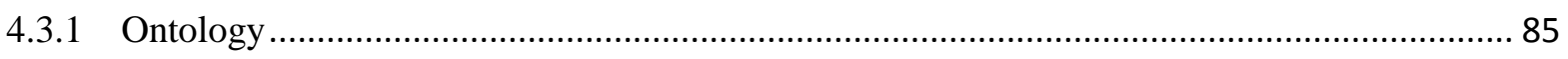

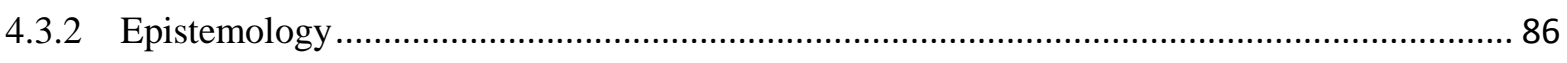

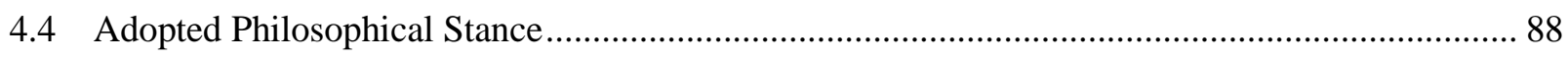

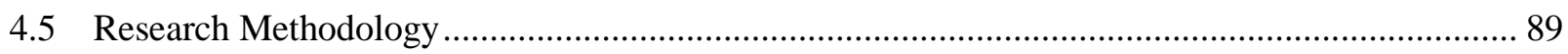

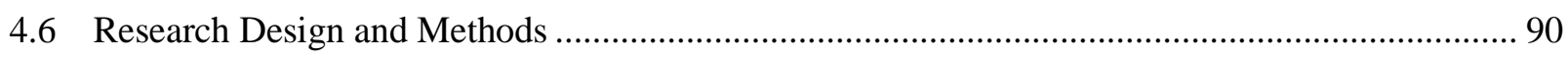

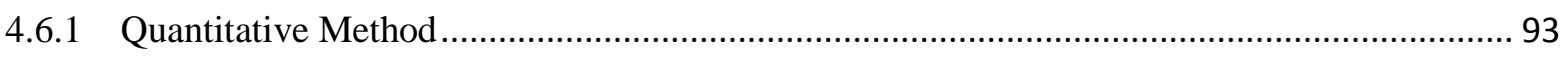

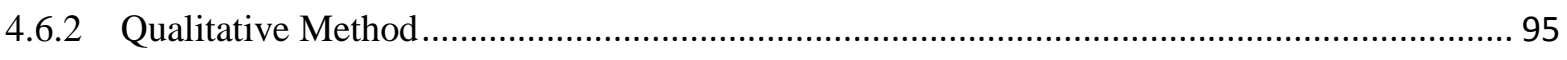

4.6.3 Adopted Research Method and Justification ....................................................................... 96 


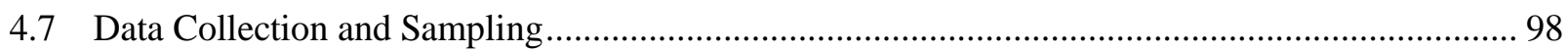

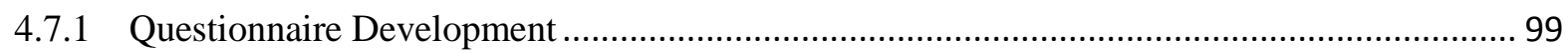

4.7.2 Data Collection and Sampling in Quantitative Study ................................................... 100

4.7.3 Data Collection and Sampling in Qualitative Study .......................................................... 103

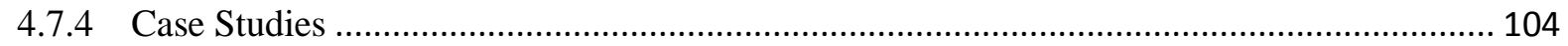

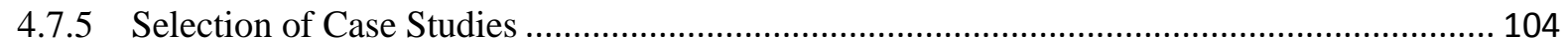

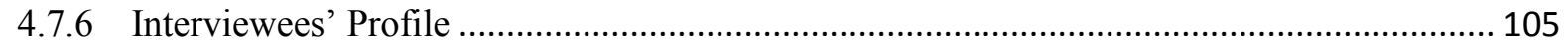

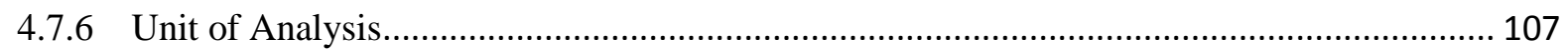

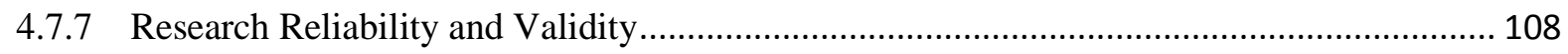

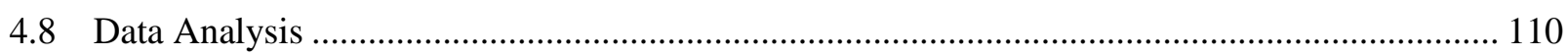

4.8.1 Approach to Quantitative Data Analysis ........................................................................ 110

4.8.2 Approach to Qualitative Data Analysis ........................................................................ 120

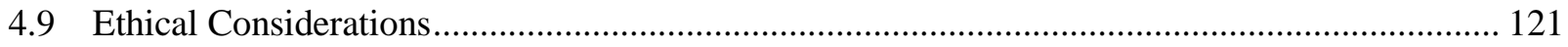

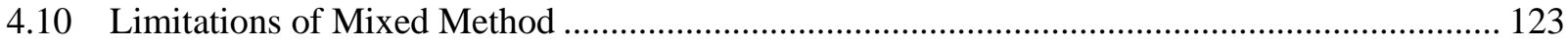

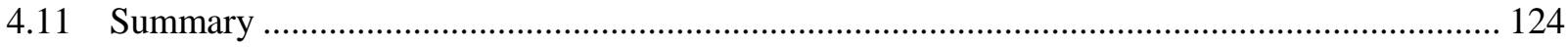

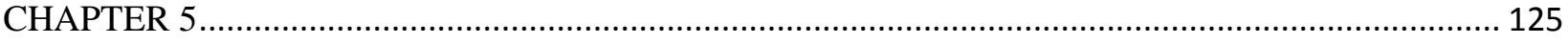

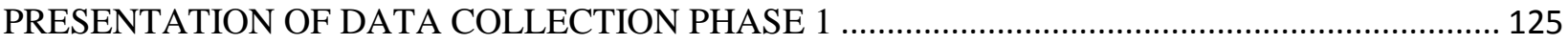

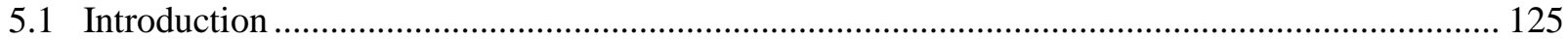

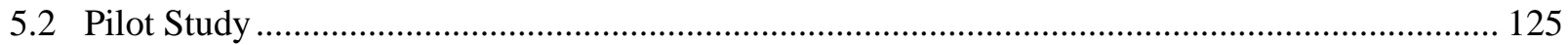

5.3 Preliminary Findings of the Quantitative Data........................................................................ 126

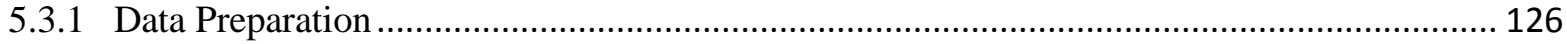

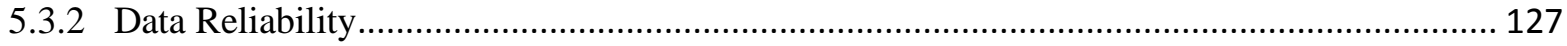

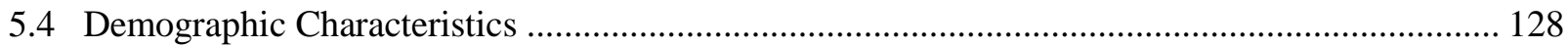

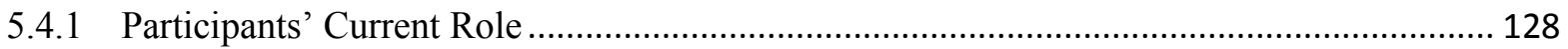

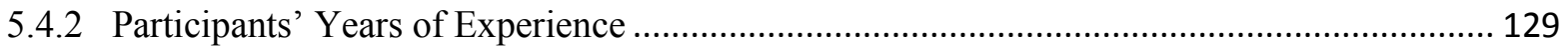

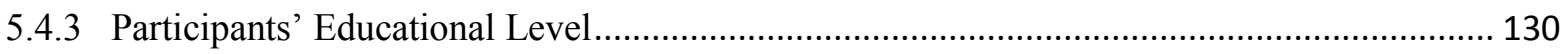

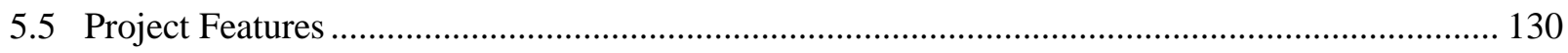

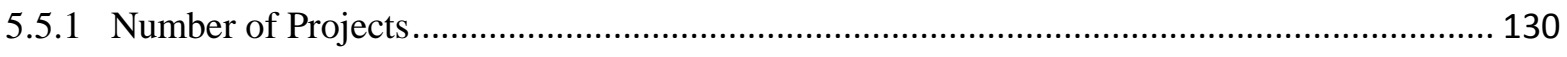

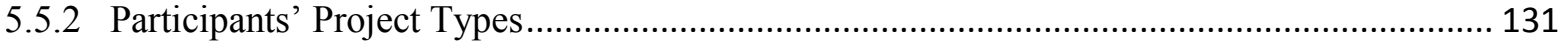

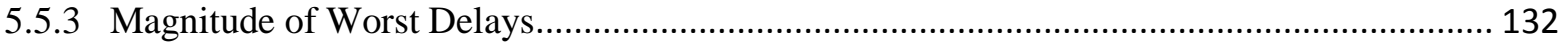

5.5.4 Completion of Project Prior to Deadline ............................................................................ 134

Completion of Project Prior to Deadline ……............................................................................ 134

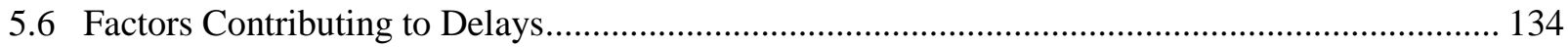

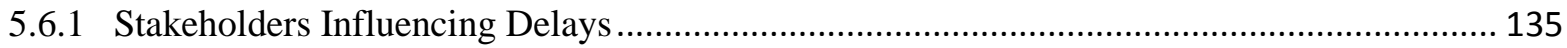


5.6.2 Construction project processes that can best minimise delays ........................................... 138

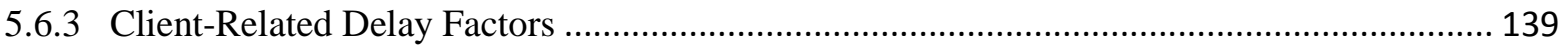

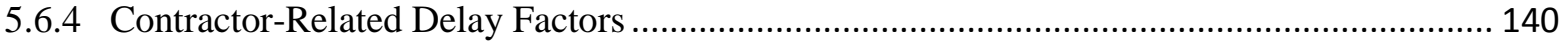

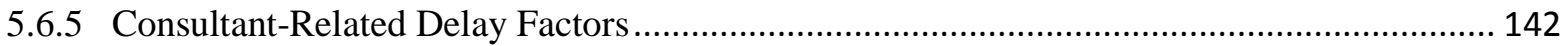

5.6.6 General Management and External (GME)-Related Delay Factors ...................................... 143

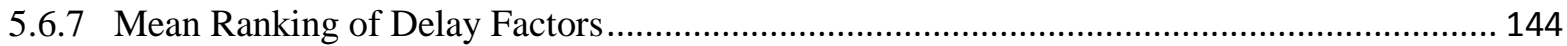

5.7 Current applications of PM Knowledge, Tools, and Techniques ............................................ 147

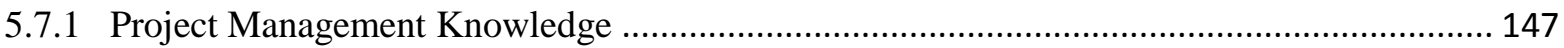

5.7.2 Project Time Management Tools and Techniques .......................................................... 150

5.7.3 Differences in Perceptions of Application of PM Tools and Techniques ............................ 156

5.8 Influence of current application of PM Tools and Techniques and Delay Factors ..................... 160

5.8.1 Project Estimating Tools and Techniques and Delay Factors ............................................ 163

5.8.2 Project Time Management Tools and Techniques and Delay Factors ................................. 165

5.8.3 Project Control Tools and Techniques and Delay Factors ................................................ 167

5.8.4 Project Planning Software and Delay Factors .................................................................... 168

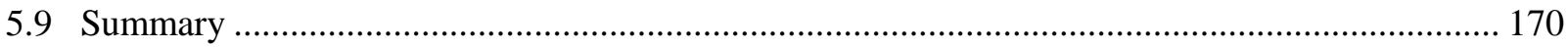

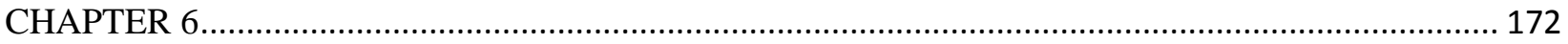

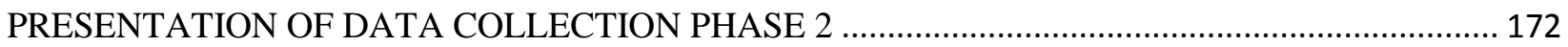

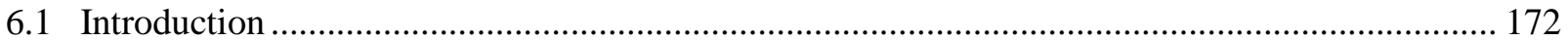

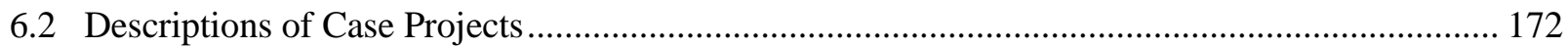

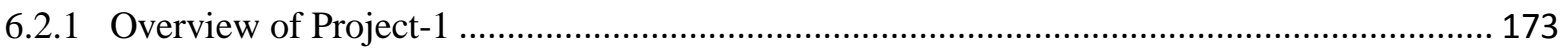

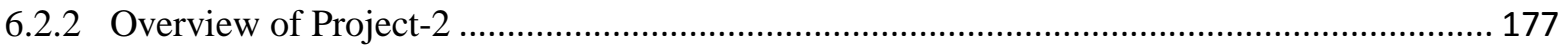

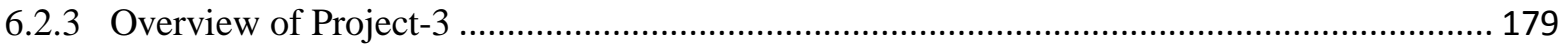

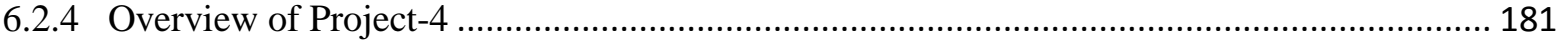

6.3 Findings from Case Studies (Cross-case Analysis) ............................................................... 183

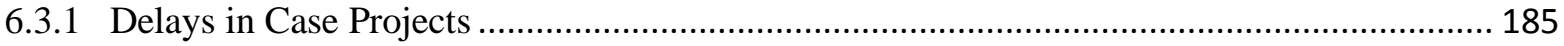

6.3.2 Application of PM Tools and Techniques and Delays ..................................................... 193

6.3.3 Application of the PM Tools and Techniques in Managing Delays..................................... 198

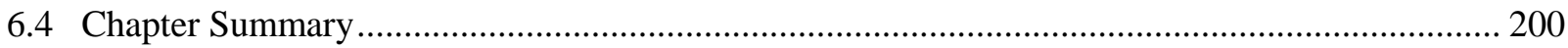

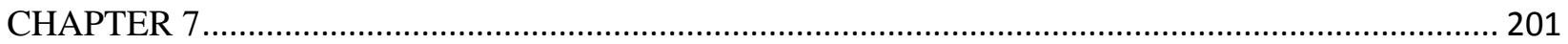

TRIANGULATION OF FINDINGS AND FRAMEWORK DEVELOPMENT ..................................... 201

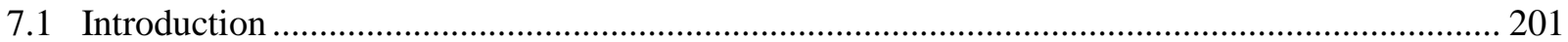

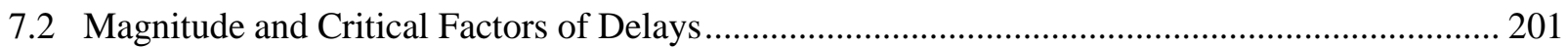

7.3 Current Use of PM Knowledge, Tools, and Techniques ......................................................... 205 
7.4 Influence of PM Knowledge, Tools, and Techniques on Delays .............................................. 208

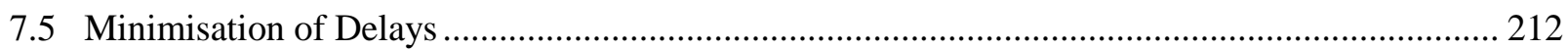

7.6 Strategies for Mitigating Critical Delays in the KSA's Public Construction Projects ................. 212

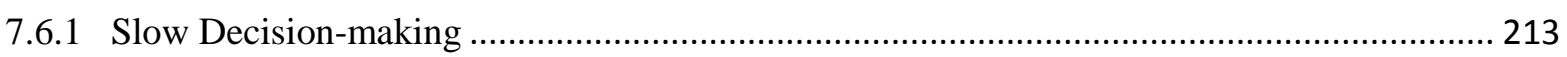

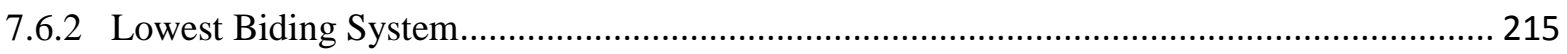

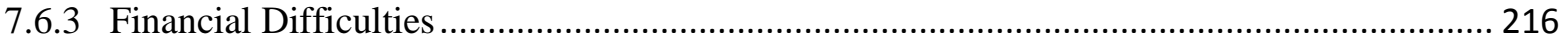

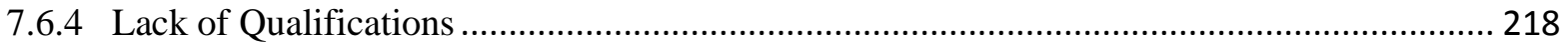

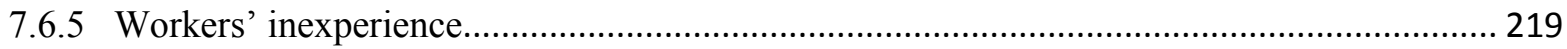

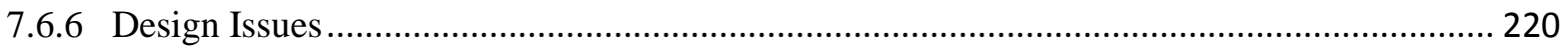

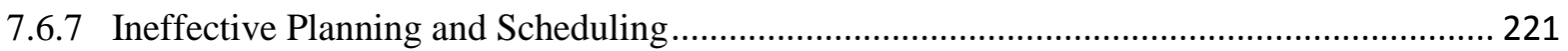

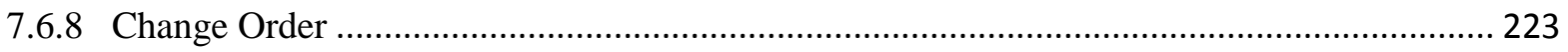

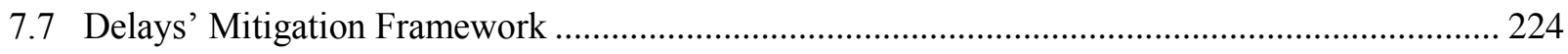

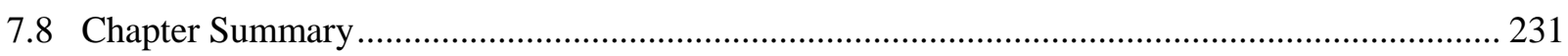

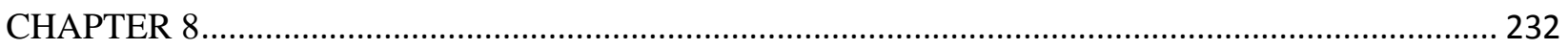

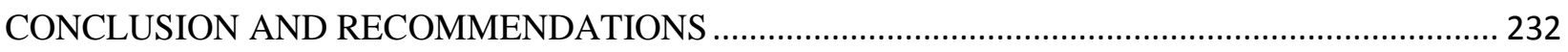

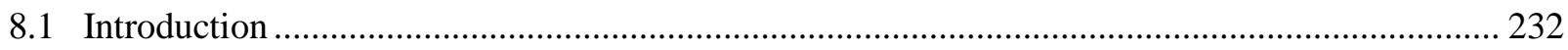

8.2 Critical Factors Causing Delays and their Relative Importance............................................... 233

8.3 Current Use of PM Knowledge, Tools, and Techniques ....................................................... 233

8.4 Impacts of PM Knowledge, Tools, and Techniques on Delays................................................ 234

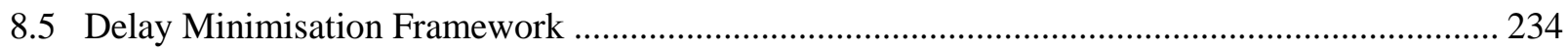

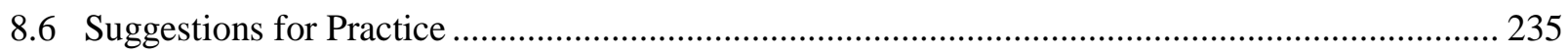

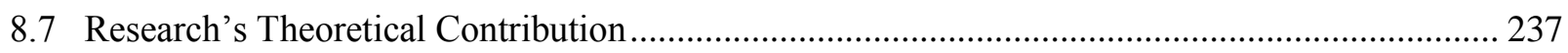

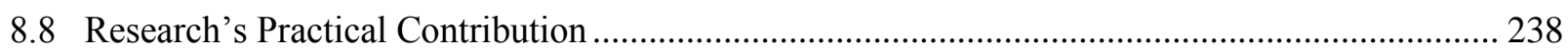

8.9 Study's Limitations and Suggested Directions for Future Work …......................................... 239

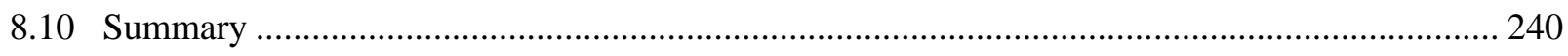

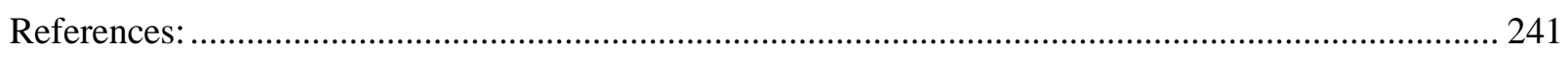

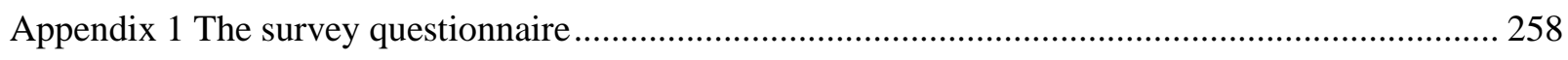

Appendix 2 Consent Form and Guideline Questions for Interview …............................................ 270

Appendix 3 Description and coding for latent variables ........................................................... 274

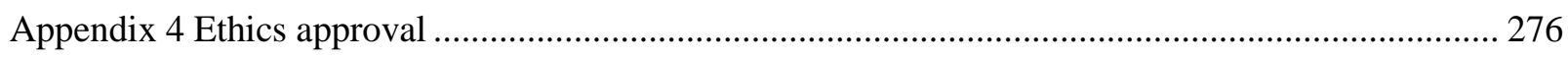

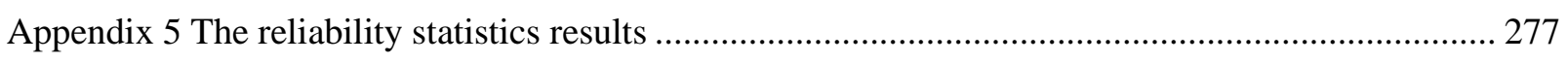

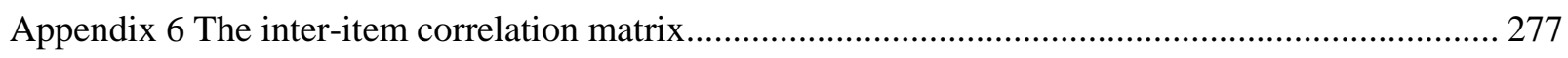

Appendix 7 Work Breakdown Structure for Construction Estimation............................................... 282 


\section{List of tables}

Table 2.1 Main Causes of Delays in Construction Projects ...................................................41

Table 2.2 Construction delay factors in the KSA ...............................................................43

Table 3. 1 Comparison of standards by four PM bodies .........................................................51

Table 3. 2 Recommended actions for contractor-related delay factor .................................... 72

Table 3. 3 Recommended actions for client-related delay factor..............................................76

Table 3. 4 Recommended actions for consultant-related delay factor .....................................78

Table 3. 5 Recommended actions for General management and external-related delay factor.....81

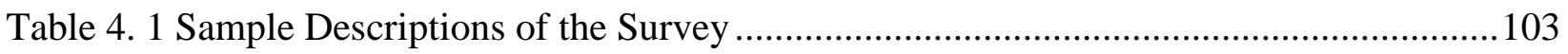

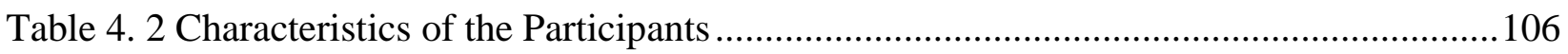

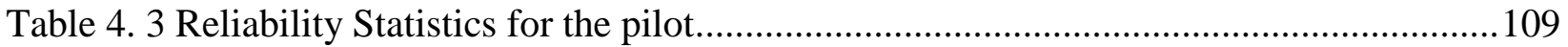

Table 4. 4 SEM-PLS in previous construction management studies .....................................113

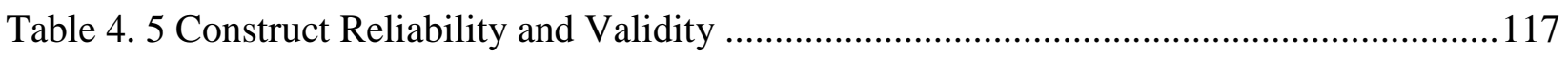

Table 4. 6 Cross loadings matrix for discriminant Validity ................................................119

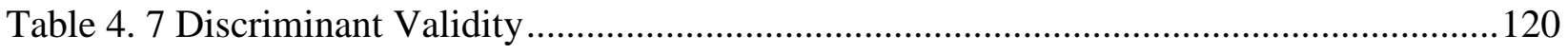

Table 5. 1 The profile of the experts who completed the pilot survey....................................126

Table 5. 2 Overview of participants' years of experience ................................................... 130

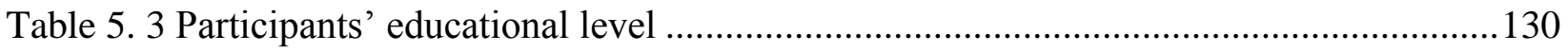

Table 5. 4 Number of projects linked to the participants .....................................................131

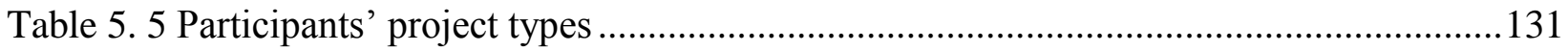

Table 5. 6 Frequency of worst delays experienced .............................................................133

Table 5. 7 Results of Chi-square application ................................................................. 138

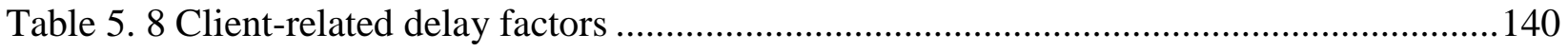

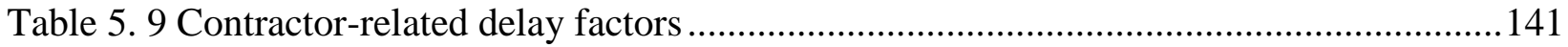

Table 5. 10 Consultant-related delay factors .................................................................. 143

Table 5. 11 General management and external-related delay factors ..................................... 144

Table 5. 12 Overview of mean ranking for delay factors......................................................145

Table 5. 13 Summary of mean ranking for delay factor categories ....................................... 146

Table 5. 14 Ranks for project management knowledge ........................................................ 149

Table 5. 15 ANOVA on ranks test statistics for project management knowledge ${ }^{\mathrm{a}, \mathrm{b}}$.................150

Table 5. 16 Application of project estimating tools and techniques (PETT) ............................151 
Table 5. 17 Application of project time management tools and techniques (TMTT).

Table 5. 18 Application of Project controlling tools and techniques (PCTT)............................154

Table 5. 19 Application of Project planning software (PPS) .............................................. 155

Table 5. 20 Summary of mean ranking for PM tools and techniques categories.......................155

Table 5. 21 Ranks for project management tools and techniques .........................................157

Table 5. 22 ANOVA on ranks test statistics for PM tools and techniques ${ }^{\mathrm{a}, \mathrm{b}}$...........................158

Table 5. 23 Path coefficient, T Statistics and P Values for the structural model.......................163

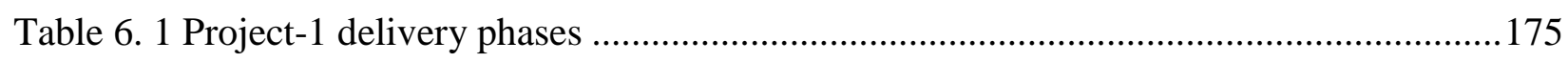

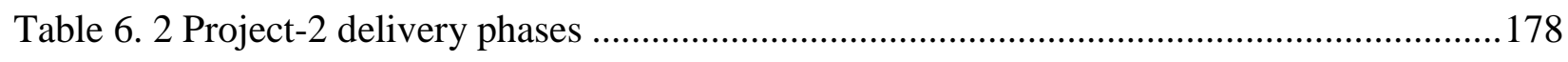

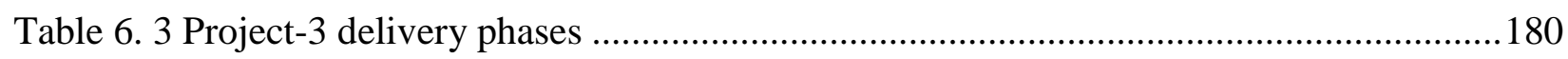

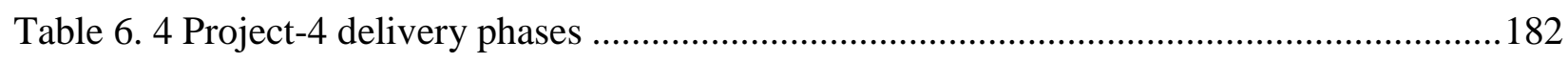

Table 6. 5 Details of the interviewees in Project................................................................ 185

Table 7. 1 Summary of mixed analysis of critical delay factors that considered input to the

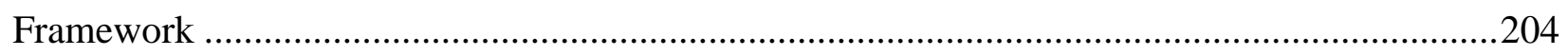

Table 7. 2 Summary of mixed analysis of the PM tools and techniques that considered input to

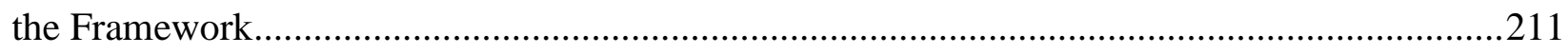

Table 7. 3 Summary of key notation adopted in proposed framework ...................................227 


\section{List of Figures}

Figure 1.1 Thesis Organisation

.26

Figure 2.1 Frequency of reasons for the delay in construction projects in the KSA (Source: Table

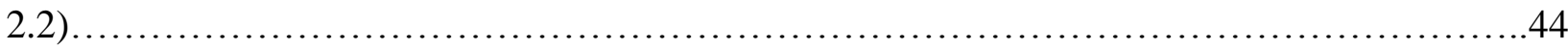

Figure 3.1 WBS examples (Source: CPM Scheduling for Construction - Best Practices and Guidelines (2014))

Figure 3.2 Example of WBS using 100\% rule (Taylor, 2003)

Figure 3.3 Examples of the CPM using Arrow Network and precedence diagrams (Source:

Carson et al., 2014; PMI, 2013) .60

Figure 3.4 Example of Critical Path Method (PMI, 2013)..................................................61

Figure 3.5 Earned Value, Planned Value, and Actual Costs (PMI, 2013) ................................64

Figure 3.6 Mapping of delay factors against PM techniques and tools (Source: Alotaibi et al., 2016).

Figure 3.7 Illustration of Construction Communication Network (PMI, 2016, p. 91) ................80

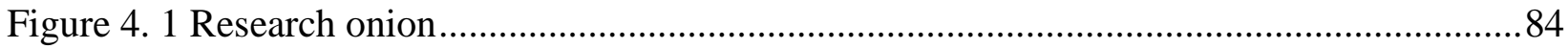

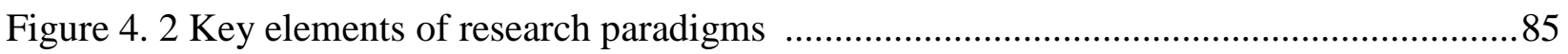

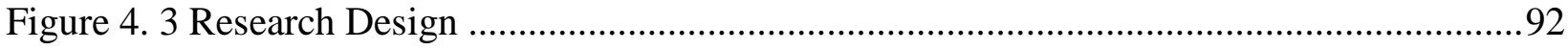

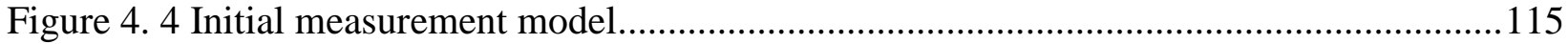

Figure 4. 5 Example of coding using NVivo. ................................................................. 121

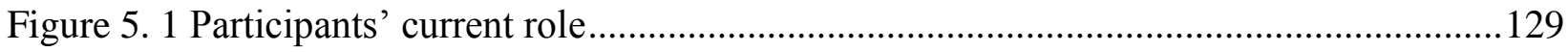

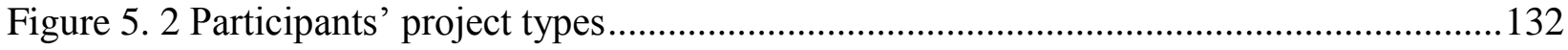

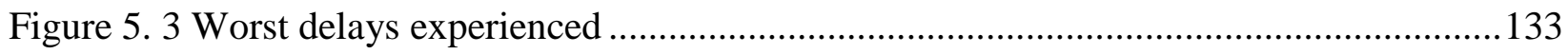

Figure 5. 4 Completion of Project Prior to Deadline ............................................................ 134

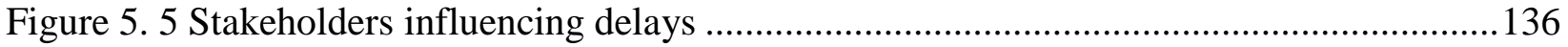

Figure 5. 6 Stakeholders influencing delays from the three parties' viewpoint........................137

Figure 5. 7 Construction project processes that can best minimise delays ..............................139

Figure 5. 8 Results of post-hoc test for differences in opinions about PM tools and techniques 160

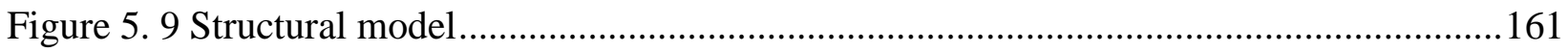

Figure 5. 10 Final Structural equation modelling in Bootstrapping ....................................... 162

Figure 5. 11 Final SEM model for project estimating tools and techniques and delay factors....164 
Figure 5. 12 Final SEM model for project time management tools and techniques and delay

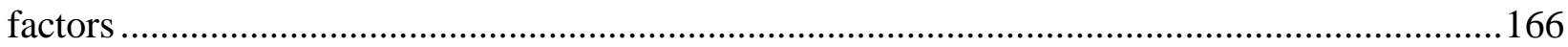

Figure 5. 13 Final SEM model for project control tools and techniques and delay factors ........167

Figure 5. 14 Final SEM model for project planning software and delay factors .......................169

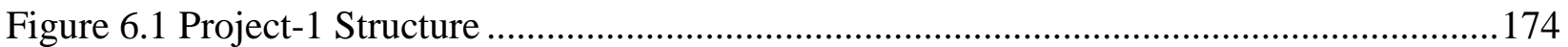

Figure 6.2 Coding structure of the main themes from case studies ....................................... 184

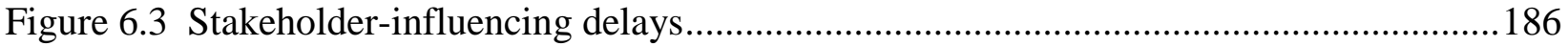

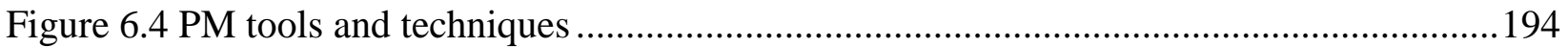

Figure 6.5 PM tools and techniques in managing delays .................................................. 198

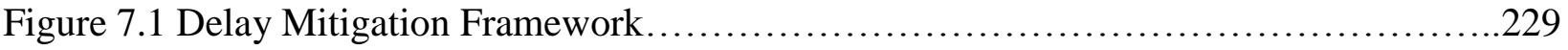

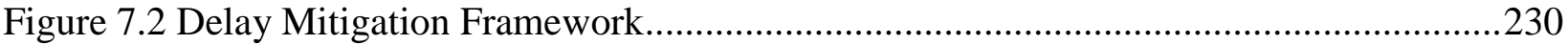




\section{List of Abbreviation}

\begin{tabular}{|c|c|}
\hline KSA & Kingdom of Saudi Arabia \\
\hline PM & Project Management \\
\hline GCC & Gulf Cooperation Council \\
\hline MEA & Middle East and Africa \\
\hline PMBOK & Project Management Body of Knowledge \\
\hline PRINCE2 & PRojects IN Controlled Environments \\
\hline APM & Association of Project Management \\
\hline PMAJ & Project management Association of Japan \\
\hline $\mathrm{P} 2 \mathrm{M}$ & Project management Association of Japan \\
\hline DBB & Design-Bid-Build \\
\hline WBS & Work Breakdown Structure \\
\hline $\mathrm{CPM}$ & Critical Path Method \\
\hline PERT & program evaluation review technique \\
\hline EVM & Earned Value Management \\
\hline PND & Precedence Network Diagram. \\
\hline PETT & Project Estimation Tools and Techniques \\
\hline TMTT & Project Time Planning Tools and Techniques \\
\hline TCTT & Project Controlee Tools and Techniques \\
\hline PPS & Project Software Package \\
\hline $\mathrm{COF}$ & Contractor related factors \\
\hline CLF & Client related factors \\
\hline $\mathrm{CSF}$ & Consultant related factors \\
\hline GMEF & General Management and External related Factors \\
\hline SEM & Structural Equation Modelling \\
\hline PLS-SEM & Partial Least Squares \\
\hline CB-SEM & Covariance-Based \\
\hline $\mathrm{CR}$ & Composite reliability $(\mathrm{CR})$ \\
\hline AVE & Average variance extracted (AVE) \\
\hline
\end{tabular}




\section{CHAPTER 1 INTRODUCTION}

\subsection{Research Background}

Delays affect construction projects globally. Construction delays have been reported in several countries around the world including Australia, India, Nigeria, Turkey, Jordan, United Arab Emirates, Thailand, and the United States (Wong and Vimonsatit, 2012; Doloi et al., 2012; Kazaz et al., 2012; Sweis, et al., 2008; Toor and Ogunlana, 2008; Faridi and El-Sayegh, 2006; Ahmed et al., 2003). Delays are prevalent, particularly within public construction projects in the Kingdom of Saudi Arabia (KSA) (Assaf and Al-Hejji, 2006; Al-Kharashi and Skitmore, 2009; Albogamy et al., 2013; Al Hammadi, 2016). Research suggested that the number of construction projects experiencing delays in the KSA increased from 700 projects in 2009 (Althynian, 2010) to 3000 projects in 2013 (Anti-Corruption Commission, 2013). According to the recent report by the AntiCorruption Commission, out of 1526 public projects between 2012 and 2014, 672 projects, representing $44 \%$ of the total were delayed (Anti-Corruption Commission, 2015). Deloitte's report puts the total value of delayed projects in the Saudi Arabian construction industry to be USD 146 billion, as of July 2012, causing pressures on the developmental drive of the oil-rich country. A construction delay is an incident that disrupts the progress of a construction project, leading to an extension in the time agreed to complete tasks or ultimately deliver the project (Stumpf, 2000; Assaf and Al-Hejji, 2006). Project management (PM) principles, on the other hand, focus on the application of appropriate standards, tools, and techniques for ensuring that the resources assigned to the projects are utilised effectively towards creating the desired beneficial change (Turner et al., 2010; PMI, 2013; Jergeas, 2008, p.96). Several construction projects funded by KSA governments have experienced significant delays in the past, thereby highlighting this concept as a deep-rooted problem in the country (Alotaibi et al., 2016). Therefore, there is a severe need to research and propose actions that could be used to address the issue.

Delays not only affect the schedule, but also the cost performance of a project, leading to unwanted disruptions when the society begins to enjoy the socioeconomic benefits of such a project 
(Enshassi et al., 2009). Also, delays will affect the perception of the efficiency of the government's funding of the projects, as well as parties or organisations participating in their delivery. It is not uncommon for the populace to become disenchanted that public funds are being wasted, with no immediate benefits accruing to them. In general, delays in delivering a project can contribute to its stakeholders' dissatisfaction and thus, diminishing the much-needed support for the project (Gao and Zhang, 2013). Also, the financial credit rating, which indicates the ability of an entity to undertake projects effectively, may suffer if it is perceived as a poor record of achieving cost, time, and quality performance in its project implementation. Other potential impacts of delays, as described in Al-Kharashi and Skitmore (2009), are the inefficient execution of budget; confusion in public development projects; and political disturbances due to public discontent and inconvenience.

Therefore, eliminating delays in these publicly funded construction projects can help reinstate confidence in the government's capacity to function, as well as portray the organisations within them as being up to the task in the delivery of their core responsibilities. Addressing the problem of constant delays in KSA's public construction projects will not only result in significant costsavings, but will also attract goodwill for the government in the country. While the governments are wholly funding most of the public construction projects in the KSA, as of now, there is a possibility that private investment into the public construction sector may be the most sensible course of action to quickly address the country's infrastructural deficits. With a track record of delayed public construction projects, it may be difficult to attract private organisations' interest in these high capital investment ventures. These organisations often source their funds from financial institutions, which may not assess projects with a possibility of massive delays to be credit-worthy.

Related literature has tended to focus on the delay factors in construction projects by including issues such as lack of communication; lack of commitment; poor site coordination; lack of clarity in project scope; improper planning; owner's several change orders; financial processes and challenges; procurement issues; errors in the construction phase; contractor's lack of experience; lack of resources; poor contractor management; and design delays (Doloi et al. 2012; Toor and Ogunlana, 2008; Sambasivan and Soon, 2007). However, there has been limited focus on the effects of the application of PM tools and techniques that explain how and why delays occur in these construction projects. For example, no publicly available study has explored this aspect in 
relation to public construction projects in the KSA. It is surprising that despite improvements in technologies and technical expertise available in the global construction industry, public construction projects in the KSA have continued to experience delays. The problem is however, eroding the confidence in the government's capacity to successfully implement projects without experiencing poor time and cost performance.

Confronting the problems influencing delays in the KSA's public construction projects requires that they are adequately understood, and practical strategies are developed to achieve that desired improvement in the performance of these projects. The role of PM tools and techniques in the attainment of targeted performance, in relation to the time and cost of construction projects, has been demonstrated in mainstream literature. For example, Abbasi and Al-Mharmah (2000) recommend that an effective use of PM techniques and tools enhances the performance of construction projects both in public and private segments. Also, studies such as Frame (2002); Abdelsnaser et al. (2005); Nguyen et al. (2004); and Koushki et al. (2005) have made strong indications that factors contributing to delays in construction projects can be better curtailed by effectively applying PM principles and measures. Following the suggestions of the above studies, this current study aims to develop an understanding about the critical factors influencing delays in the KSA's public construction projects and to determine the role that PM tools and techniques can play in addressing this problem. The outcome of this study can provide the governments and project parties, as well as practitioners involved in the execution of these projects, with a capacity and contextual knowledge to develop appropriate approaches to reduce the instances of delays.

\subsection{Research Scope}

The focus of this study is to identify the factors contributing to the incidence of delays in the KSA's construction projects and project management tactics that can be employed to minimise this problem. The scope of this research is generally limited to integrating both qualitative and quantitative data to explain the reasons for construction delays in the KSA and establish project management-related strategies for minimising these delays. This study conducts an extended, indepth review of relevant literature to initially identify delay factors in construction projects and potential PM tools and techniques for mitigating against them. Quantitative data are then collected 
from construction practitioners in the KSA using a questionnaire survey. The findings of the quantitative study are then re-checked, by conducting an extensive review study of the four cases involving building projects in the KSA. The selection of the four cases is regarded as essential to properly isolate multiple issues influencing delays in real-life projects and how these factors interrelate. The triangulation of data is considered necessary to strengthen an understanding of the concept of delays and identify more widely accepted tactics for addressing the problem based on the suggestions of experts and evidence derived from practical situations.

This study also provides a framework that captures the strategies to minimise the likelihood of delays and support the effective management of delays in public construction projects in the KSA. The framework development is based on the findings from both qualitative and quantitative studies. The framework will aid construction practitioners not just in the KSA, but globally as well, in the process of making informed decisions towards preventing the occurrence of delays that could jeopardise the successful implementation of their projects. In addition, this study offers general recommendations that aid in project planning and execution in the KSA's construction industry.

\subsection{Research Aim and Objectives}

This research aims to develop a framework that could be used to minimise the likelihood of delays and support the effective time management in public construction projects in the Kingdom of Saudi Arabia (KSA). The specific research objectives are:

- To identify the critical factors causing delays in construction projects in the KSA and their relative importance;

- To study the current applications of PM knowledge, tools and techniques in managing delays in public construction projects in the KSA;

- To evaluate the association between the application of project time management tools and incidence of project delays in the KSA's public construction industry;

- To develop a framework that could be used to minimise the likelihood of delays and support the effective management of delays in public construction projects in the KSA. 


\subsection{Significance of the Research}

Construction projects have remained a significant pillar to achieve national economic and social development globally. The importance of construction projects is further demonstrated as other commercial segments depend on them to attain their objectives. For instance, critical infrastructure such as roads, residential homes, and hospitals are provided through this platform (Sweis et al., 2008; Kaliba et al., 2009; Kazaz et al., 2012). In addition, businesses cannot function without office buildings, which are also delivered through construction activities. Given the significance of the construction sector, most nations in the world, including the KSA, depend on the industry one way or other to build their wealth. Due to their importance in socio-economic growth, governments around the world usually allocate large parts of their annual budgets to various construction-related projects. Currently, the construction industry accounts for about $13 \%$ of the global Gross Domestic Product (GDP), and the figure is projected to rise to 15\% by 2020 (Global Construction Perspectives and Oxford Economics, 2015). According to the same report, the Middle East and Africa (MEA) region is expected to record the fastest growth in the construction output in 2016, at 5.9\%. The construction industry in the KSA is the largest among the countries of the Gulf Cooperation Council (GCC) (Deloitte, 2017). In 2017, the value of the construction projects, either in the planning or delivery phases, in the oil-rich Kingdom was put at US\$1.1 trillion, which accounts for about $41 \%$ of all projects in the GCC (Deloitte, 2017). As per the Construction and Projects Multi-Jurisdictional Guide for 2013/2014, the construction of vital infrastructure projects was one of the most significant expansion goals of the Saudi Government (Husein, 2013).

To emphasise the criticality of this sector, the budget release of the Saudi Arabian Ministry of Finance (MOF) for 2018 indicated that a total of US\$61 billion was invested into construction projects in the education sector alone. Additionally, another US\$39.1 billion was allocated towards the implementation of different construction projects for the Ministry of Health and Social Affairs, which included 11 new hospital centres, 11 medical facilities, 2 medical complexes, 10 comprehensive health clinics and several primary health care centres through Saudi Arabia (MOF, 2017). Presently there are 5 medical cities and 132 new hospitals being constructed around Saudi Arabia. However, the current low-oil regime has affected the national income of the KSA as the country derives its revenue largely from the sale of its oil and gas resources. The ability of the 
KSA governments to continually provide funds required for construction projects into the longterm future cannot be guaranteed under the current economic climate. Consequently, there is a need to improve the performance of construction projects to ensure a judicious use of scarce financial resources.

The prevalence of delays within public construction projects in the KSA has remained a source of concern for governments in the KSA, especially as the country has lost significant income due to the falling prices of petroleum resources in the recent years. For example, the oil price dropped from a high of USD146 per barrel in 2008 to around USD50 in 2017. Such sharp fall in the oil prices has obviously affected the revenue target of the Kingdom. In this circumstance, minimising the current delay experience has become a necessity and will help improve the overall performance of construction projects in the KSA. However, previous research has provided a limited understanding of actions that could be employed towards achieving this objective. From the relevant literature, existing research has focused on identifying the factors contributing to construction delays, while neglecting essential issues such as the current application of project management tools and techniques and the role of this in addressing the problem of delays.

The importance of PM tools and techniques in achieving project expectations and objectives has been reported widely in the literature (e.g. Patanakul et al., 2010; Andler, 2016; Carstens, Richardson, and Smith, 2016). Zavadskas et al., (2014) have suggested that an effective application of PM knowledge, tools and techniques offers an excellent opportunity to improve overall project performance and reduce the likelihood of delays in the respective construction project. According to Murphy and Ledwith (2007), the application of PM scheduling can be very effective in managing and controlling project activities. An understanding of the current PM practices among project parties and construction practitioners would provide great insights towards developing innovative ideas to curtail delay issues in the construction projects of the KSA and other countries as well. Thus, to formulate practical strategies to prevent or minimise delays in the KSA's construction projects, there is a need not only to identify the delay factors, but also to examine how PM knowledge, tools and techniques can be maximised to achieve the desired project results. This current study is attempting to fill that gap in the existing literature towards improving the performance of public construction projects in the KSA. 
Several project management principles have underlain professional practice and have been the subjects of multiple research studies in the past half-century. These principles are documented in PMI's Project Management Body of Knowledge (PMBOK), Association of Project Management Body of Knowledge, and Engineering Advancement Association of Japan's Project and Program Management for Enterprise Innovation (P2M) (González et al.,.2013). Examples of project management tools and techniques that have continued to be crucial in the execution of projects of different features are Work Breakdown Structure (WBS), Critical Path Method (CPM), Program Evaluation Review Technique (PERT), and Earned Value Management (EVM). These project management principles, tools, and techniques are the focus of investigation in this doctoral study.

\subsection{Research Methodology}

This study employs a sequential explanatory design. A sequential explanatory approach has been described as using the results from quantitative research that have been reinforced and interpreted by qualitative data (Creswell, 2013). As usually carried out in construction management research, this study started by reviewing past studies on the concepts of delays and PM to form an initial understanding about the problem being investigated. It was found during the review of the existing literature that despite a high number of studies examining delay issues, no study was found to have directly considered the potential implications of the application of PM knowledge, tools and techniques. This discovery further confirmed the significance of this study to make considerable progress in addressing the problem of delays in the KSA's public construction projects.

Due to past research emphasising on delay factors, this study extended on that knowledge by examining the role of PM principles in addressing the problems. To gain a broader understanding of the problem and put the perspectives gathered from the literature review in the context of the KSA's public construction sector, a quantitative study was conducted. Based on a summary of the past research findings, a pilot questionnaire survey was first undertaken as a dry run. The pilot questionnaire was distributed to 20 experienced construction practitioners in the KSA to obtain their opinions regarding the overall appropriateness and effectiveness of the questions included in the questionnaire. Their responses were then incorporated to improve the development of the questionnaire. The final developed survey questionnaire (after taking the opinions of the experts 
into consideration) was then distributed through an online platform to practitioners who have been involved in the execution of construction projects in the KSA. In total, 1200 construction professionals were invited to complete the survey based on a stratified sampling technique.

The quantitative data were analysed using various statistical techniques such as Structural Equation Modelling and Mean Ranking. The results obtained were further explained by the undertaking of four case studies. Sixteen professionals who were involved in the four case construction projects were interviewed to get multiple perspectives about the issues that occurred in them; these were then compared with the information gathered from the documentary reports. The triangulation of findings obtained from both quantitative and qualitative studies were triangulated to formulate strategies for minimising delays in the KSA's public construction projects, in the form of a framework for mitigating delays.

\subsection{Thesis Structure}

This thesis is organised into eight main sections, which are: Introduction, Delay Factors in Construction Projects, PM Principles for Managing Construction Delays, Research Methodology, Delay Factors and PM Tools and Techniques, Delay Issues in Case Studies, Discussion and Framework Development, as well as Conclusion and Recommendations. The organisation of the thesis is provided in Figure 1.1. An overview of each of the chapters making up the thesis (with the exclusion of Chapter 1) is provided after that. 


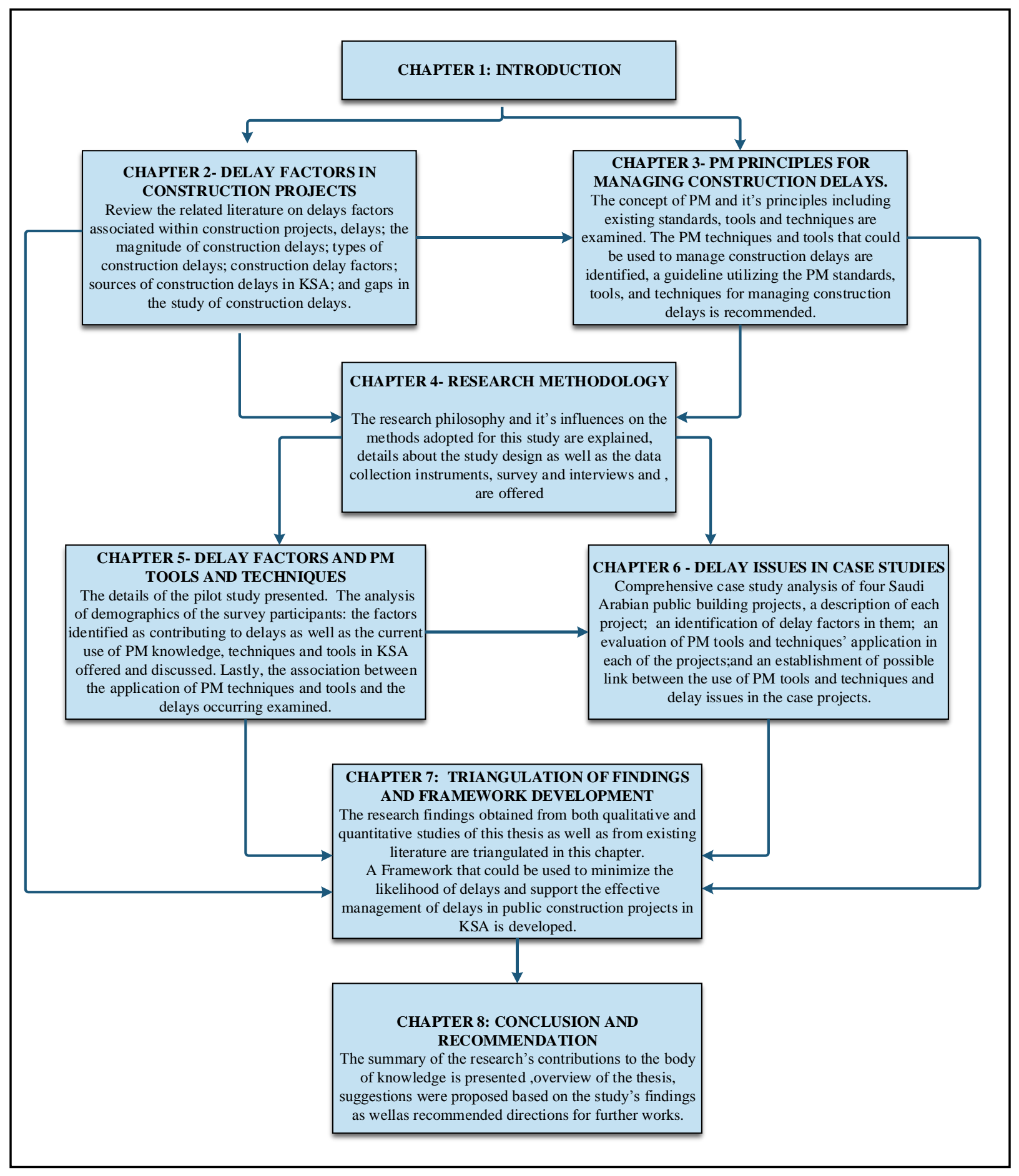

Figure 1.1 Thesis Organisation 
Chapter 2 - Delay Factors in Construction Projects: This chapter presents the findings from past studies about issues associated with a delay within the construction projects. The seven main subsections included in this chapter cover issues relating to: construction projects; delays; magnitude of construction delays; types of construction delays; construction delay factors; sources of construction delays in the KSA; and gaps in the study of construction delays. Primarily, this chapter utilises information derived from the literature to provide definitions of key terms including delays and construction projects. Statistics available in the literature were used to define the scope of the problem and study areas relating to the delays. Also, different types of construction projects and delays are discussed within this chapter. Moreover, delay factors identified across multiple studies were assessed. In summary, this chapter presents the gaps in the existing literature regarding delay issues in the KSA's public construction projects.

Chapter 3 - PM Principles for Managing Construction Delays: This chapter considers the principles of PM and their potential implications on how and why delays occur in construction projects. This chapter first discusses the concept of PM and its principles including existing standards, tools, and techniques. Second, the importance of these PM standards, tools, and techniques in managing construction delays is provided. Third, guidelines in relation to the PM standards, tools, and techniques for managing construction delays are recommended. Fourth, the current use of PM standards, tools, and techniques in the execution of construction projects in the KSA is examined. Finally, the gaps in the current literature regarding the use of PM standards, tools, and techniques in the KSA's construction projects are considered.

Chapter 4 - Research Methodology: It presents comprehensive information regarding the approach adopted for investigating the problem, including the research design. This research was undertaken based on the sequential explanatory method in which quantitative data were first collected and their results were then interpreted further using qualitative data. Within this chapter, the justifications for the chosen methods are provided. It also describes theories and philosophical assumptions guiding the selected research approach. The data collection instruments (questionnaire survey for quantitative study and case studies and interviews for qualitative research) are also described. Moreover, the sampling and data collection procedures followed in the selection of research participants, collection and analysis of the data were explained. Lastly, the research methodology's limitations are presented. 
Chapter 5 - Delay Factors and Project Management Tools and Techniques: The analysis of the responses received from the online survey is presented fully in this chapter. The chapter is structured into six main sections. The first section provides the details of the pilot study. This is followed by a section that offers the preliminary findings of the quantitative data. The next section presents the demographics of the survey participants. After that, the analysis of the factors identified as contributing to the delays is offered. Also, the data analysis in relation to the current use of PM knowledge, techniques and tools in the KSA is assessed. Lastly, the association between the application of PM techniques and tools and the delays occurring is examined.

Chapter 6 - Delay Issues in Case Studies: The analysis of the data obtained through documentary evidence, as well as the interviews conducted for the professionals involved in the four case projects is presented in this chapter. The analysis of these case projects consists of four parts: (1) a description of each project; (2) an identification of the delay factors in them; (3) an evaluation of the application of PM tools and techniques in each of the projects; and (4) an establishment of the possible link between the use of PM tools and techniques, as well as the delay issues in the case projects.

Chapter 7 - Discussion and Framework Development: The main findings of the study are interpreted and discussed in this chapter. Essentially, the findings on the three main research aspects, relating to: the magnitude of delays and their critical factors, the current use of PM knowledge, tools, and techniques, and the association between their application and the occurrence of delays in public construction projects in the KSA, are covered. Based on the interpretation of the study's findings, a framework that could be used to minimise the likelihood of delays and support the effective management of delays in public construction projects in the KSA is developed.

Chapter 8-Conclusion and Recommendations: A summary of the research's contributions to the existing body of knowledge is presented in this chapter. This conclusion chapter presents the overview of the thesis. Additionally, based on the study's findings, some suggestions and recommended directions for further works are proposed. 


\subsection{Summary of Chapter 1}

Delays are prevalent in the KSA's public construction projects. The occurrence of delays is increasing despite technological advancements in the construction industry in the recent years. Without concrete actions to confront the problem, continuous delay experiences may impact negatively on the reputation of governments in the KSA and may subsequently affect the interest in this sector. Although a large number of studies has examined the problem of delays within the KSA's public construction sector, there are currently insufficient studies that have considered the implications of PM tools and techniques when addressing the issue. This study has thus been developed to address this gap.

The main themes relating to delays have been investigated in past studies. Those studies have clearly indicated that there is a need to further research into this problem area. This chapter has provided an initial understanding about the problem. The aim of the research and its objectives, as well as the significance of the study, has been articulated. The importance of this research hinges on the need to deliver projects with better time and cost performance. The approach adopted for conducting the investigation has been described in addition to the thesis structure. The research methodology applied has been identified as sequential explanatory, in which the results of quantitative data are further clarified with quantitative data. The limitations of the study are also outlined. The next chapter presents a literature review on the delay factors in construction projects. 


\section{CHAPTER 2}

\section{DELAY FACTORS IN CONSTRUCTION PROJECTS}

\subsection{Introduction}

This chapter reviews the literature on the delay factors in construction projects. The three major topics discussed include: (1) construction projects; (2) delays in construction projects; and (3) the delay factors in construction projects. Based on this review, existing gaps in the current research on delays in construction projects are discussed in this chapter.

In the first part of this chapter, an emphasis is placed on the background information about the construction projects. There is first an introduction to the construction projects, before they are further defined. Also, a comprehensive review of previous research on construction projects is undertaken, indicating that there are generally six construction project phases (i.e., a pre-project phase, planning and design, contractor selection, project mobilisation, project operations, and project closeout and termination). The second section covers the discussions relevant to the research outcome regarding the dynamics of delays in construction projects. The next section presents the findings of the review of the current research studies on the factors contributing to the occurrence of delays in construction projects. Based on the study outcomes, a gap in the existing body of knowledge on the delay factors in the construction projects is identified.

This chapter provides the essential background for understanding the current research scope on the concept of construction project delays. This knowledge is crucial in further revealing the delay issues affecting the performance of constructions projects in the Kingdom of Saudi Arabia.

\subsection{Construction Projects}

The construction industry has contributed immensely to the socio-economic growth of the world in the last decade. Construction projects have continued to be on the rise in the KSA. Some of the infrastructure projects undertaken by the Saudi Arabian Government include the Al-dara Hospital project, estimated at US\$ 108 million; the Jeddah Corniche, a public real estate development 
valued at US\$ 461 million; the King Khalid International Airport - Terminal 5, where construction was tendered for US\$ 403 million; the Abraj Kudai Development, a multi-use complex at Mecca, estimated to cost US\$ 3.47 billion; and the King Fahad Medical City, budgeted for US\$ 613 million (Husein, 2013). Despite the magnitude of the construction projects being undertaken, they still rely on pre-planning and direct human management of vast resources and materials (Deloitte, 2017). As a result, delays have become a prominent issue with most of the construction projects around the world, especially those executed in a country like Saudi Arabia, where human capacity is still comparatively limited (Al-Kharashi and Skitmore, 2009).

The Saudi Government funds most of the construction industry projects in the Kingdom. Research has attributed nearly $67 \%$ of the construction projects in the Kingdom to being financed by the government (Bubshait and Al-Musaid, 1992). In 2011, a press release by the Kingdom's Ministry of Finance indicated that the agreements with public sector companies for public sector construction projects work totaling US\$ 38 billion had been sanctioned and signed off during that year. On the other hand, the investment in the private sector continues to increase in the construction projects in the Kingdom, in spite of the Government being the major funding contributor (Deloitte, 2017).

To gain a further understanding into the issue of delays in relative to the construction projects in the KSA, it is crucial to understand the background information about these projects. Thus, this chapter will present a discussion on the topics including definitions, types, and phases of the construction projects.

\subsection{Delays in Construction}

Delays have been defined in several studies. One common definition of 'delay' is an incident that leads to an extension of the time agreed to complete tasks or ultimately deliver the project (Assaf and Al-Hejji, 2006; Stumpf, 2000). Enshassi et al. (2009) defines 'delay' as an event that hinders the progress of the project. In their study, Sanders and Eagles (2001) describe 'delay' as an event that leads to the extension of time required for part of a project or the entire project (Sanders and Eagles, 2001), while yet another study defines 'delay' as a situation when the contractor and project owner jointly or severally contribute to the non-completion of the project within the 
original, stipulated or agreed contract period" (Aibinu and Jagboro, 2002). According to Assaf and Al-Hejji (2006, p.350), a 'delay' could also be referred to as the "time overrun either beyond completion date specified in a contract, or beyond the date that parties agree upon for delivery of a project".

\subsubsection{Magnitude of Construction Delays}

Globally, studies have indicated that delays are widespread in construction projects. For example, in Nigeria, a study has shown that nearly $70 \%$ of construction projects experienced delays during their project implementation (Odeyinka and Yusuf, 1997). The most common reasons for delays in construction projects in Nigeria were found to be extreme climatic conditions, project resource scarcity, poor management of contractors, and poor financial management by contractors and public sector agencies (Aibinu and Odeyinka, 2006).

In 2005, a study in Malaysia indicated that nearly $17.3 \%$ of the public sector's construction projects experienced delays of more than three months (Sambasivan and Soon, 2007b). Construction delays were commonly caused by a shortage of labour and materials, unavailability and failure of construction equipment, poor PM, inadequate training of workers, insufficient experience of the contractor, issues with sub-contractors, poor financial management, a delay in the payment for completed work and work-in-progress, and poor communication between the stakeholders and errors in project execution (Sambasivan and Soon, 2007b).

In the State of Kuwait, a study of data collected from a survey of 450 project stakeholders of a residential housing project, covering 27 urban districts in the state, identified three major factors which contributed to delays in construction projects, namely: inadequate contractor and worker experience, poor financial management, and a large number of changes made midway during the project execution (Koushki et al., 2005).

In Hong Kong, according to construction management practitioners, delays in construction projects in the region are caused by restrictions based on the environment, extremely low bidding of projects, variations in specifications by the client midway of project execution, and poor management of the site by consultants and supervisors and unexpected ground situations (Lo et al., 2006).

Delays in construction projects are not just limited to developing countries, but are also commonly 
found in more advanced countries. In the United Kingdom (UK), according to the National Audit Office report, nearly 7 out of 10 public sector construction projects experienced delays (Bourn, 2001). Furthermore, a study by the Building Cost Information Service found that at least $40 \%$ of all construction projects in the UK suffered from delays and had been unable to meet their completion date targets (Bourn, 2003). The major factors which gave rise to the delays in construction projects in the UK were the complex nature of projects, sequence specifications of project completion by the client, priority given to building design over construction tasks, construction form, inadequate or incomplete project information, location of the project and poor PM by the contractor (Nkado, 1995).

Wong and Vimonsatit (2012) studied the delays in construction projects in the Australian State of Western Australia and identified 48 possible causes. Moreover, the causes were narrowed down to five, based on a survey (including the 48 reasons) conducted with professionals in the construction industry. The five issues were identified as labour shortages, skillset shortages, unanticipated ground situations, economic difficulties and unrealistic project completion deadlines (Wong and Vimonsatit, 2012).

Chang (2002) studied four roadway construction projects involving engineering and environmental design in California, USA. The study classified the reasons for the delay in these projects into three categories - factors which are within the contractor's control, elements which are within the owner's control and those factors which are beyond the contractor's or owner's control (Chang, 2002). Another study in Florida, USA, done by Syed et al. (2003) blamed both the project owners and contractors for being responsible for the delays in the construction projects in that particular state. The main factors for the delay that were identified in this case were inefficient monitoring and control by the owners, non-compliance with building standards and flawed project designs.

\subsection{Types of Construction Delays}

Construction delays are not of the same kind (Bennett, 2003). Different features separate them (Bennett, 2003). Thus, construction delays have been broadly classified in the literature based on their criticality, compensability, and concurrency (Trauner et al., 2009). It is important to gain 
adequate knowledge about the different types of construction, so as to develop appropriate strategies for addressing them (Trauner, et al., 2009). Figure 2.1 presents the classification of construction delays.

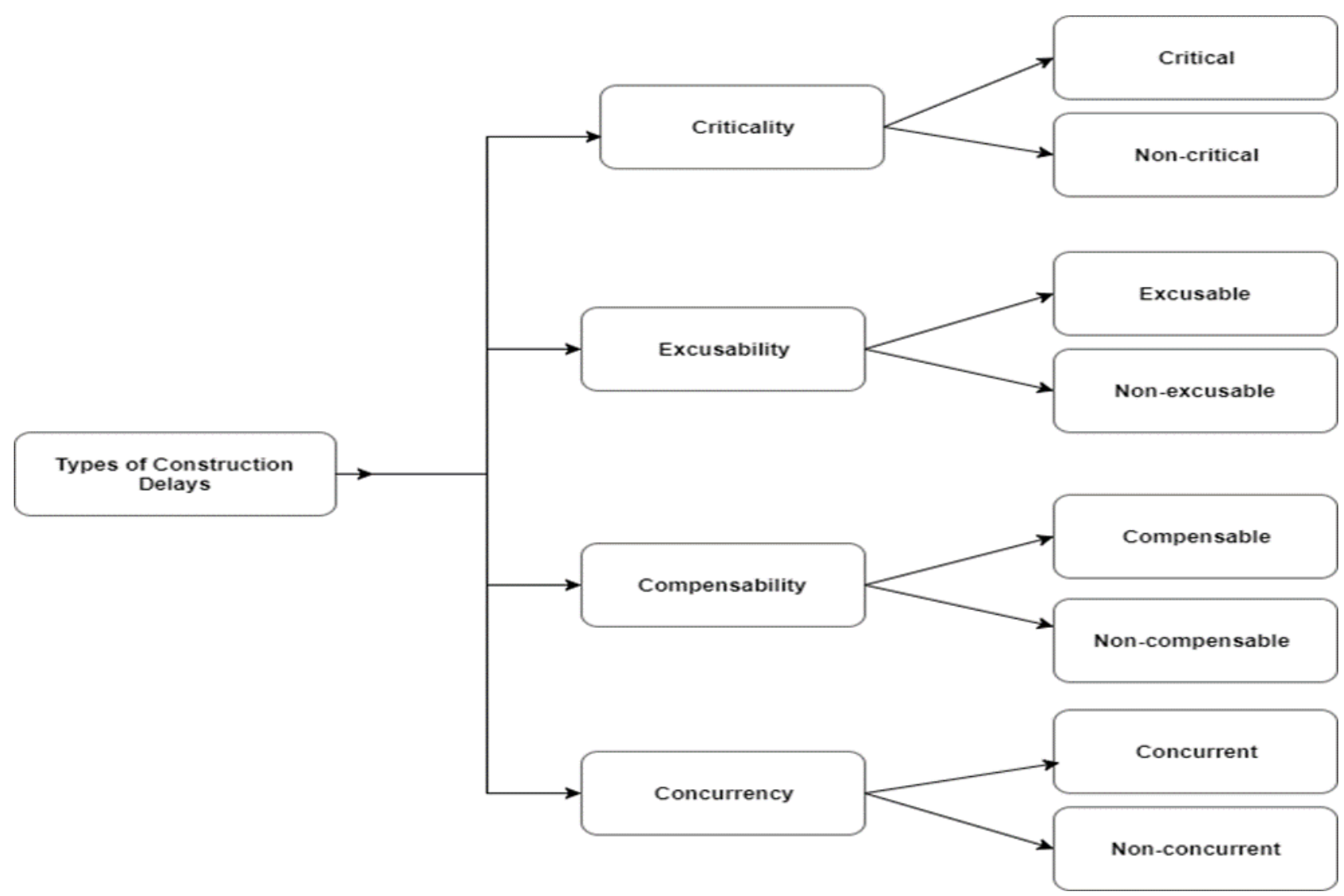

Figure 2.1 Classification of construction delays (adapted from Trauner, et al., 2009)

\subsubsection{Critical and Non-critical Delays}

Construction delays are differentiated as either critical or non-critical, depending on whether they affect the project's completion or progress (The Society of Construction Law, 2002). Construction delays that have an impact on a project's completion can either extend the contractor's proposed date of finishing all the works, or that which is stipulated in the contract signed (Trauner et al., 2009). Such delays that engender an extension in the contractor's anticipated completion date or the one in the contractual agreement are known as 'critical delay' (The Society of Construction Law, 2002). A typical example of a significant delay to a project would be the decision to change 
the structural type of steel member after the contractor has started erecting the structural steel members. Critical delays extend the completion date of a project.

On the other hand, non-critical delays only interrupt a project's progress (Callahan, 2010). In the case of non-critical delays, only the contractor's work progress is slowed down, without any considerable adverse impact on the contract's proposed completion date (The Society of Construction Law, 2002). In other words, contractors are still able to execute their work in line with the completion date, as established in the contract documents or PM plan. Non-critical delays do not usually result in any time overrun or any associated costs being incurred (Trauner et al., 2009). Mostly, contractors cannot request for a time extension in the case of a non-critical delay (The Society of Construction Law, 2002). However, contractors may be entitled to monetary compensations if such delays lead to any costly disruptions for them (The Society of Construction Law, 2002).

Construction delays can be identified as either critical or non-critical by using a technique known as 'Critical Path Method' (CPM) or through the assessment of the project schedule (Trauner et al., 2009).

\subsubsection{Excusable and Non-excusable Delays}

Construction delays can also be classified as either excusable or non-excusable, depending on whether the contractors will be able to access additional time extension or any related relief such as monetary compensation, due to the occurrence of the delay (Burr, 2016). Excusable construction delays occur due to unforeseen circumstances that are beyond what the contractors can control, such as unexpected inclement weather (Trauner et al., 2009). Excusable delays provide the contractor with an excuse from completing the contract within the initially agreed time frame, and therefore, a valid justification to request for an extension of the project's duration (The Society of Construction Law, 2002). Excusable delays can also impact non-critical tasks, and hence more descriptive analysis will be required to decide if a project's time needs to be extended or not (Burr, 2016). Contract provisions will specify that any delays which are caused by unexpected weather conditions, labour strife, issues with the client's design, changes made by the owner to the original plan are regarded as excusable delays (Burr, 2016). 
Non-excusable construction delays are caused by foreseeable events that are within the control of the contractors (Trauner et al., 2009). These non-excusable delays do not provide the contractor with any entitlement to extend the schedule or to receive any additional monetary compensation (Mubarak, 2005). Some typical examples of non-excusable delays are delays caused by suppliers and sub-contractors, sub-standard work done by contractors or sub-contractors, and labour strife resulting from the rigid strictures adopted by the contractor (Trauner et al., 2009). Callahan (2010) and Trauner et al. (2009) suggest that relevant contract clauses would determine if the delay is excusable or not. Specifically, a standard construction contract would categorise delay types and indicate which would accord extra time for the contractors (Trauner et al., 2009). For example, some contracts may exclude unusual or unexpected weather conditions from the excusable delay category, and not allow for any time extensions in those instances. Trauner et al. (2009) suggest that any unanticipated event that is outside of the contractor's control will generally be deemed as an excusable delay.

Trauner et al. (2009) provide other examples of excusable delays such as floods, fires, acts of God, labour strife, changes in the design made by the owner, omissions and error in plan and specifications, hidden conditions, government or legal interventions, non-cooperation by government agencies, and wild weather. In addition, Levy (2006) adds logistics problems and sickness or death of contractors to the list of excusable delays. Quarantine restrictions and epidemics are also often classified as excusable delays (Kelleher, 2005).

\subsubsection{Compensable and Non-compensable Delays}

Compensable delays offer the contractors an entitlement to be compensated monetarily, as well as giving them any required additional time (Callahan, 2010). However, there are some exceptional circumstances in which the contractors are only compensated financially, without any extra time being given (Callahan, 2010). Usually, compensable delays are deemed to be caused by the actions of the construction owners or their representatives (Mubarak, 2005). Typical instances of compensable delays include a failure to hand over the site to a contractor at the time agreed upon, significant changes in the scope of the project, and the inability of the client's architect to release the design plans at the time stipulated in the contractual agreement. 
Contrary to compensable delays, non-compensable delays do not provide the contractors any privilege to gain monetary compensation. However, they may have the right to extend a project's completion time (Callahan, 2010). According to Barrie and Paulson (1992), examples of noncompensable delays may include the inability of contractors to progress on their works due to a shortage or illnesses of qualified staff that could prosecute some dependent tasks. Generally, there is no hard and fast rule about which events are classified as compensable and non-compensable, as it all depends on the conditions of the contract (Mubarak, 2005).

\subsubsection{Concurrent and Non-concurrent Delays}

The exact definition of 'concurrency' as it relates to construction delays has been contentious (The Society of Construction Law, 2002). This term has been used in relation to the extension of time and compensation for prolongation (The Society of Construction Law, 2002). Concurrent construction delays are those that are caused by two or more events co-occurring simultaneously in which the contractors can claim compensation for financial loss or extension of time for at least one of them (Peter, 2003). For example, a project may have been delayed due to the fault of the contractors before the occurrence of another event caused by the client (The Society of Construction Law, 2002). In such a situation, a determination should be made on how the contractors can be compensated; however, such a decision may be tough (Burr, 2016). According to Callahan (2010), for an activity to be considered to have contributed to concurrent delays, it has to be the longest on the critical path of a project schedule. Peter (2003) notes that it is rare for two or more events to occur at the same time precisely. The author, however, suggests that events may occur at different times, but have a concurrent delayed effect on a project. Essentially, the ownercaused delay must have overlapped with the one engendered by the contractor for such to be regarded as concurrent (NcNair, 2016).

Depending on the contract's conditions, the contractors may be entitled to compensation of time extension or additional financial reprieve in some concurrent delays, while nothing of such is provided in other situations (Callahan, 2010). For example, where an owner-caused delay only occurs in between the length of time of delay caused by the contractors, the contractors will not have any entitlement to time extension in this instance. However, if the owner-caused delay precedes the starting period of the delay caused by the contractor, then the contractor will be entitled to compensation of time extension for the period the contractor causes the delays. 
Non-concurrent delays are caused by two or more non-overlapping events resulting partly from the actions of the construction owner and contractors (NcNair, 2016). In other words, the two or more events that are induced in part by the owner and contractors, but occur at different times and do not have any combined effects on the occurring delays. For example, if the actions of the contractors cause three weeks of delay and there is another two weeks of owner-caused delay, the combined five weeks of delay will be regarded as non-concurrent (NcNair, 2016). In this instance, the contractors will only be entitled to two weeks of time extension or any appropriate financial compensations to cover for the delay that they caused.

\subsection{Impact of Construction Delays}

Delays can pose several negative consequences for construction projects. For example, research has indicated that construction delays can ultimately lead to poor project performance (Assaf and Al-Hejji, 2006). In addition, delays can contribute to stakeholders' dissatisfaction and thus, a lack of support for a project (Gao and Zhang, 2013). For instance, delays in the completion of a road construction project will result in continued inconvenience for the commuters (Gao and Zhang, 2013). Another possible effect of road construction delays is traffic accidents (Weigao and Bo, 2011). Specifically, delays in road construction activities might result in the commuters having to incur high costs associated with a vehicle crash, vehicle operating, and travel delays (Gao and Zhang, 2013).

'Vehicle crash cost' can be explained in terms of the cost that road users may incur when their cars crash due to road construction activities, as roads are usually unsafe for use during maintenance. 'Vehicle operating cost' can be described as the additional cost of maintaining and fuelling the vehicles by road users due to factors such as road roughness, road width, surface moisture content for gravel, and rut depth during road maintenance. 'Travel delay cost' refers to the financial burden associated with 'time delay of travellers including speed delay, queue idling, and detour time' (Carr, 2000).

Also, Al-Khalil and Al-Ghafly (1999) suggest that delays can result in litigations and disputes. Generally, when the project is not completed within the agreed timeframe, the project owners and contractors get locked into civil disagreements (Al-Khalil and Al-Ghafly, 1999). Litigations consume time and can be highly expensive for the involved parties (Odeh and Battaineh, 2002). 
They can also increase the acrimony between the interested parties and have an impact on the capacity of the contractors to secure future contract opportunities (Odeh and Battaineh, 2002). Similarly, Sambasivan and Soon (2007) found that disputes, arbitration, litigation, and total abandonment of projects to be the consequences of construction delays in Malaysia.

A study by Al-Kharashi and Skitmore (2009) examined the impact of the delays in public sector construction projects from different viewpoints and found the disadvantages of project delays to be:

- Inefficient execution of the budget.

- Confusion in public development projects.

- Public discontent and inconvenience, which could potentially lead to political disturbances. Also, delays in construction projects can lead to cost blowouts as overhead and other expenses incurred by the contractor continue to increase as the project drags on (Al-Kharashi, and Skitmore, 2009; Chidambaram et al., 2012). Furthermore, as the contractor's funds are tied up with the project, any capital raised from the banks would continue to incur borrowing interests (Odeh and Battaineh, 2002). Delayed projects also mean a higher probability of using increased resources to enable the timely completion, a situation that could lead to more expenses being incurred and affect the project's cost performance negatively. Thus, as the cost of materials varies on a day-to-day basis, a delay in a project would result in increased spending by the contractors, if the cost of materials has increased, thus reducing their profit margin (Koushki et al., 2005).

Aibinu and Jagboro (2002) studied 61 building projects in Nigeria, and found that delays in construction projects had a significant impact on the time and cost of completion. They recommend improvements to the PM processes, acceleration of project activities, and the inclusion of suitable contingency allowance estimates in the contract to minimise the problems caused by construction project delays.

\subsection{Construction Delay Factors}

Causes of construction delays in various countries have been reported in the mainstream literature. For example, Doloi et al. (2012) conducted a research based on a questionnaire survey and personal interviews to study the causes of delays in India. The authors identified the critical factors 
contributing to the occurrence of delays in Indian construction industry as ineffective site management; improper planning; poor site coordination; lack of communication; unclear project scope; lack of commitment; and a cheap contract. In a related study, Sweis et al., (2008) found the leading causes of delays in the Kingdom of Jordan to be contractors' financial problems and owner's several change orders. The factors that were identified as contributing to construction delays in Zambia included delayed payments; financial processes and challenges; contract modification; staffing problems; inadequate supervision; labour-related issues; and procurement issues.

In Malaysia, the ten most important causes of construction delays were found to be a shortage in materials; labour issues; communication problems between concerned parties; unavailability and failure of equipment; errors in construction phase; subcontractors' related problems; contractor's ineffective planning; poor site handling by contractor; contractor's lack of experience; and financial difficulties by the client (Sambasivan and Soon, 2007). In Thailand, Toor and Ogunlana (2008) found that the most cited causes of delays in the country included: planning and scheduling; changed orders; lack of resources; shortage of labour; poor contractor management; design delays; and contractors' difficulties. As can be seen from Table 2.1, there are 20 leading causes of delay that were identified across 14 studies focusing on construction delays. 
Table 2.1 Main Causes of Delays in Construction Projects

\begin{tabular}{|c|c|}
\hline $\begin{array}{l}\text { Studies by Countries and } \\
\text { Authors }\end{array}$ & Main Causes of Delay \\
\hline $\begin{array}{c}\text { Australia (WA) } \\
\text { (Wong and Vimonsatit, 2012) }\end{array}$ & $\begin{array}{l}\text { Form of construction; Complexity of project; Project location; Lack of buildability of design; shortage of manpower; and Lack } \\
\text { of completeness and timeliness of project information. }\end{array}$ \\
\hline $\begin{array}{c}\text { Indonesia } \\
\text { (Kaming et al., 1997) }\end{array}$ & $\begin{array}{l}\text { Unstable prices of materials; Contractor's financial difficulties; Design and materials' changes; Poor resource productivity; } \\
\text { Estimation issues; Poor material management; Poor site management; Construction defects; and Shortage of skilled } \\
\text { manpower. }\end{array}$ \\
\hline $\begin{array}{c}\text { India } \\
\text { ( Doloi } \text { et al., 2012) }\end{array}$ & $\begin{array}{l}\text { Non-availability of drawing/design on time; Delay in material delivery by vendors; Financial constraints of contractor; Slow } \\
\text { in decision process from owner; Unrealistic schedule duration; and Changes in scope. }\end{array}$ \\
\hline $\begin{array}{c}\text { Kuwait } \\
\text { (Koushki et al., 2005) } \\
\end{array}$ & Contractor's financial difficulties; Cash flow problems; Design and materials' changes; and Management faults. \\
\hline $\begin{array}{c}\text { Nigeria } \\
\text { (Aibinu and Odeyinka, 2006) }\end{array}$ & $\begin{array}{l}\text { Contractor's financial difficulties; Cash flow problems; Estimation problems; Poor site management; Transportation problems } \\
\text { of resources; Management faults; Poor maintenance of works and equipment and materials; and Lack of feasibility studies. }\end{array}$ \\
\hline $\begin{array}{l}\text { Jordan } \\
\text { (Sweis, et al., 2008). }\end{array}$ & $\begin{array}{l}\text { Contractor's financial difficulties; Design and materials' changes; Estimation problems; Poor site management; Lack of } \\
\text { contractor's experience; Poor quality control; Shortage of skilled workers; Management faults; and Lack of feasibility studies. }\end{array}$ \\
\hline $\begin{array}{c}\text { UAE } \\
\text { (Faridi and El-Sayegh, 2006) }\end{array}$ & $\begin{array}{l}\text { Estimation problems; Poor site management; Lack of manpower; Shortage of skilled manpower; Construction defects; Poor } \\
\text { material management; Management faults; and Lack of feasibility studies. }\end{array}$ \\
\hline $\begin{array}{c}\text { Malaysia } \\
\text { (Sambasivan and Soon, 2007b) }\end{array}$ & $\begin{array}{l}\text { Cash flow problems; Estimation problems; Poor site management; Conflicts between the parties in the site; Construction } \\
\text { defects; Shortage of skilled workers; Lack of contractor's experience; Poor resource productivity; and Poor material } \\
\text { management. }\end{array}$ \\
\hline $\begin{array}{c}\text { Thailand } \\
\text { (Toor and Ogunlana, 2008) }\end{array}$ & $\begin{array}{l}\text { Contractor's financial difficulties; Design and materials' changes; Poor site management; Lack of contractor's experience; } \\
\text { Poor Labour productivity; Poor quality control; Contract related disputes; and Shortage of skilled workers. }\end{array}$ \\
\hline $\begin{array}{c}\text { Turkey } \\
\text { (Kazaz } \text { et al., 2012) }\end{array}$ & Design and materials; Delay of payments; Changes during the construction; Cash flow problems; and Estimation problems. \\
\hline $\begin{array}{c}\text { Vietnam } \\
\text { (Le-Hoai et al., 2008) }\end{array}$ & $\begin{array}{l}\text { Incompetence; Design problems; Market and estimate problems; Slowness and lack of constraint; Lack of financial capability; } \\
\text { Government regulations; and Shortage of skilled workers. }\end{array}$ \\
\hline $\begin{array}{l}\text { USA (Florida) } \\
\text { ( Ahmed et al., 2003) }\end{array}$ & $\begin{array}{l}\text { Ineffective planning; Financial problems; Approval for building authorisation; Poor managerial skills; Changes in order, Lack } \\
\text { of complete documentations; Changes in design; and Inspection pressures. }\end{array}$ \\
\hline $\begin{array}{c}\text { Ghana } \\
\text { (Frimpong } \text { et al., 2003) }\end{array}$ & $\begin{array}{l}\text { Payments difficulties; Poor contractor management; Poor technical performances; Poor materials' procurement; and Changes } \\
\text { in material prices. }\end{array}$ \\
\hline $\begin{array}{c}\text { Egypt } \\
\text { (Abd El-Razek } \text { et al., 2008) }\end{array}$ & $\begin{array}{l}\text { Contractor's financial difficulties during construction; Design changes by the owner; Delays payment by owner; Contract } \\
\text { issues; Slow delivery of materials; Difficulties of coordination between project parties; and Slowness in decision-making } \\
\text { process. }\end{array}$ \\
\hline
\end{tabular}




\subsection{Sources of Construction Delays in the KSA}

As discussed earlier, delays in construction projects are a major problem worldwide. However, major causes of delays are unique to the context within which the construction projects are executed (Odeh and Battaineh, 2002). All construction activities operate under different conditions: being subjected to the local environmental regulations, as well as being dependent on the available expertise, labour and other resources such as materials (Aibinu and Jagboro, 2002). In other words, the causes of construction delays would differ from one location to another due to the disparity in applicable conditions. For example, the adopted PM techniques, local building regulations and legal limitations would all contribute to the occurrence of construction delays. These factors, which are specific to the context, have a significant effect on construction PM and can potentially contribute to delays. "Although Saudi Arabia is a great source of growth for the Middle East, their construction industry has experienced significant problems that have led to project delays. These delays have caused the government to spend millions of dollars in an effort to remedy the problems" (Alofi and Kashiwagi, 2017). For this reason, it is necessary to look deeper into the sources of construction delays in the Kingdom of Saudi Arabia, which is the context of this research.

Over the years, much research has been done to examine the reasons for the delays in the construction projects in the Kingdom of Saudi Arabia. Most of these studies focused on public sector construction projects, mainly from the viewpoints of the clients, consultants and contractors (e.g., Al-Hammad, 1993; Al-Khalil and Al-Ghafly, 1999; Falqi, 2004; Assaf and Al-Hejji, 2006; Al-Kharashi and Skitmore, 2009; AlMobarak et al., 2013; Albogamy et al., 2013; Mahamid, 2013; Mahamid, 2016). Table 2.2 presents an overview of the studies examining the causes of construction delays in Saudi Arabia. Eight top factors causing construction delays in the KSA are identified from previous studies. 
Table 2.2 Construction delay factors in the KSA

\begin{tabular}{|c|c|}
\hline Construction Delay Factors & Authors \\
\hline $\begin{array}{l}\text { Ineffective planning and scheduling of } \\
\text { the project by the contractors }\end{array}$ & $\begin{array}{c}\text { Al-Ojaimi (1989); Assaf et al., (1995); Alkalil and } \\
\text { Al-Ghafly (1999); Falqi (2004); Assaf and Al- } \\
\text { Hejji (2006); Al-Kharashi and Skitmore (2009); } \\
\text { Albogamy et al., (2013); and Mahamid et al., } \\
\text { (2015). }\end{array}$ \\
\hline $\begin{array}{l}\text { Poor qualification, skills and } \\
\text { experience of the contractors' staff }\end{array}$ & $\begin{array}{l}\text { Al-Ojaimi (1989); Assaf et al.,(1995); Alkalil and } \\
\text { Al-Ghafly (1999); Falqi (2004); Assaf and Al- } \\
\text { Hejji (2006); Al-Kharashi and Skitmore (2009); } \\
\text { and Albogamy et al., (2013). }\end{array}$ \\
\hline $\begin{array}{c}\text { Delay in progress payment by the } \\
\text { client }\end{array}$ & $\begin{array}{l}\text { Al-Mudlj (1984); Al-Hazmi (1987); Al-Subaie } \\
\text { (1987); Alkalil and Al-Ghafly (1999); Falqi } \\
\text { (2004); Assaf and Al-Hejji (2006); Al-Kharashi } \\
\text { and Skitmore (2009); and Albogamy et al., } \\
\text { (2013). }\end{array}$ \\
\hline $\begin{array}{c}\text { Changes during construction by the } \\
\text { client }\end{array}$ & $\begin{array}{l}\text { Alkalil and Al-Ghafly (1999); Assaf and Al-Hejji } \\
\text { (2006); Al-Kharashi and Skitmore (2009); } \\
\text { Albogamy et al., (2013); and Mahamid et al., } \\
\text { (2015). }\end{array}$ \\
\hline $\begin{array}{c}\text { Slowness in decision-making by the } \\
\text { client }\end{array}$ & $\begin{array}{c}\text { Al-Kharashi and Skitmore (2009); Assaf and Al- } \\
\text { Hejji (2006); Falqi (2004); Mahamid (2016); and } \\
\text { Al Hammadi (2016). }\end{array}$ \\
\hline $\begin{array}{l}\text { Poor communication and coordination } \\
\text { between construction parties }\end{array}$ & $\begin{array}{c}\text { Alkalil and Al-Ghafly (1999); Falqi (2004); Assaf } \\
\text { and Al-Hejji (2006); and Al-Kharashi and } \\
\text { Skitmore (2009) }\end{array}$ \\
\hline $\begin{array}{l}\text { Assigning contracts to the lowest } \\
\text { bidder without regards to qualification }\end{array}$ & $\begin{array}{l}\text { Alkalil and Al-Ghafly (1999); Assaf and Al-Hejji } \\
\text { (2006); Al-Kharashi and Skitmore (2009); } \\
\text { Albogamy et al., (2013); and Mahamid (2016). }\end{array}$ \\
\hline $\begin{array}{l}\text { Delay in approving major changes in } \\
\text { the scope of work by consultant }\end{array}$ & $\begin{array}{c}\text { Alkalil and Al-Ghafly (1999); Assaf and Al-Hejji } \\
\text { (2006); Al-Kharashi and Skitmore (2009); and } \\
\text { Albogamy et al., (2013). }\end{array}$ \\
\hline
\end{tabular}

(Source: Alotaibi et al., 2016)

Also, the frequency of the reasons for the delays in the construction projects in the Kingdom of Saudi Arabia, as determined by these studies, is presented in Figure 2.3. As can be seen in Figure 2.3, the frequency of the reasons for delays in the construction projects within the KSA can be mostly explained by inefficient planning, as well as inadequate qualifications, skillsets and experience in the planning, implementing and management of construction projects. 


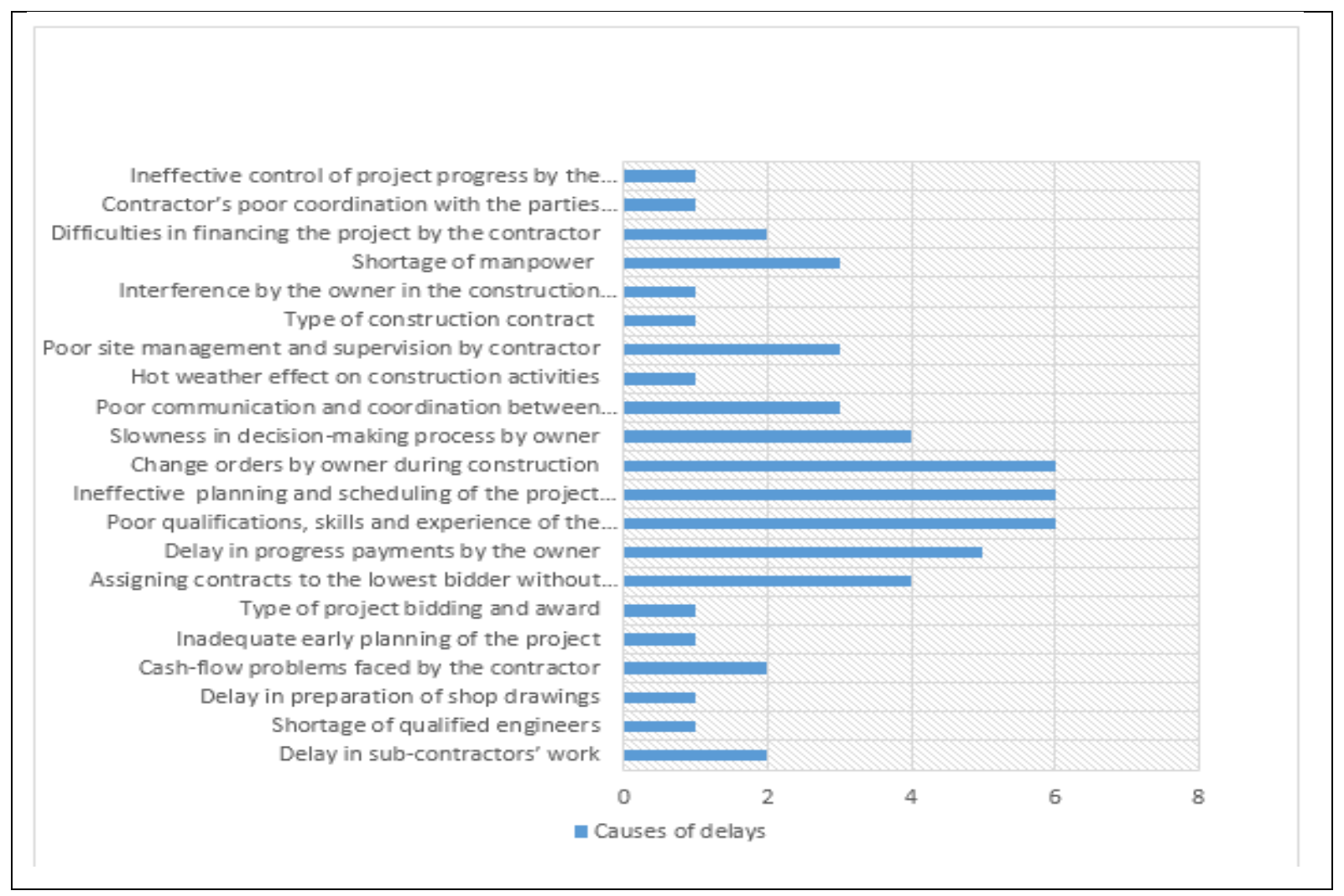

Figure 2.1 Frequency of reasons for the delay in construction projects in the KSA (Source: Table 2.2)

\subsection{Gaps in the Study of Construction Delays}

Although several studies have covered issues relating to construction delays in the Kingdom of Saudi Arabia, nonetheless, there are still gaps in this area of research that need to be filled.

On the first premise, existing research on construction delays in the KSA have focused on government projects (e.g., Alkhalil and Al-Ghafly 1999; Assaf and Al-Hejji, 2006; Al-Kharashi and Skitmore, 2009; Albogamy et al., 2013). These studies have investigated the causes or factors contributing to the construction delays in the KSA. However, they have not considered the delay issues from the PM perspective. As a result, there is a need to understand how the current use of PM tools and techniques, especially those relating to time management, may influence how and why delays occur in the KSA public construction industry. 
Also, the research has not looked into how PM knowledge, tools as well as techniques are being used towards managing the construction delays in the KSA. There is anecdotal evidence to suggest that PM principles are still not being used effectively within the construction industry in the Kingdom of Saudi Arabia. The importance of PM techniques and tools in achieving project expectations and objectives has been reported widely in the literature. PM tools and techniques offer a great opportunity to improve overall project performance and reduce the likelihood of delays in a construction project (Zavadskas et al., 2014). For instance, an application of PM scheduling has been very effective in managing and controlling project activities (Patanakul et al., 2010, PMI, 2016; Andler, 2016; Carstens et al.,). Project schedule management includes meticulous detailing for identification of delays, combined with precise assessments of the source of delays, such that the responsibilities for managing the delays can be assigned (PMBOK, 2016). Understanding the current PM practice among construction practitioners would provide great insights towards developing ideas about resolving delay problems in the country. Effective PM practices have been identified as capable of minimising poor performance in projects. Efficient strategies for minimising delays in the KSA's construction industry can be put in place if there is an awareness of the current practice of PM in the country.

Also, it is crucial to establish the real impacts of the application of PM knowledge, tools and techniques towards the delay factors, in order to adopt new applicable approaches to minimise and manage the construction delays that have long been recognised in the KSA's public projects. Although studies have emphasised the significance of PM tools and techniques in improving a project's effectiveness and performance (Frame, 2002; Patanakul et al., 2010), this area has not been covered in previous studies done in the KSA. Therefore, further studies are needed to determine the influence of the use of PM tools and techniques principles on the occurrence of delays in construction projects. Such research endeavours can help develop the models for a better management of projects, leading to a reduction in the occurrence of delays.

Lastly, research on construction delays in the KSA's public construction projects has been largely quantitative in nature, without the use of real-life case studies. Using case studies would bring about a better understanding of the problem and provide an opportunity to develop more practical solutions. Previous studies have relied on survey data from professionals, without analysing any issues that have arisen in projects that have experienced delays. 


\subsection{Summary}

The construction industry makes a significant contribution to the Gross Domestic Product (GDP) in the Kingdom of Saudi Arabia. However, delays have remained an unresolvable problem for most of the construction projects being executed in this Middle East nation. The cases of construction delays are abundant in the industry. To make an advancement in unravelling the delay problem in the KSA, there is a need for further studies that concentrate on the existing practices and for a viable solution to be recommended. This second chapter reviews the mainstream literature discussing delays within the context of construction projects. Not only does it provide background information about the magnitude and impact of delays, but it also presents the causes of the problem, as well as an overview of the research gaps in this field of study that need to be bridged.

Chapter 2 begins with a background understanding of construction projects and a discussion of the concept of delays. After that, previous studies on construction projects are examined. Within this chapter, the dynamics of delays in construction projects have also been explored. This includes identifying the factors reported in the literature as contributing to construction delays across multiple countries, as well as in the Kingdom of Saudi Arabia. Based on review findings, knowledge gaps in the study of delays in construction projects have been identified. In the next chapter, the PM principles for the management of delays in construction projects will be examined. 


\section{CHAPTER 3 \\ PROJECT MANAGEMENT PRINCIPLES FOR MANAGING CONSTRUCTION DELAYS}

\subsection{Introduction}

In this chapter, PM principles that could be useful in managing construction delays are examined. First, the concept of PM and its principles, including existing standards, tools and techniques are examined. Second, the existing project management standards from four different PM bodies are analysed. Third, the PM techniques and tools that could be used to manage construction delays are identified. Four, the importance of these project management standards, tools, and techniques in managing construction delays is provided. Five, the current use of PM standards, tools, and techniques in the execution of construction projects in the KSA is examined. Lastly, based on the literature synthesis in this research, a guideline utilising the project management standards, tools, and techniques for managing construction delays is recommended.

\subsection{Project Management Principles}

The fundamental aim of the PM principles is to apply appropriate standards, tools, and techniques to ensure that the resources assigned to the projects are utilised effectively towards creating the desired beneficial change (Turner et al., 2010; PMI, 2013). The concept of project management has been accepted widely across multiple industries (Clough et al., 2000). Due to the multidisciplinary nature of project management, several definitions have been ascribed to it. For example, Turner and Muller (2003) define project management within the context of construction as an organisation of resources (e.g. human, materials, and finances) in an ideal way, towards undertaking a unique scope of work within the constraints of given specifications, cost, and time that are defined by quantitative and qualitative objectives, to accomplish a valuable change.

Also, with a focus on all industries, Lewis (2007) defines project management as a process involving various stages and activities such as planning, controlling, designing, managing, and 
scheduling interrelated activities to achieve a project's stated goals within its stated budget and time, according to its stated standards of quality. The principles of project management revolve around several standards, tools, and techniques that have been created by different bodies such as Project Management Institute (PMI), Association of Project Management, and Engineering Advancement Association of Japan (González et al.,2013) over the last six decades. Some of these project management standards, tools, and techniques have been documented in the Project Management Body of Knowledge (PMBOK) by PMI, Association of Project Management Body of Knowledge, and Project and Program Management for Enterprise Innovation (P2M) by Engineering Advancement Association of Japan (González et al,.2013).

One of the core objectives of applying PM based standards, tools, and techniques has been to ensure that the construction projects can be completed within the anticipated duration without any delays (Sears et al., 2015). In other words, these PM standards, tools, and techniques are designed to prevent construction delays. The significance of applying these standards, tools, and techniques across the phases of a project cycle has been discussed in the literature. PMI (2017) suggests that they are crucial to prevent delays, which could lead to a project overrunning its targeted time. As many tasks are often interdependent in construction projects, it is common that delays in one task or phase can affect others, thereby extending the practical completion date (Turner et al., 2010). Evidently, a continuous application of PM standards, tools, and techniques is desirable across multiple phases of construction projects to minimise delay incidents.

\subsection{Project Management Standards}

Since the beginning of modern project management in the 1950s, different project management bodies have developed standards towards ensuring continuous improvement in project management practice. In addition, these standards are being set to describe how best to achieve given unique activities for a project. For example, the Project Management Institute, which was founded in 1969 developed its first PM Standards known as 'A Guide to the Project Management Body of Knowledge (PMBOK Guide)' in 1996 (Adams, 1997; Harrison and Lock, 2004). The current and sixth edition of PMBOK was published in 2017 (PMI, 2017). Essentially, PMBOK has provided project management practitioners with expert instructions and recommendations 
bordering on ten key knowledge areas of project management (i.e., cost, quality, procurement, time, human resources, communication, scope, integration, risk, and stakeholder management) (PMI, 2017).

Also, the Government Office in the United Kingdom (UK) established the Project in Controlled Environments (PRINCE2) process model as the standards for executing IT projects for the central government in the UK (OGC, 2011). Several organisations have now adopted the standards based on PRINCE2 across the world for the successful implementation of their projects (OGC, 2011). Fundamentally, PRINCE 2 is based on seven processes that include directing a project; starting up a project; initiating a project; managing stage boundaries; controlling a stage; managing product delivery; closing a project; and planning (PRINCE 2, 2016). Similar to PMBOK, PRINCE2 processes are designed to ensure that projects can be successfully delivered without delays.

Furthermore, the Association of Project Management (APM), a body of International Project Management Association (IPMA) has been providing its own body of knowledge since 1992, with the current and six th edition released in 2012 (APM, 2012). The standards recommended by the APM have predicated on four major categories identified as context, people, delivery, and interfaces (APM, 2012). 'Context' incorporates guidelines relating to governance and setting, while 'people' covers issues bordering on interpersonal skills and professionalism (APM, 2012). Also, standards on project delivery covers matters relating to integration, scope, schedule, financial and cost, risk, quality, and resource management (APM, 2012). Lastly, 'interfaces' relate to the factors that include accounting, health and safety, human resource management, law, security, and sustainability (APM, 2012).

The Project Management Association of Japan (PMAJ) also published its own project management-based standards referred to as 'A Guidebook of Project and Program Management for Enterprise Innovation' or P2M in abbreviated form (PMAJ, 2016). The focus of P2M has been to create value and employ a mission-approach philosophy within a complex and changing project environment (Ohara and Asada, 2009). The eleven key segments of the core focus in P2M include project strategy, finance, systems, organisation, objectives, resources, risk, information technology, relationships, value, and communication. Although P2M was originally developed to drive effective project management practice in Japan, it is being adopted across project 
organisations in several nations (Crawford, 2009). The development of P2M has been based on the quantification system of project management discipline and recognition of the criticality of integration, as well as the complexity of projects (Crawford, 2009). Like other standards discussed above, the overarching objective of P2M is to promote excellent performance of projects and prevent common issues such as delays (Ohara and Asada, 2009).

Table 3.1 compares the four standards covered in this section, based on their knowledge areas and terminologies peculiar to them. The project management phases or processes associated to each of these standards are also identified. 
Table 3.1 Comparison of standards by four PM bodies

\begin{tabular}{|c|c|c|c|c|}
\hline & PMBOK Guide & PRINCE2 Process Model & APMBOK & P2M Guidebook \\
\hline & Cost Management & Business Case & Governance & Value \\
\hline & Procurement Management & Organisation & Setting & Risk \\
\hline & Risk Management & Plans & Interpersonal Skills & Finance \\
\hline & Time Management & Risk & Professionalism & Relationships \\
\hline & Integration Management & Change & Integrative Management & Information Technology \\
\hline & Human Resources Management & Progress & Scope Management & Strategy \\
\hline & Quality Management & Quality & Schedule Management & Systems \\
\hline & Stakeholder Management & & Financial and Cost Management & Objectives \\
\hline & Communication Management & & Risk Management & Communications \\
\hline & Scope Management & & Quality Management & Organisation \\
\hline & & & Resource Management & Resources \\
\hline & & & Accounting & \\
\hline & & & Health and Safety & \\
\hline & & & Human Resource Management & \\
\hline & & & Law & \\
\hline & & & Security & \\
\hline & & & Sustainability & \\
\hline \multirow{7}{*}{ (2) } & Initiating & Starting up a Project & Initiation & Conception \\
\hline & Planning & Initiating a Project & Requirements & Design \\
\hline & Executing & Directing a Project & Planning & Implementation \\
\hline & Monitoring and Controlling & Controlling a Stage & Execution & Operation \\
\hline & Closing & Managing Product Delivery & Closure & \\
\hline & & Managing Stage Boundaries & & \\
\hline & & Closing a Project & & \\
\hline
\end{tabular}


The primary focus of this thesis is based on the principles of PMBOK (the Project Management Body of Knowledge), as PMBOK is universally and globally recognised and is applied in construction projects world-wide. PMBOK is a set of knowledge areas and processes which are widely considered as being the best practice in project management. The PMBOK Guide is a globally accepted standard, providing the basics of project management, as applied to different kinds of projects. PMBOK extensions have been developed and special standards are suitable to certain industries, such as the PMBOK Government Extension and PMBOK Construction Extension 2016. In addition, PMBOK became an ANSI norm in the year 2004 (Ilieş, et al., 2010). The application of project management standards has been found to be useful in minimising any disruption to the flow of project activities and thus reducing the risk of delays (Turner et al., 2010). The project management standards required will depend on a project's specific objectives and stages (PMI, 2013). For example, the actions needed during a project's initiation phase will be different from those required in the implementation stage. Several standards have been recommended in PMBOK and other project management literature for ensuring that projects' objectives are achieved. Specifically, this course of action can be used to prevent construction delays if effectively applied (Doloi et al., 2012).

\subsubsection{Project Management Standards in Initiation/Pre-Project Phase}

Some project management standards, as suggested in PMBOK during the initiation or pre-project stage include establishing the preliminary scope of a project; forming a project initiation team; identifying both internal and external stakeholders that can potentially influence the project; selecting a project manager; as well as developing a project charter and procedures for managing the project (PMI, 2013). Also, PRINCE2 suggests the creation of a project mandate covering logical questions, explanation of a project's purpose, and development of a project brief and setting targets for different project areas such as time, scope, and cost as important techniques required in this stage (OGC, 2009). The techniques within this phase are essentially meant to

provide an initial understanding about a project and its environment (Harrison and Lock, 2004). An important activity recommended in the initiation phase in $\triangle$ MPBOK is the definition of problem, need or opportunity that will be addressed by the project (AMP, 2012). In addition, AMPBOK indicates that the initiation stage should include the business case, criteria for success and benefits of the project by clearly defining the objectives to be delivered and achieved in terms 
of scope, cost, time, and quality amongst others. According to P2M, the conception phase involves the establishment of the requirements and objectives of the project, along with a review of guidelines, strategies, policies and action plans for meeting their attainment (Ohara, 2005, p. 15). According to Meredith and Mantel (2009), an effective implementation of the techniques during the initiation phase is important to define issues that may affect the project later in its life; for example, those that could cause problems for the realisation of a project's objectives, such as time and cost.

\subsubsection{Project Management Standards in Planning Phase}

PMBOK also provides some techniques that could be applied during the planning phase of a project (PMI, 2013). The techniques recommended in the planning stage include establishing the whole scope of a project; defining and refining the objectives; developing a series of actions for achieving those pre-set objectives; as well as production of a project management plan and several other documents important for the successful implementation of a project (PMI, 2013). According to the PRINCE2 process model, this stage should provide an outline of how the targets set for different areas of a project will be met, including what needs to be done, how, when, and who will do them (OGC, 2009). The planning stage of AMPBOK outlines the activities to be undertaken in a project towards achieving successful implementation from perspectives of the project sponsor, manager and other stakeholders. Furthermore, the planning phase in AMPBOK lays out strategies for stakeholders' management, value creation, pro-active risk management, quality management, and health and safety management at the work environment (APM, 2012). According to P2M, the value of the project is assessed during the planning phase, in terms of cost-benefit using typical methodologies such as cash flow, internal rate of return (IRR), net present value (NPV) and cost benefit analysis (CBA) (Ohara and Asada, 2009). These recommended techniques are crucial for identifying the flow of activities required during the implementation of a project (Wysocki, 2011). The techniques are required for preventing unwanted disruption to the sequencing of project activities and thus, the delays (Wysocki, 2011).

\subsubsection{Project Management Standards in Execution Phase}

Different project management bodies of knowledge have outlined some techniques that could be used to ensure the success of the execution phase (also known as directing a project (DP) or 
project operations). According to PMBOK, several techniques should be employed to achieve the overall objectives of this phase. They include effective coordination of personnel and resources such as materials and finances, management of stakeholders' expectations, as well as the performance of various project tasks as set out in the project management plan (PMI, 2013). Also, during this phase, PMBOK recommends making changes to plans and baselines such as those related to durations and risks (PMI, 2013). PRINCE2 recommends techniques ranging from setting stage boundaries for a project to the provision of an impromptu direction and guidance towards ensuring that a project's deliverables are accomplished. In the execution stage, the project scope is completely defined, with the schedule which is within the scope being determined. According to AMPBOK, the execution phase is where the allocated resources are utilised for the realisation of the project benefits (APM, 2012). The guideline suggests that the success of a project will depend largely on how the resources are maximised at this stage. According to the implementation phase, as defined in P2M, the actual management of project activities takes place in this stage (Ohara and Asada, 2009). P2M indicates that several issues are not revealed during the initiation and planning phases, but they become manifested in the implementation phase (Ohara and Asada, 2009). It is during the implementation phase that multiple components of a project system are managed and properly integrated to achieve the desired results (Ohara, 2005).

\subsubsection{Project Management Standards in Monitoring and Controlling Phase}

Some techniques have also been proposed for the monitoring and controlling phase of a project.

During this phase, PRINCE 2 suggests that work packages should be monitored and reports are to be provided on their progress (OGC, 2009). According to PRINCE 2 (2016), any problems identified should be corrected, and any daily activities associated with the project should be controlled continuously. Furthermore, PMBOK recommends some techniques in this phase, which includes tracking, reviewing, and planning the progress of a project, establishing areas where changes are necessary, and initiating the corrective measures as practically possible (PMI, 2017). Fundamentally, PMBOK indicates that this phase should incorporate actions that ensure a project's environment is continuously monitored and influenced in such a way that it is in line with the project management plans (PMI, 2017). Sometimes, this will require making trade-offs between some core objectives of a project (PMI, 2017). According to AMPBOK, there is a requirement for the formal management of change against an agreed baseline, continuous 
monitoring and management of project performance, and management of project data and documentation (APM, 2012). The monitoring and controlling phase in P2M is essentially designed to continuously monitor the progress of a project and initiate required change management based on the assessed influences of the project (Ohara and Asada, 2009). During this phase, risk is managed using appropriate quantitative methodologies to re-assess, track and make changes throughout the construction life cycle of a project (Ohara, 2005). By applying those suggested techniques, any potential interruption to a project's progress can be minimised and delays can be averted.

\subsubsection{Project Management Standards in Closing-out Phase}

In the closing-out phase of a project, some techniques have also been proposed. The essence of these techniques is to formalise the conclusion of a project and perform its handover officially (Wysocki, 2011). The techniques offered for this phase by PMBOK include obtaining the acceptance of sponsors or owners to close a project formally; undertaking post-project review; documenting of lessons learned; updating of organisational process assets; archiving of relevant project documents and assessing project teams; as well as the release of the resources. The closure phase of a project's management in both PRINCE-2 and AMPBOK is recognised as the stage at which all pertinent documents such as deliverables information, warranties and guarantees are transferred from the project team to the owners (AMPBOK, 2012; PRINCE 2, 2016). These essential documents are expected to be signed by the concerned parties and the records are to be documented appropriately and archived securely for future reference (AMPBOK, 2012; PRINCE 2, 2016).

\subsection{Techniques and Tools for Managing Construction Delays}

Prevention of delays requires an effective management of the time aspect of a construction project. Koushki et al. (2005) suggest that it is important that time be managed from the beginning of a construction's process until its final practical completion. To control time and thus delays in construction projects, several techniques and tools have been suggested in the literature. These techniques possess different functions that can complement each other to ensure that construction delays are prevented or reduced (Memon et al., 2014). Some of the techniques and tools provided in the normative literature include expert judgement, Work Breakdown Structure (WBS), 
analytical techniques, meetings, performance reviews, rolling wave planning, tasks dependence determination, group decision-making, scheduling tools, schedule network analysis, estimating techniques (e.g., bottom-up, analogous, three-point, and parametric), Critical Chain Method (CCM), Critical Path Method (CPM), Gantt chart, Program Evaluation Review Technique (PERT), resource optimisation, schedule compression, and Earned Value Management (EVM).

While there are various PM tools and techniques discussed in the research literature that can be applied to address the numerous problems confronting projects, this research will mainly focus on the possible PM tools and techniques within the application of project time management. These are defined by PMBOK and can help towards the effective time management of the construction projects with the objective of minimising project delays.

Further discussions will be offered on the most common project management techniques and tools that can be explored to manage construction delays. These include Work Breakdown Structure (WBS), Critical Path Method (CPM), Program Evaluation Review Technique (PERT), and Earned Value Management (EVM). These tools and techniques have been identified to be critical for achieving desired performances in construction projects (Martinelli and Milosevic, 2016).

\subsubsection{Work Breakdown Structure (WBS)}

The WBS was developed by the National Security Industrial Association (NSIA) in 1965 to define the work scope of the project (Fleming and Koppelman, 1998). In 1968, the US Department of Defence (DoD) issued its first Work Breakdown Structures for Defence Material Items (MIL-STD881), with subsequent revisions and the latest being done in 2011 ("SE Goldmine," 2017; MIL$S T D-881 C, 2011)$. The WBS is a process of splitting the deliverables of a construction project into smaller tasks or work packages, which are easily manageable (PMI, 2017). Through the creation of the WBS, the duration for individual project activities can be estimated, thereby motivating a timely completion of the overall project (Wysocki, 2011). The usage of WBS for organising the scope of the project has become quite common, especially with it becoming a requirement for government projects (Carson et al., 2014; Practice Standard for Work Breakdown Structures, 2006). As can be seen in Figure 3.1, WBS follows a tree structure, or an outline showing the decompositions of the efforts essential for achieving the project objectives. The WBS starts with the end objectives and then successively decomposes them into manageable sub-systems, in terms 
of duration, size and responsibilities, and components required for their achievement (Carson et al., 2014).

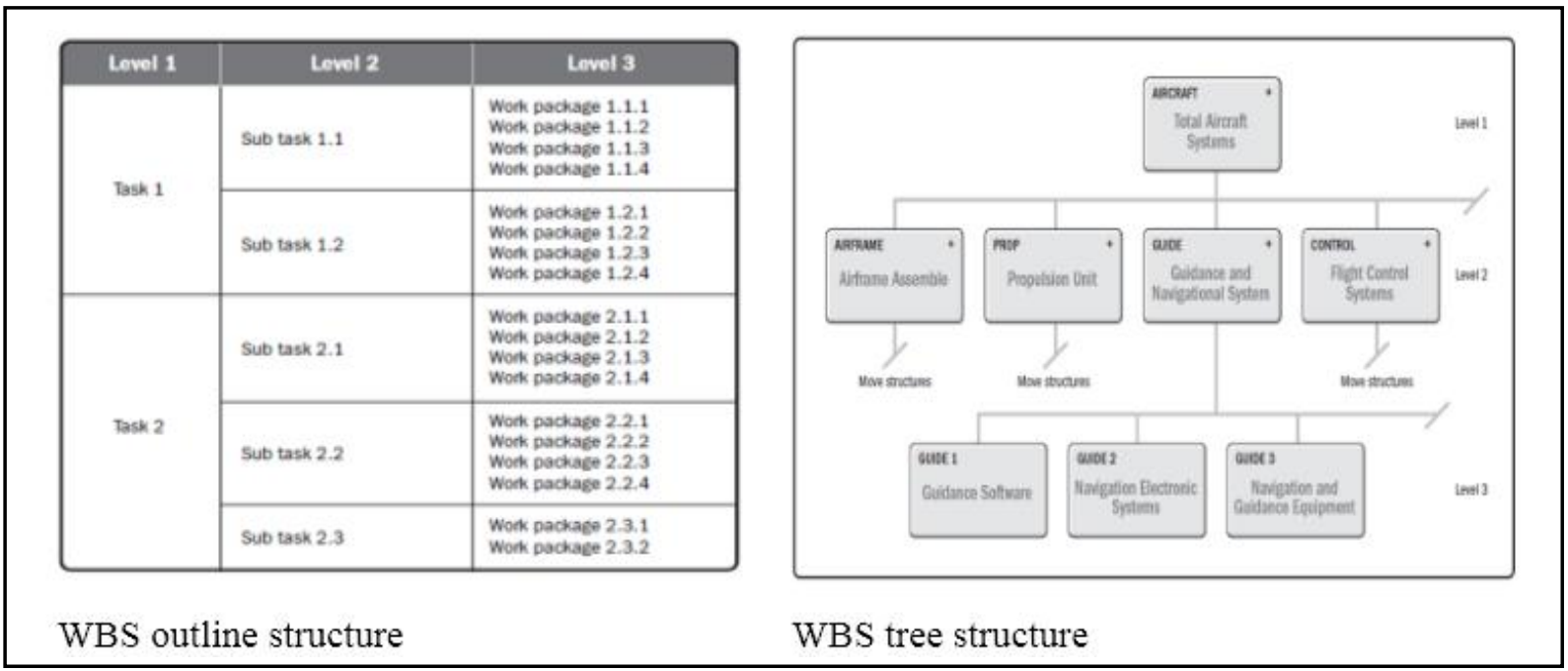

Figure 3.1 WBS examples (Source: CPM Scheduling for Construction - Best Practices and Guidelines (2014))

The WBS also considers the viewpoints of team members and provides a framework for subsequent change management (PMI, 2006). The advantages of using the WBS methodology are:

- It clearly defines the various activities and roles required for the successful completion of a project.

- It helps the team avoid missing important project tasks or activities.

- It helps in the overall estimation and management of a project's time frame, thereby reducing the chance of construction delays (Bennett, 2003).

There are three types of WBS that have been considered in the literature. They include work package-based, project phase-based, and deliverable-based WBS (PMI, 2013). In a work packageoriented WBS, a project is decomposed into the smallest manageable components based on the grouping of similar tasks (Larson and Gray, 2013). Project phase-based WBS breaks down the efforts required to complete a project along its stages (Jung and Woo, 2004). Furthermore, deliverable-based WBS is the decomposition of the project work into controllable units based on the project's expected outcomes or results.

The most important principle underlying the design of the WBS is known as 'The 100\% Rule' (Lavold, 1988). According to PMI (2006), 'The 100\% Rule' suggests that the WBS consists of 
$100 \%$ of the work defined by the project scope and captures all deliverables — internal and external, in terms of the work to be completed (including project management). 'The 100\% Rule' provides the guiding principle for the development, decomposition, and evaluation of the project activities. The rule will apply for all the hierarchical activity levels (Lavold, 1988; Taylor, 2003). The individual work, as represented by the activities for each work package, should total up to $100 \%$ of the work required for the completion of the work package (PMI,2016). An example of a WBS following 'The 100\% Rule' is presented in Figure 3.2.

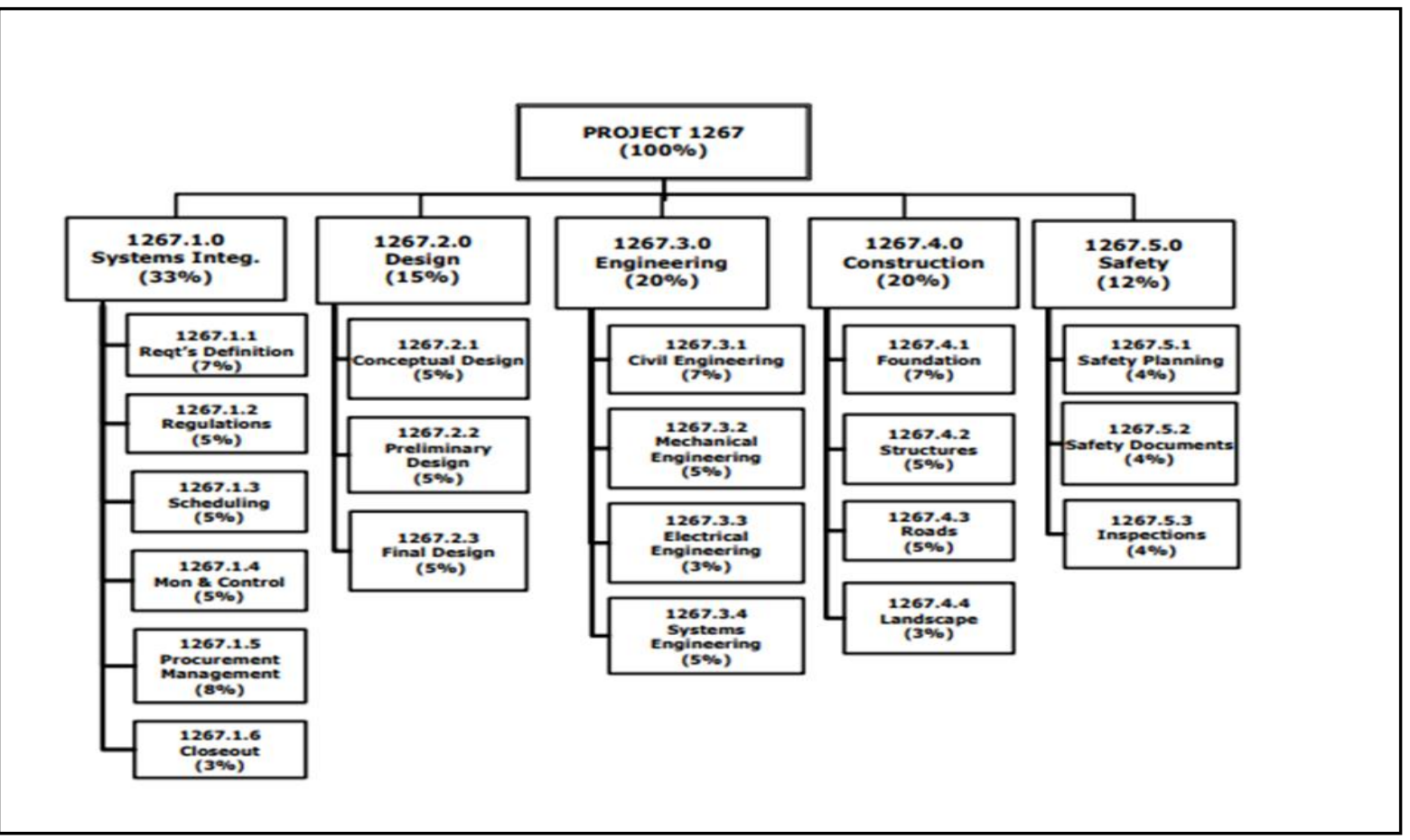

Figure 3.2 Example of WBS using 100\% rule (Taylor, 2003)

The WBS has the potential to prevent or minimise delays as it brings to the forefront all activities or tasks that need to be undertaken within a project system, so that these activities are not missed (Memon et al., 2014). Also, the WBS prevents or minimises the likelihood of delays by decomposing large project components into smallest possible units that can easily be managed, thereby helping a timely completion of a project (Memon et al., 2014). Moreover, the WBS supports the project team to understand with a higher level accuracy, the key elements concerning resource requirements, scheduling, and overall project estimation, which can better inform the integration of project components and decision-making in the project, consequently helping to avoid potential delays and rework (Zecheru and Olaru, 2016). Construction delays could be 
potentially minimised by using the WBS as it enables the management and completion of the various tasks associated with a project within the targeted periods. With the WBS assisting the time allocation to different activities of a project, overall construction delays can be managed by minimising the wastage of time.

\subsubsection{Critical Path Method (CPM)}

The Critical Path Method (CPM) was developed in 1959, in a study that was focused on reducing unproductive down-time through an improvised scheduling methodology (Kelley Jr. and Walker, 1959; Mercier and Nunnally, 1965). The CPM is a technique for scheduling project activities in a step-by-step sequence, in which both critical and non-critical tasks are identified, thereby curbing time frame issues and bottlenecks in the project progress (Deacon and Van der Lingen, 2015). The critical path is the longest path duration for a network, representing the project with different activities (Mubarak, 2015). The CPM is regarded as one of the most commonly used scheduling techniques globally in the construction industry ( $\mathrm{Lu}$ and $\mathrm{Li}, 2003$ ). One of the important benefits of the CPM is that it helps identify the activities on the longest path and without float (Keane and Caletka, 2015). According to Keane and Caletka (2015), a late completion of these critical tasks precipitate delays in the whole project. Therefore, the CPM plays an important role of ensuring that the critical activities are identified early and focusing the necessary attention on them, so as to prevent delays.

The CPM can be illustrated with the arrow and precedence diagrams, as shown in Figure 3.3 below. The project activities are represented with directional lines in the arrow diagram, while the nodes showing the estimated start and end dates of these activities are represented with circles. However, in a Precedence Network Diagram (PND), the project activities are denoted with boxes, also known as 'nodes', while the arrows indicate interdependencies between these tasks; the dependency describes the logical connection between the activities and is shown in a precedence network diagram as a line (Carson et al., 2014). 


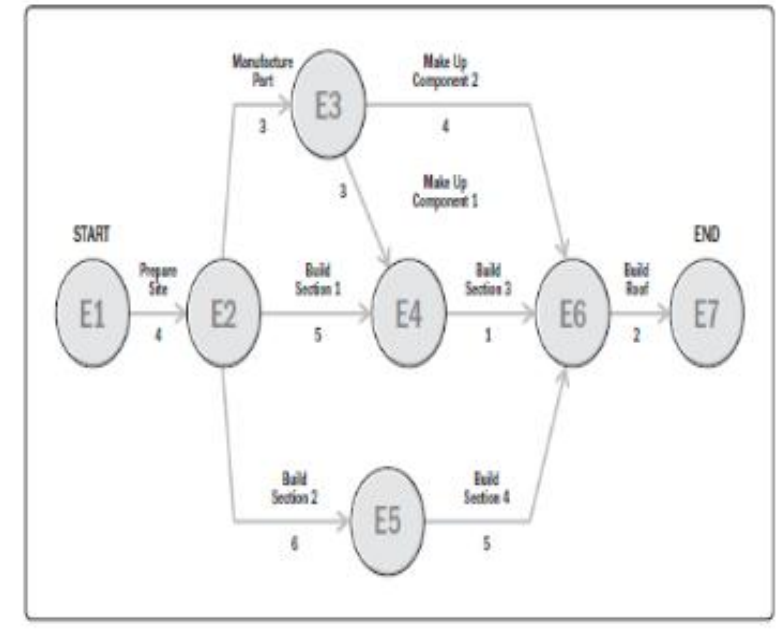

Arrow network

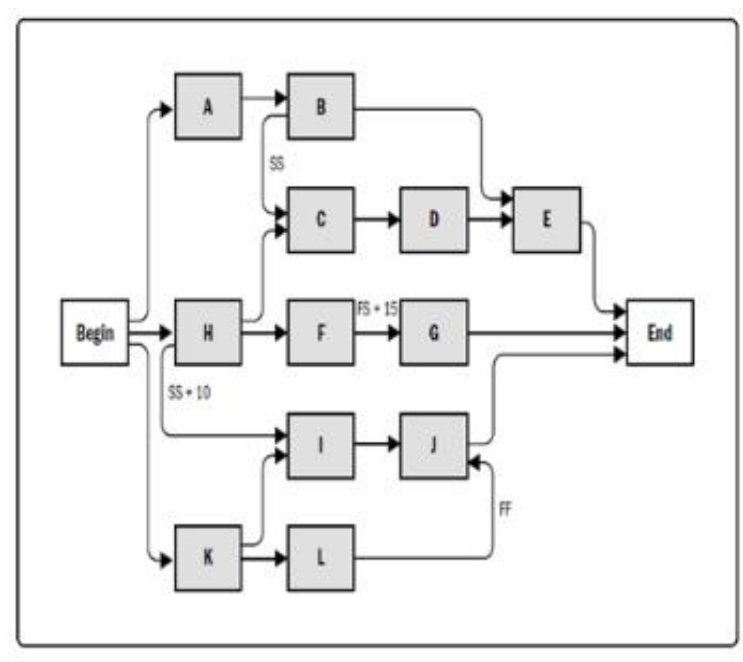

Precedence diagrams

Figure 3.3 Examples of the CPM using Arrow Network and precedence diagrams (Source: Carson et al., 2014; PMI, 2013)

The CPM calculation adopts three crucial steps. First, the process known as 'Forward Pass' defines the earliest timing that the activity should be completed. The 'Backward Pass' is the second step, which is used to determine the latest time that the activities can end, while 'Total Float' is utilised to address the result of a delay in some of the activities (East, 2015). Delaying certain activities may have more significant negative effects on the project's progress than others (East, 2015). As such, there is a need to calculate their total float, to determine which activities can be delayed and for how long (East, 2015). Depending on the applicable constraints, an activity can have positive, negative, or zero total float. For example, the free float for Activity B, in Figure 3.4, is 5 days. In the development of the CPM, it is crucial to determine the logical relationships of the activities, by considering their dependencies, lead and lag time (PMI, 2013).

The critical path methodology is applied to estimate the duration of a project and determine the possible scheduling flexibility along the schedule's logical network pathways. Essentially, the CPM is used to calculate the early start, late start, early finish and late finish timings for each activity, by executing forward and backward pass analysis through the network diagram (as shown in Figure 6), without considering any limitations of resources. As illustrated in Figure 3.4, the longest path would consist of activities A, C and D, and hence, A-C-D becomes the critical path determining the shortest project duration possible (PMI 2013). 
It should be noted that total float refers to the amount of time that an activity can be delayed without affecting the finish time of the project. Normally, the activities on the critical path have zero total floats (PMI 2013).

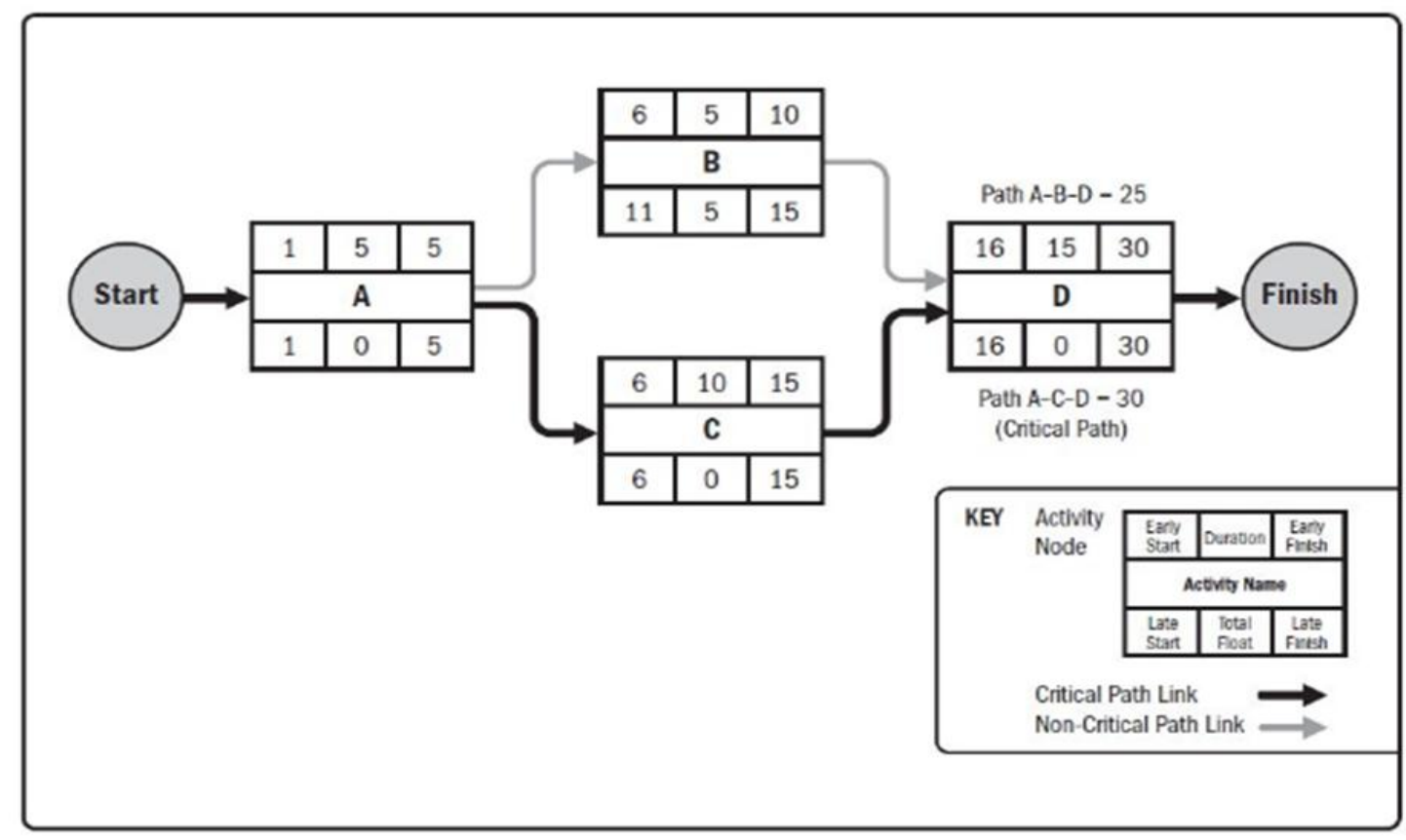

Figure 3.4 Example of Critical Path Method (PMI, 2013)

The CPM is an efficient toolset for managing a project's schedule (PMI, 2013). The CPM aids in a logical display of the sequence and time allocations of each task in a project. Furthermore, the CPM shows the interdependencies of the various tasks, thereby proving to be very useful in the time management of large and complex projects (Iromuanya et al., 2013). Also, the CPM encourages for a project to be broken down into a logical sequence of the different tasks to be completed and an estimation of the time taken for each task (Şandru and Olaru, 2013). The advantages of the CPM have been discussed widely in the literature (e.g., Kelley and Walker, 1959; Bennett, 2003) and they include:

- improving of communication and planning strategies, leading to efficient management of time;

- assisting in the calculation of an estimated time taken for the completion of a project, as well as total floats for the project activities; 
- helping to highlight critical tasks that may affect the duration of the project;

- providing a visualisation of the critical path activities and their sequences, consequently offering more understanding in which tasks' duration could be modified or reduced.

As the CPM shows the critical activities affecting the project duration, an effective use of this methodology can inform the necessary actions to be undertaken so as to minimise delays in the construction projects (Santiago and Magallon, 2009). The CPM also provides the different stakeholders of the project with warning signs about critical tasks that should be completed within time to prevent or reduce the chance of delays to the entire project (Alfaifi,2015: Şandru and Olaru, 2013). Therefore, the CPM has been identified as a tool that could be applied to highlight real time information about the progress of a project, in terms of meeting its anticipated schedule (Şandru and Olaru, 2013).

\subsubsection{Program Evaluation Review Technique (PERT)}

The Program Evaluation Review Technique (PERT) tool was developed by the US Navy for supporting the development of the Polaris missile program in 1957 (Roman, 1962). The PERT technique simulated the required tasks for developing the Polaris missile by using a logical network of interdependent sequential events (Fleming and Koppelman, 1998). However, in the mid-1960s, the US Department of Defence abandoned the PERT technique in favour of the earnedvalue concept (Fleming and Koppelman, 1998). PERT was designed as a tool for systemising and quantifying the process of project planning and control (Roman, 1962).

The PERT estimates the project completion time by considering various uncertainties, while simultaneously making a prediction of the duration of the tasks (Zhong and Zhang, 2003). In the PERT method, the duration of each of a project's activities is determined in terms of optimistic, pessimistic and most likely estimates, with the average of these taken as the average duration of that activity (PMI, 2013). Butler and Richardson (2011) describe the PERT method as a 'variable time planning model'. According to Butler and Richardson (2011), the variable time planning model is an effective strategic tool that takes into account the probability factor in the estimation of process timelines. The model developed by Butler and Richardson (2011) also has the same three-point estimates - optimistic, pessimistic, and most likely duration taken to complete a particular activity. 
PERT makes use of the following three estimates for defining a rough range for the duration of an activity:

Most likely $\left(\mathbf{t}_{\mathrm{M}}\right)$ - this is estimated on the basis of the activity duration, subject to the resources likely to be available and assigned, productivity, realistic expectation of the availability for the activity, interdependencies, participants and interruptions.

Optimistic $\left(\mathbf{t}_{\mathrm{o}}\right)$ - this is estimated on the basis of the best-case scenario for the activity to be completed.

Pessimistic $\left(t_{p}\right)$ - this is estimated on the basis of the worst-case scenario for the activity to be completed (PMI, 2013).

$$
t_{E}=\underline{t_{0}+4 t_{M}+t_{P}}
$$

6

The PERT can bring about a reduction in the delays experienced in construction projects by stimulating an improvement in the estimation of the project timeline (Zhong and Zhang, 2003). PERT can also help in the estimation of other uncertainties that exist in the timeline of the project, by allowing suitable leverage for the different tasks, thus preventing the overrunning of the project schedule and subsequently minimising delays (Zhong and Zhang, 2003).

\subsubsection{Earned Value Management (EVM)}

In 1963, the US Department of Defence (DoD) and NASA issued guidelines for the measurement of the earned-value for US defence contracts (Fleming and Koppelman, 1998). Since then, the concept of earned-value has been widely adopted by the US Government. In 1996, the National Security Industrial Association (NSIA) developed the Industry Standards Earned Value Management (EVM) system with 32 essential criteria and this was endorsed by the US DoD (Fleming and Koppelman, 1998). The criteria for EVMs have been customised by industrial engineers according to the needs of a particular industry (Fleming and Koppelman, 1998). EVM is a method of determining current variances in a project, in relation to either cost or schedule performance, by comparing the amount of actual work done against the work planned (Kim, Wells, and Duffey, 2003; PMI, 2013). Basically, EVM is useful in showing the percentage of time or budget that should have been expended, based on the completed project activities or the project's progress status (Kim et al., 2003). EVM is a control tool that is used for measuring the schedule, 
cost and scope performance of a project; EVM indicates whether a project is tending towards being behind or ahead of schedule (Lipke et al., 2009). Therefore, EVM can be successfully used for time management of construction projects, which can have implications for the occurrence of delays (Czemplik, 2014).

EVM employs two indicators: schedule performance index (SPI) and schedule variance, to determine the schedule performance or progress of a project (Morse, Barrett, Mayan, Olson, and Spiers, 2008). A schedule variance is calculated by determining the difference between the Earned Value (EV) and Planned Value (PV), which is expressed mathematically as SV = EV - PV (PMI, 2013; Vanhoucke, 2013). Schedule performance index, on the other hand, measures the efficiency of the schedule, expressing the ratio of Earned Value (EV) to the Planned Value (PV), which is expressed mathematically as SPI = EV/PV (Morse et al., 2008). It is a measurement of the efficiency of the project team in making use of time compared against the forecasted final completion schedule (Lipke et al., 2009). The SPI value, being below 1.0, is an indication that lesser work has been completed than what was originally planned. The SPI value, being above 1.0, is an indication that more work has been completed than what was originally planned (PMI, 2013).

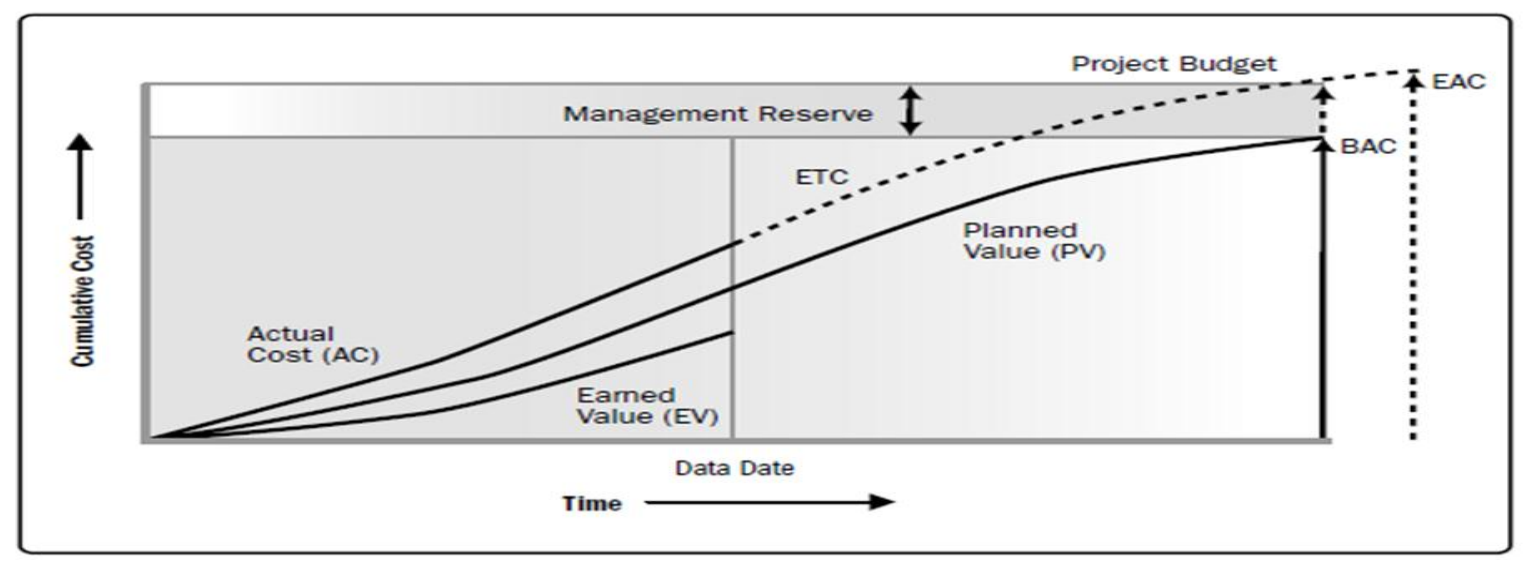

Figure 3.5 Earned Value, Planned Value, and Actual Costs (PMI, 2013)

According to Lipke et al. (2009), EVM provides a reliable forecasting technique of the final cost and duration of a project, thereby improving the capability of project managers to make informed decisions. EVM is beneficial to the project team as it provides early warning signs that a project is behind schedule or is exposed to budget overrun (Chin-Keng and Shahan, 2015). With EVM 
showing a project's schedule performance, a need for corrective actions as well as appropriate strategies for doing so can become obvious to the project teams (Anbari, 2003). EVM can be used to minimise delays in construction projects due to its ability to provide real-time information about the performance of a project's schedule. As mentioned previously, construction delays can be managed through an effective schedule control and monitoring; therefore, EVM is a viable approach to achieve this objective.

\subsection{Importance of Using PM Techniques and Tools}

Research has emphasised the significance of applying PM techniques and tools towards achieving the objectives of a project. Abbasi and Al-Mharmah (2000) make a strong case for an efficient use of the recommended techniques and tools to enhance the performance of construction projects both in public and private segments. The authors argued that an appropriate application of these techniques and tools will assist in keeping projects within budget and within the set duration. They also expressed that using them can help project managers and their teams navigate uncertain situations within projects, as well as deal more effectively with resources, both human and materials, to achieve a project's desirable outcome (Abbasi and Al-Mharmah, 2000). Also, a later study by Patanakul et al., (2010) and Carstens et al., (2016) highlighted the critical role that PM techniques and tools play in the successful implementation of a project, while indicating that delays in a project can be prevented through such effort.

In their study, Arnaboldi et al., (2004) indicate that a judicious use of these PM techniques and tools have led to an improved PM practice and capacity building among individuals involved in the direct execution of projects. The authors note that many governmental organisations have pressurised for the use of PM techniques and tools as a way of promoting a more cost-effective nature of delivering their services to the public. The same authors examined projects executed by the Italian Treasury Ministry which adopted these PM techniques and tools and found that their correct project implementation was helpful in preventing failure, as well as facilitating continuous communication and control in the projects. However, they acknowledge that this evolving field of practice still has room for improvement, in order for it to be more suitable to the constantly changing environments of contemporary projects (Koskela and Howell, 2002). 
Also, a report by PriceWaterhouseCoopers (PWC, 2007) found that organisations that did not apply PM techniques and tools reported lower performing project outcomes than those that employed them. According to the report, over $80 \%$ of high performing projects were found to have used PM techniques and tools effectively. Similar findings were reported by PMI (2015), in which the projects with effective applications of PM techniques and tools were identified as performing at a far superior level than those that were not employing them. Also, PWC (2007) found that 77\% of the organisations which were using project management software were high performers. The study found these projects to meet their objectives in terms of cost, time, and quality.

Koskela and Howell (2002) point out that whilst it may be true that the basic principles of PM have been significantly helpful in minimising project problems in construction projects, they still need to be revised and refined as many of them are either obsolete, or not a right fit for the constantly changing environments of these projects. The authors recommended a need to formulate theories that can be related directly to the project management field, so as to consolidate the importance of its practice for an overall better performance of construction projects.

\subsection{Current Application of PM Techniques and Tools}

PM techniques and tools have evolved over the years and are fast being applied across several industries, including construction, to enhance the performance of their projects. Shenhar and Dvir (2007) suggest that PM techniques and tools are used globally by organisations to drive innovation and strategic changes. Whittington et al. (1999) indicate that the application of project principles has continued to gain prominence because the top managements of several organisations are beginning to realise its importance. A report, PMI's Pulse of the Profession in 2015, found that project techniques and tools are increasingly being applied in the implementation of projects in the last decade (PMI, 2015).

PriceWaterhouseCoopers (PWC, 2007) conducted a study covering 26 countries, which included Australia, United Kingdom, United States, India, Canada, Germany, Russia, Argentina, Belgium, Netherlands, Trinidad and Tobago, Singapore, Mexico, Czech Republic, Hungary, Luxembourg, Hungary, Finland, Romania, Italy, South Africa, Slovenia, Brazil, Switzerland, and France. The 
study indicates that there has been a sharp increase in the use of PM techniques and tools across these nations over the last two decades. However, the study also found that while several organisations have spent a huge amount of money in making these techniques and tools available for their projects, some project teams are still neglecting their application.

In a study that surveyed 236 project managers in their understanding of the use of PM techniques and tools, White and Fortune (2002) showed that most of them were using PM software and Gantt charts mostly. PM software such as Microsoft and Primavera are being used widely across projects to minimise their risks of time overruns and delays (Wysocki, 2011). Also, about 50\% of these project managers reported one limitation or the other with the PM techniques and tools being used, thereby indicating the need to improve on them for better performance (White and Fortune, 2002).

There is currently no available information regarding the use of PM techniques and tools in the Kingdom of Saudi Arabia. However, it should be noted that PM practice in the KSA is not as advanced as in countries such as Australia, the United States, and the United Kingdom. Due to the limited evidence about current PM practice in the KSA, there is a need to investigate into this area, especially as public construction projects in the KSA are experiencing a high level of delays in the country. Understanding how PM techniques and tools are being employed in the KSA can serve a vital role towards developing both up-to-date and construction-industry relevant guidelines that can help minimise the pervasive problem of delays in the KSA public construction industry.

\subsection{Managing Delay Factors Using PM Techniques and Tools}

Several PM principles have been proposed for managing factors contributing to delays in construction projects. However, these suggestions have been based on the opinions of the authors rather than empirical evidence. For example, Abdelsnaser et al. (2005) suggest that construction delays can be overcome by having a strong and detailed PM plan. In another study, Nguyen et al. (2004) suggested four project management measures needed for decreasing the likelihood of construction project delays: accurate initial estimations of both cost and time; resources being readily available, and a competent project manager. Finally, when having a competent multidisciplinary project team, Koushki et al. (2005) believe that delays (on their own) can be managed 
by ensuring the adequacy of funds until the project is completed. Furthermore, they stress the need to have both a reliable contractor and competent consultant to reduce the risks of delays.

In another related study, Odeh and Battaineh (2002) recommend the ways of forestalling construction delays as including the rigorous enforcement of liquidation clauses and that contractors should be offered additional incentives for completing projects early. Furthermore, they suggested that additional training should be provided for the personnel executing construction projects to further build their capacity. Another proposition for minimising construction delays is an adoption of a new approach for awarding contracts in the tendering process, whereby more weight is placed on the contractor's track record of their past projects, experience and capacities, rather than bid costs or prices (Olaniran, 2015). Aibinu and Jagboro (2002) considered issues relating to delays in over 60 construction projects and suggested some recommendations for reducing the incidence of delays, which included that site activities should be completed quicker, and clients need to include appropriate contingency allowances.

Previous suggestions are important and provide a foundation upon which a guide for minimising delays in construction projects can be further advanced; however, they cannot be considered sufficient. The combination of these recommendations may not even provide a complete solution or framework for minimising delays due to the complexity of modern construction projects. These published suggestions may not be applicable anymore as construction project environments at the time of their publication cannot be compared to these present days. For example, the use of technologies in construction projects have advanced and as such, should have enhanced their

performance. As previous guidelines may no longer be reflecting the reality of today's construction project environments, it is important that a more up-to-date set of recommendations be developed to better manage them and prevent delays.

\subsection{Managing Delay Factors in KSA Using PM Techniques and Tools}

As mentioned previously in Chapter 2 Section 2.6, the top critical factors influencing delays in the KSA public construction projects are ineffective planning and scheduling of the project by the contractors; poor qualification, skills and experience of the contractors' staff; delay in progress payment by the client; changes during the construction by the client; slowness in decision-making 
by the client; poor communication and coordination between construction parties; assigning contracts to the lowest bidder without regards to qualification; and delay in approving major changes in the scope of work by the consultant. Al-Kharashi and Skitmore (2009) suggest that all these factors must be effectively managed to minimise the occurrence of delays in the KSA's construction projects.

Al-Mobarak et al. (2013) believe that the inability of effectively managing these contributing construction delay factors could be related to the poor application of PM principles. It was contended that PM is a relatively new field in the KSA and as such, there is a reluctance from many industry professionals to adopt its techniques and tools towards improving their project delivery. Also, it has been suggested that many of the existing guidelines being followed in the construction industry in the KSA are not reflecting the new reality of complexity associated with this field (Albogamy et al., 2013). Therefore, there is a need to upgrade an understanding of the ways in which PM techniques and tools are being applied in the KSA towards achieving significant reduction in the occurrence of construction delays in the country.

Managing construction delays in the KSA requires that factors contributing to these problems must be properly understood and integrated solutions have to be developed. Kharashi and Skitmore (2009) stress the significance of managing the factors as it contributes to delays throughout the context of PM processes in which they could occur, as well as the importance of applying appropriate PM techniques and tools. However, an effective management of construction delays demands a holistic approach that incorporates not just project management tools and techniques, but also soft management tactics. Figure 3.6 shows the mapping of the top critical factors causing delays against the PM techniques and tools that can be used to manage them within different PM knowledge areas (Alotaibi et al., 2016). 


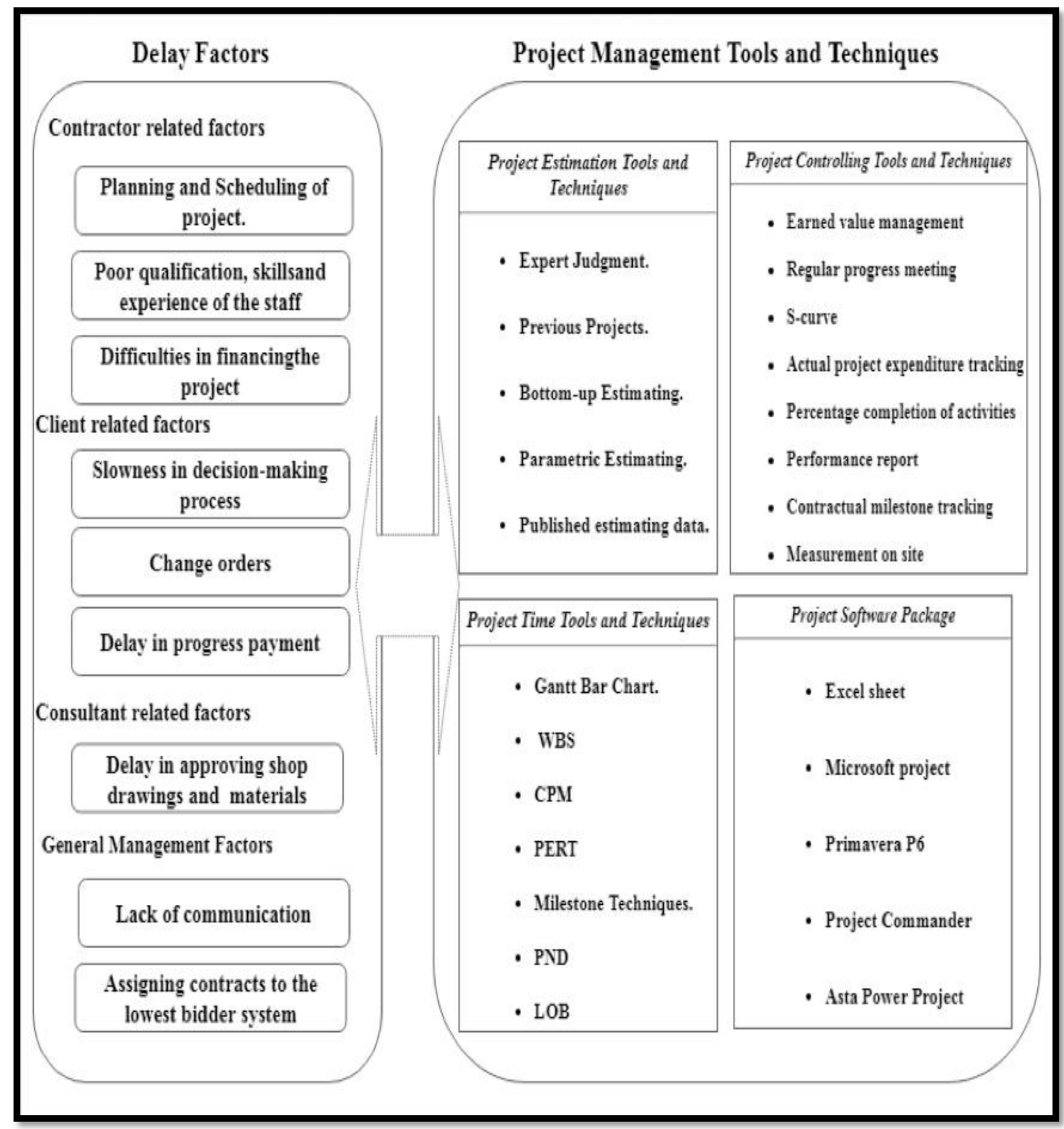

Figure 3.6 Mapping of delay factors against PM techniques and tools (Source: Alotaibi et al., 2016)

The top delay factors have been categorised based on the findings reported in past research studies that have examined the issues relating to delays in the KSA. In addition to an extensive review of 
these delay factors in Alotaibi et al. (2016), Chapter 2 of this thesis has also presented a contemporary and robust discussion on the topic. Furthermore, Alotaibi et al. (2016) suggested that PM tools and techniques identified in Figure 3.6 can potentially be used to minimise the incidence of delays and enhance the time performance of construction projects in the KSA.

The delay factors are related to contractors, clients, consultants, and general management factors. The PM tools for managing these delay factors involve the estimation, planning and control tools, as shown in Figure 3.6. Each of these techniques has different functions during the project's life cycle in providing effective time management and contribute in avoiding the incidence of potential delays.

Generally, the factors causing construction delays have been categorised as relating to client, consultant, and contractor (Albogamy et al., 2013). The implication is that these factors emerge from client's, consultant's, and contractor's actions. Some suggestions derived from the literature on how various multiple approaches can be useful in managing these identified delay factor categories are discussed further in this section.

\subsubsection{Managing Contractor-related Delay Factors}

Some of the contractor-related delay factors include ineffective planning and scheduling of the project by the contractors, poor qualification, skills and experience of the contractors' staff, and difficulties of contractors in financing the projects (Al-Kharashi and Skitmore, 2009; Albogamy et al., 2013). Several PM tools and techniques can be used to manage contractor-related factors contributing to construction delays in the KSA. Examples of these include WBS, CPM, Precedence Diagram Method (PDM), PERT, Critical Chain Method (CCM), and Gantt charts. EVM, analytical techniques, schedule compression, information systems and performance review, by contrast, are examples of PM tools and techniques that can help contractors control project activities towards reducing the likelihood of delays (APM, 2012).

The WBS decomposes project elements into separate phases, by focusing on deliverables (PMI, 2017). By using descending levels, descriptions of work activities become increasingly comprehensive, thereby making projects more manageable (Haugan, 2002). The WBS assists project managers in the efficient distribution of time to the numerous project tasks that need to be executed (Burke, 2013). In doing so, it thus promotes the timely completion of activities in the 
project. Usually, the WBS enables an easy way to schedule and plan a project holistically and in detail based on its activities (Memon et al., 2014).

The CPM is another PM tool that is often recommended. Like WBS, CPM helps in the management of time in complex projects with a wide variety of tasks (PMI, 2017). The CPM allows project managers to logically sequence and assign times to all activities in a project (Yamin and Harmelink, 2001). In addition to this, the CPM illustrates activity interdependencies, thus offering a more efficient tool for managing time in complex and large projects, thereby minimising the risks of delays (Kalltzis et al., 2007). The CPM works by breaking down the project into a series of activities that are logically sequenced and attached to time estimates (PMI, 2017). It enhances communication, planning, time management, and assist with accurate estimations. PERT, PDM and Gantt charts are other time management project tools and techniques that can be adopted, where relevant (PMI, 2017).

Table 3.2 summarises different actions that can be taken to manage contractor-related delay factors as identified in the literature. These delay factors include ineffective planning and scheduling of project; poor qualification, skills and experience of the contractors' staff; poor site management and supervision by a contractor; difficulties in financing the project by a contractor; and delay in sub-contractors' work. 
Table 3.2 Recommended actions for contractor-related delay factor

\begin{tabular}{|c|c|}
\hline $\begin{array}{l}\text { Contractor-related } \\
\text { Delay Factor }\end{array}$ & Recommended Actions \\
\hline $\begin{array}{l}\text { Ineffective planning and scheduling of } \\
\text { project }\end{array}$ & $\begin{array}{l}\text { A construction project can be planned more effectively by using a robust PM Plan at early stages (Alkalil and } \\
\text { Al-Ghafly, 1999). Also, PM tools such as CPM, WBS, PERT, expert judgment and analytical techniques can } \\
\text { be employed towards ensuring that the project activities and tasks are scheduled appropriately, thereby } \\
\text { minimising delays (PMI, 2017). By using contemporary scheduling software, timelines of a project are better } \\
\text { managed for greater performance (Assaf and Al-Hejji, 2006). The judicious use of these PM techniques and } \\
\text { tools can help over the problem of construction delays in the KSA. }\end{array}$ \\
\hline $\begin{array}{l}\text { Poor qualifications, skills and } \\
\text { experience of the contractor's staff }\end{array}$ & $\begin{array}{l}\text { Poor qualifications of the contractor's staff can be addressed by ensuring that important activities that could } \\
\text { delay the project's progress are undertaken by only personnel with relevant educational and professional } \\
\text { qualifications (PMI, 2013). For example, certified project managers should be recruited by a contractor to } \\
\text { manage the overall activities of its project. Also, the skills and experience of personnel should be evaluated } \\
\text { prior to their engagement, to ensure they have capabilities to carry out any activities that will be designated to } \\
\text { them (Al-Kharashi and Skitmore, 2009). Moreover, contractors should organise an ongoing training for their } \\
\text { staff to enhance their capacity and enrich their skills for better performance (PMI, 2013). }\end{array}$ \\
\hline $\begin{array}{l}\text { Poor site management and supervision } \\
\text { by a contractor }\end{array}$ & $\begin{array}{l}\text { A contractor can manage a construction site more efficiently by following PM principles for early detection of } \\
\text { issues that could potentially cause delay (Albogamy et al., 2013). Contractors can employ PM tools and } \\
\text { techniques such as project performance reports, earned value, monitoring controlling tools, periodic review of } \\
\text { the progress to identify and address problems confronting projects (PMI, 2013). Contractors can avoid financial } \\
\text { difficulties by adopting effective cost management plan that provides them with an understanding of cashflow } \\
\text { requirements for timely implementation of their projects (Albogamy et al., 2013). Such an action would ensure } \\
\text { that work in progress can be estimated and payments be released per schedule to ensure the smooth progress of } \\
\text { the project (PMI, 2017). }\end{array}$ \\
\hline Delay in sub-contractors' work & $\begin{array}{l}\text { Effective use of procurement management methods would ensure that sub-contractors are better managed by a } \\
\text { contractor (PMI, 2016). An adoption of project integration management would keep a contractor informed of } \\
\text { the progress that all sub-contractors are making, and actions can be taken where necessary to prevent } \\
\text { unnecessary delays (Al-Kharashi and Skitmore, 2009). }\end{array}$ \\
\hline
\end{tabular}




\subsubsection{Managing Client-related Delay Factors}

One of the most frequently cited client-related delay factors is change orders by the client. Change orders are referred to as formal documents, which are used to incorporate variations after the project has commenced (Park and Pena-Mora, 2003; Keane et al., 2010). A change or variation in construction projects is defined as any additions or deletions to the existing or agreed upon project scope or deviation from the sanctioned schedule of work (Keane et al,.2010). Often, owners issue change orders after the project's commencement (Ibbs et al., 2007). Changes in construction projects are inevitable, even when a detailed study and analysis has been done in the design phase, prior to starting the construction. This is especially prevalent in large construction projects with a long duration, where it is difficult to correctly determine the scope and schedule ahead of time (Erdogan et al., 2005). To manage this delay factor, it may be sensible to have a pre-agreed process for the identification, assessment and management of project variations. The evaluation of change orders should include information about the likely effects of alterations on the established objectives during the PM plan (Park and Pena-Mora, 2003). Given the significant consequences that change orders may have on a project's plan and scheduling, it is imperative that construction owners in the KSA are made aware of such impacts before initiating change orders. Whenever there is a need for change orders, PM principles such as expert judgement, change control toolsets, and meetings could be employed to minimise their adverse effects on the schedule, thereby instigating delays (PMI, 2017).

PM principles can also be applied to address the delays attributable to the disruption of client payments to contractors in the KSA. For example, the parametric cost estimating technique can be utilised to analyse cost data and develop an understanding of the cost models and drivers (Jorgensen and Shepperd, 2007). Such an understanding would help clients be aware of the cash flow management approach to adopt, in order to make adequate funds available to a project, as and when required across different phases (PMI, 2013). Also, a cost control approach supported with an appropriate cost management software can be deployed to establish appropriate cost control procedures and forecast future costs (Pinto, 2015). This will assist in clearly presenting information relating to project costs such that the client/owner can understand. If clients are armed with such information, they will be aware of the consequences of delaying payments. Also, this will help them correctly determine the important disbursements that need to be made at different 
times, in order to forestall delays in the project's progress. For instance, it could help them decide if advanced payments are desirable for certain phases of a project (Kaliba et al., 2009). All of these will encourage timely payments and minimise the likelihood of delays.

Slowness in the decision-making process by the owner can be managed by ensuring robust stakeholder communication, and further risk management can be employed to prevent a slow decision-making process (Albogamy et al., 2013). For example, stakeholders can be kept informed about developments in a project to ensure that their support can be secured more easily towards an on-time decision. Having good relationships with the stakeholders, continuous communication with the parties involved in a project, as well as adequate risk management would all ensure that timely decisions can be made, alongside the cutting through of bureaucratic red tape (Assaf and Al-Hejji, 2006).

For managing unrealistic project duration estimates, the client should use more technical/sophisticated methods (including PERT) or a combination of methods in estimating a realistic duration such as expert judgment, analogous estimation, parametric estimation, bottomup estimation, 3-point estimation, reserve analysis, quality cost, project management software, vendor bid analysis and group decisions (PMI, 2017). The usage of any of this would ensure that duration estimates are more realistic.

Table 3.3 presents an overview of actions suggested for addressing client-related issues identified from the literature review, as contributing to construction delays in the KSA. The delay factors attributed to clients include unrealistic project duration estimates; change orders by the owner during construction; slowness of decision-making process by the owner; delay to furnish and deliver the site to the contractor; and payment delays by the owner. The recommended actions (using PMBOK framework and other studies) for mitigating these delays are presented below in Table 3.3. 
Table 3.3 Recommended actions for client-related delay factor

\begin{tabular}{|c|c|}
\hline Client-related Factors & Recommended Actions \\
\hline $\begin{array}{l}\text { Change orders by } \\
\text { owner during } \\
\text { construction }\end{array}$ & $\begin{array}{l}\text { Change in order by the owner can be managed by putting in place an effective scope management (Park and } \\
\text { Pena-Mora, 2003), and project techniques and tools such as project integrated change control, management plan, } \\
\text { project charter, and enterprise environmental factors (e.g., organisation culture, infrastructure, market conditions } \\
\text { and administration of personnel) can be used to manage the project scope (PMI, 2017). } \\
\text { Effective scope management (Park and Pena-Mora, 2003). } \\
\text { PM tools such as project integrated change control, management plan, project charter, enterprise environmental } \\
\text { factors (e.g., organisation culture, infrastructure, market conditions and administration of personnel) can be used } \\
\text { to manage the project scope (PMI, 2017). }\end{array}$ \\
\hline Payment delays & $\begin{array}{l}\text { Payment procedures outlined in the contract as per jurisdictional laws. } \\
\text { Flexible system progress payment system. } \\
\text { Payment certificates confirm the work completion and the relevant payments collected. } \\
\text { Sufficient economic resources to release timely payments to sub-contractors (PMI, 2016, p. 131). } \\
\text { Consider payment delays in the scheduling (Sambasivan and Soon, 2007a, p. 521). } \\
\text { Interest on delayed payment clause in the contract and Advance payments (Kaliba et al., 2009, p. 530). }\end{array}$ \\
\hline $\begin{array}{l}\text { Unrealistic project } \\
\text { duration estimates }\end{array}$ & $\begin{array}{l}\text { Hire experienced project management professionals. } \\
\text { Skillsets should include expert judgment, analogous estimation, parametric estimation, bottom-up estimation, } 3- \\
\text { point estimation, reserve analysis, quality cost, project management software, vendor bid analysis and group } \\
\text { decisions (PMI, 2013). }\end{array}$ \\
\hline
\end{tabular}




\subsubsection{Managing Consultant-related Delay Factors}

The expertise and experience of external consultants are regularly required in the execution of major construction projects. Consultants are crucial to the success of construction projects as they are saddled with the responsibility of setting up the stage for emergent activities in a project, and thus, their roles are more focused with laying the foundation for a project (Kadefors, 2004). Given the importance of the role of a consultant, it has been accordingly recommended that for any project, the consultant's previous experience should be well-evaluated before their services are engaged (Berggren et al., 2001). The proficiency of the consultants is crucial for: the development of a project charter, proper direction and management of the project work, and the undertaking of a host of other necessary related activities that are a part of a project (PMI, 2013).

In order to prevent construction delays, there needs to be rapid approvals to scope changes by the consultant. The rationale is that such changes can impact the plan, documents and deliverables of the project (PMI, 2013). One way of minimising construction delays in project scope change approvals by consultants is to hire only experienced and qualified consultants who comprehend the impacts of delays on the performance of the project and possess the ability to use PM tools and techniques to effectively handle changes (Berggren et al., 2001; Albogamy et al., 2013).

Table 3.4 offers a summary of actions that could be used to manage consultant-related issues, as identified in the literature to be influencing the construction delays in the KSA. The delay factors attributed to the client include unrealistic project duration estimates; change orders; slow decisionmaking process; and delay to furnish and deliver the site to the contractor. 
Table 3.4 Recommended actions for consultant-related delay factor

\begin{tabular}{|c|c|}
\hline Consultant-related Factors & Recommended Actions \\
\hline Delay in approving design drawings & $\begin{array}{l}\text { This delay can be addressed by having a sound PM plan (PMI, 2013). Such plan should } \\
\text { incorporate strict timelines within which design drawings must be approved (Berggren } \\
\text { et al., 2001). Also, effective communication across all parties involved in a project can } \\
\text { prevent delays in getting approvals for design drawings (Albogamy et al., 2013). }\end{array}$ \\
\hline $\begin{array}{l}\text { Unclear and inadequate details in design } \\
\text { drawings }\end{array}$ & $\begin{array}{l}\text { This delay issue can be managed by facilitating corporation and effective } \\
\text { communication between the design teams and other relevant stakeholders to ensure that } \\
\text { all details in design drawings are captured (Hendrickson and Au, 2000). Having a } \\
\text { sound PM plan can provide all important information that should be fed into the design } \\
\text { drawings (PMI, 2013). }\end{array}$ \\
\hline $\begin{array}{l}\text { Poor qualifications of supervisory staff of the } \\
\text { consultant staff }\end{array}$ & $\begin{array}{l}\text { Consultants should hire qualified staff to supervise the work (PMI, 2013). For example, } \\
\text { staff with knowledge of processes of construction projects should be employed. The } \\
\text { consultant's staff should be put through ongoing training to enhance their capacity and } \\
\text { enrich their skills for better performance (PMI, 2013). }\end{array}$ \\
\hline
\end{tabular}




\subsubsection{Managing General management and external-related factors}

General management and external-related factors include a lack of communication between all project parties, contracts to the lowest bidder system and shortage of qualified manpower. The third most crucial factor which leads to a failure of construction projects in the Kingdom is poor communication management, clearly demonstrating the significance of communication between the various stakeholders (such as clients, contractors, sub-contractors, clients, government agencies) in deciding the failure or success of the project. Failing to establish clear communication channels between the different project stakeholders is an open invitation for disaster, which could arise from misunderstandings and this can lead to the consequent failure of construction projects (Ikediashi et.al. 2014).

A robust project management plan that includes a communication management plan and communications control strategy could be applied for managing communication aspects that cause delays. Communication matrix toolsets can also be used for this purpose. Public construction projects in the Kingdom could make use of these toolsets to effectively mitigate the impact of the delay factors (Alotaibi et al., 2016).

During the various phases of the project, vital data is collected, generated and distributed between the project stakeholders. There should be prior agreement between the stakeholders on the communication protocols and reporting standards to be used. The communication should be comprehensive at various levels, taking into account the cultural diversity of the audience. Productive communication must be encouraged at project meetings, along with inter-group communication. Communication protocols for handling change orders, instructions, Request For Information (RFI) and variation requests for construction projects must be established in the contract. Efficient communication can be provided by making use of Information and Communication Technology (ICT). An integrated management approach is essential for managing project documentation, with an agreement from the different stakeholders (PMI, 2016, pp. 89-98). 


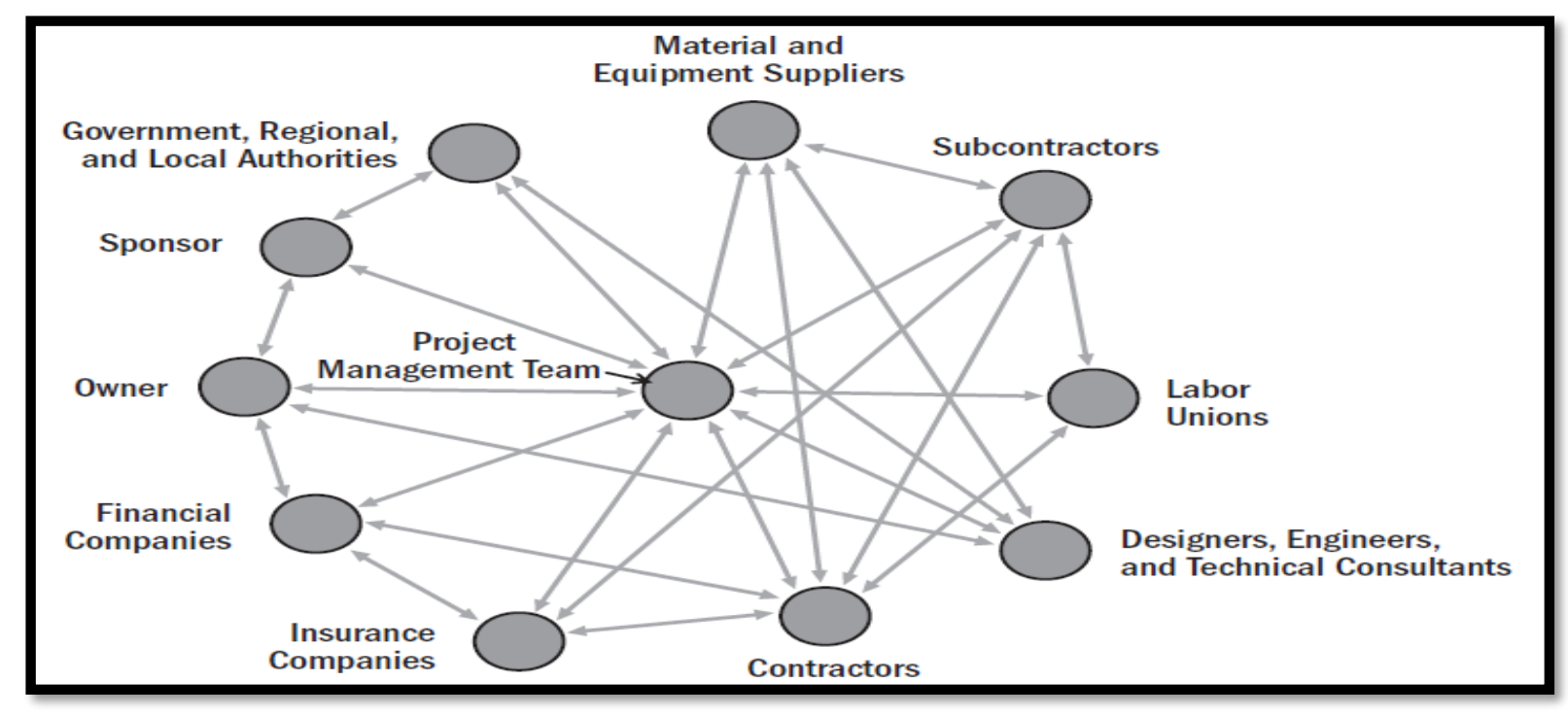

Figure 3.7 Illustration of Construction Communication Network (PMI, 2016, p. 91)

An inefficient procurement system is another major contributor of delays and poor performance in construction projects in the KSA. Studies have established that the vendors and contractors who have been awarded the contract on the basis of lowest tender submitted, were unqualified and performed poorly (Assaf and Al-Hejji, 2006: Albogamy et al., 2013). In their recent study, Alofi and Kashiwagi (2017) found that the lowest bid system practised by the procurement process in the Kingdom was a significant risk factor which had an impact on the performance of projects (Alofi and Kashiwagi, 2017). The selection of contractors can be improved by applying selection criteria such as pre-qualifications, past experience and past performance.

Table 3.5 offers a summary of actions that could be used to manage issues caused by general management and external-related factors, as identified by the literature review. The delay could be caused by poor communication between project stakeholders, a shortage of skilled/qualified manpower, the system of awarding contracts to the lowest bidder, as well as a change in the prices of materials and resources during the construction phase. 
Table 3.5 Recommended actions for General management and external-related factors

\begin{tabular}{|c|c|}
\hline $\begin{array}{l}\text { General management and } \\
\text { external- related factors }\end{array}$ & Recommended Actions \\
\hline $\begin{array}{l}\text { Lack of communication } \\
\text { between all project parties }\end{array}$ & $\begin{array}{l}\text { Robust channels of communications must be established and maintained between the different stakeholders of } \\
\text { the project at the planning stage. These communication channels must be closely monitored for organisational } \\
\text { and personnel changes and modifications should accordingly be made (PMI, 2016, p. 140; Sambasivan and } \\
\text { Soon, 2007a, pp. 524-525). } \\
\text { A robust PMP contains a communication management plan and controlling communications strategy. Tools } \\
\text { used involve the communications matrix. The KSA public construction sector could deploy these approaches } \\
\text { to better mitigate the impact caused by such factor. }\end{array}$ \\
\hline $\begin{array}{l}\text { Shortage of qualified } \\
\text { manpower }\end{array}$ & $\begin{array}{l}\text { Project Human Resources Management is recommended as a solution to review the manpower involved in a } \\
\text { project. This will be used to allocate qualified workers to the projects. }\end{array}$ \\
\hline $\begin{array}{l}\text { Contracts to the lowest } \\
\text { bidder system }\end{array}$ & $\begin{array}{l}\text { Attention to detail should not be over-looked while selecting the lowest bidder. The bid price must be compared } \\
\text { to an independent estimate, to check the variance and to make a judgement as to whether the contractor will be } \\
\text { able to complete the contract at the price he has bid for (PMI, 2016, p. 127). There must be a stringent pre- } \\
\text { qualification standards criteria against which the bidders must be evaluated before the contacts are awarded } \\
\text { (Mahamid et al., 2011, p. 308). } \\
\text { Contractors' selection criteria could be adopted to better overcome this matter. The suggested criteria to assess } \\
\text { are past performance and prequalification. }\end{array}$ \\
\hline $\begin{array}{l}\text { Changes in material and } \\
\text { resource prices during } \\
\text { construction }\end{array}$ & $\begin{array}{l}\text { The applications of project risk management and project procurement management where risk management } \\
\text { procedure involves strategies that could address this matter. The tools used are bidder conferences, techniques } \\
\text { of evaluating proposals, independent estimation, expert judgment, advertising, analytical techniques and } \\
\text { procurement negotiations (PMI, 2013). Also, project risk management plan, contingency and cost change } \\
\text { control can act as suggested strategies. }\end{array}$ \\
\hline
\end{tabular}




\subsection{Summary}

Construction delays are frequent in the KSA. It is believed that a continuous experience of this problem across construction projects in the country might be due to an ineffective use of appropriate PM techniques and tools. Already, research has indicated that PM practice is comparatively new in the KSA and construction practitioners are still reluctant to fully utilise it. Therefore, it is important to highlight that project management tools and techniques can be useful in driving construction project execution, as it helps to manage prevalent delays in the KSA. Consequently, this chapter reviewed the literature discussing the essence of PM techniques and tools in the execution of construction projects. It provided information regarding existing PM standards, techniques and tools that are potentially useful for addressing the problem of construction delays in the Kingdom of Saudi Arabia.

The chapter commenced by presenting background information about the existing PM standards from four different PM bodies. Also, the PM techniques and tools that could be used to manage construction are identified. Thereafter, the importance of these PM standards, tools, and techniques in managing construction delays is provided. Within this chapter, the current use of PM standards, tools, and techniques in the execution of construction projects in the KSA is examined. Lastly, the guidelines in relation to the PM standards, tools, and techniques for managing construction delays recommend that the promotion of the use of PM techniques and tools can minimise the risks of construction delays in the KSA.

In the next chapter of this thesis, the research methodology that has been selected to achieve the purpose of this investigation is fully discussed. 


\section{CHAPTER 4}

\section{RESEARCH METHODOLOGY}

\subsection{Introduction}

The last two chapters have identified the delay factors in construction projects and PM-based tools and techniques that could be used to manage them in the Kingdom of Saudi Arabia. This current chapter incorporates information regarding the adopted philosophy and methodology for addressing the aim and objectives of this study. The research philosophy and its influences on the methods adopted for this study are explained. Likewise, within the section on methodology, details about the study design, as well as the data collection instruments, interviews and survey, are offered. Lastly, ethical considerations in the research are also discussed.

\subsection{Research Philosophy}

The conduct of the investigation is guided by the systems which aim to generate and interpret the claims about knowledge regarding the studied reality (Myers, 2009). However, there is typically an underlying philosophy or paradigm (i.e., set of beliefs for defining a reality) that guide the process of inquiry in a research involving a group of individuals within a particular time (Mertens, 2014). Several definitions have been attributed to research philosophy. Mertens $(2014$, p.8) defines the concept as "a way of looking at the world". Denzin and Lincoln (1994) explain a philosophy as a core set of beliefs that shape any investigative or research action. These beliefs, according to Denzin and Lincoln (1994) are fundamental as they have to be accepted on faith or at face value, since there is no concrete way of ascertaining their complete truthfulness. Also, Gliner and Morgan (2000, p. 17) refer to philosophy as "a way of thinking about and conducting a research. It is not strictly a methodology, but more of a philosophy that guides how the research is to be conducted". One way of describing the type of research philosophy or paradigm is illustrated by Saunders et al. (2011) via the research onion (as shown in Figure 4.1). 


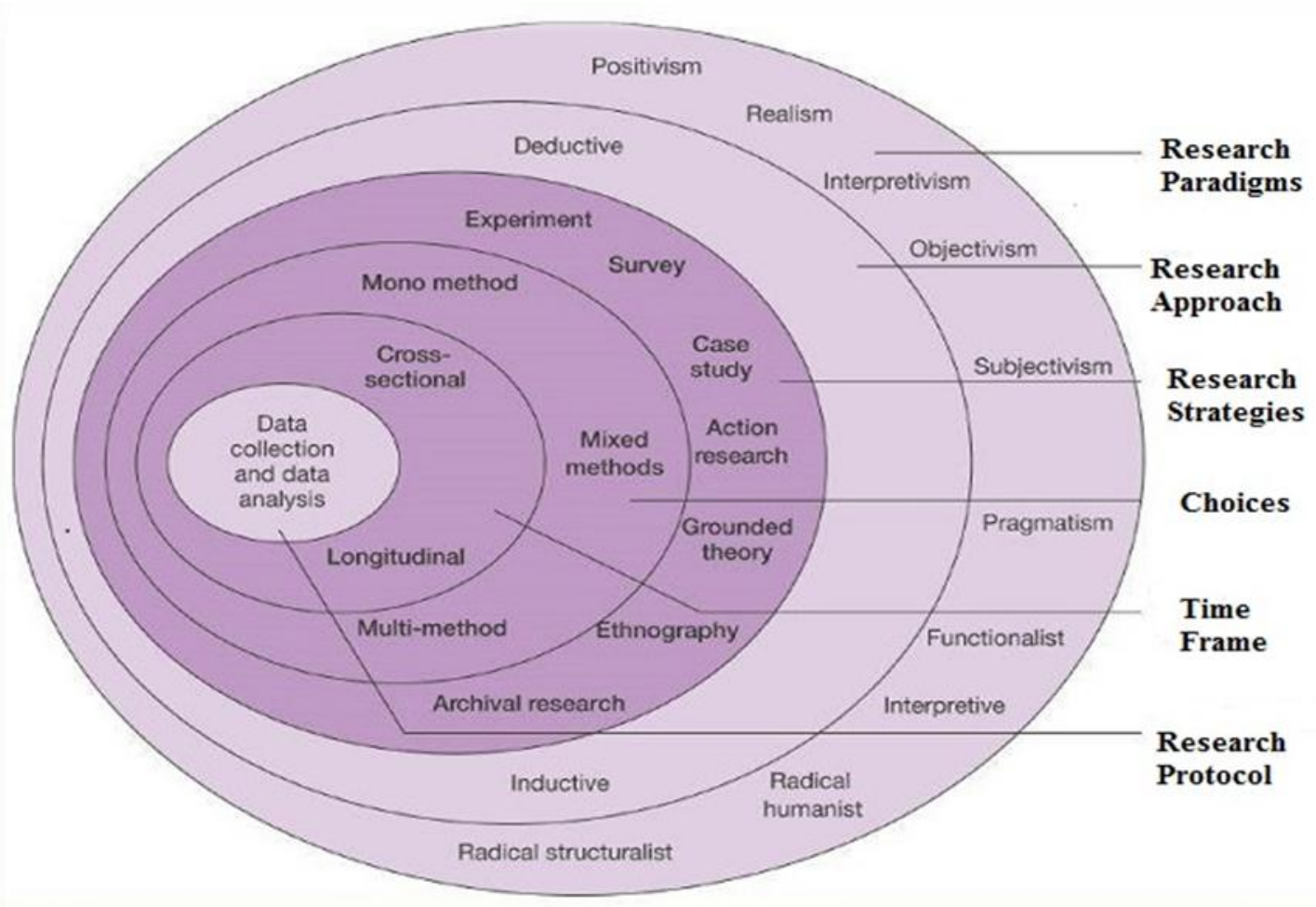

Figure 4.1 Research onion (Saunders et al., 2011)

\subsection{Philosophical Stances}

Five broad positions of the research paradigm have been identified in the literature. They are ontology, epistemological, axiology, rhetoric, and methodology (Sutrisna, 2009; Bryman, 2012). The questions that relate to the five stances include, "What is the nature of reality? What is the relationship of the researcher to that researched? What is the role of values? What is the language of research? What is the process of research?". These five questions define ontology, epistemological, axiology, rhetoric and methodology respectively. Figure 4.2 represents the key elements of research philosophies or paradigms. Sutrisna (2009) and Bryman (2012) emphasise that only two elements of research philosophy, namely ontology and epistemology, are the most necessary. Thus, these two aspects of philosophy are discussed in this section. 


\section{Research Paradigms or Philosophies}

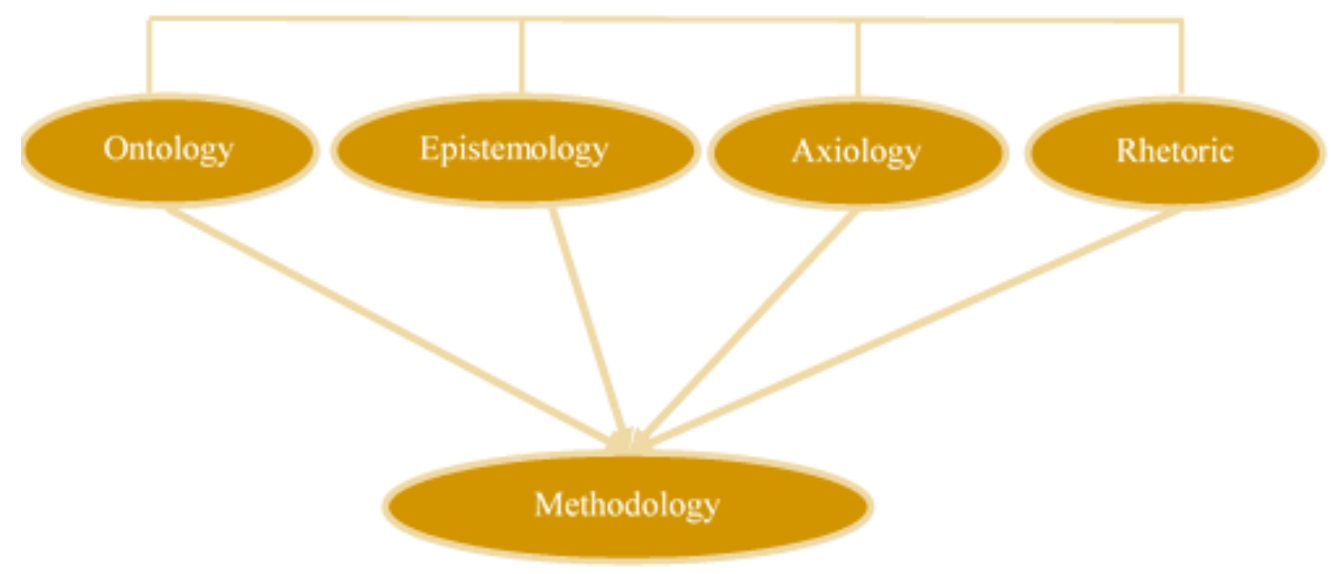

Figure 4.2 Key elements of research paradigms (Adapted from Easterby-Smith et al., 2012)

\subsubsection{Ontology}

Ontology has been defined as a collection of assumptions that underlie our understanding of the real nature or existence of the universe (Easterby-Smith et al., 2012). Ontology raises questions such as, "What is the nature of social reality?". To answer this question, philosophical assumptions are to be made about "What exists? What it looks like? What units make it up? How do these units interact with each other?" (Blaikie, 2007). Any researcher will answer the ontological question decisively through the two philosophies of either foundationalism or anti-foundationalism. The philosophy of foundationalism or essentialism contends that every proposition needs to be justified with concrete reasons and the reasons must also be validated (Blackburn, 2008; O'Brien, 2006). However, the philosophy of anti-foundationalism or anti-essentialism is based on the argument that there is no justification required for any proposition or inquiry (O'Brien, 2006).

As such, the worldview of every researcher is affected by ontological assumptions. These positions influence what the researcher believes to be real and the reasons that are attributed to such a reality. It is, therefore, significant that researchers should identify ontological assumptions underpinning their studies. Otherwise, we may not be aware of certain areas of the inquiry since the assumption is implicitly made and as such, no deliberation permitted. There are two broad ontological perspectives: realist (objectivist) and relativist (subjectivist) (Blaikie, 2007; Miller, 2016). 
Realist ontology supports a notion that social or natural facts exist without being influenced by human action or interference and that they can be objectively assessed by demarcating personal prejudice using appropriate methodology (Blaikie, 2007; Ramey and Grubb, 2009). On the other hand, relativist ontology is about the perspective that knowledge emerges from the personal point of view in which a reality is relative to another (Zimmermann, 2007; Raskin, 2008). In other words, a relativist disposition indicates that the external world or social reality is shaped by our worldview or opinion (Blaikie, 2007).

The ontological positions are determined by either subjectivism or objectivism (Hatch and Cunliffe, 2006). Subjectivism suggests that reality exists only by experiencing it. On the other hand, objectivism proposes that reality is not dependent on those who experience it. This research is based on both subjective and objective ontologies because the two prisms are required to formulate a research outcome that is balanced (Cocchiarella, 2007). Although various opinions exist as to what a reality is, the question about how it is measured remains critical. Also, another query regarding the existing knowledge about reality arises, thus leading to questions regarding epistemology.

\subsubsection{Epistemology}

The term 'epistemology' originates from the two Greek words, 'episteme' and 'logos', which mean knowledge and rational explanation respectively (Horner, 2000). While ontological philosophies are employed to establish the nature of the reality of the universe, epistemology examines world views about the methods of making an inquiry into the nature of existence of the world (EasterbySmith et al., 2012). According to Blaikie (2007), epistemology offers theoretical backgrounds for identifying the nature of knowledge that can be known and the conditions for assessing its adequacy and legitimacy. Epistemological positions are generally informed by the ontological assumptions (i.e., both are interdependent of each other) (Hatch and Cunliffe, 2006). This is explained by the notion that the philosophy of the reality of world, including knowledge, is required to form a theory about the ways of knowing the nature of existence.

The ontological positions held by any researcher influence the epistemological positions adopted. As with the case of ontology, the determination of reality in epistemology is also expressed through objectivism or realism and subjectivism or relativism (Hatch and Cunliffe, 2006). This study has 
adopted both objective and subjective epistemology. Objectivism in epistemology suggests that the existence of knowledge is external and the theory is neutral to the researcher, while subjectivism assumes that the world does not exist beyond the investigator's observations and interpretations (Eriksson and Kovalainen, 2008). The status of the world that emerges from epistemological positions can be categorised into absolute, tentative, relative, or pragmatic (Blaikie, 2007; Norton, 1997). Absolutist epistemology perspectives are categorised into empiricism and rationalism. Also, tentative perspectives are classified into falsificationism and critical realism. Relative or pragmatic notions can be based on either constructionism or pragmatic conventionalism.

Empiricism and Rationalism: Empiricism is founded on the philosophy that absolute knowledge can be produced. According to Blaikie (2007, p.24), empiricism suggests that "objective facts are arrived at by the direct observation of external reality by the unencumbered use of the human senses." The theory of empiricism asserts that a sound and practical knowledge or reality about a particular subject can only be gained through experience (Markie, 2013). The implication of this epistemology is that reality cannot be deduced by means of reasoning, but only by its actual experience. This can be illustrated by an idiomatic expression, "fact speaks for itself". Empiricism is an exact opposite of rationalism. According to the theory of rationalism, knowledge cannot be gained via experience (Markie, 2013). This school of epistemology suggests that reality can, however, be known by the ability of the researcher to apply universally acceptable and logical principles that can be deduced through mathematics (Blaikie, 2007).

Falsificationism and Critical Realism: Falsificationism asserts that knowledge, in the form of tested theories or hypotheses, is always unverifiable or tentative in order to regard it as scientific (Hansson, 2006). This philosophy is described as an inductive approach in which theories of reality cannot be proved but can be falsified. According to Blaikie (2007), falsificationism suggests that it is impossible to describe reality with any theories, but they can somewhat be applied to disprove reality as far as there are existing data to do so. Critical realism epistemology, on the other hand, is a positivist theory which propounds that the knowledge of structures and mechanisms is invariably tentative and not absolute (Scott, 2005). This is because a researcher's way of seeing and interpreting the world around is influenced by "the effects of language, culture, preconceptions and expectations, and scientific perspectives and theories" (Blaikie, 2007, p.24). Critical realism 
depicts the coexistence of 'intransitive knowledge objects' (entities that exist independently of a person's experience of them) and 'transitive objectives' (whereby a person's theories and experiences are used to produce knowledge); thus the epistemological stance acknowledges the existence of dimensions that are both subjective and objective (Losch, 2009).

Constructionism: Constructionism (also referred to as constructivism) is a theory in epistemology that suggests that the creation of knowledge or reality is based on relative interpretations by humans' cultural and social perspectives (Fosnot, 2013). According to Blaikie (2007), constructionism epistemology produces relevant knowledge in the sense that no true reality except for a relative one is based on different constructions. The standpoint of a constructionist is both practical and relativistic. It propounds that knowledge is constructed by the researchers and not through strict scientific methods, because no single methodology is appropriate (Schwandt, 1994). The main implication of a constructivist viewpoint is that reality does not exist as suggested by the ontological position, but rather it is constructed through a researcher's lenses.

Conventionalism: Conventionalist epistemology is described as "the view that priori truths, logical axioms, or scientific laws have no absolute validity but are disguised conventions representing one of a number of possible alternatives" (Norton 1997, p.121). From the viewpoint of a conventionalist, the veracity status of the philosophies for explaining reality is not consequential but rather, the theories allow the researchers to do what they do (Blaikie, 2007). In other words, the usefulness of the philosophies in manipulating or describing the knowledge of the world is more important than their truth status. For instance, the truthfulness of a perspective about a phenomenon is irrelevant but rather, the focus is on what the standpoint allows us to do. The implication is that the philosophical stance should be applied to do whatever it will enable the researchers to do. Conventionalism is, therefore, pragmatic in nature (Blaikie, 2007).

\subsection{Adopted Philosophical Stance}

The adopted philosophical stance for this study is critical realism. This philosophy intermarries the philosophy of both science and social science (Losch, 2009). While science has been described as positivist-inclined, social science is more suited to the interpretivist approach of conducting research (Blaikie, 2007). The selection of critical realism hinged on its incorporation of the 
characteristics of both subjectivism and objectivism, thereby providing an opportunity to maximise their combined strengths (Losch, 2009). The epistemological position of this study is that the researcher's inputs are critical to creating and constructing sound knowledge within a social and cultural system that is located in a particular time and position. While this investigator recognises the need for the researcher to be actively engaged in deciding the course of any study, there is also a need to incorporate the separate opinions of others, in order to present a balanced reality. Consequently, both quantitative and qualitative (mixed) methodologies have been adopted in this study because they were considered appropriate for addressing the aim and objectives of this study. The application of both methodologies was to ensure the quality and generalisability of the research process and outcome. A full discussion on the two approaches and justifications for selecting both quantitative and qualitative approaches in this research will be discussed thoroughly in the following section.

\subsection{Research Methodology}

Research methodology can be described as the positions adopted with regards to the way or approach of obtaining knowledge scientifically (Gomm, 2004; Kumar, 2010; Walliman, 2006). Walliman (2006) suggests that research methodology performs the following functions:

- It defines the constituents of a research undertaking.

- It captures the research model and by extension, identifies concepts and associated statements of the study.

- It aids in the establishment of methods or techniques to apply in the research, as well as yardsticks for measuring progress and determining success.

- It also outlines the communication strategy for different areas of the research, such as structure and deliverables.

The methodological stance adopted is generally informed by other components of research paradigms which are ontology, epistemology, axiology and rhetoric (Popkewitz, Tabachnick, and Zeichner, 1979). Therefore, the process selected in addressing the aim and objectives of the study are defined by the nature of knowledge, relationship between the researcher and what is known, 
role of values and language of the research. Methodology deals with the question of how the researcher can go about finding knowledge or reality that can be known. In general, the research methodology incorporates information concerning research design and methods, data collection and sampling, data analysis, and data credibility.

\subsection{Research Design and Methods}

The research design defines the study type and clarifies the direction towards obtaining evidence for addressing the inquiry's aim and questions (Kumar, 2010). This research was undertaken as a sequential explanatory study rather than a descriptive one. A typical descriptive study purely describes the phenomena, while an explanatory study seeks to understand the effect of one variable on another (Bryman, 2012). In the sequential explanatory design, qualitative data are collected to explain further findings gathered from the quantitative study (Creswell, 2013; Flick, 2011). The aim and objectives of this study were addressed using data collected through the survey questionnaire and interviews. Also, this research was undertaken as a cross-sectional study rather than a longitudinal one. The latter form of study involves a more-than-once collection of research data and, therefore, could be a very expensive and complicated exercise to manage (Kothari, 2004). The funds and time available for $\mathrm{PhD}$ studies would not have supported the execution of a longitudinal study. The two broad research methods have been identified as quantitative and qualitative.

In the process, the quantitative and qualitative results were summarised by a merger in the form of a discussion. This complies with the convergent design approach suggested by Bryman (2012), where the general structure and the themes/sub-themes of both the survey-questionnaire and interviews were more or less similar. In the process, the quantitative and qualitative results were summarised by a merger in the form of a discussion.

The merged results were compared and interpreted to see the ways and extent to which the qualitative findings were able to expand on the quantitative findings and also, how the merged results answered the research questions. 
Finally, the framework was developed based on the analysis of the data collected from the literature review, questionnaire survey and interviewees. The research design is shown in Figure 4.3. This framework captures all the activities that were undertaken in the research. 


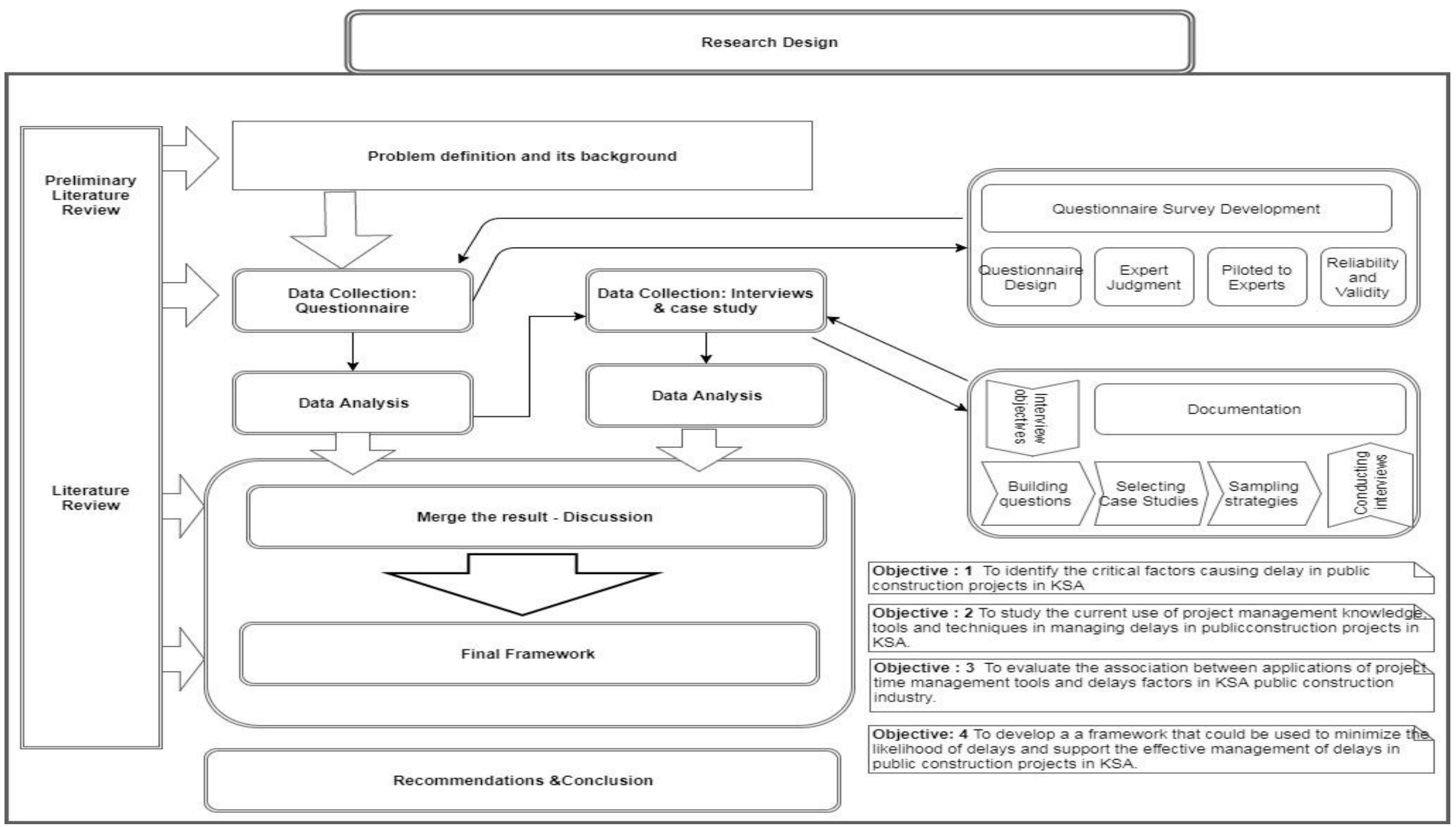

Figure 4.3 Research Design 


\subsubsection{Quantitative Method}

Quantitative research is typically linked to traditional, essentialist, objectivist, positivist, experimental, empiricist, or deductive approaches (Aliaga and Gunderson, 2003; Flick, 2011; Gomm, 2004; Kumar, 2010). Quantitative methods typically involve the collection of quantifiable data to describe a specific situation or occurrence scientifically (Kumar, 2010). According to Aliaga and Gunderson (2003, p. 208), the underlying idea of this approach is "explaining phenomena by collecting numerical data that are analysed using mathematically based methods". The main work in this research method is the ability to separate data, count and then model them statistically (Kumar, 2010). The significance of this method is that it describes, as well as examines the relationships between variables, and determines the cause and effect of the connections between them (Robson, 2011). This research approach relies on measurement; as such, it highly depends on the ability of the researcher to identify the variables and measure them (Creswell, 2013). The failure in defining appropriate variables will affect the accuracy of the study findings (Neuman, 2006). For the outcome of the study to be reliable, the set of measurements or measurement instrument must be correct (Ackermann and Hartman, 2000).

The quantitative methodology focuses on grouping data according to their distinct features, numbering them, and constructing statistical models as a way of interpreting what is observed (Babbie, 2012). The main characteristics of quantitative methodology, as stated by Babbie (2012) are:

- Data is collected using instruments that are more structured.

- Outcomes are usually based on larger sample sizes than normally used in qualitative.

- Due to typically large sample sizes, the research findings are considered more reliable and generalisable to the wider research population.

- Researcher has a clearly defined research questions that require objective answers.

- All aspects of the study are carefully designed before data are collected.

- Data are in numerical form and therefore suitable for statistical analysis.

- The project can be used to generalise concepts more widely, predict future results, or investigate. 
- Questionnaires are the most popular instrument for collecting numerical data for the quantitative study.

Several attributes have been credited to the underlying idea of quantitative methods. The guiding theories of the method makes it the most appropriate approach to use when large quantities of data are to be collected and analysed (Kaplan, 2004). This method is also considered to be more objective than the qualitative approach because the result is usually quantifiable and relatively independent of the researcher (Kumar, 2010). Since the data generated in this method is numerical and considered objective, it can be generalised to a larger population (Neuman, 2006). Another positive point of this method is that the data collected can be easily compiled onto a chart or graph since they are numerical, thereby providing a clear interpretation of the research findings (Walliman, 2006). Also, data analysis in this method is comparatively more straightforward and time-consuming as it is usually analysed using statistical software (Christensen and Johnson, 2004).

The central issue with the use of this method is inflexibility. For instance, the questions and responses are fixed without any option of probing the respondents further (Punch, 2013). Also, since the researcher has no role in the further interpretation of questions to the respondents, there could be mistakes on the part of the participants that could affect the reliability of the research findings. In addition, this method is regarded as more expensive to use than the qualitative method since it requires the use of statistical software that may be costly (Kumar, 2010). Furthermore, survey or written questionnaires, which are usually the instrument of collecting data in this methodology, may be difficult for some participants to fully understand and may not provide all the needed information for correct interpretations of data findings, due to either inappropriate wording of the questionnaires or a total lack of comprehension of questions by the participants (Gill and Johnson, 2002).

Generally, quantitative methodology is more suitable for research that will employ 'science of numbers' or a large amount of data to formulate meaning about the nature of specific phenomena (Mertens, 2014). The choice of adopting quantitative methods is typically argued to be appropriate when the ontological position is founded on essentialism or foundationalism principles. Therefore, quantitative research is typically considered in line with objectivist epistemology, in which the researcher is independent of the outcome of the research. 


\subsubsection{Qualitative Method}

Qualitative methodology is typically linked to constructivist, relativist, naturalistic, phenomenal, experimental, interpretive, post-positivist, postmodern, or inductive methods (Kothari, 2004; Kumar, 2010; Welman; Kruger, and Mitchell, 2005). In qualitative methods, experiences of the participants are captured in words and actions and are described in a narrative or descriptive manner to explain the phenomenon being studied (Maykut and Morehouse, 1994). This method generally involves the researcher undertaking a subjective assessment of expressions, thoughts, attitudes and suggestions offered by the participants. The outcome of the qualitative method is based on the impressions and insights of the investigator (Creswell, 2013). The implication is that the qualitative method is regarded as how the researcher views and interprets the opinions and perceptions gained from participants' experiences to explain or define a phenomenon. In which case, social phenomenon is understood or interpreted by the researcher from the perspectives of the participants.

The primary aim of a qualitative method is to provide answers to questions regarding a concept such as 'what', 'how' or 'why', instead of 'how many' or 'how much', which are more appropriately answered by the quantitative method (Myers, 2009). In keeping with the aim of the methodology, the data collection process is geared towards describing problems, behaviours or events, as well as providing narrative descriptions of people's thoughts and opinions about their experiences, attitudes, and beliefs (Sofaer, 2002). Consequently, data collection techniques usually employed in this research methodology are in-depth interviews, semi-structured interviews, focus group interviews, participant or non-participant observation, ethnographic fieldwork, and project techniques (Denzin, 2009).

The major strength of qualitative research is its ability to provide complex textual descriptions of how people experience a particular research issue (Eriksson and Kovalainen, 2008). It highlights information about the 'human' side of an issue - that is, the often opposing behaviours, principles, ideas, emotions, and relationships of individuals (Denzin and Lincoln, 2000). Generally, qualitative methodology is believed to stimulate a deeper understanding of a research problem as compared to quantitative, particularly when not much is known about the phenomenon (Gill et al., 2008). As with everything that has good sides, certain weaknesses have been attributed to the qualitative method. One of the common reservations against this method is that the samples are usually small and may not adequately represent the opinions of the larger population, so the results achieved through this methodology may not be 
generalisable (Polit and Beck, 2010). Also, the research findings through the qualitative approach are generally regarded as lacking in rigour, unlike in the quantitative methodology, where the outcomes are deduced rigorously through statistical analysis (Robson, 2011). Data gathered in the qualitative methodology are typically more subjective than those in the quantitative approach and can therefore be too hard to generalise and compare systematically (Bogdan and Biklen, 1998).

In sum, qualitative research is appropriate when a valid and cognitive means of understanding people's experience is required in order to develop an understanding about the nature of phenomena (Schwandt, 2007). The choice of qualitative methodology is typical if the ontological position is based on non-essentialism or anti-foundationalism principles. In addition, qualitative research is in line with subjectivist epistemology, in which the researcher shapes the outcome of what is being researched.

\subsubsection{Adopted Research Method and Justification}

This research was conducted using a mixed methods approach, which involves the combination of two or more study strategies (Creswell, 2013). Research in construction management has been undertaken mainly through three methods namely quantitative, qualitative and mixed methods. Studies that have employed these three methods include Chan et al. (2004); Koushki et al. (2005); Olander and Landin (2005); and Assaf and Al-Hejji (2006). For example, Chan et al. (2004) conducted a quantitative research involving the administration of a postal survey to explore the potential critical success factors for partnering construction projects within the context of Hong Kong. Koushki et al. (2005) undertook a qualitative study by interviewing 450 owners and developers of private residential projects in the metropolitan of Kuwait to determine the factors contributing to delays and cost increases in these projects. The same approach was employed by Olander and Landin (2005), using case study analysis to evaluate the influence of stakeholders in the execution of construction projects. Although all three studies mentioned above have utilised a single research approach, however, authors such as Creed et al. (2010), as well as Park and Papadopoulou (2012) combined two or more research methods.

The mixed methods approach incorporates techniques associated with qualitative and quantitative studies, which can be combined sequentially or concurrently (Creswell and Plano 
Clark, 2007). The importance of mixed methods has been underscored in the literature. Robson (2011) identifies the benefits of mixed methods to include:

- “Triangulation": This research approach allows for greater corroboration between qualitative and quantitative data, which improves the results' validity.

- "Completeness": Mixed methods helps generate a more holistic, comprehensive, and complete picture of the research subject.

- “Offsetting weaknesses and providing stronger inferences": By combining two or more research methods, the limitations of each research approach on its own can be neutralised, while the shared strengths can be amplified. This results in stronger inferences.

- “Answering different research questions": Designs that use multiple approaches have the capacity to address a broader range of research questions than possible, as compared to when only one method is used.

- "Ability to deal with complex phenomena and situations": Combining different research methods is particularly beneficial in real world settings because phenomena in such settings are often quite complex and a variety of perspectives need to be considered.

- "Explaining findings": Each different research method can be used to describe the data generated by the other approach - i.e., results from the quantitative survey can be explained more thoroughly by interviewing a proportion of those sampled. This is especially useful in the cases where unexpected or abnormal results are found.

- "Illustration of data": Qualitative data can be used further to shed light on quantitative findings, helping to draw a bigger and better picture of the phenomenon being investigated. This was colloquially referred to as, "putting the meat on the bones", on the lean quantitative data by Bryman (2006).

- "Refining research questions (hypothesis development and testing)": The qualitative phase in a research project can be used to assist in developing the theory better, or refining issues which set them up to be better tested when it comes to the quantitative phase afterwards. 
- "Instrument development and testing": The qualitative phase in a research project can assist in generating items such as a test, scale, or questionnaire, that can be used in the quantitative phase.

- "Attracting funding for a project": Institutions that fund research projects are demonstrating greater and increased interest in interdisciplinary research that collaborates different disciplines which, traditionally, uses differing methods.

This research was founded on both inductive and deductive reasoning. Inductive reasoning is based on contextual observations and assessments of a research problem in order to develop some broad conclusions about it (Axelrod and Tesfatsion, 2006). Inductive reasoning is sometimes referred to as a bottom-up approach to investigating a phenomenon (Minnameier, 2010). Contrastingly, deductive reasoning is a top-down approach to investigating a problem by looking at it from a more general aspect and then narrowing it down to a specific issue (Axelrod and Tesfatsion, 2006). In this study, the quantitative (survey) research was based on deductive reasoning involving the investigation of the delay problem from a general understanding of the issue. The results obtained from the survey study were utilised to support deductive reasoning, taking into account the findings from an extensive review of existing literature on construction delays globally and within the context of Saudi Arabia, as well as exploring potential PM tools and techniques. The literature review study was undertaken to develop an initial or fundamental knowledge about the problem. Subsequently, the case studies were conducted following inductive reasoning, in which the research problem was explored further from specific instances, to form general conclusions about the matter being researched. The findings from both inductive and deductive reasonings were combined to develop a process model that could be used to minimise the likelihood of delays and support the time management performance in public construction projects in the KSA.

\subsection{Data Collection and Sampling}

As both quantitative and qualitative methods to the inquiry were adopted in this research, the data collection methods reflected this. In this instance, different data collection processes were applied as the quantitative and qualitative parts of the research. In keeping with the aim of the qualitative method, the data collection process is geared towards describing problems, behaviours or events, as well as providing narrative descriptions of people's thoughts and 
opinions about their experiences, attitudes, and beliefs (Sofaer, 2002). Consequently, data collection procedures usually employed in this form of research are in-depth interviews, semistructured interviews, focus group interviews, participant or non-participant observation, ethnographic fieldwork, and project techniques (Denzin, 2009). Unlike its qualitative counterpart, quantitative study aims to interpret problems using numerical data, which are collected mostly using questionnaire survey, which allows them to be analysed statistically (Robson, 2011). Apart from the data collection method, a sampling technique is equally essential for the reliability and validity of the research's findings (Kothari, 2004).

\subsubsection{Questionnaire Development}

The questionnaire was developed specifically to address the research aim and objectives. The questions contained in the questionnaire were generated after undertaking an exhaustive review of the existing literature. The purpose of the survey was to gather empirical evidence regarding the factors that contributed to the occurrence of delays, as well as the application of PM tools and techniques in the past public projects executed for the Saudi Arabian governments at provincial and federal levels. Therefore, the focus of the questionnaire was to generate specific issues identified by the respondents as relating to delays and the use of PM tools and techniques in the projects identified by them.

The questionnaire (Appendix 1) consisted of mostly closed-ended questions. The questionnaire was developed mainly using the Likert Scale that ranks from 1 to 5. Both nominal and ratio data were applied to questions relating to respondents' demographics and background of the projects identified to have experienced delays. In addition, the Likert Scale was used to determine the PM practice and use of PM tools and techniques in the delayed projects. So overall, there were five sections to the questionnaire based on the objectives of this study and information obtained from the literature. They include:

1. Demographic

2. Background Information

3. Delay Factors

4. Project Management Practice

5. Project Management Tools and Techniques

The first section of the questionnaire focused on the demographics of the respondents. Therefore, this part asked questions relating to the respondents' organisational type, their roles, 
years of experience within the KSA's public construction projects, their level of education, and their usual type of projects in the last decade, among others. The primary benefit of this section was that it helped to establish the significance, reliability, and representativeness of the information provided by respondents for the remaining parts of the questionnaire.

The second section of the questionnaire served the purpose of gathering the initial information regarding the delayed projects, which formed the basis of answers provided by the respondents. The closed-ended questions were used throughout this section to ensure the uniformity of data gathered, so that standard measurement could be applied. Some of the questions posed to respondents in this part include those relating to the magnitude of delays experienced, and the frequency of delays they have encountered in their projects within the last ten years.

Section three of the questionnaire attempted to elicit information regarding the critical factors identified by the survey respondents as influencing delays in the projects they have been involved with. This section addressed one of the primary objectives of this study. Essentially, respondents (representing clients, consultants, and contractors) were asked questions to indicate their level of agreement (on a 5-point Likert Scale, ranging from strongly disagree to strongly agree) towards several statements that relate to issues they perceived as contributing to the occurrence of delays in construction projects. These factors were categorised as relating to client, consultant, and contractor respectively.

Sections four and five were based on questions that aimed to address PM practices, as well as tools and techniques in the delayed public construction projects. Fundamentally, the questions sought to determine the respondents' opinions regarding if PM tools and techniques could be used to mitigate the occurrence of delays in public construction projects. Also, the current scope of the application of PM tools and techniques, as well as software packages in the construction industry in the KSA was also incorporated into questions posed to respondents in these parts. The questions in these sections were also measured using the 5-point Likert Scale.

\subsubsection{Data Collection and Sampling in Quantitative Study}

The quantitative study commenced with the administration of a pilot survey to 20 construction experts within the construction industry in the KSA. The pilot study was aimed to evaluate the designed questions and improve upon them, where necessary, prior to them being used in the main survey research (van Teijlingen and Hundley, 2001). Further information about the participants in the pilot study is provided in Section 5.2. The quantitative study was conducted 
to address the first three of the research objectives, which are: to identify the critical factors causing delays in construction projects in the KSA and their relative importance; to study the current use of PM knowledge, tools and techniques in managing delays in public construction projects in the KSA; and to evaluate the association between the application of project time management tools and incidence of project delays in the KSA's public construction industry.

The main quantitative data were collected through a survey that was conducted via an online platform, thereby making it easy for the respondents to participate anywhere, and at their convenient time, subject to internet access (Dillman, 2011). Considering the busy work schedules of the targeted population, an online survey was determined as being more appropriate to ensure a high rate of participation. In addition, the responses gathered through an online survey can be collected and analysed more conveniently as they are already electronically available, unlike those conducted over the phone or through postal mails analysis, which would need to be input electronically first before being analysed (Dillman, 2011). The first part of the survey presented the background information about the research activity including its aim and objectives, as well as statements regarding the rights of the participants and steps taken to protect their privacy, as well as the anonymity of their participation in the survey. The survey questionnaire instrument can be found in Appendix 1.

After setting up the online survey, emails containing the link to the survey were sent to the construction practitioners. Given that a $100 \%$ response rate is unusual, far more than the targeted minimum number of respondents had to be invited (Kline, 2007). Thus, a total of 1200 professionals, comprising 400 each from clients, consultants, and contractors in the KSA's public construction industry were invited to participate in the survey. The criteria for inviting the respondents included their extensive experience in the execution of construction projects, appropriate educational qualifications, membership status with the Ministry of Public Works and the Council of Engineering Authority in the Kingdom of Saudi Arabia. The provided responses online were downloaded and analysed using suitable descriptive and inferential statistical tools.

The population sample for the quantitative study was drawn using the stratified sampling technique. The stratified sampling approach involves the categorisation of the research population into groups known as strata (Ding, Hsieh, Wu, and Pedram, 1996). In this instance, professionals who work for three groups: construction clients, contractors, and consultants, were represented in the sample. To select the participants for each group, the databases from 
the Saudi Council of Engineers, the Council of Saudi Chambers, and the Ministry of Municipal and Rural Affairs in KSA were searched. The search yielded a total of 470 practitioners who are attached to 26 project management offices in different ministries and government departments in the KSA; a total of 806 with contractor organisations; and a total of 580 with consulting companies, overall totalling 1,856 potential respondents, which is then considered as the population. To determine an adequately large sample size, the following equation was applied (Kotrlik and Higgins,2001):

$$
\mathrm{N}=\frac{\mathrm{Z}^{2} \mathrm{P}(1-\mathrm{P})}{\mathrm{C}^{2}}
$$

Where:

$\mathrm{N}=$ Sample Size;

$\mathrm{Z}=\mathrm{Z}$ value (for a standard confidence level of $95 \%$, the $\mathrm{Z}$ value is 1.96 );

$\mathrm{P}=$ Percentage picking a choice in decimal format (here, the value 50\% is expressed as 0.5 );

$\mathrm{C}=$ Margin of Error (here, a margin of error of $10 \%$ will be used, expressed as a value of 0.1 ).

Filling in the variables with the appropriate values:

$\mathrm{N}=\underline{1.96^{2} * 0.5(1-0.5)}=96.04$

$0.1^{2}$

This gave $\mathrm{N} \sim 97$ respondents as the minimum appropriate sample size for this research. From the 1,856 professionals identified from the databases, 400 individuals were selected in each of the categories or strata following simple sampling techniques (i.e., totalling 1,200 respondents). Out of the 1,200 professionals invited to participate in the online survey, 387 of them completed the survey. Of the 387 responses received, eighteen were incomplete, while some gave the exact same value for every question and had to be removed from the main data analysis. In total, 369 responses were considered valid and acceptable for the data analysis.

Re-calculating the margin of error for the 369 samples:

$$
c=\sqrt{\frac{z^{2} p(1-p)}{N}}=\sqrt{\frac{1.96^{2} * 0.5(1-0.5)}{369}}=0.051=5.1 \%
$$




\section{Profile of the Sample Data}

A total of 369 responses were considered valid and acceptable for the data analysis. According to Bagozzi and Yi (2012), a sample of more than 200 has been recommended for Structural Equation Modelling to achieve good results. Table 4.1 presents the basic descriptions of the sample, out of which 95 were from client/owner, 122 from contractor, and 152 from consultant organisations.

Table 4.1 Sample Descriptions of the Survey

\begin{tabular}{lccc}
\hline Sample Groups & $\begin{array}{l}\text { Number of Expected } \\
\text { Sample Responses }\end{array}$ & $\begin{array}{l}\text { Number of Received } \\
\text { Sample Responses }\end{array}$ & Response Rate (\%) \\
\hline Client/Owner & 400 & 95 & 23.75 \\
\hline Contractor & 400 & 122 & 30.50 \\
\hline Consultant & 400 & 152 & 38.00 \\
\hline Total & 1200 & 369 & 30.75 \\
\hline
\end{tabular}

\subsubsection{Data Collection and Sampling in Qualitative Study}

Like the quantitative study undertaken as a part of this research, the qualitative inquiry part was conducted to address the first three objectives of this empirical investigation. The qualitative data for this research were collected using semi-structured interviews based on four case studies. This instrument has been identified as commonly used for exploring a wide range of deeply embedded issues in a research subject (Lincoln, 2009). In this instance, a set of predetermined questions was developed ahead of the interviews, to ensure coverage. However, the interviewees were still allowed to talk outside the pre-set questions, so long as the information was deemed relevant to the concept being researched (Hanson et al., 2011). The interviews were conducted to explore the opinions of professionals in the KSA about issues relating to construction delays in the country.

At the start of interviews, the participants were introduced to the broad research aim and objectives. All the interviews were undertaken face-to-face with the participants, to afford them the chance to talk comprehensively without barriers on the topics under consideration (Polit and Beck, 2010). The plan was to interview all the interested construction practitioners until a saturation point is achieved, in which no new information could be further gathered (Glaser 
and Strauss, 2009). The saturation point was reached in this research after conducting 16 interviews, with no further knowledge provided by the $17^{\text {th }}$ interviewee (Malterud et al., 2016).

The sample of professionals who participated in the semi-structured interviews was selected using a purposive or judgmental sampling technique, where they were selected based on their knowledge on the research topics. In this instance, individuals who participated in the case studies that had experienced delays in the educational sector in the KSA were chosen. As indicated by Berg (1989, p.179), "certain types of individuals or persons displaying certain attributes" are normally selected in purposive sampling.

\subsubsection{Case Studies}

As previously indicated, the qualitative study was generally predicated on four case studies. The case studies were aimed to validate the results obtained in the quantitative study of this research. Luck et al. (2006) describe case studies as exhaustive and detailed investigations into a specific contextual bounded phenomenon undertaken in real world settings. The use of case studies as a strategy for collecting qualitative data is to explore the research area more deeply and meaningfully. To create formal designs suited to case-study style investigations, Yin (2009) recommends the following five elements for case studies: study questions, theoretical framework propositions, identification of a unit of analysis, logical connection between the data to theory, and selected criteria to interpret results. Essentially, case studies are undertaken using the following approaches; (1) documentation; (2) direct observation; (3) interviews; (4) archival records; (5) physical artefacts; and (6) participant-observation (Yin, 2003). Yin (2003) suggests that each of these methods has its own set of pros and cons, and as such, researchers should be cautious in deciding which method is the most suitable to achieve the aims of their study. The data analysis approach for the case studies is described later in Section 4.8.2.

\subsubsection{Selection of Case Studies}

There are several recently completed or ongoing construction projects valued in the billions (US Dollars) across the Kingdom of Saudi Arabia, the country of focus for this study. Some of the ongoing or recently completed projects in the KSA include King Abdullah's US\$27 billion Economic City in Rabigh, the US\$24.4 billion re-development of the Makkah Grand Mosque, King Abdulaziz's US\$7.2 billion International Airport, and the Kingdom's US\$1.23 billion Tower in Jeddah, that is expected to be world's tallest building by the time it is completed. To be able to learn important lessons regarding delays and the impact of using PM tools to address 
the problem projects that were executed, the framework of traditional PM phases (e.g., initiation, planning, construction, monitoring and controlling, and close off) were considered most suitable for this case study. Therefore, government officials in the Ministry of Education in Saudi Arabia were approached to gather relevant information about the construction projects that are currently being executed or have been completed with delays.

The case projects were selected using the purposive sampling method. The selection of appropriate case studies commenced by organising background meetings with the officials within the Ministry of Education in Saudi Arabia, where they were briefed about the aim and objectives of this research. The officials were interested in participating in this study, since they believed that the outcome could help them design policies to prevent delays in their projects in the future. After a series of meetings with the senior officials within the Ministry, four public university-based projects that were recently completed with significant delays in Saudi Arabia were considered most ideal for this study. These selected case projects were appropriate to satisfy the objectives of this research because they experienced critical delays as examined in this thesis.

The details of the contractors and consultants that worked on the four identified projects were collected from the officials of the Ministry of Education during the researcher's interactions with them. The purpose of obtaining the selected projects' contractors and consultants' details, as also explained to the officials, was to enable the researcher to gather personal experience of these participants and compare them as such with the clients (i.e., government officials in this instance). Confidentiality was regarded as paramount through the data collection for the case studies. Therefore, the selected four projects were identified with serial codes: Cases 1, 2, 3, and 4, to ensure that their identities were preserved. The chosen cases are described in Chapter 6. The selected projects are currently being executed or have been completed, as this was necessary to ensure that the participants were fully aware of the issues that contributed to the delays experienced in them.

\subsubsection{Interviewees' Profile}

The issues relating to delays and the application of PM tools and techniques in the case projects were investigated by analysing the available archival documents (i.e., secondary data) and interviews conducted with professionals involved with their execution. The interviewees have worked or are working for at least one of the three main stakeholders in the case projects (owners or clients, contractors, and consultants). The roles of these stakeholders have been 
identified in Table 4.2. To ensure that relevant information was obtained, only those with a significant knowledge of the case projects were interviewed. The interviewees were given ample opportunity to discuss their projects in detail. Accordingly, each interview lasted between 62 and 87 minutes, and they were all digitally recorded with permission from the interviewees.

Table 4.2 presents a profile of the interviewees. It can be noticed from Table 4.2 that there were 16 interviewees and their work roles ranged from supervision, management and consultation to planning. Similarly, Table 6.2 revealed in detail the role of each interviewees in each project, as it can be noticed that the interviewees play three roles including a supervisor, consultant and manager. Therefore, the three groups have in-depth knowledge about the delay issues and application of PM tools and techniques. On the other hand, the relevant project documents are analysed in order to support the information from the interviews. The secondary data included in the analysis includes the 'Project Initiation Report' and 'Project Progress Reports'. Both the interviews and documentary sources provided useful and vital information regarding delay issues and application of PM tools and techniques in the case project.

Table 4.2 Characteristics of the Participants

\begin{tabular}{lll}
\hline Number of participants & & 16 \\
\hline Respondents' work role & Project Supervisor & 4 \\
& Project Manager & 4 \\
& Project Consultant & 4 \\
& Planning Manger & 2 \\
& Construction manager & 2 \\
\hline Respondents' experience in construction projects in the KSA & Min & 6 \\
& Max & 22 \\
& Median & 9.5 \\
\hline
\end{tabular}

Source: Secondary and interview data

The main aims of the interviews were to: (1) identify the critical factors that caused the delays experienced in the case project; (2) examine the application of PM tools and techniques to deal with the delays in Project-1; and (3) find out if there is any link between the application of PM tools and techniques and the delays experienced in the case project. Initially, the interviewsessions revealed that the interviewees have gained tremendous experience in public 
construction projects within the KSA, after being deeply involved in other several projects apart from this one. Thus, their opinions can be trusted as they are experienced and highly skilled professionals. The interviews were semi-structured, with prepared questions used. However, there was flexibility in how the respondents could answer the questions. The Participant Consent Form and Guideline Questions for the interview can be seen in Appendix 2. Some additional questions outside the prepared ones were asked during the exercise. Some indicative questions asked during the interviews were:

- Can you please provide a brief and basic description of the project?

- What is the name of your organisation and what is your role in this project?

- Have you experienced any delays in this project and what factors would you say have contributed to the delays experienced?

- Were there any methodologies, tools and techniques of the management of the project that have been used and implemented? Please specify.

- Do you think these tools and techniques have been or are being used effectively in the project? Why?

- Do you think that the manner in which the tools and techniques are being used/applied have contributed to the delays experienced?

\subsubsection{Unit of Analysis}

A unit of analysis is the main element that forms the basis of analysis being undertaken in research (Bryman, 2015). A unit of analysis can include individuals, groups, organisations, geographical locations (e.g., town, state, and nations), artefacts (articles, books, newspapers, and photos), activity processes, organisational routines, forms of leadership or managerial styles, among others (Pentland and Feldman, 2005; Lewis-Beck, Bryman, and Liao, 2003). Yin (2013) suggests that the identification of a unit of analysis is essential in the case study. In the case study, the units of analysis depend on the scope of the issues being addressed (Yin, 2013).

In this research, the construction projects that were deemed to have experienced delays formed the units of analysis (each delay factor and their influences on the cases were examined). Therefore, the features of these projects were assessed and taken into consideration when drawing conclusions about them. The activities undertaken by the organisations involved in the execution of these projects have directly or indirectly influenced the occurrence of the delays, and as such, these were also units of analysis. To ensure an objective interpretation of the issues addressed in the cases, individuals who have participated in the projects were 
interviewed. These professionals acted as key informants to bring different perspectives to concepts that were difficult to understand literarily. The information provided by them were considered crucial for identifying core actions or decisions that have led to the development of delays in these projects. Throughout the case studies, the key players in the examined projects were engaged via interviews, so as to clarify issues when needed.

\subsubsection{Research Reliability and Validity}

Research reliability and validity are widely accepted terms in quantitative research. They are used to describe the quality of the research (Cohen et al.,2011; Fink 2009). However, its meaning and applicability within qualitative research are still under debate, thereby culminating in the development of various hypotheses and typologies (Onwuegbuzie and Johnson, 2006; Seale, 1999). Nonetheless, a group of studies has attempted to transfer established reliability and validity measures within quantitative research to qualitative ones (LeCompte and Goetz, 1982; Mason, 2002). Also, the research identified and developed unique strategies for establishing reliability and validity within the qualitative study (Guba and Lincoln, 1994; Morse et al., 2008). Onwuegbuzie and Johnson (2006) have argued that assessing reliability and validity in mixed methodology is particularly complex, as a result of this approach integrating the complementary strengths and non-overlying weaknesses of both the quantitative and qualitative aspects.

Research reliability and validity have been described as essential tools of objectivist ontology and epistemology (Winter, 2000). Consequently, they are of great significance in any quantitative research. Reliability is defined as the uniformity of results recorded when a similar instrument is applied to collect the same data repetitively, with the same circumstances and using the subjects (Neuman and Robson, 2004).

For instance, the reliability of a survey questionnaire is assured if the result achieved is the same when the instrument is re-administered repeatedly under the same set of conditions. Essentially, reliability is about the replicability and repeatability of research results with the same instruments and under constant circumstances (Wolf, 1986). Reliability in quantitative research has been broadly categorised into internal and external (test/retest) (Morse et al., 2008). External (test/re-test) reliability assesses the repeatability or replicability of the research results using the same instrument twice (Morse et al., 2008).

Certain steps were taken to ensure both external and internal reliability in the quantitative aspect of this study. They included a firm adherence to the design protocol for the questionnaire 
survey, as well as the administration procedures for the instrument and measurement procedures (De Vos, Delport, Fouché, and Strydom, 2011). The reliability of the questionnaire used in this study was enhanced by piloting it to a selected group of construction industry practitioners. This action was undertaken to receive their feedback regarding the suitability and reliability of the questionnaire in addressing the aim and objectives of this research. All the participants in the pilot study agreed that the questionnaire was suitable and reliable, with only a suggestion that a question be slightly reworded for better clarity. In addition, the internal reliability of the instrument used for the research investigation was assessed using Cronbach's Alpha (Cronbach, 1946). This tool calculates the correlation values of the questions asked in the study and separates them in diverse manners (De Vos et al., 2011).

The following formula was used to compute Cronbach's Alpha:

$\alpha=\frac{N}{N-1}\left(1-\frac{\sum_{i=1}^{N} \sigma_{Y_{i}}^{2}}{\sigma_{X}^{2}}\right)$

where $N$ is the number (items), $\sigma_{X}^{2}$ is the variance of observed total test scores for the sample, and $\sigma_{Y}^{2}$ is the variance of component $i$.

The table below illustrates the results of the reliability analysis that was conducted on the pilot data, demonstrating a Cronbach's Alpha of 0.82, well above the accepted level of reliability. The reliability score given in the below table is for the items of the entire questionnaire.

Table 4.3 Reliability Statistics for the pilot

\begin{tabular}{ll}
\hline Cronbach's Alpha & $\begin{array}{l}\text { Cronbach's Alpha based on standardisation Number of Items } \\
\text { of items }\end{array}$
\end{tabular}

0.82

0.83

61

On the other hand, validity refers to an "integrated evaluative judgment of the degree to which empirical evidence and theoretical rationales support the adequacy and appropriateness of interpretations and actions based on test scores or other modes of assessment" (Messick, 1990, p.1). For instance, the validity of a questionnaire survey is determined by an extent to which it measures the social phenomena it has been designed to assess. Basically, reliability determines 
the replicability of the results, while validity determines the accuracy of the means of measurement (Golafshani, 2003). The content validity of the instrument was determined to ensure that the incorporated questions measured the constructs underlying this research, based on the available evidence found in the literature. The content validity ratio (CVR) was calculated based on the outcome of the pilot study, to measure the content validity of the quantitative instrument. The following formula was used to compute the CVR:

$$
\mathrm{CVR}=\frac{\left(\mathrm{n}_{\mathrm{e}}-\mathrm{N} / 2\right)}{(\mathrm{N} / 2)}=\frac{10-13 / 2}{13 / 2}=0.54
$$

Where $n_{e}$ is the number of pilot study participants who indicated that the questionnaire is essential and $\mathrm{N}$ is the total number of pilot study participants.

The CVR value of +0.54 shows that half of the construction experts piloted rated the instrument to be essential, suggesting its content validity (Wilson et al., 2012). In addition, the face validity of a research instrument (i.e., its representativeness), the questionnaire used in this study, was not only cross-checked by industry experts to ascertain its suitability, but also by the researcher's team of supervisors.

\subsection{Data Analysis}

The data collected by both quantitative and qualitative studies are designed to answer research questions, therefore, they must be analysed and interpreted using appropriate techniques that ensure they provide meaning to the research context. Six data analysis procedures recommended by Creswell and Clark (2011) include: (1) preparing the data analysis; (2) exploring the data; (3) analysing the data; (4) presenting the data analysis; (5) interpreting the results; and (6) validating the data. The data collected in this study were analysed following a recommendation by Creswell and Clark (2011), and using different suitable approaches.

\subsubsection{Approach to Quantitative Data Analysis}

Quantitative data analysis involves inspection, measurement or counting and transformation of the data collected by the researcher, in order to present information that could be used to either validate or invalidate positions and draw conclusions or recommendations about a phenomenon being studied (Bendat and Piersol, 2011). To ensure accuracy and thoroughness, the data gathered from the online questionnaire survey were inferential analysed using partial least 
square structural equation modelling (PLS-SEM) from SMARTPLS software. This analysis technique allows the exploration of relationships among variables and compare groups of data (Hair et al., 2014).

The quantitative data collected underwent also multiple statistical analyses using Statistical Package for the Social Sciences (SPSS) version 20. The choice of SPSS was generally based on its efficiency and ability to manage the analysis of large volumes of data with more accuracy and carefulness than a manual method such as Microsoft Excel (Pallant, 2010).

The descriptive statistics of the data were first created to gain the knowledge of the collected data characteristics. After that, the internal consistency reliability of the data was checked using Cronbach's Alpha, which is an index for determining that various items designed to measure a similar construct produce the same results (George and Mallery, 2003). The descriptive statistics were used as a frame of reference for conducting the inferential analysis. Following the determination of the survey data reliability, the data were inferentially analysed. Inferential analysis enables conclusions to be made about the opinions of a population represented by a sample in the research (Zikmund et al., 2010). In addition, this data analysis method assists in identifying relationships among various variables to draw conclusions about how the research findings address the questions being sought (Punch, 2003). The inferential analyses conducted in this study include: Kruskal-Wallis $(\mathrm{H})$ test; mean ranking; Relative Importance Index (RII); and Structural Equation Modelling (SEM).

The Kruskal-Wallis (H) test, which is sometimes called one-way ANOVA on ranks, is a ranked-based non-parametric test that is used to compare significant differences between two or more groups, either as ordinal or continuous variables, which are independent of each other (Pallant, 2010). For example, the Kruskal-Wallis test was employed to determine if there were significant differences in terms of factors contributing to the occurrence of construction delays, based on the public project type. The formula for the Kruskal-Wallis $(\mathrm{H})$ test is presented below.

$$
H=\frac{12}{n(n+1)} \sum_{i} \frac{R_{i}^{2}}{n_{i}}-3(n+1)
$$

On the other hand, the Relative Importance Index (RII) is used to establish the relative contribution of each predictor variable to the results, considering a particular predictor's direct and combined effects with others (Johnson and LeBreton, 2004). In this current study, for 
example, RII was utilised to rank the importance of each of PM tools and techniques according to the respondents' perceptions. Relative Importance Index (RII) was calculated using the following formula:

$$
R I I=\frac{\sum \mathrm{W}}{\mathrm{A} * \mathrm{~N}}(0 \leq R I I \leq 1)
$$

In the formula above, $\mathrm{W}$ represents the weight allocated to each factor identified by the respondents as contributing to the occurrence of construction delays, ranging from 1 to 5 . Using the Likert scale, where ' 1 ' denotes strongly disagree, while ' 5 ' represents strongly agree. In addition, A signifies the highest weight (which is 5 in this instance), while $\mathrm{N}$ denotes the total number of participants.

Structural Equation Modelling (SEM) is one of the most recent statistical modelling techniques created (Siddiqui et al., 2014). It is considered one of the most powerful tools that allows researchers to define the relationships among unobservable and latent constructs; defining latent variables; as well as conducting correlation regression, path and factor analyses (Richter et al, 2016; Mahmood et al., 2011).

Two methods are generally applied for SEM: factor-based or covariance-based SEM (CBSEM) and composite-based partial least squares SEM (PLS-SEM). These two have differences in terms of statistical methodology applied, requirements and objectives (Richter et al, 2016) (Hair et al., 2011).

CB-SEM "has been widely applied in the field of social science during the past several decades and is still the preferred data analysis method for confirming or rejecting theories through testing of hypothesis" (Wong, 2013). CB-SEM is applied using software packages such as MPLUS, AMOS, EQS, and LISREL.

PLS-SEM is a general methodology for the estimation of relationships in the path models involving latent constructs that are measured indirectly using different indicators (Hulland, 1999). PLS-SEM is majorly focused on analysing and estimating the relationship between the latent variables. This exercise happens with the help of the component-based approach. A component-based approach that is identical to the principal components factor analysis is used by PLS-SEM. PLS-SEM can be acquired in PLS and SMART PLS-Graph (Hair et al., 2014). (Rahman et al., 2013). 
However, soft modelling, as deployed in this thesis, is based on the optimal prediction of the specific structural relationships among the various variables interested (Sosik et al., 2009). For situations involving soft theory, PLS-SEM is better suited as predictive and exploratory requirements are to be satisfied (Sosik et al., 2009). It is also more effective for explaining and analysing complicated relationships between the latent variables and models (Fornell, 1982; Wold, 1985 and Wong, 2013). Since this study deals with such a situation, the choice of PLSSEM is reasonable for conducting the quantitative analysis.

PLS-SEM path modelling has been successfully used in previous studies in construction management fields, as seen in Table 4.4.

Table 4.4 SEM-PLS in previous construction management studies

\begin{tabular}{|c|c|}
\hline Author & Journal Title \\
\hline Rahman et al., (2016) & $\begin{array}{l}\text { Projects Delay Factors of Saudi Arabia } \\
\text { Construction Industry Using PLS-SEM Path } \\
\text { Modelling Approach }\end{array}$ \\
\hline Rahman et al., (2013) & $\begin{array}{l}\text { Application of PLS-SEM to Assess the } \\
\text { Influence of Construction Resources on Cost } \\
\text { Overrun }\end{array}$ \\
\hline Hameed and Abdulrahaman (2014) & $\begin{array}{l}\text { SEM-PLS Analysis of inhibiting Factors of } \\
\text { cost performance for Large Construction } \\
\text { Project in Malaysia: Perspective of Client and } \\
\text { Consultants }\end{array}$ \\
\hline Gde AgungYana et al., (2015) & $\begin{array}{l}\text { Analysis of Factors Affecting Design } \\
\text { Changes in Construction Project with Partial } \\
\text { Least Square (PLS) }\end{array}$ \\
\hline Altarawneh et al., (2018) & $\begin{array}{l}\text { Analysis of Critical Success Factors } \\
\text { Influence on Critical Delays for Water } \\
\text { Infrastructure Construction Projects in the } \\
\text { Abu Dhabi emirate Using PLS-SEM Method }\end{array}$ \\
\hline Omini et al., (2017) & $\begin{array}{l}\text { Project Cost Overrun Management in } \\
\text { Universities Using Partial Least Squares- } \\
\text { Structural Equation Modelling }\end{array}$ \\
\hline
\end{tabular}


SEM-PLS consists of two sub-models: the inner and outer models. The inner model defines the relationship between the dependent and independent latent variables. The inner model defines the linear relationships between the latent variables and provides path coefficients of the model (Mahmood et al., 2011), whereas the outer model specifies the relationships between the latent variables and their observed. "The measurement models include the unidirectional predictive relationships between each latent construct and its associated observed indicators" (Hair et al., 2011). It helps a researcher in defining latent variables, conducting reliability and validity (Mahmood et al., 2011). An assessment of the reliability and validity of the model can be done using either convergent validity and/or discriminant validity. Convergent validity measures the internal consistency, ensuring that the assumed items for measuring certain construct actually measures it and that it is not measuring some other construct. Also, it is to be noted that discriminant validity measures the level to which a given construct is different from the other constructs (Rahman et al.,2013).

SEM model simulation is done by the calculation and assessment of the different parameters with tests of reliability, loading and validity. Henseler et al. (2009) suggest a two-step process involving a separate calculation of the PLS model parameters, by solving for the measurement model, followed by the estimation of the path coefficients of the structural model (Memon and Rahman, 2014).

\section{Initial Measurement Modelling}

The initial measurement model is presented in Figure 4.4. A variable used in constructing structural equation model could either be endogenous or exogenous. An endogenous variable has at least one path which leads to it representing the effect by the other variables. An exogenous variable has all the path arrows pointing outwards and no path leading to it (Wong, 2013). 


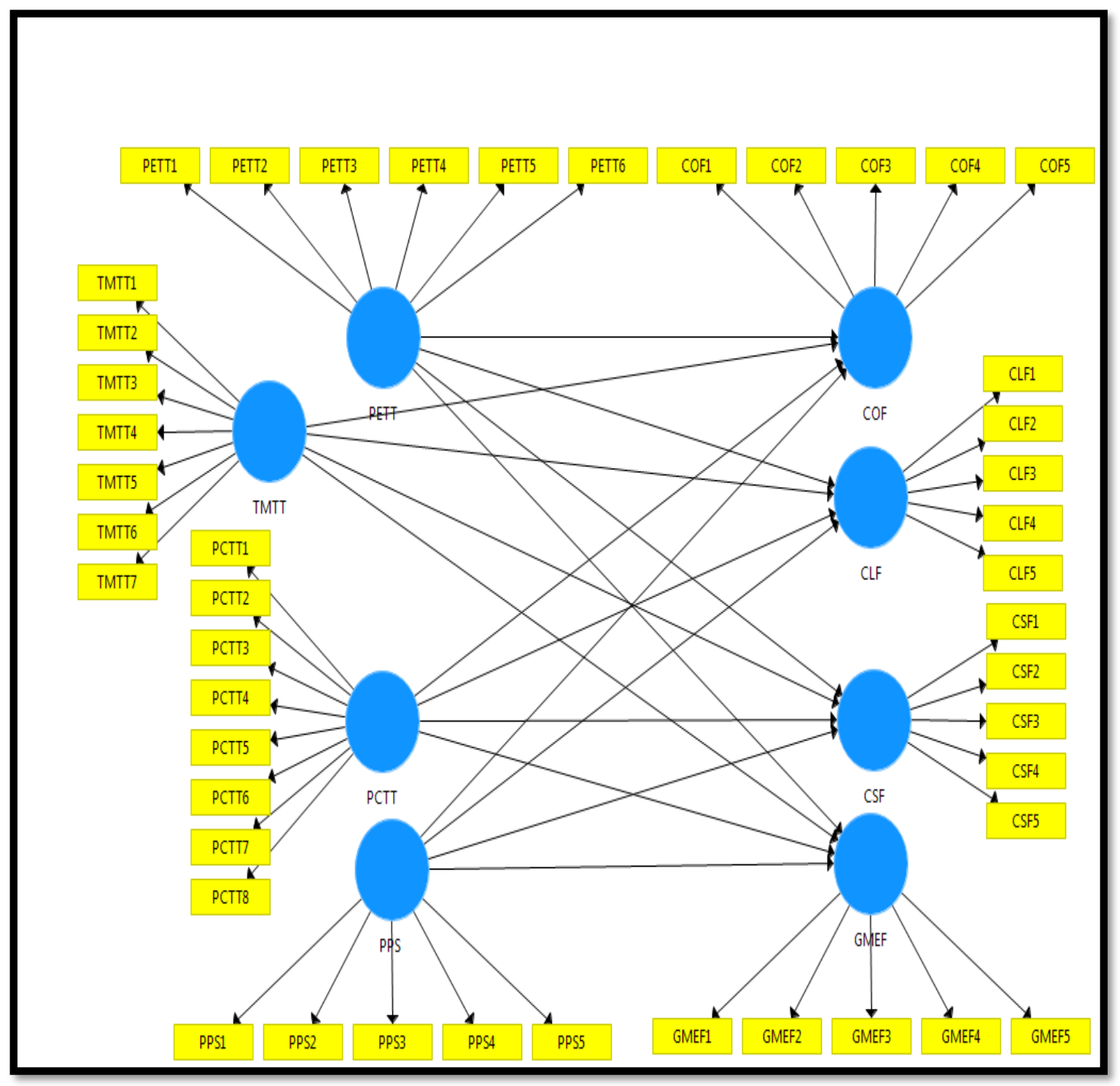

Figure 4.4 Initial measurement model

As presented in the above Figure 4.4, project time management tools and techniques are treated as an exogenous variable, which is denoted by the four latent variables, denoted as the blue circles, namely; project estimation techniques and tools (PETT), time planning tools and techniques (TMTT), project controlling tools and techniques (PCTT) and project software packages (PPS). The delay factors are also presented by four latent variables, and these are contractor related factors (COF), client (CLF), consultant (CSF) and general management and external factors (GMEF). Previous studies nominated these factors as top delays factors within the targeted industry. Each of the latent variables is measured by several items (indicators in yellow rectangles); these are displayed in Appendix 3 where the description and coding for 
latent variables are captured. A detailed discussion on the relationship between the mentioned latent variables is provided in Section 5.8 of Chapter 5.

\section{Assessment of the Initial Measurement Model}

Hair et al., (2014) recommend that the reliability and validity of the data used in the Structural Equation Model should be evaluated at the initial stage to ensure that the results are free of errors. Accordingly, before conducting a final measurement modelling showing the relationships between exogenous and endogenous variables used in this study, the data were evaluated to ensure that they were reliable and valid. In SEM-PLS modelling, three tests can be used to examine the validity of the measure construct: Cronbach's Alpha, Composite Reliability (CR), and Average Variance Extracted (AVE). The convergent validity of the datasets was also undertaken. CR measures the similarity in the latent constructs that measure the same single construct. Convergent validity indicates the association between the research constructs and indicators that purport to measure them (Connolly et al., 2007). Convergent validity of the data was undertaken by considering the outer loadings and Average Variance Extracted (AVE). The following formula for AVE, as suggested by Fornell and Larker (1982), was used:

$$
\mathrm{AVE}=\frac{\Sigma\left[\lambda_{\mathrm{i}}^{2}\right] \operatorname{Var}(\mathrm{X})}{\Sigma\left[\lambda_{\mathrm{i}}{ }^{2}\right] \operatorname{Var}(\mathrm{X})+\Sigma\left[\operatorname{Var}\left(\varepsilon_{\mathrm{i}}\right)\right]}
$$

$\lambda_{i}=$ the loading of indicators of a variable $\mathrm{X}$ represented by $\mathrm{x}_{\mathrm{i}}$;

Var= variance;

$\varepsilon_{\mathrm{i}}=$ measurement error of $\mathrm{x}_{\mathrm{i}}$

AVE values and outer loadings of 0.7 and above have been suggested as the most suitable for showing the existence of convergent validity between the data variables and their indicators. However, Hair et al., (2014) recommend that values of 0.4 and above should be considered when a new research data instrument is used. Most of the questions used in this study were newly developed to suit the settings of the Kingdom of Saudi Arabia, the country of focus for this investigation. The AVE analysis was undertaken using SPSS SMPLS functions and Excel. The convergent validity values for the data shows that most of the items have values above the recommended 0.4 for AVE. However, some of them have AVE values of below 0.4 reported. As such, these indicators were removed from the final measurement modelling accordingly. Since the items were reduced, therefore, the inter-item consistency coefficient was ensured. All inter-item consistency coefficients showed excellent inter-item consistency (George and 
Mallery, 2003). George and Mallery (2003, p. 231) provided the following rules of thumb: "> .9 - Excellent, > .8 - Good, > .7 - Acceptable, > .6-Questionable, > .5 - Poor, and <.5Unacceptable". Construct reliability and validity for the measures was also demonstrated. All composite reliability measures crossed the threshold of 0.70 (Lee et al., 2007). For validating constructs, convergent and discriminant validities were confirmed. The outer loadings were above the threshold of 0.5 (at $\mathrm{p}<0.05$ ), which provided evidence of convergent validity (Fraj et al., 2006). Moreover, the square root of each construct's Average Variance Extracted was found to be larger than its corresponding correlation coefficients (Table 4.7). This revealed the evidence of discriminant validity (Lee et al., 2007). Table 4.5 presents the treatment of the indicators that had AVE values of below 0.4 , which presents Construct Reliability and Validity.

Table 4.5 Construct Reliability and Validity

\begin{tabular}{|c|c|c|c|c|c|}
\hline Constructs & Items & Loadings & $\begin{array}{l}\text { Cronbach's } \\
\text { Alpha }\end{array}$ & $\begin{array}{l}\text { Composite } \\
\text { reliability } \\
\text { (CR) }\end{array}$ & $\begin{array}{l}\text { Average } \\
\text { variance } \\
\text { extracted } \\
\text { (AVE) }\end{array}$ \\
\hline \multirow{6}{*}{ PETT } & PETT1 & $\mathrm{D}$ & \multirow[t]{6}{*}{0.725} & \multirow[t]{6}{*}{0.836} & \multirow[t]{6}{*}{0.564} \\
\hline & $\begin{array}{l}\text { PETT2 } \\
\end{array}$ & 0.659 & & & \\
\hline & PETT3 & 0.817 & & & \\
\hline & PETT4 & 0.855 & & & \\
\hline & PETT5 & $\mathrm{D}$ & & & \\
\hline & PETT6 & $\mathrm{D}$ & & & \\
\hline \multirow{7}{*}{ TMTT } & TMTT1 & 0.646 & \multirow[t]{7}{*}{0.828} & \multirow[t]{7}{*}{0.877} & \multirow[t]{7}{*}{0.646} \\
\hline & TMTT2 & 0.897 & & & \\
\hline & TMTT3 & 0.791 & & & \\
\hline & TMTT4 & 0.610 & & & \\
\hline & TMTT5 & 0.884 & & & \\
\hline & TMTT6 & $\mathrm{D}$ & & & \\
\hline & TMTT7 & $\mathrm{D}$ & & & \\
\hline \multirow[t]{4}{*}{ PCCT } & PCTT1 & 0.819 & \multirow[t]{4}{*}{0.806} & \multirow[t]{4}{*}{0.868} & \multirow[t]{4}{*}{0.622} \\
\hline & PCTT2 & 0.823 & & & \\
\hline & PCTT3 & $\mathrm{D}$ & & & \\
\hline & PCTT4 & $\mathrm{D}$ & & & \\
\hline
\end{tabular}




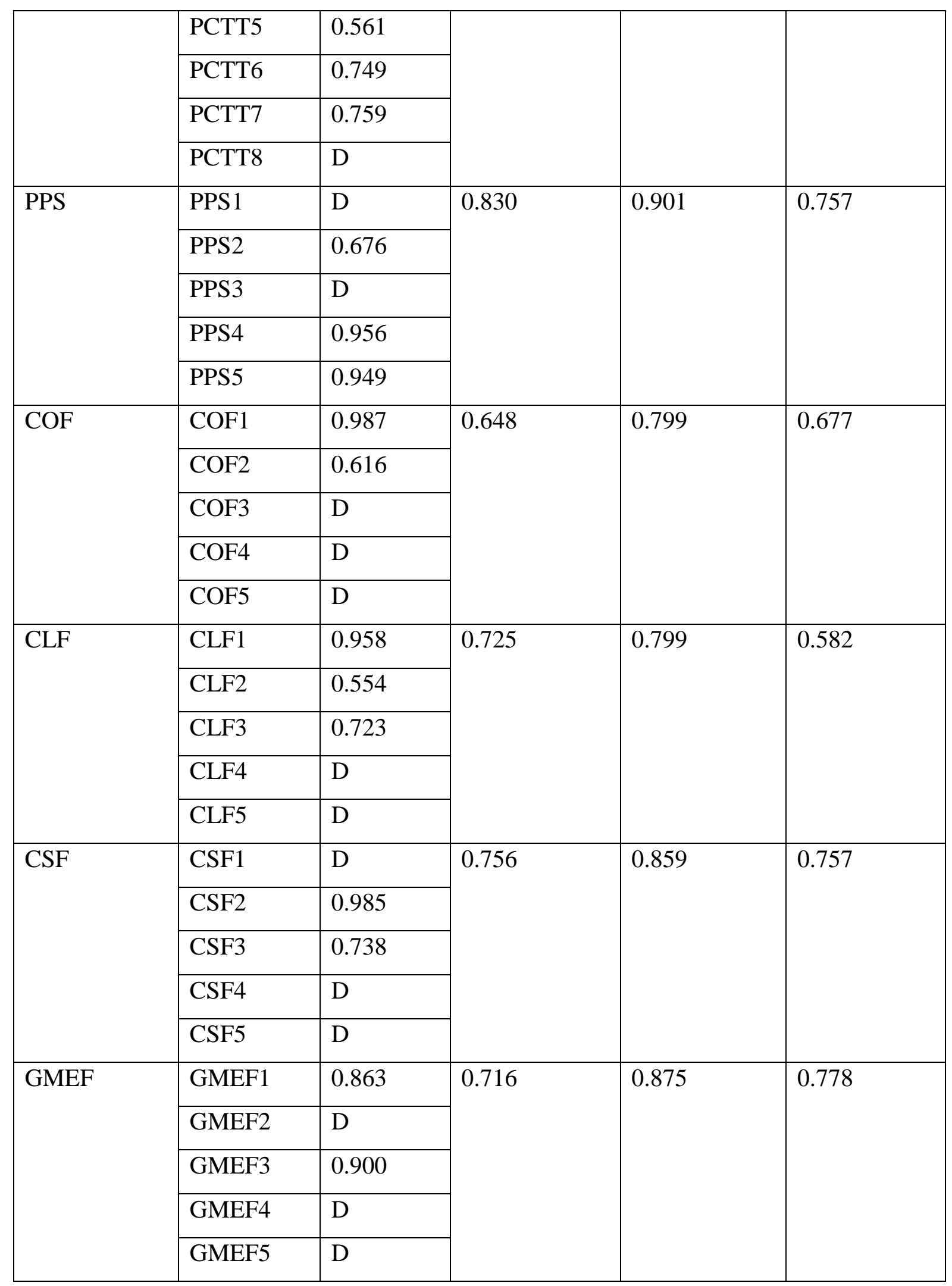




\section{Cross loadings matrix for discriminant Validity}

For the assessment of discriminant validity, an indicator's loading with its associated latent construct should be higher than its loadings with all the remaining constructs (i.e., the cross loadings) (Hair et al., 2011).

Table 4.6 Cross loadings matrix for Discriminant Validity

\begin{tabular}{lcccccccc}
\hline & CLF & COF & CSF & GMEF & PCTT & PETT & PPS & TMTT \\
\hline CLF1 & $\mathbf{0 . 9 5 8}$ & 0.206 & 0.265 & 0.284 & 0.017 & -0.053 & 0.044 & 0.087 \\
\hline CLF2 & $\mathbf{0 . 5 5 4}$ & 0.195 & 0.264 & 0.247 & 0.073 & -0.018 & 0.005 & 0.043 \\
\hline CLF3 & $\mathbf{0 . 7 2 3}$ & 0.245 & 0.324 & 0.306 & 0.034 & -0.003 & 0.005 & 0.055 \\
\hline COF1 & 0.235 & $\mathbf{0 . 9 8 7}$ & 0.041 & 0.237 & -0.037 & -0.092 & 0.099 & -0.005 \\
\hline COF2 & 0.194 & $\mathbf{0 . 6 1 6}$ & -0.002 & 0.183 & 0.038 & -0.001 & 0.057 & 0.030 \\
\hline CSF2 & 0.313 & 0.004 & $\mathbf{0 . 9 8 5}$ & 0.286 & -0.068 & -0.028 & -0.106 & 0.006 \\
\hline CSF3 & 0.256 & 0.151 & $\mathbf{0 . 7 3 8}$ & 0.199 & -0.002 & -0.029 & 0.043 & 0.057 \\
\hline GMEF1 & 0.273 & 0.258 & 0.274 & $\mathbf{0 . 8 6 3}$ & 0.008 & 0.040 & 0.012 & 0.122 \\
\hline GMEF3 & 0.307 & 0.183 & 0.236 & $\mathbf{0 . 9 0 0}$ & 0.103 & 0.019 & 0.019 & 0.182 \\
\hline PCTT1 & 0.039 & -0.037 & -0.038 & 0.072 & $\mathbf{0 . 8 1 9}$ & 0.016 & 0.230 & 0.615 \\
\hline PCTT2 & 0.017 & -0.014 & -0.058 & 0.059 & $\mathbf{0 . 8 2 3}$ & -0.003 & 0.226 & 0.509 \\
\hline PCTT5 & 0.047 & -0.024 & 0.021 & 0.010 & $\mathbf{0 . 5 6 1}$ & -0.075 & 0.131 & 0.418 \\
\hline PCTT6 & -0.012 & 0.010 & -0.065 & 0.005 & $\mathbf{0 . 7 4 9}$ & -0.038 & 0.235 & 0.509 \\
\hline PCTT7 & 0.032 & -0.022 & -0.034 & 0.044 & $\mathbf{0 . 7 5 9}$ & -0.032 & 0.194 & 0.503 \\
\hline PETT2 & -0.064 & -0.074 & 0.010 & 0.037 & -0.013 & $\mathbf{0 . 6 5 9}$ & 0.014 & 0.063 \\
\hline PETT3 & 0.000 & -0.059 & -0.026 & 0.036 & 0.027 & $\mathbf{0 . 8 1 7}$ & 0.049 & -0.009 \\
\hline PETT4 & -0.030 & -0.070 & -0.053 & 0.006 & -0.018 & $\mathbf{0 . 8 5 5}$ & 0.020 & -0.018 \\
\hline PETT5 & -0.013 & -0.007 & -0.031 & 0.013 & -0.043 & $\mathbf{0 . 6 5 1}$ & -0.007 & -0.020 \\
\hline PPS2 & 0.047 & 0.045 & -0.061 & 0.026 & 0.305 & 0.006 & $\mathbf{0 . 6 7 6}$ & 0.261 \\
\hline PPS4 & 0.036 & 0.117 & -0.067 & 0.016 & 0.233 & 0.033 & $\mathbf{0 . 9 5 6}$ & 0.155 \\
\hline PPS5 & 0.017 & 0.085 & -0.083 & 0.007 & 0.215 & 0.034 & $\mathbf{0 . 9 4 9}$ & 0.148 \\
\hline TMTT1 & 0.110 & 0.092 & 0.092 & 0.041 & 0.417 & -0.015 & 0.112 & $\mathbf{0 . 6 4 6}$ \\
\hline TMTT2 & 0.076 & 0.001 & 0.033 & 0.177 & 0.599 & 0.019 & 0.163 & $\mathbf{0 . 8 9 7}$ \\
\hline TMTT3 & 0.098 & 0.031 & 0.020 & 0.098 & 0.588 & 0.021 & 0.184 & $\mathbf{0 . 7 9 1}$ \\
\hline TMTT4 & -0.014 & 0.028 & -0.060 & 0.058 & 0.494 & -0.058 & 0.309 & $\mathbf{0 . 6 1 0}$ \\
\hline TMTT5 & 0.073 & -0.027 & 0.008 & 0.172 & 0.563 & 0.018 & 0.143 & $\mathbf{0 . 8 8 4}$ \\
\hline & & & & & & & & \\
\hline
\end{tabular}




\section{Discriminant Validity}

Table 4.7 Discriminant Validity

\begin{tabular}{lrrrrrrrr}
\hline & \multicolumn{1}{l}{ CLF } & \multicolumn{1}{l}{ COF } & CSF & GMEF & PCTT & PETT & PPS & TMTT \\
\hline CLF & $\mathbf{0 . 7 6 3}$ & & & & & & & \\
\hline COF & 0.247 & $\mathbf{0 . 8 2 3}$ & & & & & & \\
\hline CSF & 0.323 & 0.036 & $\mathbf{0 . 8 7 0}$ & & & & & \\
\hline GMEF & 0.330 & 0.247 & 0.288 & $\mathbf{0 . 8 8 2}$ & & & & \\
\hline PCTT & 0.030 & -0.026 & -0.059 & 0.067 & $\mathbf{0 . 7 8 8}$ & & & \\
\hline PETT & -0.043 & -0.083 & -0.030 & 0.032 & -0.010 & $\mathbf{0 . 7 5 1}$ & & \\
\hline PPS & 0.036 & 0.099 & -0.080 & 0.018 & 0.278 & 0.030 & $\mathbf{0 . 8 7 0}$ & \\
\hline TMTT & 0.087 & 0.001 & 0.018 & 0.175 & 0.681 & 0.016 & 0.203 & $\mathbf{0 . 8 0 4}$ \\
\hline
\end{tabular}

\subsubsection{Approach to Qualitative Data Analysis}

After validating the responses, the data received were analysed. Prior to analysing the data, all the recorded audio files from the interviews were first translated and then transcribed by a professional transcriber. Also, as the interviews were conducted in Arabic, the interview transcripts were translated into English. Each transcript was initially assessed and summarised to aid data analysis. The interview was analysed using a thematic analysis approach, which was facilitated by a Computer Assisted Qualitative Data Analysis Software (CAQDAS) known as NVivo 10. Thematic analysis is "a method for identifying, analysing and reporting patterns (themes) within data" (Braun and Clarke, 2006, p.79). NVivo 10 has been described as the software for managing, shaping and making sense of rich-text data, as well as providing deep levels of analysis for them (QSR, 2014). Themes were identified and categorised for each transcript. Similar themes were classified together, while the different ones were separated. The reasons for discordance were particularly ascertained.

To extract useful conclusions from the raw data collected, this study adopts various forms of qualitative analysis, including transcribing the recorded interviews conducted, nodding and coding of the transcribed interviews, through to assigning summative attributes to transcribed data. The coding process allows for the extraction of insight from the unstructured data collected (Morse and Richards 2002).

Coding the text allows access to the main ideas and assesses what is happening in the data examined (Saghatforoush et al., 2013). It is utilised in the qualitative analysis, usually referring to a word or short phrase that symbolically represents an essence-capturing or evocative attribute for the underlying data (Saldana 2009). Therefore, to enable an easy identification of emerging themes in the interview data, three coding techniques including open, axial, and 
selective were applied in line with the suggestion of Strauss and Corbin (1998). The open coding was undertaken by analysing the interview data line-by-line, with references to various themes of interest coded to specific nodes (Auerbach and Silverstein, 2003). In axial coding, relevant references within the interview transcripts were coded under the sub-category (Auerbach and Silverstein, 2003). Selective coding involved merging themes that were considered similar, to prevent the unnecessary duplication of themes (Miles et al., 2013).

The use of NVivo allowed for the identification of emerging themes, as well as the reexamination of themes during the analysis, thereby ensuring that the process is not confined to revealing only a pre-determined set of categories (Silverman, 2016). Figure 4.10 gives an example of the themes derived from the thematic analysis of the interview, with the aid of NVivo. A detailed discussion on the main themes is provided in Chapter 6.

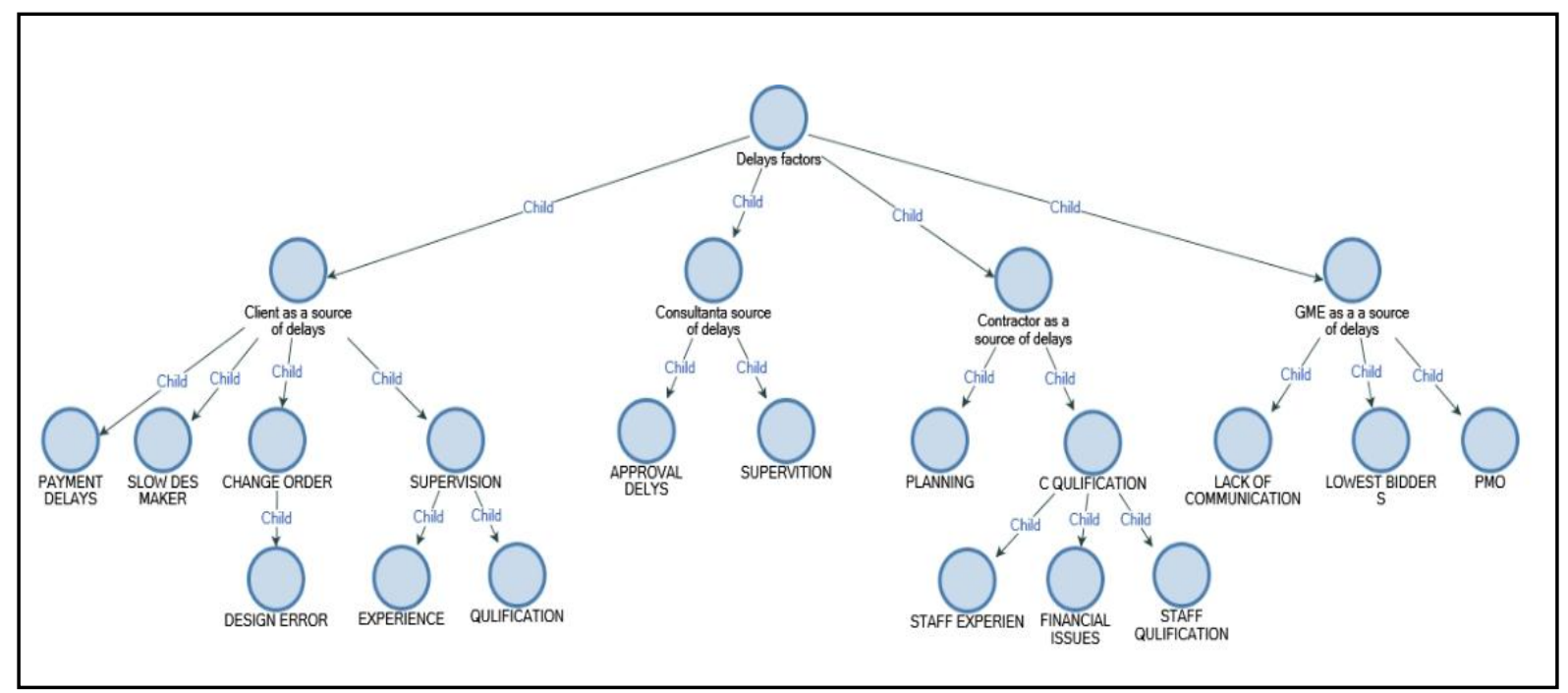

Figure 4.5 Example of coding using NVivo.

\subsection{Ethical Considerations}

Ethics is defined by the Oxford English Dictionary as "relating to morals, treating of moral questions; morally correct, honourable... Set of principles of morals... Science of morals, moral principles, rules of conduct, the whole field of moral science" (Burgress, 2005, p.1). Ethics, in research, generally covers the practical guidelines for a responsible conduct in a study (Burgess, 2005; Guillemin and Gillam, 2004). In any research involving humans, it is a requirement that considerations for ethics are to be made a significant priority (Bryman, 2012). According to the National Statement on Ethical Conduct in Human Research, the nitty-gritty 
of ethical conduct in human research is to prevent the research activities from hurting the participants and ensure that the research benefits individuals and the society (NSECHR, 2007).

In accordance with the Australian National Health and Medical Research Council's guidelines for research involving humans, ethics approval for this research was obtained in 2015. The approval letter is attached (as seen in Appendix 4)

The four ethical principles that underpin this research, as suggested by National Statement on Ethical Conduct in Human Research and also supported by Curtin University, are merit of the research, justice, beneficence and respect for persons. The merit of the research was justified by its potential contributions to the body of knowledge, oil and gas industry, as well as the wider society (NSECHR, 2007). Justice is entrenched in the research by ensuring that its scope and objectives were appropriate; the recruitment of participants went through a fair process; and that there was reasonable distribution of benefits of participation among the participants (NSECHR, 2007). Beneficence was exercised by evaluating the risks of harm and possible benefits of the research to the potential participants (NSECHR, 2007). Consequently, appropriate actions were taken to minimise the risks of harm and maximise the benefits to the participants, by being sensitive to their rights and implications of the exercise to their employment (NSECHR, 2007). The respect for persons involved in the research was fostered by maintaining their anonymity through the research process (Kimmel, 2007).

Ethical aspects of this research were effectively addressed, as proposed by Kimmel (2007), in the following manner:

- First, informed consents of participants for both questionnaire survey and semistructured interview were obtained before involving them in the research exercise.

- Second, participants in the research were not subjected to coercion in any way. Participation in both the questionnaire survey and interview was voluntary without any obligation; participants could opt out of the exercise at any stage of the research.

- Third, anonymity or privacy of the research participants was maintained by not collecting and personal data that could reveal the identities of the persons involved in the research.

- Fourth, all the research participants were debriefed about the aims and objectives of the study before the primary data collection process started. 
- Fifth, the works that do not belong to the author of this research have been acknowledged using an appropriate format.

- Sixth, mismanagement of the collected data was guided against throughout the research process.

\subsection{Limitations of Mixed Method}

Some of the advantages of employing the mixed method in this study have been identified as including: harmonisation of different approach; expansion of knowledge on research phenomenon; better transferability; and convergence of research results (Jick, 1979; Onwuegbuzie and Collins, 2007). Despite the benefits of the mixed method in this research, certain constraints were also established. One of the issues encountered was difficulty in aligning the different conceptual stances in the mixed methods approach (Teddlie and Tashakkori, 2010). Due to various paradigm stances of both qualitative and quantitative methodology, a reconciliation of those world views could not have been perfect (Morgan, 2007).

Another methodological constraint is related to subjectivity. Although mixed methodology seeks a convergence of different procedural perspectives to produce more robust results, a combination of quantitative and qualitative methodology could have subjected the research to subjectivity. According to Onwuegbuzie and Leech (2005), and Morgan (2007), the qualitative approach incorporates subjectivity, while the quantitative approach integrates objectivity. However, a combination of the two methods often leads to inter-subjectivity (Morgan, 2007). For instance, an interpretation and alignment of results obtained from both quantitative and qualitative aspects of this study were carried out with inputs and perceptions of the researcher. As a result, the researcher's bias could have influenced the research outcome.

Also, another limitation could be described as the problem of drawing inferences in mixed methods (Teddlie and Tashakkori, 2010). The researcher faced a lot of challenges trying to harmonise the results obtained from the questionnaire survey and interviews respectively. This involved an inspection and thorough comparison of perspectives from both approaches. Despite taking concerted efforts in ensuring a good harmonisation of results, there was a small chance of error in the interpolation of data obtained from both approaches. 
Despite proneness to some constraints, the implementation of mixed methods in this study was carried out in full and strict compliance with the standard rules guiding its usage. Although these constraints have been acknowledged in this study, however, they have not diminished the originality, objectivity and thoroughness of this research to address cost overrun problems within hydrocarbon megaprojects. These constraints have, rather, lent credence to the perspective that no methodological approach is perfect (Johnson and Gray, 2010). Nonetheless, the significance of mixed methodology in providing more valid research results cannot be underscored.

\subsection{Summary}

This chapter has discussed the research design and methodology adopted in the study. The research method is identified as the backbone of any research activity. Based on the research aim and objectives, a mixed method incorporating both quantitative and qualitative (case studies and interviews) studies were used to address the pertinent issues in this thesis. The justifications for the adopted research methodology, including the philosophy underlying the research, were also discussed within this chapter.

The quantitative study was undertaken to gather empirical evidence regarding the critical factors influencing the delays in public construction projects in the Kingdom of Saudi Arabia. Also, the current PM practice, especially the use of PM tools and techniques, was examined to draw a relationship about how this could have affected the time performance of the delayed projects. Essentially, this chapter described the quantitative methodology; presented detailed information about the data collection instrument (questionnaire survey), as well as data analysis techniques such as Cronbach's Alpha, descriptive statistics, and Structural Equation Modelling. Within this chapter, the sampling method for the quantitative research sample was presented. The reliability and validity of the data assisted in determining the suitability of generalising the results obtained.

This chapter offered the details of the case studies and the interview data collection technique that was followed in the conduct of the research. In addition, the sampling process for the professionals who participated in the interviews was thoroughly explained. The qualitative data were analysed using the thematic analysis approach, and the summary of the processes followed in the management and analysis of the data was described. The details of the quantitative analysis are presented in the next chapter (Chapter 5). 


\section{CHAPTER 5}

\section{PRESENTATION OF DATA COLLECTION PHASE 1}

\subsection{Introduction}

The preceding chapter has indicated that this study was conducted based on the triangulation approach, which involved the application of both quantitative and qualitative methods to understand and explain issues contributing to the construction delays in the KSA, as well as link the problem to the current use of PM tools and techniques. This present chapter presents an analysis of the quantitative data obtained through a survey conducted among construction professionals in the KSA. The analysis of the data was undertaken using a wide range of descriptive and inferential statistics such as means, standard deviation, Kruskal-Wallis, Mean Ranking, Relative Importance Index and Structural Equation Modelling among others.

The chapter is structured into six main sections. The first section provides the details of the pilot study. This will be followed by the subsequent section that offers the preliminary findings of the quantitative data. The next section presents the demographics of the survey participants. After that, there will be an analysis of the factors identified as contributing to the delays. Also, the data analysis, in relation to the current use of PM knowledge, techniques and tools in the KSA will be assessed. Lastly, the association between the application of PM techniques and tools and the delays occurring will be examined.

\subsection{Pilot Study}

As indicated in Chapter 4, a pilot study was undertaken to pre-test the survey questionnaire to identify any issues with it (such as unclear wording). Thus, the survey questionnaire was distributed to 20 construction experts in Saudi Arabia. Out of the 20 practitioners, 13 of them completed the survey, representing a response rate of $65 \%$. The profile of the 13 construction experts who completed the pilot survey is presented in Table 5.1. 10 out of the 13 participants who completed the pilot survey $(n=10)$ indicated that the questionnaire was straightforward to understand and answer. The remaining three respondents suggested for two of the questions to be slightly reworded for better clarity in the questionnaire. Accordingly, those two items were 
modified in line with the recommendations by the practitioners to ensure the clarity of the questionnaire.

Table 5.1 The profile of the experts who completed the pilot survey

\begin{tabular}{ccc}
\hline Job role & Number & Percentage \\
\hline Academic & 4 & $31 \%$ \\
\hline Project Manager & 3 & $23 \%$ \\
\hline Senior Construction Manager & 2 & $15 \%$ \\
\hline Construction Manager & 2 & $15 \%$ \\
\hline Engineering Consultant & 1 & $8 \%$ \\
\hline Civil Engineer & 1 & $8 \%$ \\
\hline
\end{tabular}

\subsection{Preliminary Findings of the Quantitative Data}

Prior to the thorough analysis of the data collected through the survey, they were initially checked. This was to ensure that they were free of any data-related errors that could make them unusable and compromise the findings derived from them. Some of the problems that are usually associated with quantitative data are outliers, missing data, and lack of normality in the data distribution. Consequently, the survey data were examined for these abovementioned problems. Also, the reliability and validity of the questionnaire was checked by following the appropriate steps.

\subsubsection{Data Preparation}

To ensure that the quantitative data were organised in a suitable format for their analysis, the data had to be prepared. According to Zikmund et al. (2013), raw data cannot be used to reach a logical inference without first being developed and converted to a format that can be analysed. Therefore, the preparation of the raw data for an analysis started with coding them, screening for missing items, checking them for outliers (i.e., the extreme values), and finally entering them into the IBM SPSS statistical software. In addition, the normality of a data distribution was necessary for Structural Equation Modelling (Hair et al., 2014). Consequently, data normality was undertaken within the SPSS software. 
The coding was undertaken to identify each of the items in the dataset by using numbers and other characters (Zikmund et al., 2013). Each element of the dataset was identified by coded symbols, which can be seen in Appendix 3. After entering the data into the SPSS software, the eighteen responses with missing values were removed. Furthermore, a box-plot test within the SPSS software was employed to check for outliers (i.e., those items that lie at a significant distance from others). The normality of the data was also verified as it is a critical issue in Structural Equation Modelling (Hair et al., 2014). The Shapiro-Wilk test was conducted to determine the normality of the data. The Shapiro-Wilk test is usually computed using the following formula:

$$
W=\frac{\left(\sum_{i=1}^{n} a_{i} x_{(i)}\right)^{2}}{\sum_{i=1}^{n}\left(x_{i}-\bar{x}\right)^{2}}
$$

Where: $x_{i}$ represents the ranked random sample values; $a_{i}$ denotes the constants derived from the variances, covariances, and means of the sample size, n, of a sample with normal distribution. Based on the test results, $p<0.05$, the data were judged to be normally distributed.

\subsubsection{Data Reliability}

Before conducting a detailed analysis of the data, the reliability of each item in the survey questionnaire was tested. This is line with the suggestion by Drost (2011), that it is essential for the reliability tests of data to be carried out so as to ensure that they are free of random error. The Cronbach's (1951) Alpha ( $\alpha$ ) coefficient is the most frequently used method for measuring data reliability and internal consistency (Sijtsma, 2009). This technique assesses the consistency of the instrument and questions in measuring the specified constructs (Drost, 2011). The reliability estimates are determined by an average proportion of intercorrelations between the different items within the questionnaire instrument (Sijtsma, 2009). An item is typically considered reliable if a value of 0.70 and above is obtained (Sijtsma, 2009). The reliability statistics of the ordinal data are presented in Appendix 5, indicating that all items were well above 0.7, and are therefore reliable. The inter-item correlation matrix (Appendix 6) was derived from IBM SPSS Statistics version 24 and it shows a high level of data reliability.

As previously mentioned in Section 4.7.7, the validity of the questionnaire administered in the quantitative study was determined using the results obtained from the pilot study. The content 
validity ratio of the responses received from the pilot study was found to be CVR +0.54 , indicating that more than half of the participants considered the questionnaire to be an effective and valid instrument (Wilson et al., 2012). The experts who participated in the pilot study were also asked to comment on the accuracy of the content of the questionnaire. Based on the feedback, the accuracy of the questions included in the questionnaire.

\subsection{Demographic Characteristics}

An analysis of the survey demographic was undertaken to determine the detailed characteristics of the respondents. The sample groups, which also indicated the organisational type (i.e., client/owner, contractor, and consultant) that the respondents represented, have been previously provided in Section 5.3.1. Other characteristics of the respondents that will be considered in this section include participants' current role, years of working experience, and their level of education.

\subsubsection{Participants' Current Role}

The majority of the respondents, 129 , representing $35 \%$ of the total sample, identified themselves as currently working as a Project Manager on public construction projects in the KSA. Eighty-four [22.8\%] of the respondents indicated their current role in their organisations to be that of an Engineering Consultant. Also, 55 [14.9\%] suggested their present position to be an Engineering Supervisor. Among the 369 who completed the survey, the current title of $49[13.3 \%]$ of them was identified as Site Engineer. Lastly, 53 [14\%] of the respondents' current work titles were identified as others such as Planning Manager, Planning Engineer, Chief Executive Officer (CEO), and IT consultant. Figure 6.1 shows the overview of the participants' current role. 


\section{Participants' current role}

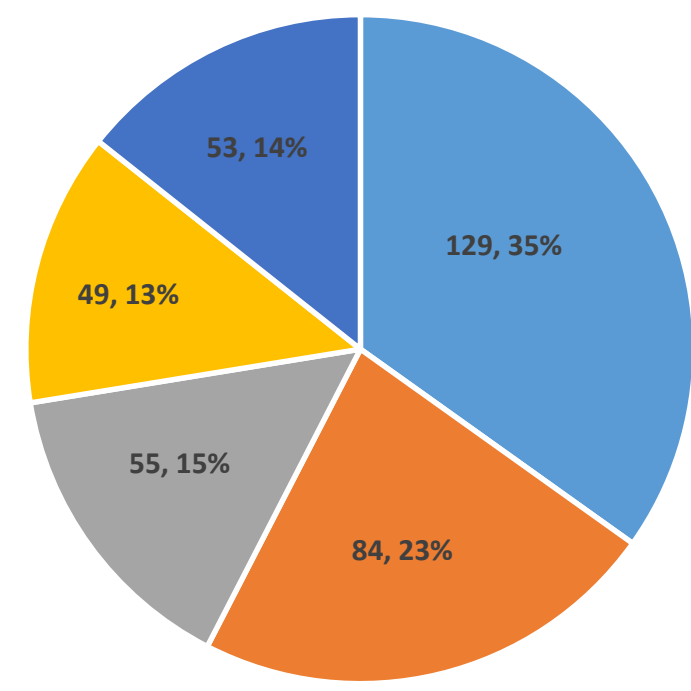

- Project Manager $\quad$ Engineering Consultant $\quad$ Engineering Supervisor $\quad$ Site Engineer $\quad$ Others

Figure 5.1 Participants' current role

\subsubsection{Participants' Years of Experience}

The descriptive analysis of the respondents' years of working experience in the KSA's construction sector shows that 109 [29.5\%] of them have had between 0 and 5 years of professional experience. Of all the respondents, 100 [27.1\%] indicated that they have gathered working experience spanning 6 to 10 years within the industry. Another 71 [19.2\%] of the survey participants claimed they have been working in the KSA's construction segment for the last 11 to 15 years. Additionally, 31 [8.4\%] of the total respondents to the survey suggested they have had between 16 and 20 years of working experience in the construction industry. The highest category of working experience of more than 20 years were claimed by 58 [15.7\%] of the survey participants. Table 5.2 presents the summary of the participants' years of experience. 
Table 5.2 Overview of participants' years of experience

\begin{tabular}{ccc}
\hline Years of Experience & Number of Responses & Percentage of Responses \\
\hline $0-5$ years & 109 & $29.5 \%$ \\
\hline $6-10$ years & 100 & $27.1 \%$ \\
\hline $11-15$ years & 71 & $19.2 \%$ \\
\hline $16-20$ years & 31 & $8.4 \%$ \\
\hline More than 20 years & 58 & $15.7 \%$ \\
\hline
\end{tabular}

\subsubsection{Participants' Educational Level}

The majority of the respondents, 288 [78\%] identified themselves as holders of a Bachelor degree or equivalent. The second largest number or percentage of the participants, 69 [18.7\%] indicated they possessed a Master's degree or its equivalent. The remaining 12 [3.3\%] of the participants added that they were holders of a $\mathrm{PhD}$ certificate. The summary of the results of this analysis, which revealed that the respondents to the survey were highly-educated, is presented in Table 5.3 below.

Table 5.3 Participants' educational level

\begin{tabular}{ccc}
\hline Level of Education & Number of Responses & Percentage of Responses \\
\hline Bachelor or equivalent & 288 & $78.0 \%$ \\
\hline Master of equivalent & 69 & $18.7 \%$ \\
\hline PhD or equivalent & 12 & $3.3 \%$ \\
\hline
\end{tabular}

\subsection{Project Features}

The characteristics of the projects that the participants have been involved are discussed in this section. Consequently, the analysis of the number of public construction projects that the participants were involved in, specifically the project types undertaken, the worst and best nodelays experienced by them, as well as the relevant results are provided in this section.

\subsubsection{Number of Projects}

In total, the participants suggested that they have been involved with 4357 projects in the last 10 years. It should be noted that it is highly probable that two or more respondents could have 
participated in the same project. Out of the total 4357 projects, 2725 [62.5\%] were identified as building projects. Also, 1092 [25.1\%] of the total number of projects that the participants were involved with in the last 10 years were indicated to be infrastructure projects. The remaining 540 [12.4\%] projects associated with the participants were road projects. Table 5.4 presents the statistics summary.

Table 5.4 Number of projects linked to the participants

\begin{tabular}{ccc}
\hline Project Category & Number of Projects & Percentage of Projects \\
\hline Building & 2725 & $62.5 \%$ \\
\hline Infrastructure & 1092 & $25.1 \%$ \\
\hline Roads & 540 & $12.4 \%$ \\
\hline
\end{tabular}

\subsubsection{Participants' Project Types}

Most of the participants, 236 [64\%] indicated that they were normally involved in public building projects in the KSA. The second most common project that the respondents were usually involved with is infrastructure, as 90 [24.4\%] of them suggested a participation in this form of project. The least number or percentage of the participants, 43 [11.7\%] claimed they are mainly involved in road construction projects. An overview of the participants' project type is presented in Table 5.5 below.

Table 5.5 Participants' project types

\begin{tabular}{ccc}
\hline Project Type & Number of Responses & Percentage of Responses \\
\hline Building & 236 & $64.0 \%$ \\
\hline Infrastructure & 90 & $24.4 \%$ \\
\hline Roads & 43 & $11.7 \%$ \\
\hline
\end{tabular}




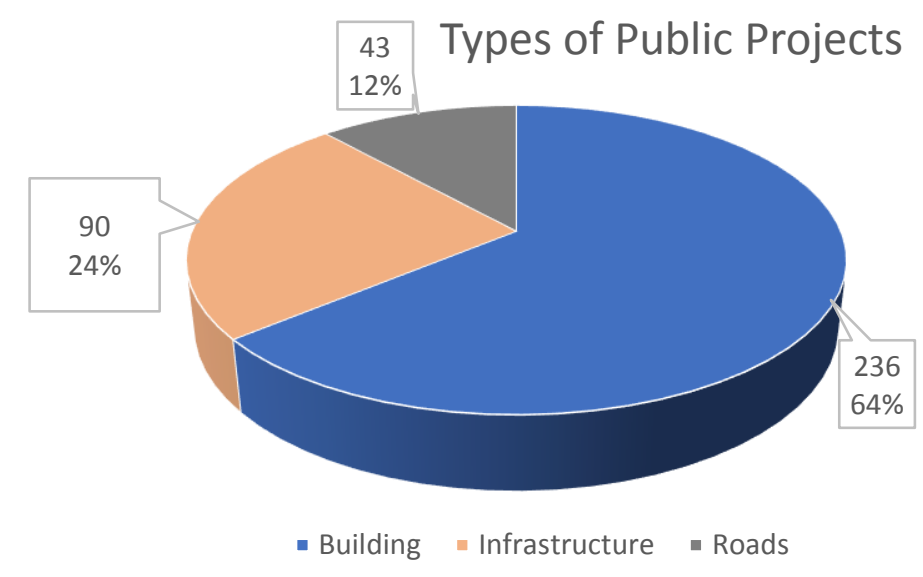

Figure 5.2 Participants' project types

\subsubsection{Magnitude of Worst Delays}

The respondents to the survey were asked about the magnitude of delays experienced in the projects they have been involved with in the last 10 years. Out of the 4357 projects that the participants have participated in, they reported around 2489 projects being delayed. Running the Chi-Square Goodness of Fit test for the level of delays to be equal for all projects, gives us $\chi^{2}=1843.89, \mathrm{df}=51$, significance $\sim 0.000$, giving strong evidence in favour of the null hypothesis.

The magnitude of delays found in this research is lower than those previously reported by Zain Al-Abidien (1983), in which 70\% of the KSA's public construction projects were identified as delayed. However, it is higher than $40 \%$ of 2379 Saudi Arabian public construction projects reportedly delayed in the study conducted by Falqi (2004). Also, the magnitude of delays reported in this study is more significant than between $10 \%$ and $30 \%$ found in Assaf and Hejji (2006).

The respondents also provided information regarding the worst delay situations that their projects had experienced. It would have been preferable if there were more recent studies to compare against the magnitude of delays reported here. Also, there were no available published studies that have discussed the magnitude of delays in specific months or years. However, the magnitude of delays in this survey was considered in months. Furthermore, when asked for the worst delays experienced, more than $60 \%$ of the participants have experienced a percentage of $50 \%$ time overrun, as shown in Table 5.6. 
Table 5.6 Frequency of worst delays experienced

\begin{tabular}{lccc}
\hline Delay Percentages & $\begin{array}{c}\text { Number of } \\
\text { Participants }\end{array}$ & Proportion & $\begin{array}{c}\text { Cumulative } \\
\text { Proportion }\end{array}$ \\
\hline Delay between $0-25 \%$ & 44 & $11.92 \%$ & $11.92 \%$ \\
\hline Delay between $26-50 \%$ & 90 & $24.39 \%$ & $36.31 \%$ \\
\hline Delay between $51-75 \%$ & 73 & $19.78 \%$ & $56.09 \%$ \\
\hline Delay between $76-100 \%$ & 69 & $18.7 \%$ & $74.79 \%$ \\
\hline Delay over $100 \%$ & 93 & $25.2 \%$ & $100 \%$ \\
\hline
\end{tabular}

Moreover, the statistical distribution of the worst delays experienced by the projects that the respondents have been involved with are presented in Figure 5.3. The distribution was normal as the kurtosis and skewness values were 0.242 and 0.413 respectively. The mean value (M) of the worst delays at $95 \%$ confidence interval was found as 21.28 months and standard deviation (SD) as 12.347 months. The minimum worst delay situation was one month, while the maximum was 70 months. The worst delays, in terms of $25^{\text {th }}$ and $75^{\text {th }}$ percentile, were 12 and 30 months respectively, while the interquartile range of 18 months was also obtained.

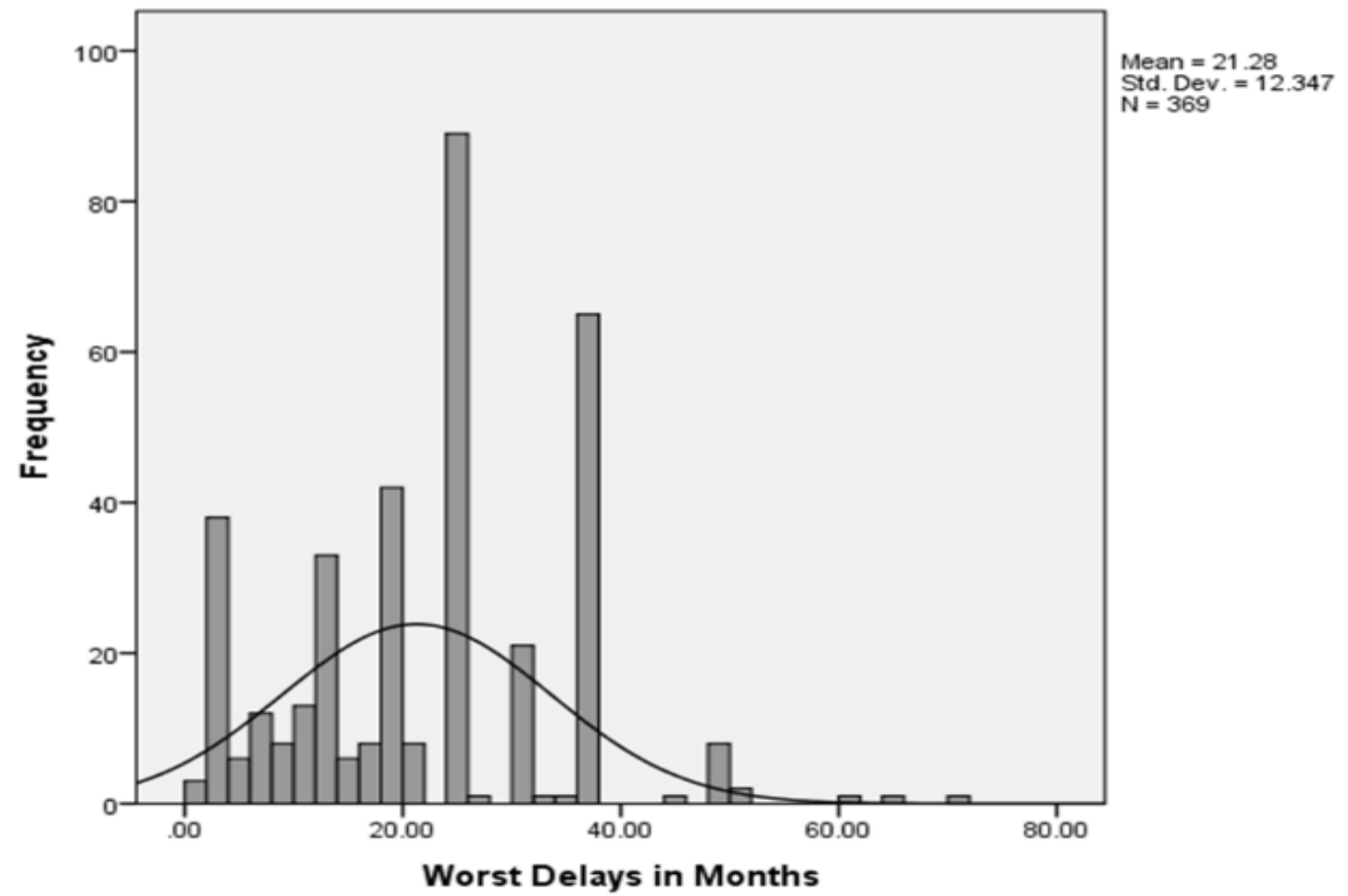

Figure 5.3 Worst delays experienced 


\subsubsection{Completion of Project Prior to Deadline}

The respondents were also requested to provide an estimate of the best no-delay situations encountered in the projects they have been involved with in the last 10 years. Figure 5.4 presents the statistical distribution of the best no-delay situations provided by the respondents. 100 out of 369 participants indicated that they have experience completing their projects before the estimated duration. The kurtosis value was 8.942, indicating that the distribution was leptokurtic, having a higher peak. The skewness value of 2.729 showed that the distribution was skewed positively. The mean (M) was 5.73 months and standard deviation (SD) was 11.295 months.

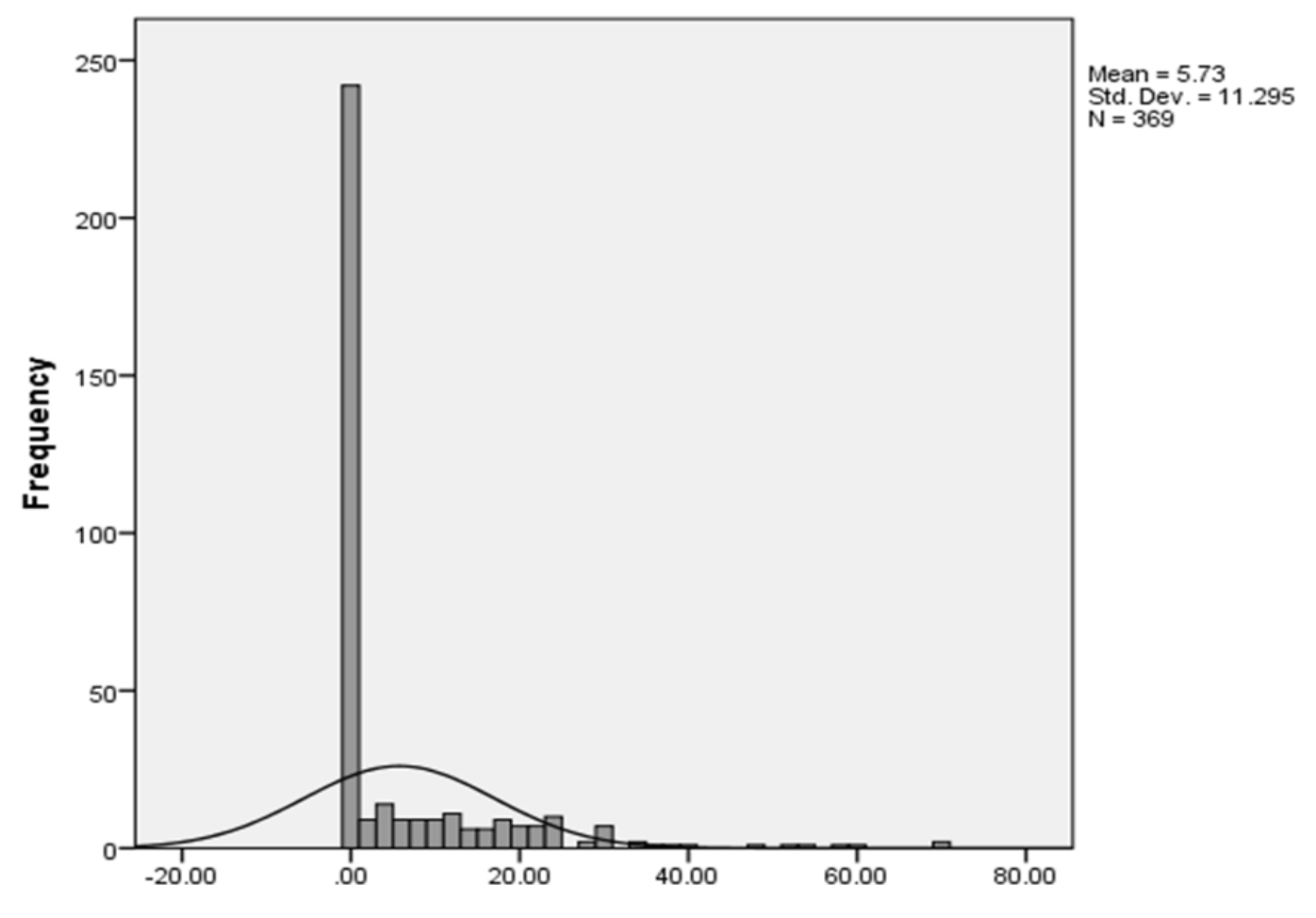

Completion of Proiect Prior to Deadline

Figure 5.4 Completion of Project Prior to Deadline

\subsection{Factors Contributing to Delays}

This section reports on the issues identified in the quantitative analysis as influencing the development of delays in the public construction projects in the Kingdom of Saudi Arabia. In the first instance, the actions of potential stakeholders who have an impact on the occurrence of delays were determined. After that, the opinions of the respondents, in relation to the 
principle critical client's, contractor's, and consultant's related factors contributing to construction delays were confirmed.

\subsubsection{Stakeholders Influencing Delays}

As indicated previously, the respondents to the survey represented three major stakeholders in any typical project, namely the client, contractor, and consultant. Existing research has suggested that these key stakeholders contribute mostly to the delays experienced in the construction projects. Accordingly, the respondents were asked questions regarding the stakeholders they thought had influenced delays experienced in their executed projects.

Majority of the respondents, 202 [55.7\%], considered the contractor to be the stakeholder contributing mostly to the delays experienced in the construction projects in the KSA. The second largest number of respondents, 130 [35.2\%], believed that most of the delays occurring in the projects they were involved with could be attributed to the client or owner. The least number or percentage of the respondents, 37 [10.1\%], indicated that the consultant influenced the delays that manifested in the projects that they participated in. Figure 5.5 presents the results graphically. According to Mahamid (2013), the most significant causes of delays relate to the contractors. In the previous study conducted by Khalil and Al-Ghafly (1999) and Al-Kharashi and Skitmore (2009), it was reported that the stakeholders want to blame each other as responsible for the delays. For example, participants from the client's organisation are likely to identify the contractors as the cause of delays in their projects. However, this study has tried to address this bias by asking further responses from the participants, so as to arrive at more realistic results. 


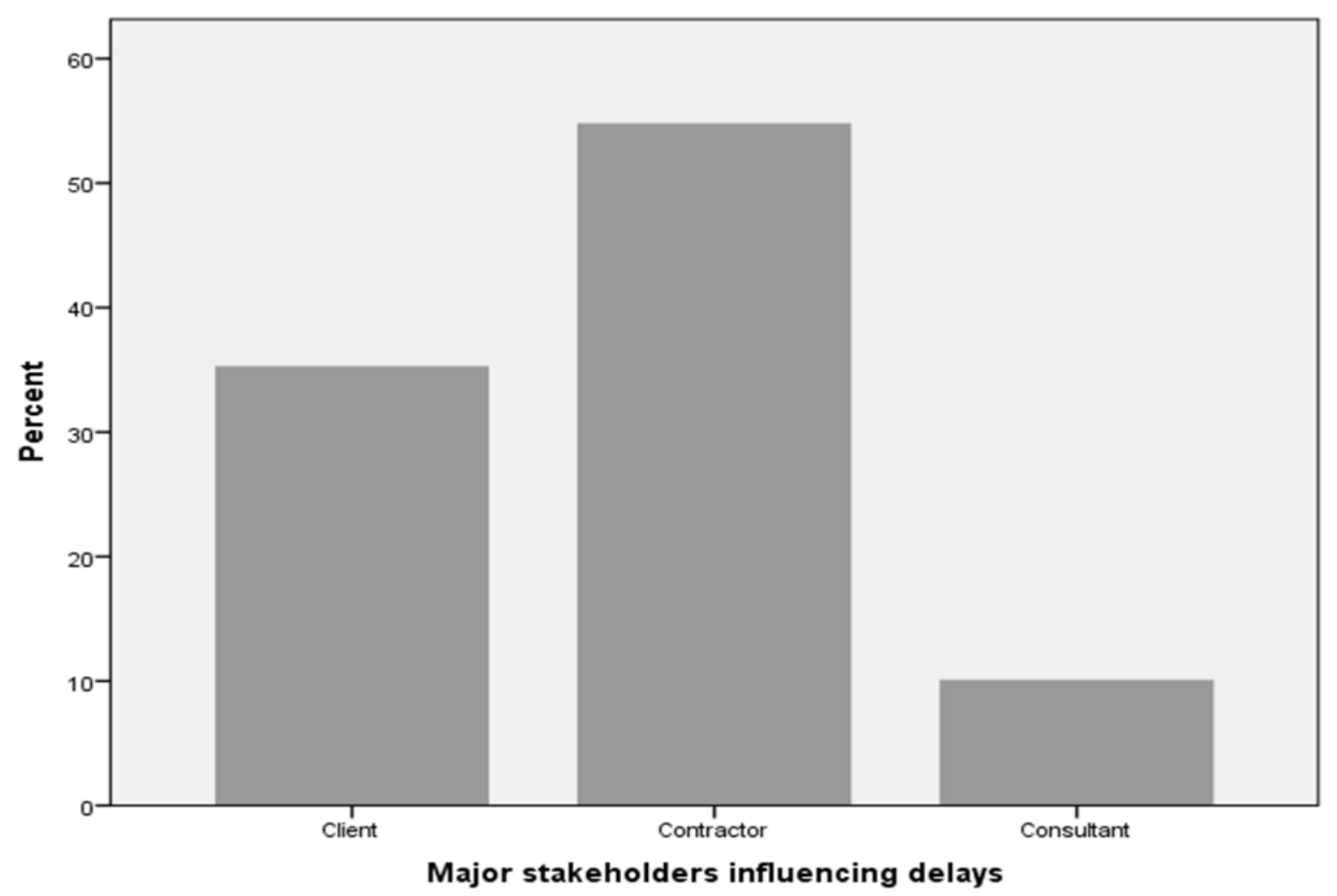

Figure 5.5 Stakeholders influencing delays

Looking at the results from the different perspectives of each of the stakeholders, clients mainly identified contractors as the major source of delays, accounting for $75 \%$ of the delays. Clients also admitted their responsibility for the delays, accounting for $32 \%$, while they perceived the remaining $2 \%$ of delays to be due to the consultants. Contractors, however, perceive most of the delay sources $(48 \%)$ to be the clients. Contractors assumed $30 \%$ of the responsibility for delays and attributed $22 \%$ to the consultants. From the consultants' perspective, the contractors are responsible for the delays (62\%), while the clients are responsible for $35 \%$ and the consultants admit to a 5\% responsibility. Each of the stakeholder categories tends to shift the blame to the others, but a collective examination of the groups' perception shows that contractors are responsible for most delays (55\%), followed by clients with $35 \%$. 


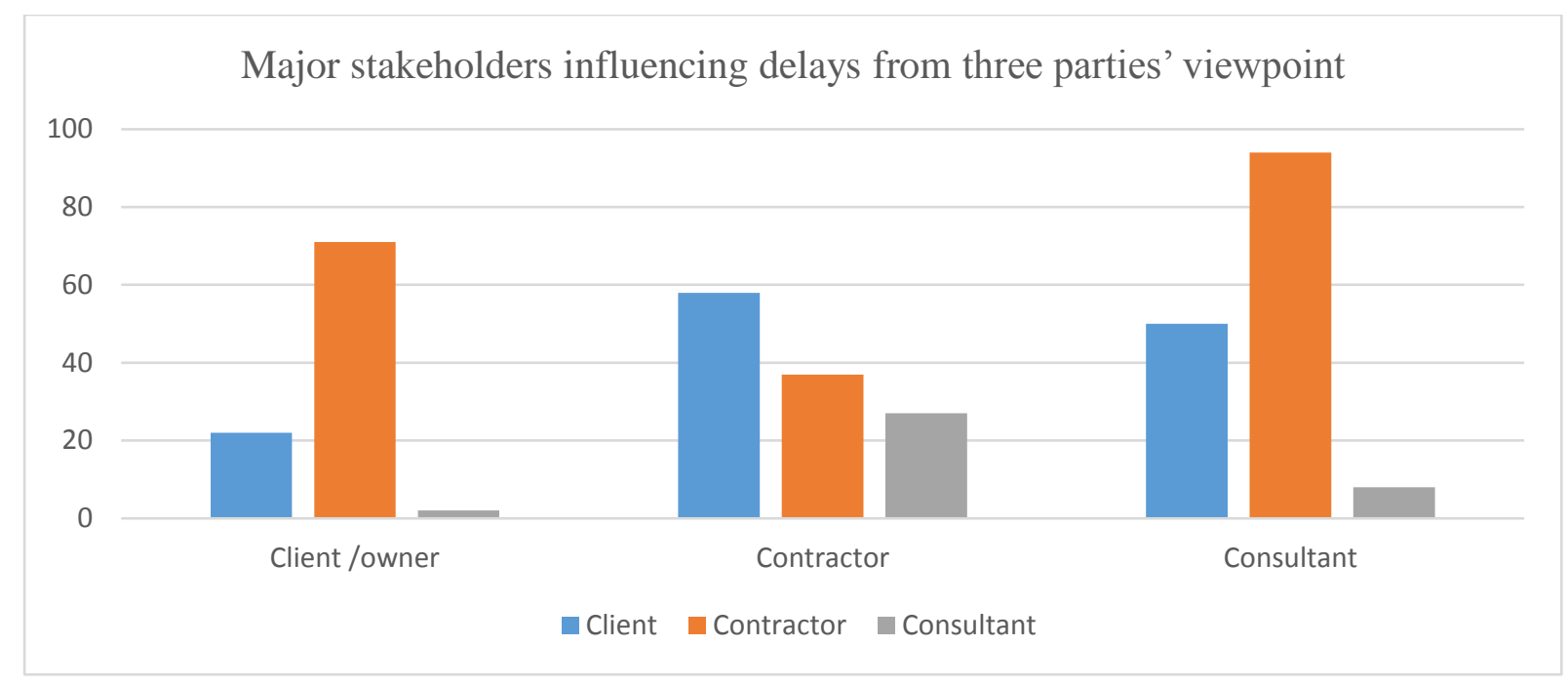

Figure 5.6 Stakeholders influencing delays from the three parties' viewpoint

\section{Chi-Squared test}

For testing if the selected decisions are significantly influenced by their backgrounds (i.e., client, consultant or contractor), the non-parametric Chi-squared test was performed as an objective test for k-independent samples. This test measures the distribution of the respondents from various backgrounds, when they answer the question about the stakeholders' influence on delays, and verifies if their backgrounds have an impact on them. The non-parametric Chisquared test for k-independent samples is a straight extension of the non-parametric Chisquared for two independent samples.

The assumption of ordinal data is made for the decision-making model, as the question presents a choice of decision options. As the frequencies in the discrete categories (ordinal or nominal) constitutes the research data, the Chi-squared test can be utilised for the determination of the significance of differences among the k-number of independent groups (Siegel, 1956). The hypotheses test can be framed as below:

$\mathrm{H}_{\mathrm{o}}$ : the respondents from each background are not selecting the answer randomly;

$\mathrm{H}_{1}$ : the respondents from each background are selecting the answer randomly.

At the significance level of 5\% ( $\alpha=0.05)$, as both the type I and type II errors are considered to be significant equally.

The Chi-squared formula:

$$
\chi^{2}=\sum_{i=1}^{r} \sum_{j=1}^{k} \frac{\left(o_{i j}-E_{i j}\right)^{2}}{E_{i j}}
$$


Where $o_{i j}$ is the observed value at the $\mathrm{i}^{\text {th }}$ row and $\mathrm{j}^{\text {th }}$ column; $E_{i j}$ being the expected value under the null hypothesis at the $\mathrm{i}^{\text {th }}$ row and $\mathrm{j}^{\text {th }}$ column; degrees of freedom $d f=$ $(r-1)(k-1)$ where $r$ is the number of categories (rows) and $k$ is the number of groups (columns).

If $\chi^{2}<\chi_{\alpha, d f}^{2}$, then the null hypothesis is rejected.

Table 5.7 Results of Chi-square application

\begin{tabular}{|lcccc|cccc|}
\hline \multicolumn{3}{l}{ Observed Vales } & \multicolumn{4}{c|}{ Expected Values } \\
\hline & Client & Contractor & Consultant & Client & Contractor & Consultant \\
\hline Client & 22 & 71 & 2 & 95 & 33.47 & 52.01 & 9.53 & 95 \\
\hline Contractor & 58 & 37 & 27 & 122 & 42.98 & 66.79 & 12.23 & 122 \\
\hline Consultant & 50 & 94 & 8 & 152 & 53.55 & 83.21 & 15.24 & 152 \\
\hline & 130 & 202 & 37 & 369 & 130 & 202 & 37 & 369 \\
\hline
\end{tabular}

$$
\begin{gathered}
\chi^{2}=\sum_{i=1}^{r} \sum_{j=1}^{k} \frac{\left(o_{i j}-E_{i j}\right)^{2}}{E_{i j}}=58.25 \\
d f=(r-1)(k-1)=(3-1)(3-1)=4 \\
\alpha=0.05
\end{gathered}
$$

From the Chi-square table, $\chi_{\alpha, d f}^{2}=\chi_{\alpha=0.05, d f=4}^{2}=0.711$

Since in this case $\chi^{2}>\chi_{\alpha, d f}^{2}$, the null hypothesis is not rejected. Hence, the respondents are not randomly selecting the answers, and the answers might be influenced by their background.

\subsubsection{Construction project processes that can best minimise delays}

The respondents to the survey were asked which project phase they felt the delays to be best minimised from. The findings of this study indicated that the construction phase is the project phase that most respondents feel that the delays can be best minimised. The opinions of the respondents, in relation to the project process, is presented in Figure 5.7. The majority of the respondents $(61.5 \%)$ identified the construction phase as the process in which delays can be best minimised. This was followed by the identification of the planning phase $(47.7 \%)$, designing phase $(41.5 \%)$, and lastly the tendering phase $(28.5 \%)$. Moreover, this result is consistent with previous studies, where the construction phase was also identified as the lead cause of delays among all the project phases (Ramanathan et al., 2012). 


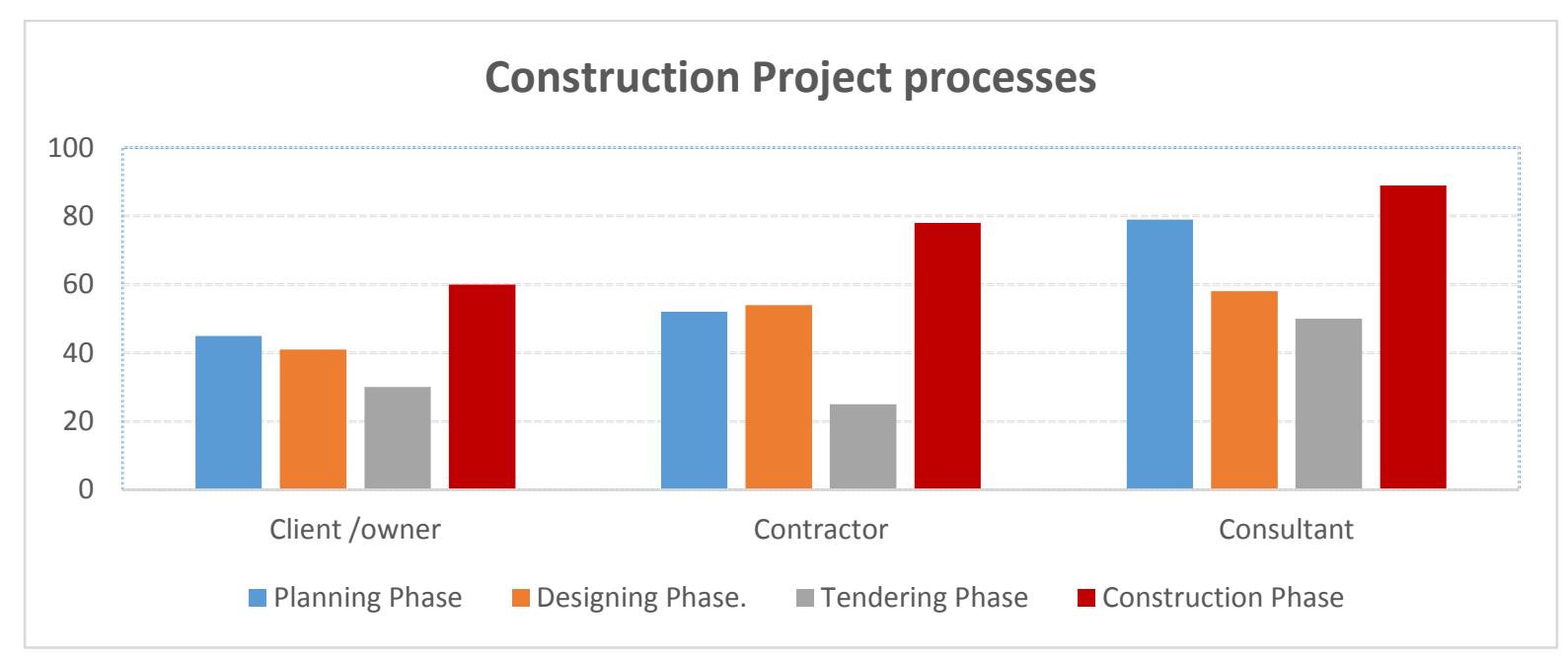

Figure 5.7 Construction project processes that can best minimise delays

As can be seen from the diagram above, all of the stakeholder groups reported the construction stage to be the best phase to reduce delays. Consultants and clients agreed that the planning phase followed the construction phase as the best stage to reduce delays, while contractors believed that the designing phase was the next best phase for minimising delays. For consultants and clients, the designing and tendering phases then followed respectively, while the planning and tendering phases followed respectively for contractors.

\subsubsection{Client-Related Delay Factors}

In addition to the stakeholders, the leading critical factors contributing to the occurrence of construction delays in the KSA were examined from the perspectives of the survey respondents. The respondents were asked to rank client-related factors that have contributed to delays in the public projects they have been involved in. Using mean rank, the views of the respondents representing three different stakeholder organisations: client, contractor, and consultant, were collected. Out of the five client-related factors identified, slowness in the decision-making process received the highest ranking from the respondents. The mean score of this factor was 4.260 .

This result indicated that majority of the respondents considered slowness in the decisionmaking process as an important client-related factor contributing to delays. Another clientrelated factor that received the second highest ranking was change orders, with a mean score value of 4.114. Delay in delivering the site to the contractor emerged as the lowest ranking 
client-related factor influencing delays in the public construction projects in the KSA. Table 5.8 presents the results in detail. This finding is similar to what is reported in Al-Kharashi and Skitmore (2009). Al-Kharashi and Skitmore (2009) also found owner's slowness in making decisions as the top most popular client-related factor that causes delays. Likewise, AlHammadi and Nawab (2016) identified slow decision-making as a significant trigger of delays associated with clients. Akin to the outcome reported in this study, Assaf and Hejji (2006) found change orders to be among the most critical factors contributing to the occurrence of delays in public construction projects in the KSA. A delay in the progress payment to the contractors has also been identified in previous studies undertaken by Al-Kharashi and Skitmore (2009) and Al-Hammadi and Nawab (2016). However, unrealistic estimates for the duration and delays in delivering the site to contractors have not been found in the previous research as being triggers for delays.

Table 5.8 Client-related delay factors

\begin{tabular}{lll} 
Client-related delay factors & Mean & Rank \\
Unrealistic estimates for duration & 3.951 & 3 \\
Change orders. & 4.114 & 2 \\
Slowness in decision-making process. & 4.260 & 1 \\
Delay in delivering the site to contractor & 3.266 & 5 \\
Delay in progress payment. & 3.678 & 4 \\
\hline
\end{tabular}

\subsubsection{Contractor-Related Delay Factors}

Most of the respondents (clients, contractors, and consultants) ranked planning and scheduling of a project as a contractor-related factor contributing to the occurrence of construction delays in the KSA. This factor had a mean score of 4.111. Also, project finance difficulty has been rated second among the contractor-related factors, contributing to the occurrence of delays, with a mean score of 4.014. In this category, poor site management and supervision was a factor considered to have the lowest influence on construction delays in the KSA by most of the respondents.

The suggestion of this result was that majority of the respondents agreed that the planning and scheduling of a project was the most significant contractor-related factor stimulating the emergence of delays in public construction projects within the Kingdom of Saudi Arabia. Also, 
a majority of respondents opined that project finance difficulty constituted another contractorrelated factor motivating the development of delays in the KSA's public construction sector. On the other hand, the respondents agreed that project site management and supervision was the most insignificant contractor-related factor contributing to the occurrence of construction delays in the KSA. The details of the result are provided in Table 5.9.

The research outcome, in relation to contractor-related delay factors, is not much different from what has been reported previously in Al-Ojaimi (1989); Al-Khalil and Al-Ghafly (1999); Odeh and Battaineh (2002); and Al-Kharashi and Skitmore (2009). Similar to this study's finding, a poor scheduling of the project activities by contractors has been identified as a critical source of delays in studies such as Al-Ojaimi (1989); Al-Khalil and Al-Ghafly (1999); and AlKharashi and Skitmore (2009). While this problem has not been identified as the most important contractor-related delay factor in the previous studies, the current level of magnitude of projects being executed in the KSA must have elevated the criticality of this problem in this research. It appears that the problem of scheduling has increased in intensity, with the increasing numbers of large-scale construction projects being funded by the KSA government in the recent years. Specifically, Albogamy et al., (2013) and Mahamid et al., (2015) reported that planning and scheduling have become critical delay factors in the construction industry in the KSA. It should be noted that poor scheduling and planning by the contractor can be related to a lack of qualifications, skills, and experience, which has also been identified as a contractorrelated delay factor or it may relate directly.

Table 5.9 Contractor-related delay factors

\section{Contractor-related delay factors}

Planning and scheduling of project

Poor qualification, skills and experience

Poor site management and supervision.

Difficulties in financing the project.

Delay in sub-contractors' work.

\section{Mean Rank}

$4.111 \quad 1$

$3.981 \quad 3$

$3.764 \quad 5$

$4.014 \quad 2$

$3.875 \quad 4$ 


\subsubsection{Consultant-Related Delay Factors}

Construction delays in the KSA have been attributed to the actions of consultants. Consequently, the survey respondents were asked to rank the consultant-related factors as to which they felt caused more delays in comparison to the others. Out of the five consultantrelated factors put forward for the respondents' consideration in the survey, unclear and inadequate design details was an issue ranked highest by most of them. Apart from the respondents representing client organisations who ranked this factor as second, others from both contractor and consultant groups agreed to it being the most significant consultant-related factor responsible for triggering delays within the public construction sector in the Kingdom of Saudi Arabia. The consultant-related factor ranked as the second most important contributor to the occurrence of delays in the KSA's public construction projects is poor qualifications of supervisory staff or the consultant engineer. The lowest ranked consultant-related delay factor was an ineffective control of the progress of the project. This result compares with previous studies conducted by Al-Ojaimi (1989); Al-Khalil and Al-Ghafly (1999); and Al-Kharashi and Skitmore (2009). Al-Khalil and Al-Ghafly (1999) and Al-Kharashi and Skitmore (2009) found that poor qualifications of the consultant staff to be responsible for the delays in their studies. According to Al-Ojaimi (1989), the experience and capabilities of the consultants are crucial in the successful implementation of construction projects, and cannot be overemphasised. However, Al-Kharashi and Skitmore (2009) suggest that consultant organisations involved in the KSA's public construction projects often employ limited number of staff, thereby likely to encounter delays when carrying out their functions. Unclear and inadequate designs, as well as a delay in completing designs were also identified in Al-Kharashi and Skitmore (2009) as being contributors to the occurrence of construction delays. All these mentioned issues can still be linked to poor qualifications or inadequate staffing level. An overview of the results obtained in relation to the consultant-related factors causing public construction delays in the KSA is presented in Table 5.10. 


\section{Consultant-related delay factors}

Delay in approving sample materials

Unclear and inadequate design details

Not completing design drawing on time

Ineffective control progress of project

Poor qualifications of supervisory staff or consultant engineer

$\begin{array}{ll}\text { Mean } & \text { Rank } \\ 3.713 & 4 \\ 3.943 & 1 \\ 3.753 & 3 \\ 3.615 & 5 \\ 3.799 & 2\end{array}$

\subsubsection{General Management and External (GME)-Related Delay Factors}

In addition to client, contractor, and consultant-related delay factors, other general management and external issues that could contribute to the experience of construction delays within the public projects in the KSA were also examined from the perspectives of the respondents. The respondents were requested to rank their agreement regarding the contribution that these general management and external-related factors might have made to the occurrence of delays in the public projects they had participated in the KSA. The general management and externalrelated factor that was ranked highest by the respondents was that of assigning or awarding contracts to the lowest bidder. The second highest ranked general management and externalrelated factor identified as contributing to construction delays in public projects within the KSA was a lack of communication between all project parties. Apart from the respondents from client organisations who ranked this factor third most significant, the respondents from both contractor and consultant organisations rated it as the second highest discriminator of delay occurrence in the projects they have participated in. The lowest ranked general management and external-related delay factor was weather effects such as unfavourable hot or wintry weather conditions. Respondents from all the organisational categories agreed with this choice.

A lack of communication between all project parties has been referred to in a previous study by Al-Khalil and Al-Ghafly (1999), as well as Al-Kharashi and Skitmore (2009) as influencing delays. Also, the assigning of contracts to the lowest bidder has been suggested in Al-Hammadi and Nawab (2016) as being a frequent delay factor in construction projects. This result is also supported by Mahamid et al. (2012), who found that the award of projects based on the lowest bid price is one of the main contributors to delays. According to Falqi (2004), adopting a tendering system that favours the selection of the lowest bidding contractor in public projects 
may lead to the choosing of contractors who do not have adequate qualifications or resources such as financial means to execute the projects successfully. However, research conducted by both Al Saudi et al. (2011), as well as Alofi and Kashiwagi (2017) have recommended that there is a need to adopt procurement systems that do not give priority to the lowest bidding contractors, such as performance information procurement system, as suggested in Kashiwagi (2011). Moreover, Olaniran (2015) also indicates that effective and inclusive contractor prequalification systems can be applied to ensure that contractors are chosen based on a fair consideration of multiple criteria, rather than only the lowest bidding price.

Similar to the outcome of this study, Al-Kharashi and Skitmore (2009) also identified changes in the prices of materials as an important delay factor. This can be a major problem considering that the actual inflation rate is difficult to predict into the future, which can affect the prices of materials over the course of implementing a project. Such changes are known to affect project costs, which can instigate delays (Al-Kharashi and Skitmore, 2009). A sudden increase in the cost of materials may affect their availability during the construction phase, thus disrupting the satisfactory progress of project. A summary of the GME-related delay factors is presented in Table 5.11.

Table 5.11 General management and external-related delay factors

\section{GME-related delay factors}

Lack of communication between all project parties

Shortage of qualified manpower

Assigning contracts to the lowest bidder system

Changes in material and resources prices during construction

Weather effect (hot, rain, etc.)

$\begin{array}{ll}\text { RII } & \text { Rank } \\ 3.902 & 2 \\ 3.894 & 3 \\ 4.122 & 1 \\ 2.997 & 4 \\ 2.751 & 5\end{array}$

\subsubsection{Mean Ranking of Delay Factors}

Table 5.12 summarises all delay factors that have been ranked by the respondents, which are represented by client, contractor, and consultant organisations. As mentioned previously in Section 4.5, the delay factors were categorised into four groups including client, contractor, consultant, as well as general management and external. The combination of all these factors was undertaken in order to rank all the delay factors based on the agreement of the respondents. Out of the 20 delay factors assessed by the respondents, the client-related factor, slowness in 
decision-making process, received the highest mean score of 4.26. Most of the respondents from all stakeholder organisations including client, contractor, and consultant rated this factor as the most important contributor to the occurrence of delays in public construction projects within the Kingdom of Saudi Arabia.

Table 5.12 Overview of the mean ranking for delay factors

\begin{tabular}{lll}
\hline Client-related delay factors & Mean & Rank \\
Unrealistic estimates for duration & 3.951 & 7 \\
Change orders & 4.114 & 3 \\
Slowness in decision-making process & 4.260 & 1 \\
Delay in delivering the site to contractor & 3.266 & 18 \\
Delay in progress payment & 3.678 & 16
\end{tabular}

\section{Contractor-related delay factors}

Planning and scheduling of project

$\begin{array}{ll}4.111 & 4 \\ 3.981 & 6 \\ 3.764 & 13 \\ 4.014 & 5 \\ 3.875 & 11\end{array}$

\section{Consultant-related delay factors}

Delay in approving sample materials

$3.713 \quad 15$

Unclear and inadequate design details

$3.943 \quad 8$

Not completing design drawing on time

$3.753 \quad 14$

Ineffective control progress of project

Poor qualifications of supervisory staff or consultant engineer

\section{GME-related delay factors}

Lack of communication between all project parties

$3.902 \quad 9$

Shortage of qualified manpower

$3.894 \quad 10$

Assigning contracts to the lowest bidder system

$4.122 \quad 2$

Changes in material and resources prices during construction

$2.997 \quad 19$

Weather effect (hot, rain, etc.)

2.751 20

The second issue that attributed to the cases of delays that had occurred in the projects executed previously by the respondents was the assigning or awarding contracts to the lowest bidder 
system. This GME-related factor got an average mean score of 4.122. On average, change orders, a client-related factor, obtained the third highest mean score of 4.114 , based on the evaluation of the respondents. The respondents awarded the fourth highest average mean ranking to planning and scheduling, a contractor-related delay factor. Also, difficulties in financing of the project, another contractor-related issue was considered the fifth most significant factor in stimulating the emergence of construction delays with the public projects in the Kingdom of Saudi Arabia.

The average mean score for each of the delay factor categories (that is client, contractor, consultant, and general management and external) was also determined. This was to enable a comparison of the factors' level in influencing the occurrence of construction delays. Table 5.13 shows the summary of the mean score for the four delay factor categories. In the order of ranking, contractor-related factors came first with a total mean score of 3.949 , followed by client-related (3.854), consultant-related (3.764), and lastly, GME-related factors (3.533).

The differences in the ranking by the different participant groups were investigated by conducting an ANOVA test. The f-ratio value was found to be 1.12158, while the p-value was 0.369754 . This result indicated that the differences were not statistically significant at $\mathrm{p}<0.05$.

Table 5.13 Summary of mean ranking for delay factor categories

\begin{tabular}{lll}
\hline Client-related delay factors & Mean & Rank \\
Unrealistic estimates for duration & 3.951 & 7 \\
Change orders & 4.114 & 3 \\
Slowness in decision-making process & 4.260 & 1 \\
Delay in delivering the site to contractor & 3.266 & 18 \\
Delay in progress payment & 3.687 & 16 \\
Total average & 3.854 & 2 \\
Contractor-related delay factors & & \\
Planning and scheduling of project & 4.111 & 4 \\
Poor qualifications, skills and experience & 3.981 & 6 \\
Poor site management and supervision & 3.764 & 13 \\
Difficulties in financing the project & 4.014 & 5 \\
Delay in sub-contractors' work & 3.875 & 11 \\
Total average & $\mathbf{3 . 9 4 9}$ & $\mathbf{1}$ \\
Consultant-related delay factors & & \\
Delay in approving sample materials & 3.713 & 15 \\
Unclear and inadequate design details & 3.943 & 8
\end{tabular}




\begin{tabular}{|c|c|c|}
\hline Not completing design drawing on time & 3.753 & 14 \\
\hline Ineffective control progress of project & 3.615 & 17 \\
\hline $\begin{array}{l}\text { Poor qualifications of supervisory staff or } \\
\text { consultant engineer }\end{array}$ & 3.799 & 12 \\
\hline Total average & 3.764 & 3 \\
\hline GME-related delay factors & & \\
\hline $\begin{array}{l}\text { Lack of communication between all project } \\
\text { parties }\end{array}$ & 3.902 & 9 \\
\hline Shortage of qualified manpower & 3.894 & 10 \\
\hline $\begin{array}{l}\text { Assigning contracts to the lowest bidder } \\
\text { system }\end{array}$ & 4.122 & 2 \\
\hline $\begin{array}{l}\text { Changes in material and resources prices } \\
\text { during construction }\end{array}$ & 2.997 & 19 \\
\hline Weather effect (hot, rain, etc.) & 2.751 & 20 \\
\hline Total average & 3.533 & 4 \\
\hline
\end{tabular}

\subsection{Current applications of PM Knowledge, Tools, and Techniques}

The results relating to the current application of PM tools, techniques and methodologies in managing delays in public projects within the context of the KSA are presented in this section.

\subsubsection{Project Management Knowledge}

The perceptions of the participants regarding the current awareness of project management knowledge, tools, and techniques in the KSA differed. While 162 [43.9\%] of the participants strongly disagreed or disagreed that the project management concepts were well-known within the public construction sector in the KSA, 128 [35.5\%] strongly agreed or agreed with that notion. However, 76 [20.6\%] were not certain as to whether or not project management concepts have gained acceptance in the KSA's public construction sector. The responses provided by the participants in this aspect showed that they did not generally consider project management knowledge to have gained widespread acceptance in the public construction projects in the KSA. This result supports the findings in Mitra and Tan (2012) that there is a growing awareness of project management principles in the KSA's construction projects. 
However, the authors suggest that the project management principles are yet to be nationally and adequately accepted in the country.

The PM tools, and techniques are not being effectively applied in the execution of public construction projects in the KSA. Most of the survey respondents, 245 [66.3\%], either strongly agreed or agreed that the use of PM tools, and techniques is ineffective, despite being recognised to some extent in the KSA. 62 [16.8\%] of the respondents strongly perceived that PM tools, and techniques are being actively utilised in the implementation of public construction projects in the KSA. Also, 88 [23.8\%] of them were neutral in their opinions as to whether PM tools, and techniques are being efficiently applied. Furthermore, a majority of the respondents, 292 [79.2\%], agreed to the notion that PM tools, and techniques are only used in a limited number of public projects within the KSA. This research outcome is in line with Mitra and Tan (2012) who found the application of PM concepts in the KSA's construction projects examined to be ineffective. Ineffective implementation of PM principles may be related to a lack of experience. Previous studies such as Al-Kharashi and Skitmore (2009), as well as Assaf and Al-Hejji (2006) have reported that a lack of PM experts is an important problem militating against a high performance of construction projects in the KSA.

To highlight the limited application of PM knowledge in most of the public construction projects in the KSA, there was a consensus by the majority of participants in recognising the need for further use and application of PM tools and techniques in managing public construction projects in the KSA; almost all the respondents made a case for its better use. Out of the 369 respondents, 336 [91\%] of them indicated that there was a need for an improvement in the application of PM knowledge within the public construction projects being implemented in the KSA. Mir and Pinnington (2014) have also recommended the need for improvement in the application of PM concepts in developing countries such as the KSA.

The differences between the opinions of the respondents from the three independent groups of stakeholders that are usually involved in the execution (i.e., client, contractor, and consultant) were analysed using the Kruskal-Wallis $\mathrm{H}$ test, otherwise known as One-way Analysis of Variance (ANOVA) on ranks. This test has been recommended for determining the differences in the responses of independent groups in relation to questions measured on an ordinal scale (Sueyoshi and Aoki, 2001). This test would help provide a balance of opinions and better understanding of the position of participants on the issues covered (González-Rodríguez et al., 
2012). The ranks of the responses from the three separate groups represented in the survey are shown in Table 5.14.

Table 5.14 Ranks for project management knowledge

\begin{tabular}{|c|c|c|c|}
\hline & $\begin{array}{l}\text { Organisational } \\
\text { Type }\end{array}$ & $\mathrm{N}$ & $\begin{array}{l}\text { Mean } \\
\text { Rank }\end{array}$ \\
\hline $\begin{array}{l}\text { Project management } \\
\text { knowledge is not new, } \\
\text { already widely known } \\
\text { in the KSA's public } \\
\text { construction sector }\end{array}$ & $\begin{array}{l}\text { Client /owner } \\
\text { Contractor } \\
\text { Consultant } \\
\text { Total }\end{array}$ & $\begin{array}{r}95 \\
122 \\
152 \\
369\end{array}$ & $\begin{array}{l}189.07 \\
195.02 \\
174.41\end{array}$ \\
\hline $\begin{array}{l}\text { Project management } \\
\text { knowledge is widely } \\
\text { recognised or } \\
\text { implemented in the } \\
\text { KSA }\end{array}$ & $\begin{array}{l}\text { Client /owner } \\
\text { Contractor } \\
\text { Consultant } \\
\text { Total }\end{array}$ & $\begin{array}{r}95 \\
122 \\
152 \\
369\end{array}$ & $\begin{array}{l}173.81 \\
181.67 \\
194.66\end{array}$ \\
\hline $\begin{array}{l}\text { Project management } \\
\text { knowledge is accepted } \\
\text { and understood, but is } \\
\text { generally not being } \\
\text { used effectively in the } \\
\text { KSA }\end{array}$ & $\begin{array}{l}\text { Client /owner } \\
\text { Contractor } \\
\text { Consultant } \\
\text { Total }\end{array}$ & $\begin{array}{r}95 \\
122 \\
152 \\
369\end{array}$ & $\begin{array}{l}184.34 \\
177.80 \\
191.19\end{array}$ \\
\hline $\begin{array}{l}\text { Project management } \\
\text { knowledge is only } \\
\text { popular or used in } \\
\text { certain construction } \\
\text { projects in the KSA }\end{array}$ & $\begin{array}{l}\text { Client /owner } \\
\text { Contractor } \\
\text { Consultant } \\
\text { Total }\end{array}$ & $\begin{array}{r}95 \\
122 \\
152 \\
369\end{array}$ & $\begin{array}{l}187.67 \\
187.65 \\
181.21\end{array}$ \\
\hline $\begin{array}{l}\text { There is a need for an } \\
\text { improvement in the } \\
\text { application of the } \\
\text { project management } \\
\text { knowledge in public } \\
\text { construction projects in } \\
\text { the KSA }\end{array}$ & $\begin{array}{l}\text { Client /owner } \\
\text { Contractor } \\
\text { Consultant } \\
\text { Total }\end{array}$ & $\begin{array}{r}95 \\
122 \\
152\end{array}$ & $\begin{array}{l}196.01 \\
175.86 \\
185.46\end{array}$ \\
\hline
\end{tabular}

The results of the Kruskal-Wallis $H$ test (as shown in Tables 5.14 and 5.15) undertaken indicated there was no statistically difference in the perceptions of the respondents (from the three major stakeholder organisations) regarding the current awareness of project management knowledge in the public construction sector of the KSA. As can be seen in Table 5.13, $\chi^{2}(2)=$ $2.921,2.673,1.174,0.376$, and 2.712 and $p$ values $>0.05$ for each ranked element at 0.232 , 
$0.263,0.556,0.829$, and 0.258 . The mean ranks in relation to respondents' perceptions about the current awareness of project management knowledge in the KSA can be seen in Table 5.15.

Table 5.15 ANOVA on ranks test statistics for project management knowledge $\mathrm{a}^{\mathrm{a}, \mathrm{b}}$

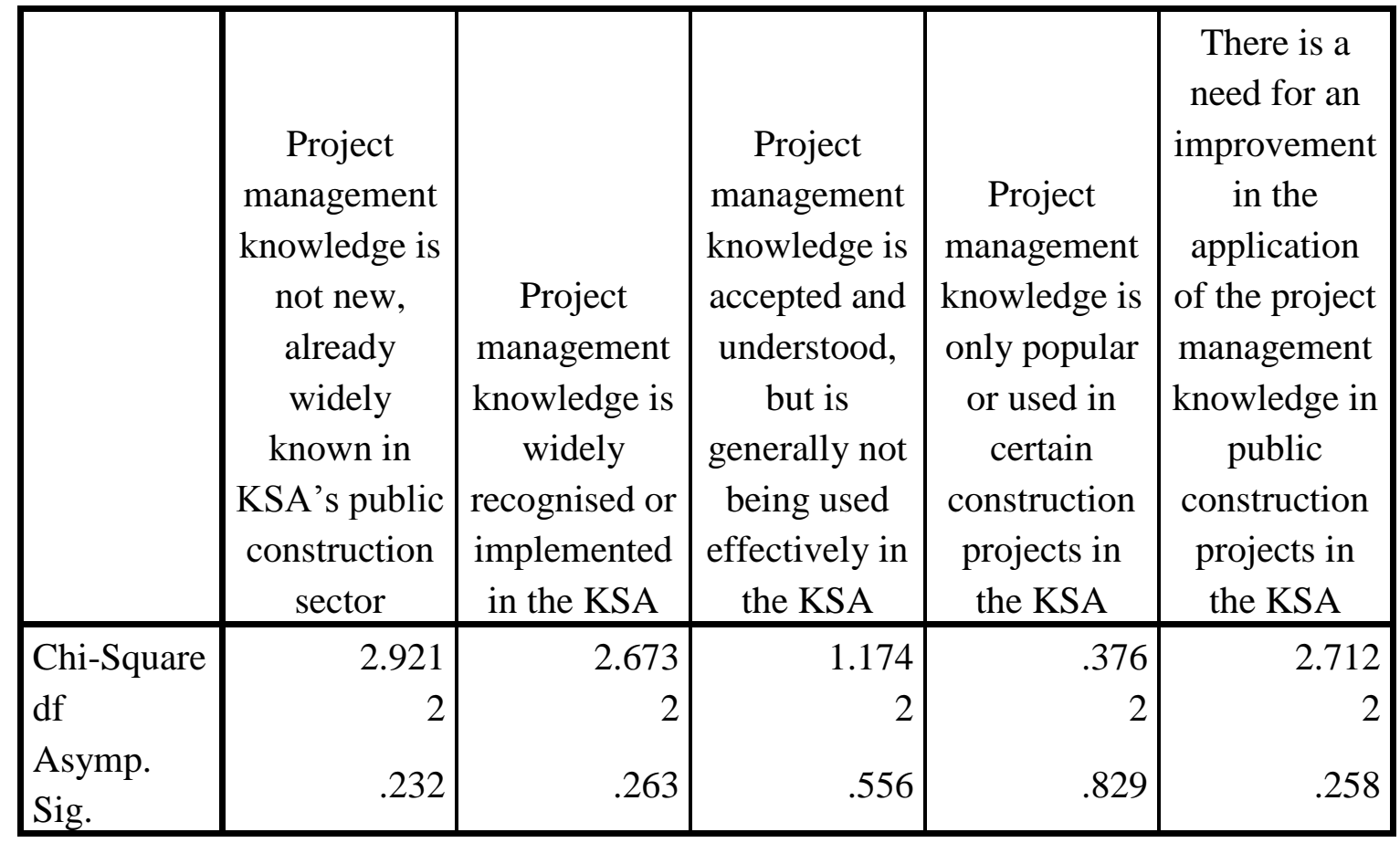

a. Kruskal Wallis Test

b. Grouping Variable: Organisational Type

\subsubsection{Project Time Management Tools and Techniques}

The survey respondents were asked in relation to the current level of implementation/use about various PM tools and techniques in the KSA's public construction projects. The project time management tools and techniques were categorised into project estimating, time planning, controlling, and project planning software.

\section{Project estimating tools and techniques}

The current application of different estimating tools and techniques for the project duration within the KSA's construction sector was determined from the perspectives of the respondents. The results showed that estimating tools and techniques such as expert judgment, previous project data, bottom-up estimating, parametric estimating, and published data estimating were mostly not being used in the KSA.

Table 5.16 presents a summary regarding the application of different project estimating tools and techniques in the KSA's public construction projects that the respondents have participated 
in. The outcome of this study supports previous research by Jørgensen (2007) that demonstrated the growing acceptance of expert judgment as an important estimating tool and technique in PM. Also, both expert judgment and lesson learnt have been described as important estimating tools and techniques that can be employed to improve project performance (PMI,2017; Larson and Gray, 2013). Therefore, it was logical that these techniques have been accepted in the KSA. However, it was surprising that bottom-up and parametric estimating were not found as being employed in the project estimation activities in the KSA's construction projects, despite their prominent application globally. This situation can only be explained by the relatively new adoption of PM concepts in the KSA. A low level of application of published estimating data can also be attributed to the same reason.

Table 5.16 Application of project estimating tools and techniques (PETT)

\begin{tabular}{|c|c|c|c|}
\hline PETT & $\begin{array}{c}\text { Never or Rarely } \\
\text { applied }\end{array}$ & $\begin{array}{c}\text { Sometimes } \\
\text { applied }\end{array}$ & $\begin{array}{c}\text { Frequently or Always } \\
\text { applied }\end{array}$ \\
\hline Expert judgement & $218[59.1 \%]$ & - & $151[40.9 \%]$ \\
\hline Lessons learnt & $66[17.9 \%]$ & - & $303[82.1 \%]$ \\
\hline $\begin{array}{c}\text { Bottom-up } \\
\text { estimating }\end{array}$ & $181[49.06 \%]$ & $140[37.94 \%]$ & $48[13 \%]$ \\
\hline $\begin{array}{c}\text { Parametric } \\
\text { estimating }\end{array}$ & $228[61.79 \%]$ & $92[24.93 \%]$ & $49[13.28 \%]$ \\
\hline $\begin{array}{c}\text { Published } \\
\text { estimating data }\end{array}$ & $320[86.72 \%]$ & - & $49[13.28 \%]$ \\
\hline
\end{tabular}

\section{Project time planning tools and techniques}

The results of the survey revealed that time management tools and techniques were generally not being used in the planning of public construction projects in the KSA. The timemanagement tools and techniques identified as seriously unused in the KSA were Gantt Bar Chart, WBS, CPM, PERT, milestone technique, Precedence Network Diagram (PND), and elemental trend analysis or Line of Balance (LOB).

Many of the survey responses, 250 [68.8\%], identified Gantt Bar Chart as seriously being unused in the planning of time management of public construction projects in the KSA. According to 243 [67.85\%] of the survey respondents, the WBS is rarely or never being used 
in KSA's public construction projects, while 119 [32.3\%] of them believed that this technique was being applied frequently or always. The Critical Path Method was suggested by a significant number of the respondents, 296 [72.5\%], as being applied in planning the time management of a project. In addition, PERT was found to be unpopular in the implementation of public construction projects in the KSA by 293 [79.4\%] of the respondents. The milestone technique was identified to be rarely used in managing project time in the KSA by 219 [59.35\%] of them. Majority of the respondents, 301 [81.57\%], indicated that PND was not frequently or always in use in most of the KSA's public construction projects. Furthermore, $334[90.51 \%]$ of the respondents indicated that the application of LOB in these projects was not frequent.

An overview of the application of project time tools and techniques is presented in Table 5.15. This result supports previous research that identified the application level of project time management tools and techniques to be generally low in developing countries, due to a lack of adequate education, knowledge, and awareness about them (Sawalhi and Enshassi, 2012; Golini et al. 2015). For example, $44 \%$ of the respondents to the survey conducted by Sawalhi and Enshassi (2012) on the use of project time management tools and techniques in the Gaza Strip indicated they have never used the WBS, while $17 \%$ of them reported that they were always using the method. Also, Memon et al. (2014) identified a low application of time management techniques in Malaysian construction projects.

Table 5.17 Application of project time management tools and techniques (TMTT)

\begin{tabular}{|c|c|c|c|}
\hline TMTT & $\begin{array}{c}\text { Never or } \\
\text { Rarely applied }\end{array}$ & $\begin{array}{c}\text { Sometimes } \\
\text { applied }\end{array}$ & $\begin{array}{c}\text { Frequently or } \\
\text { Always applied }\end{array}$ \\
\hline Gantt Bar Chart & $177[48.8 \%]$ & $76[20.6 \%]$ & $116[31.4 \%]$ \\
\hline $\begin{array}{c}\text { Work Breakdown Structure } \\
\text { (WBS) }\end{array}$ & $170[46.1 \%]$ & $80[21.7 \%]$ & $119[32.2 \%]$ \\
\hline $\begin{array}{c}\text { Critical Path Method (CPM) } \\
\text { Program Evaluation and } \\
\text { Review Technique (PERT) }\end{array}$ & $119[27.1 \%]$ & $119[27.4 \%]$ & $186[45.5 \%]$ \\
\hline Milestone Technique & $129[35.0 \%]$ & $90[24.4 \%]$ & $150[40.7 \%]$ \\
\hline
\end{tabular}




\begin{tabular}{|c|c|c|c|}
\hline $\begin{array}{c}\text { Precedence Network Diagram } \\
\text { (PND) }\end{array}$ & $301[81.57 \%]$ & - & $68[18.40 \%]$ \\
\hline Line of balance (LOB) & $334[90.51 \%]$ & - & $72[19.6 \%]$ \\
\hline
\end{tabular}

\section{Project controlling tools and techniques}

Some of the project controlling tools and techniques identified by most of the respondents as not being used frequently or always in the execution of public construction projects in the KSA included EVM, S-curve, and contractual milestone tracking. Table 5.18 displays the summary of the results concerning the use of project controlling tools and techniques. Research has identified the importance of EVM in controlling projects from failing to perform as expected (Patanakul and Milosevic, 2010). It can be seen from the table that $85.6 \%$ of the respondents showed that they never or rarely used EVM in the execution of their projects. This corroborates with earlier findings reported in Sawalhi and Enshassi (2012), which suggested an ineffective application of EVM and canvassed the need for more training courses for practitioners to enable them to use this technique to improve project performance.

The project controlling tools and techniques identified by most of the respondents as not being used frequently or always in the execution of public construction projects in the KSA included EVM, S-curve, and contractual milestone tracking. Nearly all the respondents, 316 [85.64\%], agreed that EVM was hardly being used to manage the execution of public construction projects in the KSA. Also, 296 [80.22\%] of the respondents suggested that the S-curve method was barely being applied. Lastly, 228 [61.79\%] of them believed that contractual milestone tracking was not being conducted in public construction projects within the KSA. Contrastingly, a larger percentage of the respondents indicated that regular progress meetings [86.70\%], actual project expenditure tracking [56.64\%], and percentage completion of activities [91.30\%] were being used frequently or always in the projects. Likewise, performance report and measurement at site were reported being used at most times by $52.85 \%$ and $60.98 \%$ of the respondents respectively. 
Table 5.18 Application of Project Controlling Tools and techniques (PCTT)

\begin{tabular}{|l|c|c|c|}
\hline \multicolumn{1}{|c|}{ PCTT } & $\begin{array}{c}\text { Never or Rarely } \\
\text { applied }\end{array}$ & $\begin{array}{c}\text { Sometimes } \\
\text { applied }\end{array}$ & $\begin{array}{c}\text { Frequently or Always } \\
\text { applied }\end{array}$ \\
\hline $\begin{array}{l}\text { Earned Value } \\
\text { Management (EVM) }\end{array}$ & $316[85.6 \%]$ & - & $53[14.4 \%]$ \\
\hline Regular progress meeting & $49[13.3 . \%]$ & - & $320[86.7 \%]$ \\
\hline S-curve & $296[80.2 \%]$ & - & $73[19.8 \%]$ \\
\hline Actual project expenditure & $69[18.7 \%]$ & - & $300[81.3 \%]$ \\
tracking & $32[8.7 \%]$ & - & $337[91.3 \%]$ \\
\hline Percentage completion of \\
activities & $54[14.7 \%]$ & - & $195[52.8 \%]$ \\
\hline Performance report & $59[16.0 \%]$ & $115[31.2 \%]$ & $141[38.2 \%]$ \\
\hline Contractual milestone \\
tracking
\end{tabular}

\section{Project planning software}

Project planning or scheduling software are not commonly used in the execution of public construction projects within the KSA based on the opinions of the respondents. Apart from the Excel Sheet and Primavera P6, other project planning software identified were regarded by the respondents as not being frequently or always used. Table 5.19 presents the summary of the application of project planning software by the respondents. A large proportion of the respondents suggested they have either never or rarely used both Project Commander and Asta Power Project in the projects that they have engaged in. This result may be attributed to Memon et al. (2014)'s findings that these two planning software are among the most ineffective in achieving desired project performance. Coincidentally, Microsoft project, Excel sheet, and Primavera P6 were identified as the most effective planning software by Memon et al. (2014), who also reported them as being most widely used among the survey respondents. 
Table 5.19 Application of Project planning software (PPS)

\begin{tabular}{|l|c|c|c|}
\hline \multicolumn{1}{|c|}{ PPS } & $\begin{array}{c}\text { Never or } \\
\text { Rarely applied }\end{array}$ & $\begin{array}{c}\text { Sometimes } \\
\text { applied }\end{array}$ & $\begin{array}{c}\text { Frequently or Always } \\
\text { applied }\end{array}$ \\
\hline Excel Sheet & $41[11.1 \%]$ & - & $328[88.9 \%]$ \\
\hline Microsoft Project & $115[31.2 \%]$ & $135[36.6 \%]$ & $119[32.2 \%]$ \\
\hline Primavera P6 & $105[28.5 \%]$ & - & $264[71.5 \%]$ \\
\hline $\begin{array}{l}\text { Project } \\
\text { Commander }\end{array}$ & $353[95.6 \%]$ & - & $16[4.4 \%]$ \\
\hline $\begin{array}{l}\text { Asta Power } \\
\text { Project }\end{array}$ & $354[96.0 \%]$ & - & $15[4.0 \%]$ \\
\hline
\end{tabular}

\section{Relative Importance for PM tools and techniques}

The relative importance analysis of all the PM tools and techniques identified was also conducted to determine their current usage within the public construction projects in the KSA. The results of the analysis are presented in Table 5.20.

Table 5.20 Summary of relative importance index for PM tools and techniques categories

\begin{tabular}{lll}
\hline & \multicolumn{2}{c}{ Average } \\
Project Estimating Tools and Techniques & RII & Rank \\
Expert judgment & 0.562 & 13 \\
Previous project data & 0.698 & 6 \\
Bottom-up estimating & 0.489 & 17 \\
Parametric estimating & 0.450 & 21 \\
Published estimating data & 0.460 & 20 \\
& & \\
P. Time Management Tools and Techniques & & \\
Gantt Bar Chart & 0.540 & 15 \\
Work Breakdown Structure & 0.545 & 14 \\
Critical Path Method & 0.637 & 9 \\
Program Evaluation and Review Technique & 0.505 & 16 \\
Milestone date programming Technique & 0.595 & 11 \\
Precedence Network Diagram & 0.488 & 18 \\
\hline
\end{tabular}




\section{Project Controlling Tools and Techniques}

$\begin{array}{lll}\text { Earned Value Management } & 0.463 & 19 \\ \text { Regular progress meeting } & 0.729 & 3 \\ \text { S-curve } & 0.488 & 18 \\ \text { Actual project expenditure tracking } & 0.694 & 7 \\ \text { Percentage completion of activities } & 0.746 & 2 \\ \text { Performance report } & 0.705 & 5 \\ \text { Contractual milestone tracking } & 0.619 & 10 \\ \text { Measurement on site } & 0.727 & 4\end{array}$

\section{Project Planning Software}

$\begin{array}{lll}\text { Excel sheet } & 0.762 & 1 \\ \text { Microsoft Project } & 0.581 & 12 \\ \text { Primavera P6 } & 0.663 & 8 \\ \text { Project Commander } & 0.356 & 23 \\ \text { Asta Power Project } & 0.333 & 24\end{array}$

\subsubsection{Differences in Perceptions of Application of PM Tools and Techniques}

The Kruskal-Wallis H (ANOVA on ranks) test was undertaken to determine significant differences that might exist in the perceptions of respondents from client, contractor, and consultant organisations regarding the application of PM tools and techniques in the KSA. Tables 5.21 and 5.22 present the results of the ranks of responses and ANOVA on ranks test statistics. The results indicated that there was a statistical difference in the opinions of the survey responses from different groups (client, contractor, and consultant) in relation to the application of certain PM tools and techniques in the public construction projects in the KSA. These tools and techniques, as highlighted in Table 5.22, include previous project data, bottomup estimating, WBS, CPM, PERT, milestone technique, PND, LOB, EVM, and S-curve method. As can be seen in Table 5.22, $\chi^{2}(2)=11.095,6.946,11.932,8.064,12.858,11.039$, $8.106,11.415,10.729$ and 19.777 and $p$ values $>0.05$ for each of these elements respectively. 
Table 5.21 Ranks for project management tools and techniques

\begin{tabular}{|c|c|c|c|}
\hline Tools and Techniques & Organisational Type & $\mathbf{N}$ & Mean Rank \\
\hline \multirow[t]{4}{*}{ Expert judgment } & Client/owner & 95 & 180.54 \\
\hline & Contractor & 122 & 176.77 \\
\hline & Consultant & 152 & 194.39 \\
\hline & Total & 369 & \\
\hline \multirow[t]{4}{*}{ Previous project data } & Client/owner & 95 & 208.48 \\
\hline & Contractor & 122 & 162.64 \\
\hline & Consultant & 152 & 188.27 \\
\hline & Total & 369 & \\
\hline \multirow[t]{4}{*}{ Bottom-up estimating } & Client/owner & 95 & 166.99 \\
\hline & Contractor & 122 & 179.48 \\
\hline & Consultant & 152 & 200.69 \\
\hline & Total & 369 & \\
\hline \multirow[t]{4}{*}{ Parametric estimating } & Client/owner & 95 & 177.66 \\
\hline & Contractor & 122 & 183.27 \\
\hline & Consultant & 152 & 190.97 \\
\hline & Total & 369 & \\
\hline \multirow[t]{4}{*}{ Published estimating data } & Client/owner & 95 & 168.99 \\
\hline & Contractor & 122 & 189.17 \\
\hline & Consultant & 152 & 191.66 \\
\hline & Total & 369 & \\
\hline \multirow[t]{4}{*}{ Gantt bar chart } & Client/owner & 95 & 184.03 \\
\hline & Contractor & 122 & 190.40 \\
\hline & Consultant & 152 & 181.28 \\
\hline & Total & 369 & \\
\hline \multirow[t]{4}{*}{ WBS } & Client/owner & 95 & 153.33 \\
\hline & Contractor & 122 & 196.01 \\
\hline & Consultant & 152 & 195.96 \\
\hline & Total & 369 & \\
\hline \multirow[t]{4}{*}{$\mathrm{CPM}$} & Client/owner & 95 & 158.99 \\
\hline & Contractor & 122 & 192.44 \\
\hline & Consultant & 152 & 195.28 \\
\hline & Total & 369 & \\
\hline \multirow[t]{4}{*}{ PERT } & Client/owner & 95 & 160.32 \\
\hline & Contractor & 122 & 177.16 \\
\hline & Consultant & 152 & 206.71 \\
\hline & Total & 369 & \\
\hline \multirow{4}{*}{$\begin{array}{l}\text { Milestone Date Programming } \\
\text { Technique }\end{array}$} & Client/owner & 95 & 155.48 \\
\hline & Contractor & 122 & 189.79 \\
\hline & Consultant & 152 & 199.61 \\
\hline & Total & 369 & \\
\hline \multirow[t]{2}{*}{ PND } & Client/owner & 95 & 164.70 \\
\hline & Contractor & 122 & 179.68 \\
\hline
\end{tabular}




\begin{tabular}{|c|c|c|c|}
\hline & $\begin{array}{l}\text { Consultant } \\
\text { Total }\end{array}$ & $\begin{array}{l}152 \\
369 \\
\end{array}$ & 201.96 \\
\hline \multirow[t]{4}{*}{ LOB } & Client/owner & 95 & 162.97 \\
\hline & Contractor & 122 & 176.85 \\
\hline & Consultant & 152 & 205.31 \\
\hline & Total & 369 & \\
\hline \multirow[t]{4}{*}{ EVM } & Client/owner & 95 & 158.53 \\
\hline & Contractor & 122 & 184.16 \\
\hline & Consultant & 152 & 202.22 \\
\hline & Total & 369 & \\
\hline \multirow[t]{4}{*}{ Regular progress meeting } & Client/owner & 95 & 172.08 \\
\hline & Contractor & 122 & 183.12 \\
\hline & Consultant & 152 & 194.58 \\
\hline & Total & 369 & \\
\hline \multirow[t]{4}{*}{ S-curve method } & Client/owner & 95 & 146.74 \\
\hline & Contractor & 122 & 187.84 \\
\hline & Consultant & 152 & 206.63 \\
\hline & Total & 369 & \\
\hline \multirow{4}{*}{$\begin{array}{l}\text { Actual project expenditure } \\
\text { tracking }\end{array}$} & Client/owner & 95 & 185.84 \\
\hline & Contractor & 122 & 185.06 \\
\hline & Consultant & 152 & 184.43 \\
\hline & Total & 369 & \\
\hline \multirow[t]{4}{*}{$\%$ completion of activities } & Client/owner & 95 & 196.47 \\
\hline & Contractor & 122 & 182.66 \\
\hline & Consultant & 152 & 179.71 \\
\hline & Total & 369 & \\
\hline \multirow[t]{4}{*}{ Performance report } & Client/owner & 95 & 188.03 \\
\hline & Contractor & 122 & 178.45 \\
\hline & Consultant & 152 & 188.36 \\
\hline & Total & 369 & \\
\hline \multirow[t]{4}{*}{ Contractual milestone tracking } & Client/owner & 95 & 182.65 \\
\hline & Contractor & 122 & 174.46 \\
\hline & Consultant & 152 & 194.92 \\
\hline & Total & 369 & \\
\hline \multirow[t]{4}{*}{ Measurement on site } & Client/owner & 95 & 177.71 \\
\hline & Contractor & 122 & 174.75 \\
\hline & Consultant & 152 & 197.78 \\
\hline & Total & 369 & \\
\hline
\end{tabular}

Table 5.22 ANOVA on ranks test statistics for PM tools and techniques ${ }^{\mathrm{a}, \mathrm{b}}$

\begin{tabular}{|l|l|l|l|}
\hline \multicolumn{1}{|c|}{ Tools and Techniques } & \multicolumn{1}{c|}{ Chi-Square } & df & Asymp. Sig \\
\hline Expert Judgement & 2.214 & 2 & .331 \\
\hline Previous project data & 11.095 & 2 & $.004 *$ \\
\hline
\end{tabular}




\begin{tabular}{|l|l|l|l|}
\hline Bottom-up estimating & 6.946 & 2 & $.031^{*}$ \\
\hline Parametric estimating & 1.041 & 2 & .594 \\
\hline Published estimating data & 3.210 & 2 & .201 \\
\hline Gantt Bar Chart & .532 & 2 & .766 \\
\hline WBS & 11.932 & 2 & $.003 *$ \\
\hline CPM & 8.064 & 2 & $.018^{*}$ \\
\hline PERT & 12.858 & 2 & $.002^{*}$ \\
\hline Milestone Technique & 11.039 & 2 & $.004^{*}$ \\
\hline PND & 8.106 & 2 & $.017^{*}$ \\
\hline LOB & 11.415 & 2 & $.003 *$ \\
\hline EVM & 10.729 & 2 & $.005 *$ \\
\hline Regular progress meeting & 2.937 & 2 & .230 \\
\hline S-curve method & 19.777 & 2 & $0.000^{*}$ \\
\hline Actual project expenditure tracking & .011 & 2 & .994 \\
\hline$\%$ completion of activities & 1.732 & 2 & .421 \\
\hline Performance report & .746 & 2 & .689 \\
\hline Contractual milestone tracking & 2.718 & 2 & .257 \\
\hline Measurement on site & 4.136 & 2 & .126 \\
\hline
\end{tabular}

a. Kruskal Wallis Test

b. Grouping Variable: Organisational Type

* Reject the null hypothesis (the difference is significant)

Based on the results of the Kruskal Wallis test, a post-hoc test was undertaken to determine where the differences between the opinions of the survey respondent groups lie. A Dunn's test, available in SPSS, was carried out in this regard. The results of the post-hoc test in Figure 5.5 shows that the difference lies between the contractor and client. In other words, the results indicated that the opinions of survey respondents regarding the application of the PM tools and techniques from the client organisational group differ significantly from those contractors with $p$ values $>0.05$. Contrastingly, the perceptions of respondents from the contractor group do not differ from the consultant organisations, which in turn are not significantly dissimilar from those of the client/owner group with $p$ values $>0.05$. The difference can be explained since the participants come from a range of backgrounds where differing tools and techniques are applied. The difference can also be attributed to the general awareness of PM tool and techniques application among the three main parties. For example, the percipients on different tools and techniques may yet be fully developed, where some participants can be very familiar with certain tools, whereas another group of participants could have no experience in using such tools. 


\section{Pairwise Comparisons of Organisational Type}

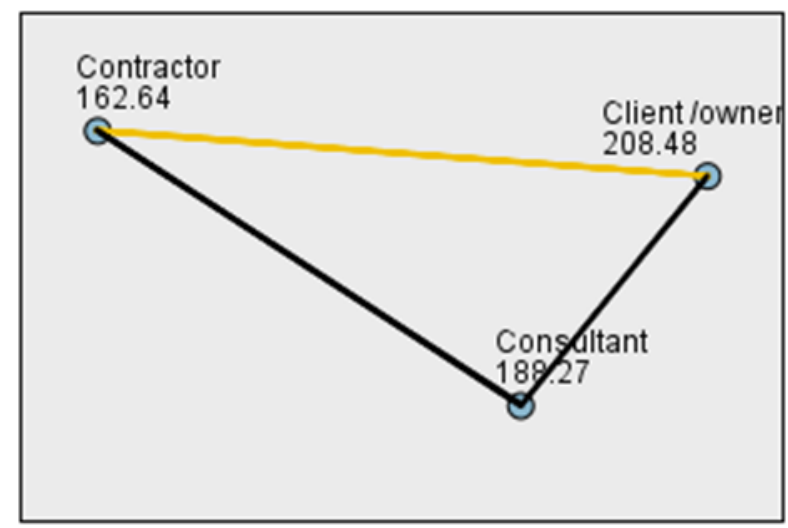

Each node shows the sample average rank of Organisational Type.

\begin{tabular}{|l|ccccc|}
\hline Sample1-Sample2 & $\begin{array}{c}\text { Test } \\
\text { Statistic }\end{array}$ & $\begin{array}{c}\text { Std. } \\
\text { Error }\end{array}$ & $\begin{array}{c}\text { Std. Test } \\
\text { Statistic }\end{array}$ & Sig. & Adj.Sig. \\
\cline { 2 - 7 } Contractor-Consultant & -25.634 & 12.375 & -2.071 & .038 & .115 \\
\hline Contractor-Client /owner & 45.840 & 13.931 & 3.291 & .001 & .003 \\
\hline Consultant-Client /owner & 20.206 & 13.315 & 1.518 & .129 & .387 \\
\hline
\end{tabular}

Each row tests the null hypothesis that the Sample 1 and Sample 2 distributions are the same.

Asymptotic significances (2-sided tests) are displayed. The significance level is .05 .

Figure 5.8 Results of post-hoc test for differences in opinions about PM tools and techniques

\subsection{Influence of current application of PM Tools and Techniques and Delay Factors}

The possible influence of current application of PM tools and techniques in public construction projects in the KSA on the occurrence of various categories of delay factors that have been identified was examined. The relationship between these constructs was undertaken using Structural Equation Modelling (Hoyle, 2012). This inferential analysis aimed to address the third objective of this research study. The delay factors have been previously identified as relating to client, contractor, and consultant, and other general management and external issues. The preliminary structural model, which displays the relationships between the main constructs, is shown in Figure 5.9. 


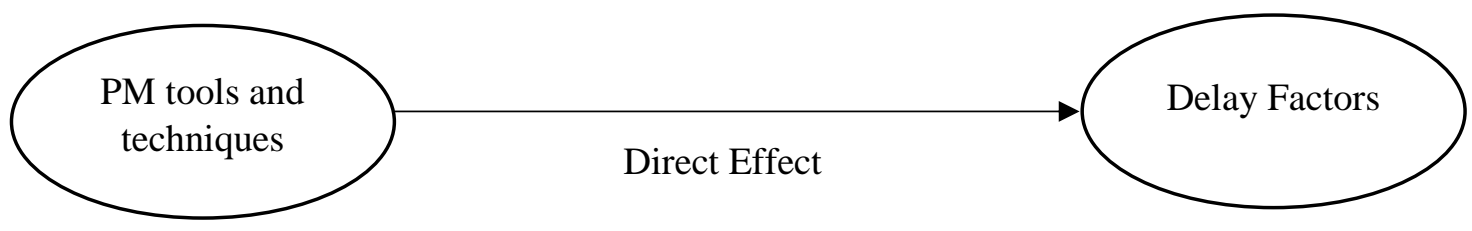

Figure 5.9 Structural model

Structural Equation Modelling (SEM) is used in this study to evaluate the influence of the application of project time management tools and techniques on delay factors in the KSA's public construction industry. SEM also allows researchers to test the relationships among the unobservable and latent constructs (Richter et al, 2016).

\section{Final SEM - PLS Path model}

After the validity and reliability has been tested, as shown in Chapter 4, an assessment of the structural model is done by bootstrapping (re-sampling) and examining the relationship between the various latent variables. This is done by evaluating the impact path of the current application of PM tools on the various delay factors. Bootstrapping involves the non-parametric process that permits the testing of the statistical significance of various PLS-SEM results. These include the P-value, as well as the T-statistic of the path coefficients. In this research, bootstrapping is done using a minimum number of bootstrapping samples of 5000 being run for assessing the path coefficients (Hair et al., 2011). 


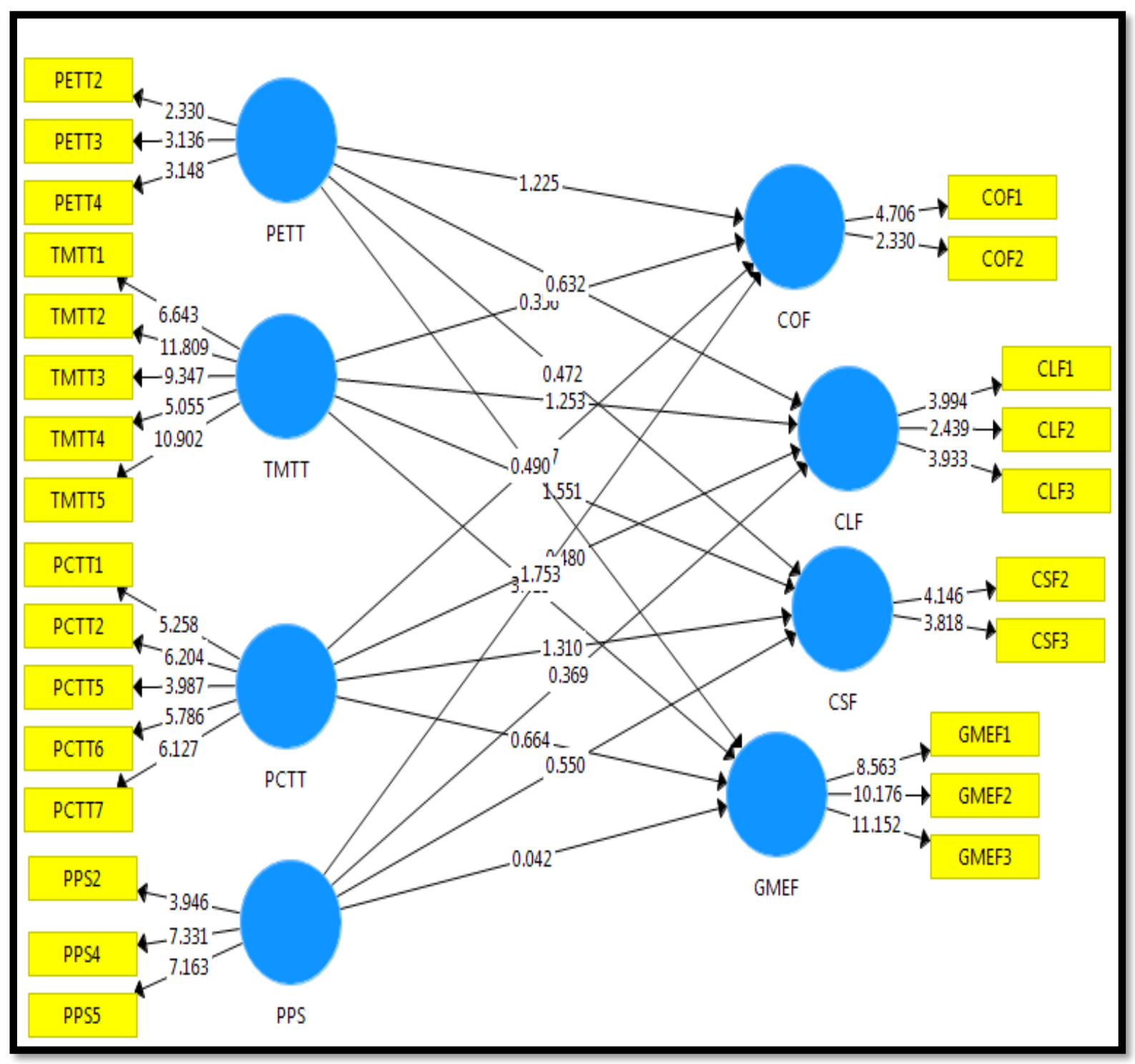

Figure 5.10 Final Structural Equation Modelling in Bootstrapping

\section{Final Result PLS - Path model}

The Path coefficient is a standardised regression coefficient (beta), which shows the direct effect of an independent variable on a dependent variable in the path model. This could be used for testing the total effect of the relationships among the latent variables in the Structural Equation Modelling approach (Hair et al., 2014).

The values between -1 and +1 have been standardised by a coefficient. For instance, this means that the estimated path coefficient close to +1 represents a strong positive relationship (and vice versa for the negative values). Amdur et al (2013) also clarify that a path model represents a diagram that illustrates a set of linear equations. Each of these paths in the model also signifies 
a "casual effect" of one variable on another. Moreover, each of the path coefficient quantifies the strength and direction of the total effect. The path coefficients are also used to specify the degree of change on the criterion variable that would occur in response to a one-unit change on the antecedent variable, just like the standardised betas in the multiple regressions.

Additional acceptable values that were suggested by Hair et al., (2011) were T-Values of 1.96 $($ significant level $=5 \%), 1.65($ significant level $=10 \%)$, and $2.58($ significant level $=1 \%)$. These significant total effects are capable of being tested using the t-statistics in the bootstrapping procedure (Richter et al, 2016).

The overall results for each SEM presented above is displayed in Table 5.23.

Table 5.23 Path coefficient, T-Statistics and P-Values for the structural model

\begin{tabular}{|c|c|c|c|}
\hline \multicolumn{4}{|l|}{ Path relationships } \\
\hline & Original Sample $(O)$ & T Statistics (|O/STDEV|) & $\begin{array}{l}\mathbf{P} \\
\text { Values }\end{array}$ \\
\hline PCTT $>$ CLF & -0.064 & 0.517 & 0.605 \\
\hline PCTT $>$ COF & -0.083 & 0.749 & 0.454 \\
\hline PCTT $>$ CSF & -0.125 & 1.321 & 0.187 \\
\hline PCTT -> GMEF & -0.095 & 1.091 & 0.275 \\
\hline PETT $->$ CLF & -0.047 & 0.565 & 0.572 \\
\hline PETT $>$ COF & -0.088 & 1.059 & 0.290 \\
\hline PETT $>$ CSF & -0.031 & 0.438 & 0.662 \\
\hline PETT -> GMEF & 0.028 & 0.439 & 0.660 \\
\hline PPS $->$ CLF & 0.030 & 0.422 & 0.673 \\
\hline PPS $->$ COF & 0.118 & 1.768 & 0.077 \\
\hline PPS $->$ CSF & -0.070 & 0.745 & 0.456 \\
\hline PPS -> GMEF & -0.005 & 0.093 & 0.926 \\
\hline TMTT $->$ CLF & 0.125 & 1.150 & 0.250 \\
\hline TMTT $->$ COF & 0.035 & 0.406 & 0.685 \\
\hline TMTT $->$ CSF & 0.111 & 1.311 & 0.117 \\
\hline TMTT -> GMEF & 0.240 & 3.409 & 0.000 \\
\hline
\end{tabular}

The following sections will explain the nature of the relationship between PM tools and techniques and delay factors.

\subsubsection{Project Estimating Tools and Techniques and Delay Factors}

The association between project estimating tools and techniques, as well as delay factors were examined using SEM. The essence of this modelling was to determine how a lack of effective 
usage of project estimating tools and techniques have an influence on the development of factors identified as contributing to the delays in public construction projects in the KSA. Three indicators including previous project data, bottom-up estimating and parametric estimating were used for measuring project estimating tools and techniques. Also, delays were described using client-related factors (slowness in decision-making process; unrealistic estimates for project duration; and change orders), contractor-related factors (planning and scheduling of project, as well as poor qualification, skills and experience of the staff), consultant-related factors (unclear and inadequate design details and not completing design drawing on time), and GME-related factors (lack of communication between all projects parties; assigning contracts to the lowest bidder system; and shortage in qualified manpower). The Structural Equation Modelling that shows the relationship between the variables of project estimating tools and techniques, as well as the delay factors, is shown in Figure 5.11.

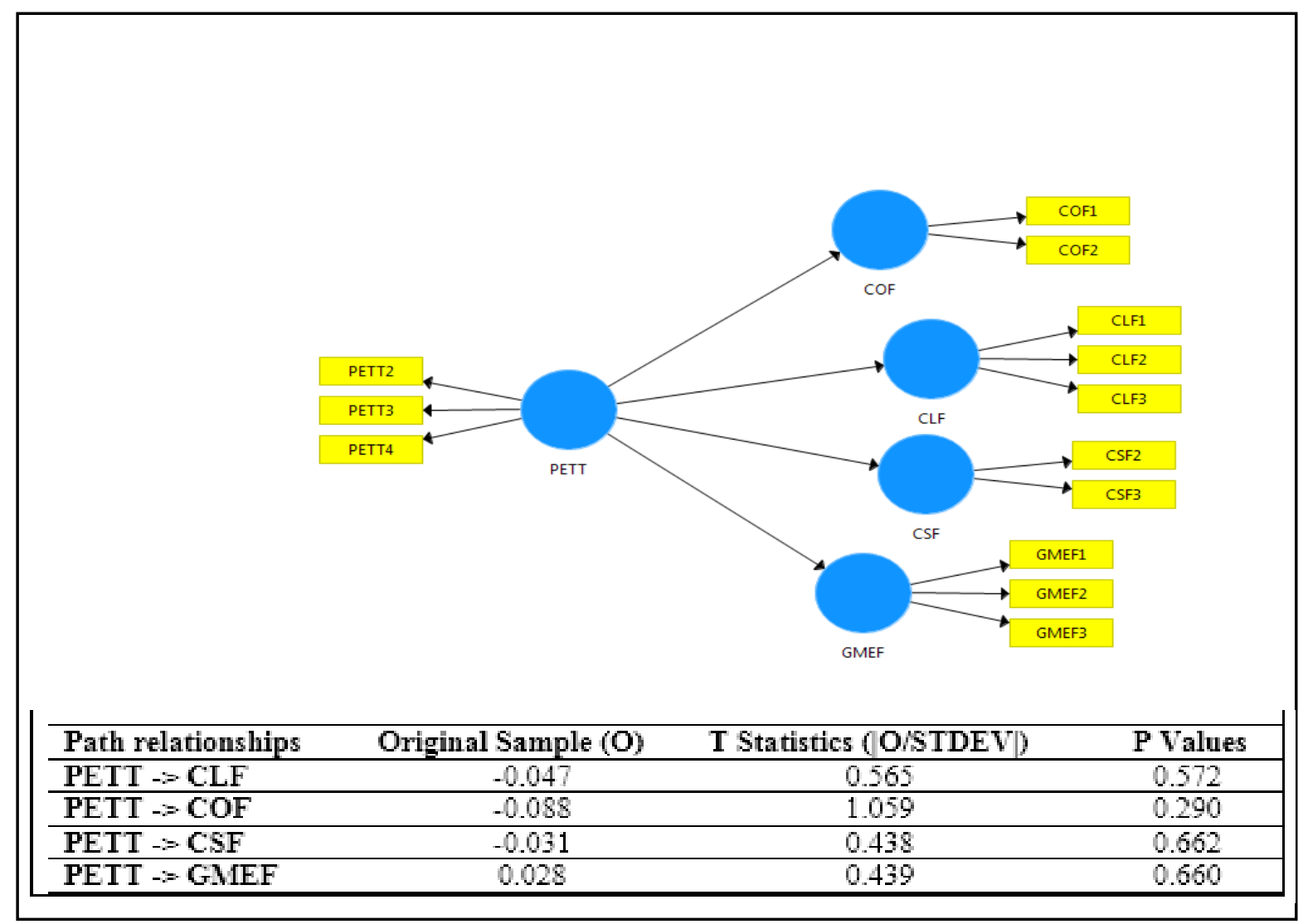

Figure 5.11 Final SEM model for project estimating tools and techniques and delay factors

The Structural Equation Model in Figure 5.11 above shows the path coefficient of the relationship between the application of project estimating tools and techniques and delay 
factors. In this structural equation modelling, project estimating tools and techniques are treated as an exogenous variable, while the endogenous variables were client, contractor, consultant, general management and external-related delay factors. This is because the study is attempting to examine the influence that the application of PM tools and techniques have on the various delay factors. The results of the path coefficients indicate an inverse relationship between the project estimation tools and delay factors, in which the amount of change in the association between the project estimating tools and techniques for each of the factors is identified as contributing to the occurrence of delays in public construction projects in the KSA. From the results shown, increasing the application of project estimating tools and techniques leads to the decreases of the likelihood of contractor, client, consultant-related delay factors. This study shows that the application of project estimating would lead to the reduction in the occurrence of delay factors.

Also, the application of project estimating tools and techniques was found to reduce client and consultant delay factors by 0.06 and 0.04 respectively. This study shows that the application of project estimation can lead to the reduction in the occurrence of delay factors. While there is no available study that has attempted to specifically identify the link between project estimating tools and techniques and delays in the KSA's construction, research focusing on other countries have done so. For example, research conducted by Kaliba et al., (2009), as well as Mezher and Tawil (1998) have earlier suggested that a poor application of project estimating tools and techniques have led to delays in construction projects executed in Zambia and Lebanon respectively.

\subsubsection{Project Time Management Tools and Techniques and Delay Factors}

The relationship between project time management tools and techniques, as well as delay factors was also assessed by SEM. The indicators of project time management tools and techniques included in this modelling were Work Breakdown Structure, Critical Path Method, Program Evaluation and Review Technique, Milestone Technique, and Precedence Network Diagram. Figure 5.12 displays the relationship between these variables of project time tools and techniques and the delay factors. 


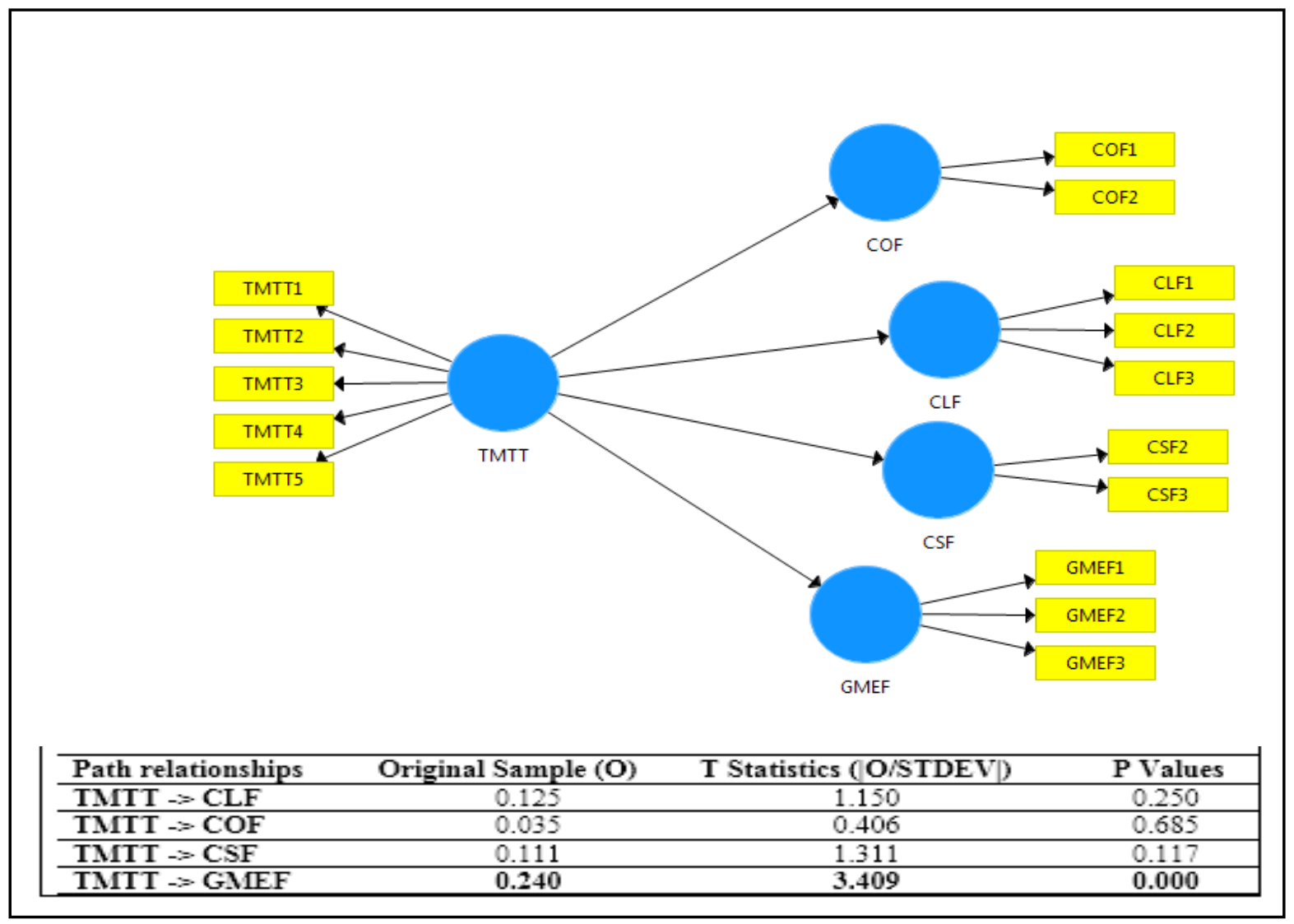

Figure 5.12 Final SEM model for project time management tools and techniques and delay factors

The Structural Equation Model in Figure 5.12 above indicates that the relationship between project time management tools and techniques, as well as the delay factors is a positive one. The findings suggest that a low or inadequate level of using project time tools and techniques have been significantly related to delays attributed to general management and external delay factors $($ Path coefficient $=0.240 ; T$-value $=3.409 ; \mathrm{p}>0.001)$. In other words, a lack of application of project time management tools and techniques is highly associated with the likelihood of occurrence of general management and external-related delay factors. The result obtained in this regard has validated the position of Patanakul et al. (2010), that an effective application of time management tools and techniques is key to preventing problems such as delays. Also, Abbasi and Al-Mharmah (2000) earlier suggested that the efficient use of project time management concepts can lead to better time performance. Surprisingly, this current study found no significant relationship between project time management planning tools and techniques and contractor, client and consultant-related delay factors. However, this could be explained by the fact that the current procurement system leads to the selection of low-qualified contractors. As a result, the performance of employees is set at a low level. The lowest bid 
system that is often adopted thus leads to the selection of employees with low level of skills (Al Saudi et al., 2011). However, there was also a possibility that the relevant tools and techniques have not been used efficiently due to the lack of highly qualified professionals, which has been reported as a major problem affecting the performance of construction contractors in the KSA (Al-Khalil and Al-Ghafly, 1999; Al-Kharashi and Skitmore, 2009).

\subsubsection{Project Control Tools and Techniques and Delay Factors}

The direct effect of the application of project control tools and techniques on the delay factors was also explored using SEM. The indicators for project control tools and techniques included in the modelling were Earned Value Management, regular progress meeting, project expenditure tracking, performance report, and contractual milestone tracking. The path of the relationships between these variables are represented in Figure 5.13.

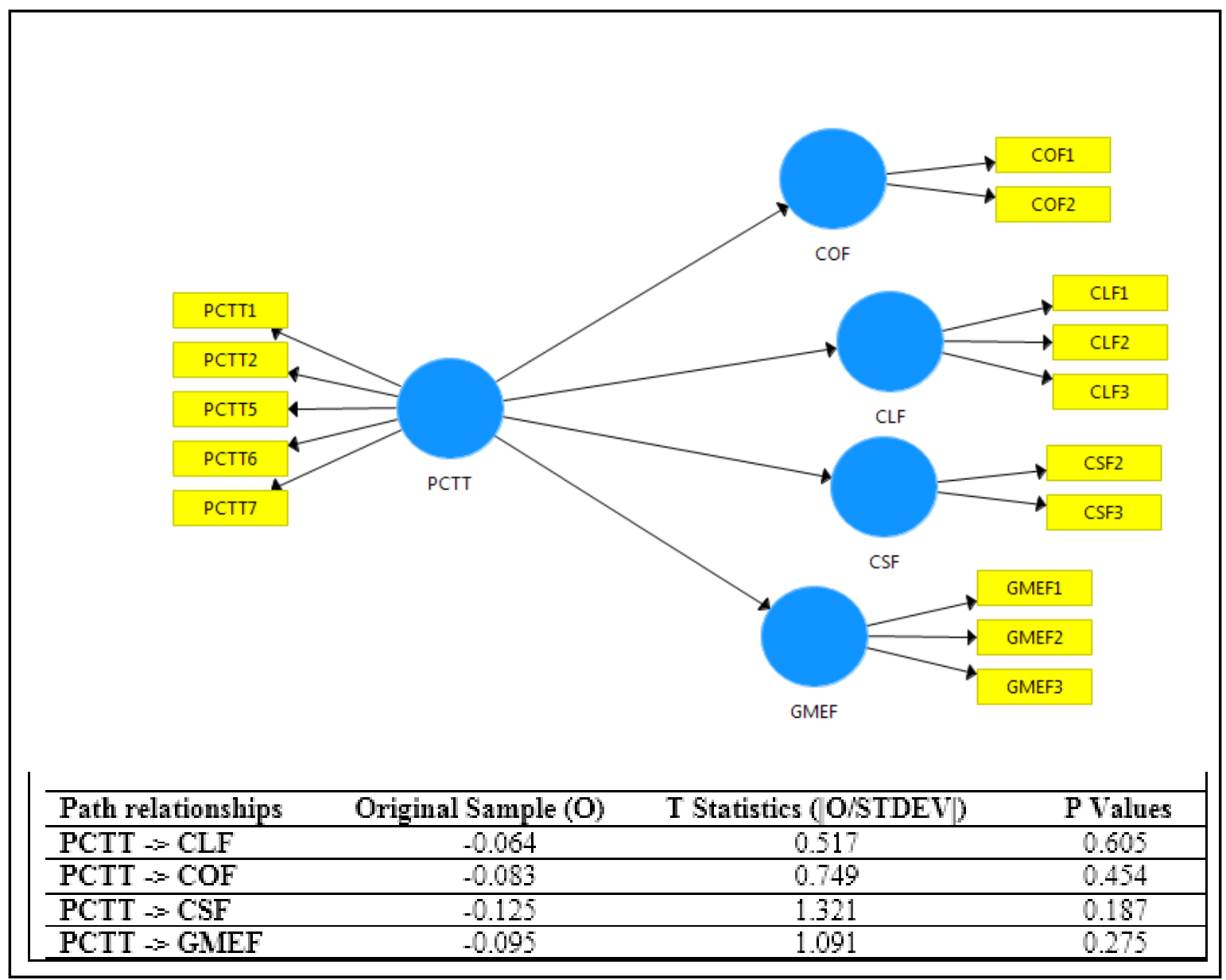

Figure 5.13 Final SEM model for project control tools and techniques and delay factors

The path coefficient of the relationship between project control management tools and techniques, as well as delay factors show that the relationship between these variables is 
inversely proportional. As can be seen in Figure 5.13, a lack or poor application of project control tools and techniques contributed to delay problems caused by client, contractor, consultant and general management factors with the negative loading of $-0.064,-0.083,-0.115$ and -0.095 respectively. In other words, the findings suggest that a reduction of application of project control management tools and techniques leads to an increase in the likelihood of the occurrence of delay factors. This result can be interpreted to mean that the oversight functions of all project parties over the satisfactory progress of public construction projects in the KSA are being hindered due to an improper use or a non-application of project control tools and techniques. The significance of using control methods to minimise delay issues has also been emphasised by Martinelli and Milosevic (2016). It is apparent from this study's findings that public construction projects in the KSA have not been benefitting from the application of these important control tools and techniques, especially Earned Value Management.

\subsubsection{Project Planning Software and Delay Factors}

The direct association between the application of project planning software and the identified delay factors was checked with the aid of SEM. The indicators of the project software were Microsoft Project, Project Commander, and Asta Power Project. The path of the relationships between these variables are represented in Figure 5.14. 


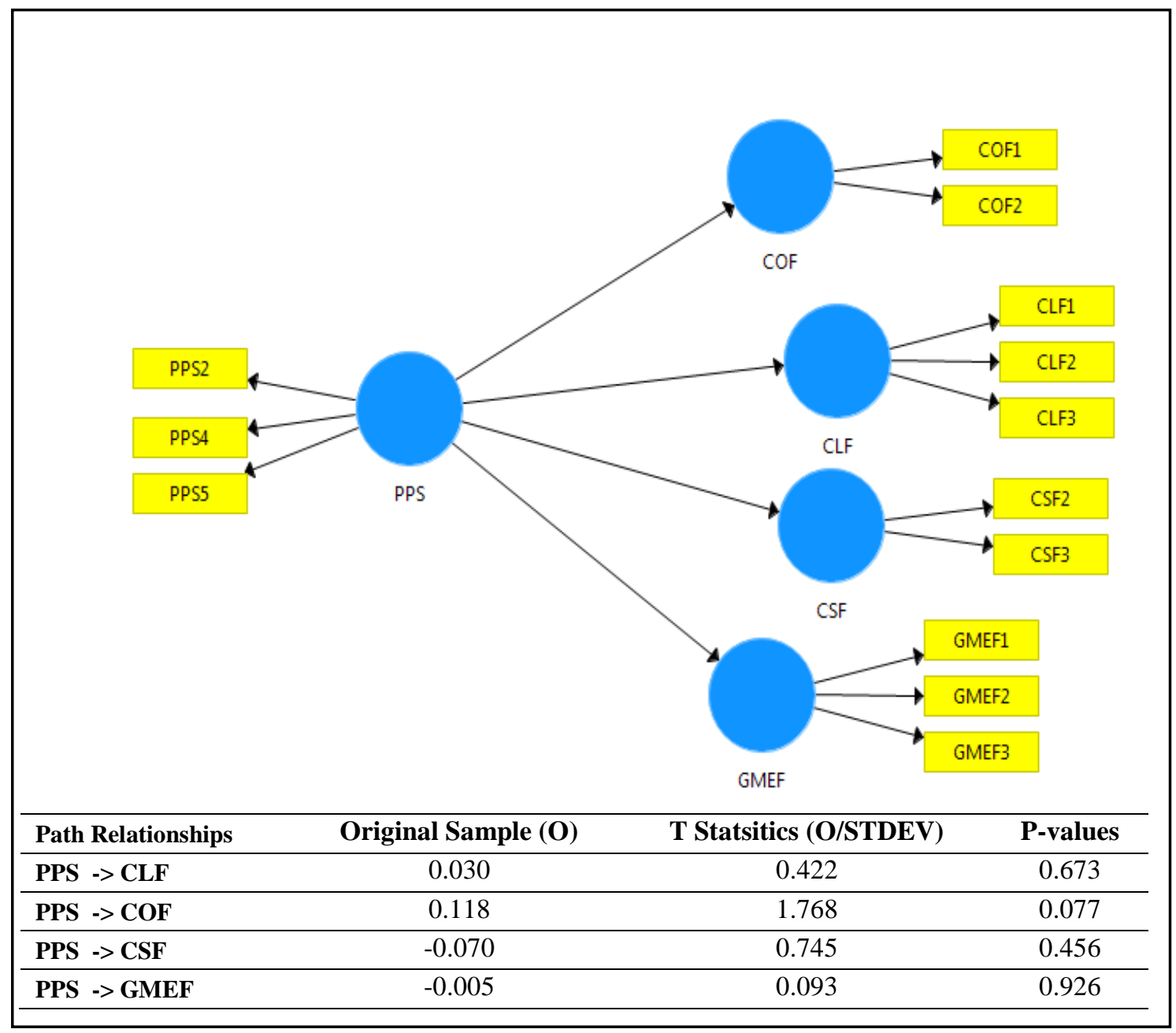

Figure 5.14 Final SEM model for project planning software and delay factors

Based on the path coefficient values shown in Figure 5.14, there is no significant association between the observed and latent variables, indicating that a lack or poor application of project planning software influences the occurrence of delays related to the contractor. However, it can be observed that a lack or poor application of the project planning software triggers the development of consultant and general management-related delay factors, as the path coefficient revealed that there is a negative total effect between these latent variables. This result supports earlier findings reported in Sawalhi and Enshassi (2012), which suggested that an effective application of project planning software can reduce the incidence of delays in construction projects. There is no association between the observed and latent variables, indicating that a lack or poor application of project planning software influences the occurrence of delays related to the client. 


\subsection{Summary}

This chapter presents an analysis of the quantitative data obtained through a survey conducted among construction professionals in the KSA. The analysis of the data was undertaken using a wide range of descriptive and inferential statistics such as means, standard deviation, KruskalWallis, Mean Ranking, Relative Importance Index, and Structural Equation Modelling among others.

The analysis of the data revealed several factors contributing to the development of delays in public construction projects within the KSA. The respondents identified all three major stakeholders involved in the execution as culpable in the occurrence of delays. However, the largest portion of blame was attributed to the contractors, which can be understood from the point of view that they normally assume the most central position of implementing the core deliverables of all construction projects. Based on the stakeholders responsible for the execution of public construction projects in the KSA, delays were found from the analysis of the data to relate to consultant, client, contractor, and general and external factors. Using the results obtained from the Relative Importance Index analysis of the data, the five top factors found to be influencing delays were: slowness in decision-making; awarding contracts to the lowest bidder system; change orders; planning and scheduling of project; and difficulty in financing the project.

A further analysis of the data showed that PM concepts are gaining acceptance across public construction projects in the KSA. However, the application of PM tools and techniques were reported to be generally poor among public construction projects. This situation is attributable to poor qualifications and a lack of adequate experience among professionals who are saddled with the responsibility of executing these projects. One-way ANOVA indicated that there was no significant difference in the opinions of the three main project stakeholder groups involved in the execution of these public projects in the KSA. This outcome confirmed the need for better education of the professionals on the use of PM tools and techniques to achieve better performance for the projects. Also, the five most commonly used PM tools and techniques were found to be the Excel sheet, percentage completion of activities, regular progress meeting, measurement on site, and performance report.

The results of the Kruskal Wallis-H and the post-hoc tests indicated that there were differences in the opinions between the three stakeholders regarding the application of PM tools and techniques. The differences were found to be between contractor and client, with the 
perceptions of the client organisational group identified as significantly different from those of the contractor group. Contrastingly, the perceptions of the respondents from the contractor group are not different from the consultant organisations, which in turn are not significantly dissimilar from those of the client/owner group. In addition, the relationship between the delays and application of PM tools and techniques was examined. The results confirmed that a low level or inducate poor or ineffective application of PM tools and techniques could lead to delays. Accordingly, there is a need to encourage an effective application of these PM tools and techniques in the KSA to minimise the incidence of delays. The next chapter of this thesis presents the results of the case studies. 


\section{CHAPTER 6}

\section{PRESENTATION OF DATA COLLECTION PHASE 2}

\subsection{Introduction}

This chapter presents the case study analysis of four Saudi Arabian public building projects (identified as Project-1, Project-2, Project-3, and Project-4). These projects were evaluated as a means of cross-validating the delay issues in the Saudi Arabian public construction sector (as previously identified in Chapter 5) with that of the KSA, towards developing a common framework that can be employed to mitigate delays. The assessment of real-life projects is significant in providing an appropriate contextual understanding to the problems being studied. The analysis of these case projects consists of four parts: (1) a description of each project; (2) an identification of the delay factors in them; (3) an evaluation of PM tools and techniques' application in each of the projects; and (4) an establishment of the possible link between the use of PM tools and techniques and delay issues in the case projects.

The analysis of these projects was based on the information and comments derived from the relevant documentary sources and interviews. The documentary sources include the 'Project Close-out Reports' and 'Project Agreements'. The information such as the project's procurement methods, progress reports, and performance evaluation were obtained from these documents. In addition, interviews were undertaken with 16 professionals involved in the execution of the case projects, to further understand the delay issues and PM practice (i.e., the application of PM tools and techniques) in these projects.

\subsection{Descriptions of Case Projects}

This section provides background information of the four public construction projects in the KSA used as case studies in this research. An overview of the case projects is described including its phases and structure. This information was gathered by examining evidentiary documents and transcripts of interviews conducted in relation to the case studies. It is worth mentioning that all public construction project contracts are given on a re-measured basis and are subject to the Saudi Government Tendering and Procurement Regulations, as issued by 
Royal Decree M/58, and generally managed based on the Public work contract (AECOM, 2013).

\subsubsection{Overview of Project-1}

Project-1 is a university hospital project (first phase) with a capacity of 215 beds. The hospital building, that is under construction for a publicly owned university, is located in a northwestern city of the Kingdom of Saudi Arabia. When completed, it will serve the educational aspects on one hand and citizens on the other. This project is considered one of the vital projects under the strategic plan of building the university city.

The University has a student population of about 32,000 (both local and international students), with the presence of state-of-the-art facilities on its campuses. The University currently has 14 colleges that are spread around multiple locations within its campus.

It is planned for this multi-purpose building to incorporate 91 specialised outpatient clinic rooms, 31 operating rooms, $32 \mathrm{x}$-ray rooms, 17 classrooms, and the administrative offices. The building covers a gross floor area (GFA) of about 134,000 square meters.

This project, funded by the Kingdom's government, is estimated to cost about US\$85 million. The Ministry of Education (MOE) in the KSA is the direct client for this project, who is assuming overall responsibility for its implementation from the start to finish. First, the client engaged the services of an organisation (as a consultant) who supervised the designs and engineering of the project components. Based on the initially-produced design and engineering documents, tendering and pre-qualification processes were developed, leading to the selection of the main contractor. After the selection of the main contractor, a project supervision consultancy organisation was also hired by the MOE.

This consultant has the overall responsibility of supervising the activities of the project's main contractor. The main contractor's primary duty is to refine the design and engineering documents utilising expertise within its own design team and build the facilities in accordance to agreed specifications with the supervising consultant and client. This project is being delivered using the Design-Bid-Build (D-B-B) approach based on the lowest bid tendering and subject to the relevant KSA's Public Works Contract Regulations. The project was originally scheduled to be completed by April 2013. However, due to multiple cases of delays experienced, the practical completion date for the project was shifted to October 2017 (as per secondary and interview data). 
Figure 6.1 shows the structure of Project-1. The main actors in the execution of this project are the client, supervising consultant and main contractor, with all of them collaborating to ensure the project's milestones are reached accordingly and that the pre-determined deliverables are achieved within the agreed time, quality, cost, and other objectives.

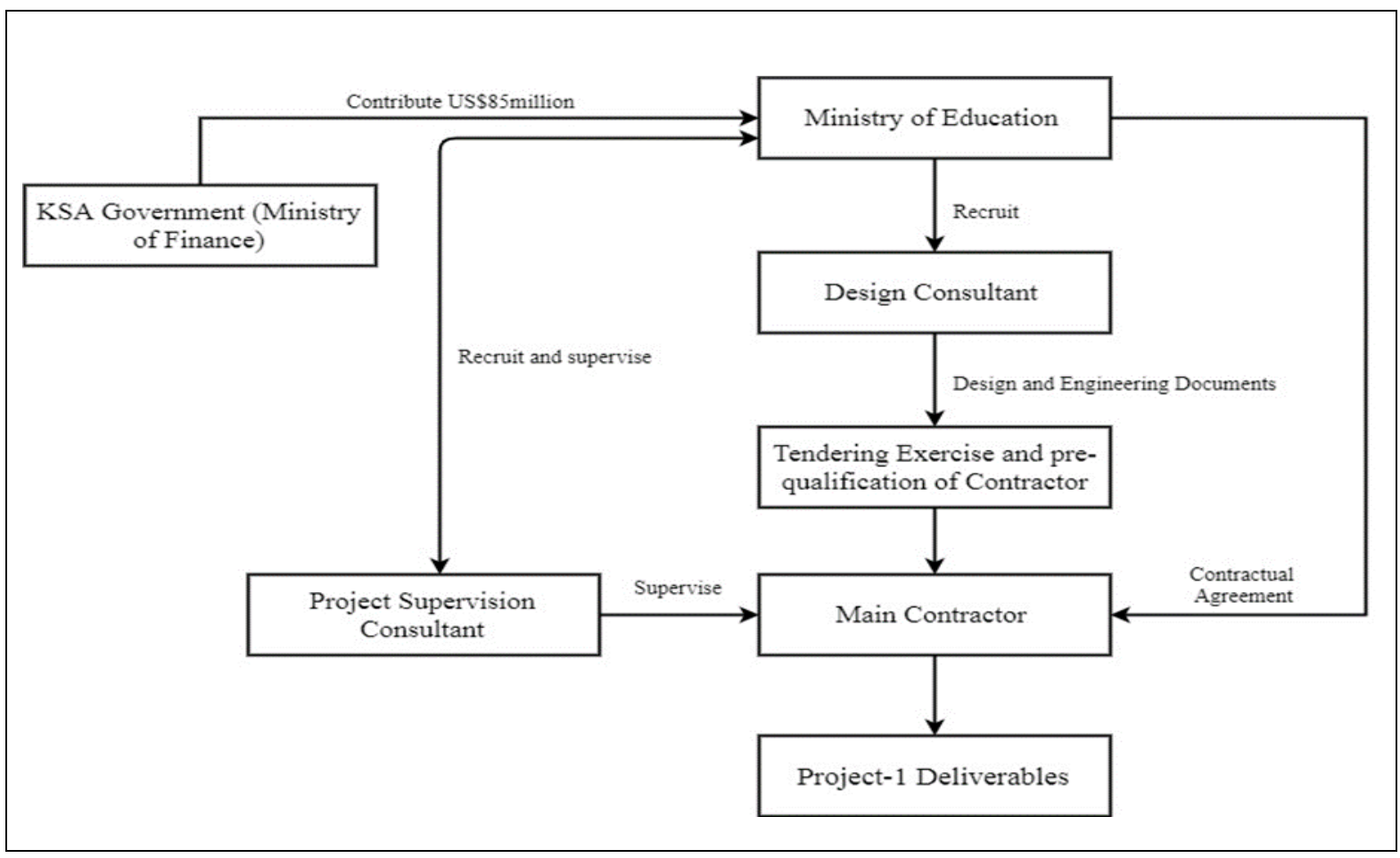

Figure 6.1 Project-1 Structure

(Source: Secondary and interview data)

It is worth mentioning that the main contractor has a significant task of undertaking the project's main activities such as detailed design and engineering, production of bill of quantities in consultation with the client, procurement of the required materials and equipment, and the actual construction of the building, amongst others. Accordingly, the main contractor must engage the services of multiple sub-contractors and suppliers to assist them in achieving the numerous tasks of this case project. The activities of all these recruited sub-contractors and engaged suppliers are co-ordinated directly by the main contractor and all of them are working in partnership to deliver the project's goals and objectives. For example, mechanical, electrical and plumbing activities are sub-contracted to another organisation. Also, several small organisations supplied the materials used in the construction of the building facilities. 


\section{Delivery Phases of Project-1}

Research has suggested that the impact of delays on the practical completion of a construction project is dependent on the phases in which they occur (Kazaz et al., 2012). Accordingly, there is a need to understand the phases within which Project-1 is being delivered. Table 6.1 presents an overview of the project phases with each planned time frame identified. It can be seen from Table 6.1 that five key phases define the delivery process of this case project, with the remaining two being linked to the operation and eventual disposal of the constructed building. The project phases are: initiation; preliminary design; detailed design and engineering; tendering and construction; handover for occupancy; operation and maintenance; and end of occupancy and facility disposal.

Table 6.1 Project-1 delivery phases

\begin{tabular}{|c|c|c|}
\hline Project-1 Phases & Deliverables & Time frame \\
\hline \multirow{5}{*}{ Initiation } & Business case & \multirow{5}{*}{ January 2008} \\
\hline & Feasibility study report & \\
\hline & Project management office & \\
\hline & Project charter & \\
\hline & Selection of design consultant & \\
\hline \multirow{7}{*}{ Preliminary Design } & Basis of design & \multirow{7}{*}{ June 2009} \\
\hline & Geotechnical survey & \\
\hline & Quality control statement & \\
\hline & Building footprint and orientation & \\
\hline & Conceptual site plan & \\
\hline & $\begin{array}{c}\text { Topography survey of the campus } \\
\text { site }\end{array}$ & \\
\hline & $\begin{array}{l}\text { Preliminary schematic design for } \\
\text { architecture, structural, } \\
\text { mechanical/electrical/plumbing, } \\
\text { telecommunications/audio- } \\
\text { visual/security, and furnishings for } \\
\text { all the building }\end{array}$ & \\
\hline & Comprehensive basis of design & \multirow[b]{2}{*}{ June 2009 - } \\
\hline & & \\
\hline
\end{tabular}




\begin{tabular}{|c|c|c|}
\hline \multirow{12}{*}{ Planning and Design } & $\begin{array}{c}\text { Reports, drawings, and other } \\
\text { documents showing compliance } \\
\text { with environmental management } \\
\text { requirements }\end{array}$ & \\
\hline & $\begin{array}{l}\text { Updated topographic and } \\
\text { geotechnical surveys }\end{array}$ & \\
\hline & Updated quality control statement & \\
\hline & $\begin{array}{l}\text { Technical specifications for required } \\
\text { systems and equipment for the } \\
\text { building such as elevators }\end{array}$ & \\
\hline & Detailed floor plans & \\
\hline & $\begin{array}{l}\text { Detailed design plans for } \\
\text { mechanical, electrical, plumbing, } \\
\text { fire protection systems. For } \\
\text { example, HVAC }\end{array}$ & \\
\hline & $\begin{array}{l}\text { Detailed design plans for facilities } \\
\text { within the building such as } \\
\text { telecommunication/audio- } \\
\text { visual/security systems. Laboratory } \\
\text { rooms, lecture rooms and others }\end{array}$ & \\
\hline & Whole life-cycle cost analysis & \\
\hline & $\begin{array}{l}\text { Design plans for structural activities } \\
\text { such structural title sheet and notes } \\
\text { for construction }\end{array}$ & \\
\hline & Comprehensive project schedules & \\
\hline & $\begin{array}{l}\text { Comprehensive occupational and } \\
\text { health safety plans }\end{array}$ & \\
\hline & $\begin{array}{l}\text { List of technical and non-technical } \\
\text { specifications }\end{array}$ & \\
\hline \multirow{7}{*}{ Tendering } & Procurement planning document & \multirow{8}{*}{$\begin{array}{c}\text { Feb } 2010- \\
\text { August } 2010\end{array}$} \\
\hline & Development of tender process & \\
\hline & Tender evaluation criteria & \\
\hline & Invitation to submit tender & \\
\hline & Evaluation of the submitted tender & \\
\hline & Selection of winning tender & \\
\hline & Award of project contracts & \\
\hline Implementation & Updated design documents & \\
\hline
\end{tabular}




\begin{tabular}{|l|r|r|}
\multirow{7}{*}{ Handover for occupancy } & \multicolumn{1}{|c}{ October 2010- } \\
\cline { 2 - 2 } & $\begin{array}{r}\text { Review of design and procurement } \\
\text { documents }\end{array}$ & \\
\cline { 2 - 2 } & $\begin{array}{r}\text { Construction planning report } \\
\text { Construction monitoring and control } \\
\text { documents }\end{array}$ & \\
\cline { 2 - 2 } & Preliminary Handover & \multirow{2}{*}{ Nov-17 } \\
\cline { 2 - 2 } & Project handover note & \\
\hline
\end{tabular}

Source: Secondary and interview data

\subsubsection{Overview of Project-2}

Project-2 comprises of two educational buildings that were developed for the use of the Colleges of Education and Applied Medical Science at a young public university in a city located in the Riyadh province in the KSA. The university has over 10,000 domestic and international students that are currently enrolled into its 21 colleges and faculties. The scope of the project involved two three-storey buildings, having a total of 24 tutorial rooms, five big lecture halls, two conference rooms, staff offices, administrative offices, research suites and laboratories, leisure spaces, and cafes for the use of both students and staff members within the Colleges of Education and Applied Medical Science of this university. These buildings cover a gross floor area (GFA) of about 30,000 square metres.

The Kingdom Government also funded this project. The contract for this case project was signed by the KSA's Minister of Higher Education in 2011, at a cost of Saudi Riyal 202 million, approximately US\$54 million. Accordingly, the Ministry of Higher Education in the KSA was the client for this project, having the final authority on the course of actions to be taken in the implementation of Project-2. Similar to Project-1, Design-Bid-Build (D-B-B) was an adopted procurement route for this project. The KSA's Ministry of Higher Education hired and paid a design company to produce the preliminary designs and engineering for this project. Based on the initially-produced design and engineering documents, a tendering process was used to choose the main contractor for the case project. In addition, the client also hired the services of a consultancy firm to provide a broad supervision of the main contractor's activities towards achieving the project's objectives. The main contractor engaged the services of their own design organisation to update the preliminary design and engineering documents. The contractor was responsible for the actual construction of the buildings, in accordance to the specifications agreed upon with the client. 
The structure of the case project was similar to that of Project-1. The major stakeholders are also, the client (Ministry of Education, the KSA), project supervising consultant, and main contractor. All the stakeholders worked in collaboration to ensure that the project deliverables were produced according to the pre-determined objectives. Furthermore, the project was delivered based on the traditional method. From the information gathered from the 'Project Progress Reports', the case project had several delays, which led to it being completed 16 months later than planned. The case project was initially scheduled to be completed in January 2013. However, it was practically finished in May 2015 (secondary data).

\section{Delivery Phases of Project-2}

The project phases and the related time frame planned for each of them are described in Table 6.2. The phases identified from the 'Project Charter and Project Management Plan' documents were: initiation; planning and design; procurement; implementation; commissioning; facility use and maintenance; and disposal.

Table 6.2 Project-2 delivery phases

\begin{tabular}{|c|c|c|}
\hline Project-2 Phases & Deliverables & Time frame \\
\hline \multirow{5}{*}{ Initiation } & Business case & \multirow{5}{*}{$\begin{array}{l}\text { January } 2010- \\
\text { January } 2011\end{array}$} \\
\hline & Feasibility study report & \\
\hline & $\begin{array}{l}\text { Constitution of project } \\
\text { management office }\end{array}$ & \\
\hline & Project charter & \\
\hline & Selection of design consultant & \\
\hline \multirow{6}{*}{ Planning and Design } & Comprehensive basis of design & \multirow{6}{*}{$\begin{array}{l}\text { February } 2010- \\
\quad \text { March } 2011\end{array}$} \\
\hline & $\begin{array}{c}\text { Geotechnical and topographical } \\
\text { survey }\end{array}$ & \\
\hline & Project cost estimates & \\
\hline & Buildings survey & \\
\hline & $\begin{array}{c}\text { Conceptual design and engineering } \\
\text { report }\end{array}$ & \\
\hline & $\begin{array}{c}\text { Review of design and engineering } \\
\text { documents }\end{array}$ & \\
\hline \multirow[t]{6}{*}{ Tendering } & Development of tender process & \multirow{6}{*}{ April 2011} \\
\hline & Tender evaluation criteria & \\
\hline & Invitation to submit tender & \\
\hline & Evaluation of the submitted tender & \\
\hline & Selection of winning tender & \\
\hline & Award of project contracts & \\
\hline \multirow[t]{2}{*}{ Implementation } & Updated design documents & \\
\hline & Pre-construction meeting & \\
\hline
\end{tabular}




\begin{tabular}{|l|c|c|}
\hline & $\begin{array}{c}\text { Review of design and procurement } \\
\text { documents }\end{array}$ & \multirow{2}{*}{$\begin{array}{c}\text { February 2011 - } \\
\text { May 2015 }\end{array}$} \\
\cline { 2 - 2 } & $\begin{array}{c}\text { Construction planning report } \\
\text { Construction monitoring and } \\
\text { control documents }\end{array}$ & \\
\cline { 2 - 2 } & $\begin{array}{c}\text { Preliminary Handover, } \\
\text { Construction closure report, and } \\
\text { Lessons learnt document }\end{array}$ & \multirow{2}{*}{ July 2015 } \\
\cline { 2 - 2 } & $\begin{array}{c}\text { Updated construction closure } \\
\text { report }\end{array}$ & \\
\cline { 2 - 2 } & Final Project handover note & \\
\hline
\end{tabular}

Source: Secondary and interview data

\subsubsection{Overview of Project-3}

Project-3 is a five-storey Pharmacy College building for a publicly-owned University located in a south-eastern city of the KSA. The project's major deliverables were lecture halls, administrative offices, research suites and laboratories designed for conducting experiments within the college, among other facilities that could be used for the training of Pharmacy students and conducting relevant research in the University. The building covers a gross floor area (GFA) of 8,152 square meters.

The KSA Ministry of Education provided the funds for this project. Therefore, the client or project owner in this instance is the KSA's Ministry of Education. The contract for the execution of the project was awarded at a cost of approximately SAR 120 million or US\$40 million. As prevalent in most public construction projects in the KSA, the Design-Bid-Build (D-B-B) procurement approach was utilised to deliver this case project. The main planning and execution of the project commenced with the development of construction and engineering designs by a consultant, whom the client recruited. The initially-developed construction and engineering designs were then used for preparing the tender process. The tender process led to the selection of the main contractor who facilitated the actual execution of the project. In addition, the client also hired another consultant to act on its behalf, by supervising the activities of the main contractor in accordance to the established project's objectives. The contractor engaged worked in concert with the supervising consultant and the client, to refine the details of the project's deliverables and objectives based on changing or new conditions.

The structure of the case project followed Projects-1 and 2, and its delivery method was also the same, based on the information from the archival documents of the project. The project duration was set at 24 months starting from January 2013 (when the project was sanctioned by the Minister for Education in the KSA and awarded to the main contractor). However, the 
project was completed in November 2015, ten months after its expected end date. It was reported in the accessed archival documents that the project experienced delays, which culminated in the time overrun of 10 months.

\section{Delivery Phases of Project-3}

The main delivery phases of this case project, as identified from the archival sources, are similar to Project-2: initiation; planning and design; procurement, implementation; commissioning; facility use and maintenance; and disposal.

Table 6.3 Project-3 delivery phases

\begin{tabular}{|c|c|c|}
\hline Project-3 Phases & Deliverables & Time frame \\
\hline \multirow{6}{*}{ Initiation } & Business case & \multirow{6}{*}{$\begin{array}{c}\text { January } 2011- \\
\text { April } 2011\end{array}$} \\
\hline & Feasibility study report & \\
\hline & $\begin{array}{l}\text { Constitution of project } \\
\text { management office }\end{array}$ & \\
\hline & Project charter & \\
\hline & Selection of design consultant & \\
\hline & Phase review report & \\
\hline \multirow{5}{*}{ Planning and Design } & $\begin{array}{l}\text { Geotechnical and topographical } \\
\text { survey }\end{array}$ & \multirow{5}{*}{$\begin{array}{l}\text { May } 2011- \\
\text { Feb } 2012\end{array}$} \\
\hline & Project cost estimates & \\
\hline & Building survey & \\
\hline & $\begin{array}{c}\text { Conceptual design and engineering } \\
\text { report }\end{array}$ & \\
\hline & $\begin{array}{l}\text { Review of design and engineering } \\
\text { documents }\end{array}$ & \\
\hline \multirow[t]{7}{*}{ Tendering } & Procurement planning document & \multirow{7}{*}{$\begin{array}{l}\text { March 2012- } \\
\text { October } 2012\end{array}$} \\
\hline & Development of tender process & \\
\hline & Tender evaluation criteria & \\
\hline & Invitation to submit tender & \\
\hline & Evaluation of the submitted tender & \\
\hline & Selection of winning tender & \\
\hline & Award of project contracts & \\
\hline \multirow[t]{6}{*}{ Implementation } & Updated design documents & \multirow{6}{*}{$\begin{array}{l}\text { January } 2013- \\
\text { November } 2015\end{array}$} \\
\hline & Pre-construction meeting & \\
\hline & $\begin{array}{l}\text { Review of design and procurement } \\
\text { documents }\end{array}$ & \\
\hline & Construction planning report & \\
\hline & $\begin{array}{l}\text { Construction monitoring and } \\
\text { control documents }\end{array}$ & \\
\hline & Constructed building & \\
\hline Handover & $\begin{array}{c}\text { Preliminary Handover, } \\
\text { Construction closure report, and }\end{array}$ & November 2015 \\
\hline
\end{tabular}




\begin{tabular}{|l|c|c|}
\hline & Lessons learnt document & \multirow{2}{*}{$\begin{array}{c}\text { Updated construction closure } \\
\text { report }\end{array}$} \\
& $\begin{array}{c}\text { Project handover note } \\
\end{array}$ \\
\cline { 2 - 3 }
\end{tabular}

Source: Secondary and interview data

\subsubsection{Overview of Project-4}

Project-4 comprises of two educational buildings that were developed for the College of Engineering of a university located in the southwest part of the Kingdom of Saudi Arabia. The college consists of four departments. It was proposed that the buildings would have four lecture theatres, six tutorial classes, administrative offices, two research suites, four computer rooms, four laboratories and the college library, among other facilities that could be used for the training of students and conducting world-class research in the University. The buildings cover a gross floor area (GFA) of about 15,630 square metres. The site area is 92,510 square metres.

The project was funded by the KSA's Ministry of Education. Accordingly, the KSA Ministry of Education served as an owner and client for the project. The project was awarded at a contract sum of SAR 180 million or equivalent of approximately US\$50 million in Feb 2012. The project was also delivered following the Design-Bid-Build (D-B-B) method. The initiation of the project was undertaken within the Ministry of Education by a special project team constituted for that purpose. During this period, a consultant was also recruited to produce initial design and engineering packages for the project. The design and engineering documents were used as a basis for developing the tender procedures, which culminated in the choice of the main contractor for the project. The main contractor was given the overall responsibility of refining the preliminary design and engineering, as well as that of constructing the facility. To provide adequate supervision of the main contractor's progress and activities, a consultant was also hired by the client to perform this function. The project supervising consultant acted as a representative of the client on many fronts and was contacted by the main contractor for several project decisions. For example, the consultant was involved in ratifying any change requests or alterations in the project progress.

The structure of the case project followed those described previously, with its relevant information gathered from the interviewees and archival documents of the project. This case project was determined to experience several delays during the actual construction of the facility, that practically shifted the completion date for the project to February 2017. 


\section{Delivery Phases of Project-4}

The major phases for the delivery of the project, as identified in the archival documents are: initiation; planning and design; procurement, implementation; commissioning; facility use and maintenance; and disposal.

Table 6.4 Project-4 delivery phases

\begin{tabular}{|c|c|c|}
\hline Project-4 Phases & Deliverables & Time frame \\
\hline \multirow{6}{*}{ Initiation } & Project initiation team & \multirow{6}{*}{ January 2010- } \\
\hline & Feasibility study report & \\
\hline & Business case report & \\
\hline & Project charter & \\
\hline & Selection of design consultant & \\
\hline & Phase review report & \\
\hline \multirow{6}{*}{ Planning and Design } & $\begin{array}{c}\text { Conceptual project management } \\
\text { plan }\end{array}$ & \multirow{6}{*}{$\begin{array}{c}- \\
\text { June } 2011\end{array}$} \\
\hline & $\begin{array}{c}\text { Geotechnical and topographical } \\
\text { survey }\end{array}$ & \\
\hline & Project cost estimates & \\
\hline & Building survey & \\
\hline & $\begin{array}{c}\text { Conceptual design and engineering } \\
\text { report }\end{array}$ & \\
\hline & $\begin{array}{c}\text { Review of design and engineering } \\
\text { documents }\end{array}$ & \\
\hline \multirow[t]{7}{*}{ Tendering } & Procurement planning document & \multirow{7}{*}{$\begin{array}{l}\text { Julay } 2011- \\
\text { Dec } 2011\end{array}$} \\
\hline & Development of tender process & \\
\hline & Tender evaluation criteria & \\
\hline & Invitation to submit tender & \\
\hline & Evaluation of the submitted tender & \\
\hline & Selection of winning tender & \\
\hline & Award of project contracts & \\
\hline \multirow[t]{6}{*}{ Implementation } & Updated design documents & \multirow{6}{*}{$\begin{array}{l}\text { February } 2012- \\
\text { October } 2016\end{array}$} \\
\hline & Pre-construction meeting & \\
\hline & $\begin{array}{c}\text { Review of design and procurement } \\
\text { documents }\end{array}$ & \\
\hline & Construction planning report & \\
\hline & $\begin{array}{l}\text { Construction monitoring and } \\
\text { control documents }\end{array}$ & \\
\hline & Constructed building & \\
\hline \multirow[t]{3}{*}{ Handover } & $\begin{array}{l}\text { Construction closure report } \\
\text { Lessons learnt document }\end{array}$ & \\
\hline & $\begin{array}{l}\text { Updated construction closure } \\
\text { report }\end{array}$ & \\
\hline & Project handover note & \\
\hline
\end{tabular}

Source: Secondary and interview data 


\subsection{Findings from Case Studies (Cross-case Analysis)}

This section provides the main themes that emerged from the analysis of the case studies using archival sources and interviews. Utilising a cross-case analysis of the case projects, the current chapter addresses the research questions. By using thematic analysis, the cross-case analysis compares and contrasts the data of the project cases along with the available documentary data. Based on the coding of the archival sources and interview transcripts associated to the case projects, the factors that contributed to the delays experienced were identified. Also, the impact of the application of PM tools and techniques on the reported delays in the case projects was found from their analysis. Finally, the coding structure of the main themes that emerged from the case studies are presented in Figure 6.2. 


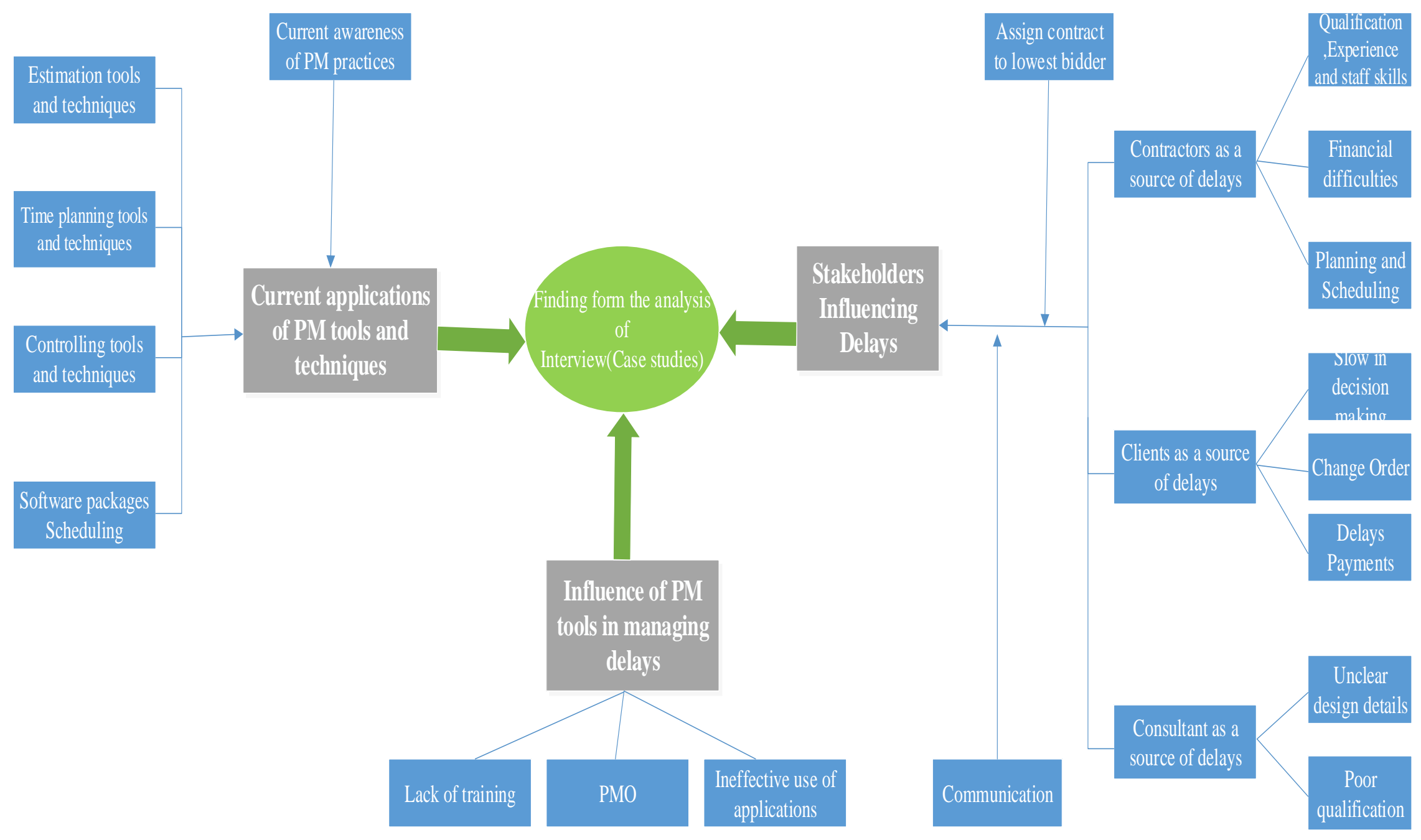

Figure 6.2 Coding structure of the main themes from case studies

Source: Secondary and interview data 
Table 6.5 Details of the interviewees in the projects

\begin{tabular}{|l|l|c|c|}
\hline Case Projects & \multicolumn{1}{|c|}{ Role } & Serial Codes & Organisation represented \\
\hline Project-1 & Project supervisor & PS-1 & Client \\
\cline { 2 - 4 } & Project manager & PM-1 & Contractor \\
\cline { 2 - 4 } & Construction manager & CM-1 & Contractor \\
\cline { 2 - 4 } & Project consultant & PC-1 & Consultant \\
\hline Project-2 & Senior manager & SM-2 & Client \\
\cline { 2 - 4 } & Planning manager & PLM-2 & Contractor \\
\cline { 2 - 4 } & Project manager & PM-2 & Contractor \\
\cline { 2 - 4 } & Project consultant & PC-2 & Consultant \\
\hline Project-3 & Project manager & PM-3 & Contractor \\
\cline { 2 - 4 } & Construction supervisor & CS-3 & Contractor \\
\cline { 2 - 4 } & Senior project manager & SPM-3 & Client \\
\cline { 2 - 4 } & Project consultant & PC-3 & Consultant \\
\hline Project-4 & Project supervisor & PS-4 & Client \\
\cline { 2 - 4 } & Construction manager & CM-4 & Contractor \\
\cline { 2 - 4 } & Project scheduler & PSC-4 & Contractor \\
\cline { 2 - 4 } & PM Consultant & PMC-4 & Consultant \\
\hline
\end{tabular}

Source: Secondary and interview data

\subsubsection{Delays in Case Projects}

The thematic analysis of the cases revealed that multiple factors facilitated the delays experienced by them. This supports the notion that an interaction of several factors often lead to construction delays (Fugal and Agyakwah-Baah, 2010). From the analysis of both the documentary evidence associated with the four case projects and interview data, all stakeholder parties involved in the case projects were identified to have contributed in one way or other to the delays that occurred. While the level of involvement in the projects differs from one party to another, all main stakeholders influenced the occurrence of delays to a certain degree (PM1, PC-1, and SPM-3). However, the majority of participants interviewed consider the contractor to be held responsible largely for the delays occurring. Overall, the same pattern was found in the quantitative and qualitative data - the contractors were most frequently deemed to be a major source of delays, and the consultants were least frequently deemed to be a major source of delay within the KSA's public construction projects. 
Also, the majority of respondents revealed that the construction phase is where most delays can be minimised, followed by the design and mobilisation phases (PS-1, PC1, SM-2, PC-2, PM-3, and PS-4). This result is consistent with previous studies, where the construction phase has been identified as the leading phase for delays to occur in the construction projects (Ramanathan, et al. (2012).

A more in-depth discussion, in terms of the causes of delays, and how this aligns with the results obtained from the interviews conducted with construction professionals in Saudi Arabia, will be covered in the following section. It should be noted that in the analysis presented below, to reflect a form of support for the respective statements, the interviewees' code are placed in parenthesis. Figure 6.0 shows the stakeholder-influencing delay factors.

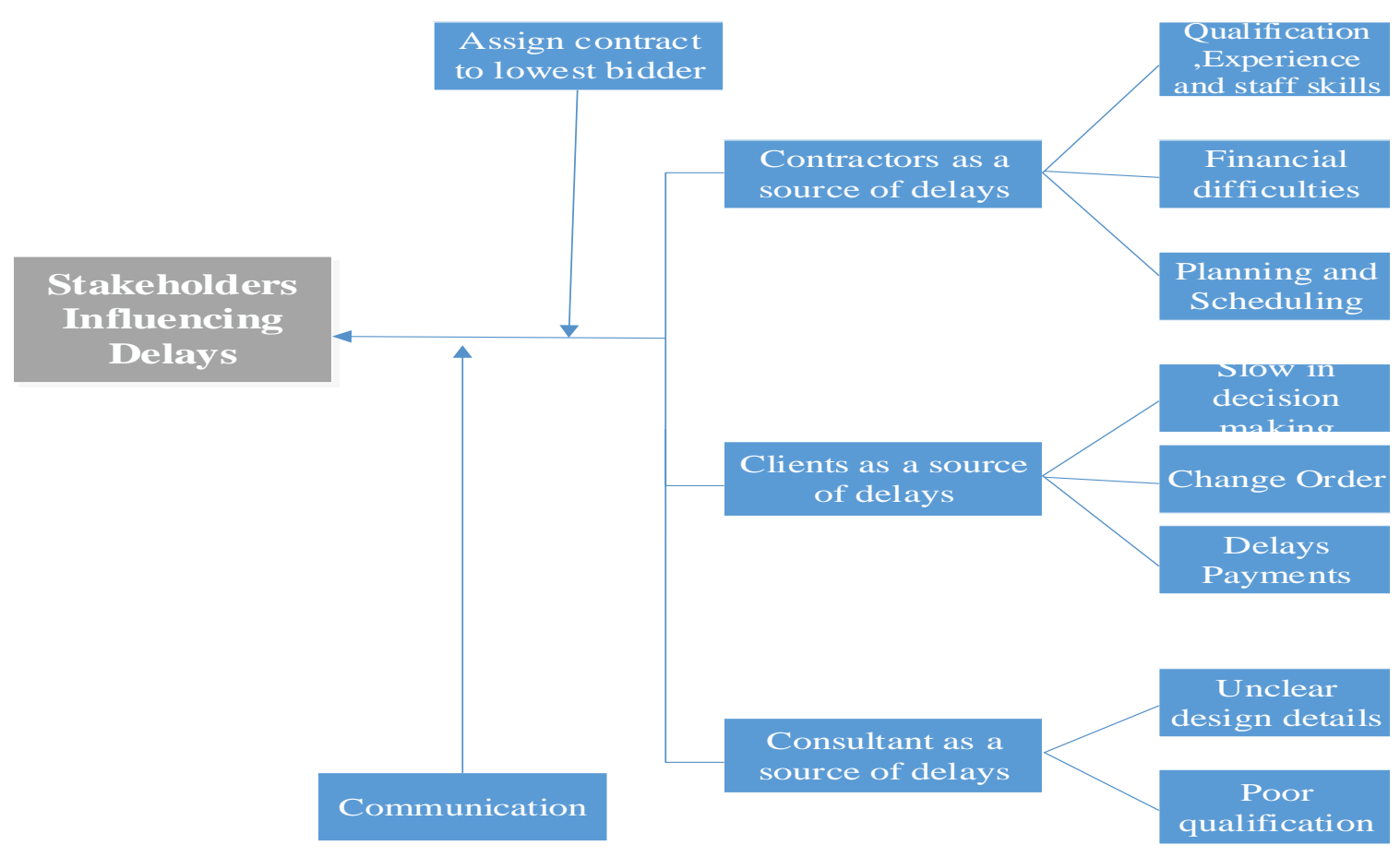

Figure 6.3 Stakeholder-influencing delays

\section{Contractor as source of delays}

The crucial role of the contractors is to bear the responsibility for the execution of the case projects and therefore, they have a major part to play in influencing the delays occurred. For instance, contractors' inadequate qualifications, a deficient experience of their staff, as well as their poor financial capabilities (resulting in limited cash flow with negative effects on the 
planned progress of the case projects), were particularly noted by the participants as contributing to delays in the four case projects. It was also identified that the delays that occurred in the case projects were due to the contractor's ineffective project planning and scheduling (PC-1 and PMC-4). These problems have also been indicated in the findings reported in previous studies (e.g., Al-Kharashi and Skitmore, 2009; Al-Hammadi and Nawab, 2016). A lack of experience by the employees involved in the project was a lead cause in the project delivery; this is an issue that is partly caused by the inability of the contractor to hire skilled workers due to financial constraints (PS-1).

Another common theme derived from the studied project cases shows that a poor financial status of the contractors contributed greatly to the delays occurring in all cases. This outcome signifies the severity of this issue in addressing the delay syndrome in the KSA's public construction projects. Most of the respondents believed that the problem stemmed from the lowest bid system that been ingrained into the regulations that are guiding public work contracts in the KSA. It is evident from documentary sources related to the four case projects that the contractors engaged were chosen based on their competitive bidding cost, with little emphasis placed on evaluating their past financial history. Apparently, these contractors were limited in their financial resources, which thereby increased the probability of delays experienced. This is in line with the suggestion in Alofi and Kashiwagi (2017) that the lowest bidding system means that the contractors' financial capacity is not well-considered and prioritised before contracts are awarded to them. Such a situation often leads to the selection of contractors without wherewithal to fulfill their obligations, thereby exposing projects to avoidable disruptions (Olaniran, 2015). One of the respondents, a senior manager, stated that the adoption of the lowest bidding approach is a usual practice in the award of nearly all public projects in the KSA and that this culture might be connected to the fact that governments have many projects competing for limited resources, so there is a need to optimise capital expenditures.

A possible explanation in relation to a contractor's financial difficulties leading to project delays is that the tendering process in the KSA for public projects takes a long time for the bids to be finalised, thus leading contractors to place bids for more than one project simultaneously. Sometimes, a contractor will (not necessarily purposefully) end up winning more than one contract, and thus run short of financial resources in the attempt to cover numerous projects. This result was not pointed out by any of the investigated studies as being a critical contributor to contractors' financial difficulties. However, an improvement to the tendering system would 
put a stop to contractors having to spread themselves so thin over different projects, thus reducing relevant finance-associated delays (PM-4).

The professionals provided some in-depth details into this issue, by linking the award of the contract to the lowest bidder as the foundation for contractors with poor financial standing to hire low-cost employees with inadequate experience in the efficient utilisation of PM tools and techniques (PS-4 and PS-1). This can be seen as the respondents (PC-1, CM-1, PM-2, PLM-2, and CM-4) also indicated that the delays experienced in the case projects might be attributed to ineffective project planning and scheduling by the contractors. With the technical staff of the contractors lacking in core skills and experience, it was likely they were either unable to cope with challenges or lacked an understanding of the project complexity, both of which have been identified as pre-cursors to poor performance and delays in construction projects (Agumba and Fester, 2011; Albogamy et al., 2013; Ibrahin et al., 2016; Alofi and Kashiwagi, 2017).

\section{Client as source of delays}

From the available documentary evidence and interviews concerning public construction project cases, the client, usually governments in the KSA, was also identified as a major contributor to the occurrence of delays. Clients typically have significant impacts on the course of a project as they own it and are expected to provide the funding necessary for its completion (Boyd and Chinyio, 2008). Additionally, they influence the end result of a construction procedure and therefore, their actions can trigger delays (Vennström and Eriksson, 2010). Three client-related delay factors that emerged from the collective analysis of both documentary evidence and interview data relating to the case projects were: slow decisionmaking, change orders, and delay in progress payment.

Nearly all the respondents shared an opinion that failure of the client (the KSA's government) to make progress payment (according to the contractual agreement with the contractors) impacted the case projects negatively and resulted in the delays experienced. The participants believed that an ineffective payment structure triggered a situation where disbursement to the contractors were significantly disrupted, leaving them with significantly insufficient funds to carry on with important project tasks (SPM-3, PM-2, and CM-1). Delays in progress payments by the client has been earlier identified by Assaf and Al-Hejji (2006) as an important contributor to delays in the KSA's public construction projects. 
Indeed, literature has emphasised that a lack of motivation, in terms of improper remuneration for the construction workers, can lead to poor work rate, which may ultimately facilitate some details being missed and the commission of errors (Dai, 2009). Errors during construction activities can be time-consuming and costly to rectify, and this could bring about avoidable delays (Haydl and Nikiel, 2000). In a circumstance where the owners fail to pay the contractors according to the agreed payment terms, we can expect a pattern where there is a scarcity of financial resources to motivate the workers to perform optimally. The detrimental effect of this problem might have been compounded, considering that the contractors involved in the case studies have been already identified, based on the responses from the interviewees (CM-4, PS1, and CM-1), as lacking financial liquidity. This notion has been expressed in previous studies (e.g., Al-Momani, 2000; Odeh and Battaineh, 2002; Frimpong et al., 2003; Koushki et al., 2005; Alghbari et al. 2007; Al-Najjar,2008; Asnaashari et al., 2009; Mahamid et al., 2012). It can be anticipated that denying the contractors of regular payments would likely slow down their performance, thereby making delays inevitable.

It should be noted that delays in progress payments to the contractors are attributed to a long protocol that needed to be followed before a cheque could be issued from the KSA's governments (PM-2, CS-3, and CM-4). Approvals for payments to contractors are usually required to be passed through various departments, including the Ministry of Finance. Obtaining approvals is often a long process and has continually affected Saudi's public construction projects for the past three decades. For instance, research found that the delay of payments or non-payment to contractors in Saudi Arabia has become the predictor of delays in public projects (Al-Mudlej, 1997; Al-Hazmi, 1987; Al-Subaie, 1987; Al-Khalil and Al-Ghafly, 1999; Al-Sedairy, 2001). Both Arain et al. (2006) and Assaf et al. (1999) stress the importance of stabilising the contractors' financial situation, in order to improve the performance of projects in the KSA. It should be noted that the KSA's government has recently taken actions to address the problem, by increasing the initial mobilisation value for contractors from $5 \%$ to $20 \%$. This must be the explanation why delays in payment progress is not among the top 10 factors identified as contributing to delays in the KSA in the findings of the quantitative study. Another client-related factor that influenced the delays that occurred in all the cases examined was slow decision-making. The participants had the perception that major decisions that were essential for the progress of the case projects were not made on time, thereby causing delays for other dependent activities (PM-2, PM-3, and PM-1). Although the decision-making by the stakeholders in all the cases was considered slow, however, the problem was suggested to be 
most rampant with the client (governments in the KSA). The interviewees were of an opinion that the bureaucratic atmosphere of the government system in the Kingdom of Saudi contributed to slow decision-making, which consequently slowed down the completion of activities necessary to avoid these delays. In some instances, the respondents indicated that the problem of bureaucracy in the government resulted in undesirable slowness in making important decisions that would have ensured that delays were avoided in the case project (PS1 and SM-2). For instance, PM-1 said they had to wait for three weeks beyond the expected time to gain the approvals for some major revisions in the building designs. According to him, too much power was concentrated in few hands, which made them extremely powerful. This was in addition to the fact that these individuals were also responsible for other projects that the government was executing concurrently. Issues like these were mentioned by most of the respondents as contributing to avoidable delays in the project's progress, thus stalling important decisions to be made as and when required (SM-2).

The problem of slowness in the client's decision-making approach is not a new discovery, as it has received attention in previous studies. For example, Long et al. (2004); Assaf and AlHejji (2006); Al-Kharashi and Skitmore (2009); and Holoi et al. (2012) have all identified the factor of slow decision-making from the client as being an impediment to project performance. In a study undertaken by Holoi et al. (2012), their regression model showed that a client's slow decision-making process contributes to the delays in Indian projects. Likewise, Al-Kharashi and Skitmore (2009) found that slow decision-making on the part of the owner is one of the top five delay factors in public construction projects. This position has, therefore, been confirmed by the results obtained in this current study.

While the interviewes (PM-2, PM-3, PS-1, and PM-1) believed that a slow decision-making process cultivated the grounds for the occurrence of delays in their case projects, some of them also commented that some improvements have been made in the government circle to reduce red-tape and cut decision-making times in the recent years. For example, PS-1 stated the following,

"I think recent decentralisation of some decision-making powers in the recent times have reduced lengthy period of waiting for approvals to be obtained. Unlike in the past, some middle managers in the government circle have now been given authority to make decisions without requiring permission from Minister" (PS-1). 
However, the benefits of these changes are expected only to be felt in future public construction projects in the KSA.

Lastly, the issue of slow decision-making is also linked to poor communication between project stakeholders. This happens when there is a lack of laws to regulate the time period for exchanging documents/conducting transactions. Furthermore, a lack of a robust communication plan that determines the estimation time required for the exchange and processing of documents in order to get approvals from project parties is considered a contributing factor to the impeded decision-making process (PM-3 and PSC-4).

Change orders was another dominant factor identified from the analysis of the documentary sources and interviews as influencing delays in public construction projects. The evidence synthesised from the data (progress report) revealed that when change orders were requested and actioned, it triggered delays in the progress of certain activities in most of the case projects. Change order was identified by the interviewees (PS-1, PM-1, and CM-4) involved in the execution of Projects-1 and 4. Although cases of change orders were also detected in the documentary sources for Projects-2 and 3, it was not mentioned by the interviewees associated with them as contributing to the delays experienced in the projects. The professionals involved in the affected projects suggested that changes were necessitated mostly by design errors or omission of details in the construction procedures (PS-1, PM-1, and CM-4).

Similar to the findings reported in this study, change orders have also been identified in previous studies as an important delay factor in public construction projects. Research undertaken by Al-Momani (2000); Assaf and Al-Hejji (2006); Sambasivan and Soon (2007); and Sweis et al. (2008) have all indicated that change orders, mostly from clients, can influence delays. Assaf and Al-Hejji (2006) found that change orders had an impact on the KSA's construction projects analysed in their study. In the case of Sambasivan and Soon (2007), all participants claimed a variation to the orders as the most common reason for delay in Malaysian construction projects. Change orders usually invoke delays as a result of the additional time required to execute the variation, which may disrupt other project activities, thereby impacting the progress negatively (Alnuaimi et al., 2009). However, the respondents in this study believed that change orders are unavoidable in the KSA's public construction projects, if the project scope definition at the initial and planning phases is not done effectively. 


\section{Consultant as a source of delay}

Two consultant-related factors featured prominently, based on the information gathered from the cases studied, as being contributors to the occurrence of delays. They were "unclear and inadequate design details", as well as "poor qualifications of the consultants or their staff". These issues have also been identified in the quantitative study of this thesis as the top two delay factors in public construction projects in the KSA. The importance of the consultant in the achievement of a project's core objectives has been demonstrated in the literature

Unclear and inadequate design details have been suggested as a crucial consultant-based delay factor in Projects-1, 2, and 4. The evidence from the projects' documents and the interviews showed that the consultants hired for the designs and engineering in the studied cases failed to provide clear and sufficient details, which led to the misinterpretation of the designs by the construction contractors and thus, delays were experienced. As indicated by CM-1, the design details and specifications provided by the consultant were ambiguous and difficult to interpret, thus contributing to poor construction performance and delays. A lack of clear design details and specifications have been identified as making construction tasks problematic (Arain et al., 2004).

Unclear design details in the cases could be linked to a lack of a cohesive working relationship between the design consultant and client. This was explicitly evident in the case of Project-1, in which there was evidence of poor communication between both parties. For example, it was noted in some of the project's progress reports that the design consultant incorrectly interpreted certain details, due to an apparent lack of follow-up and clarification for understanding from both parties (PM-2). This point was also raised by PS-1 as he stated that “...there were mistakes with the design because the consultant failed to communicate the details of the design concepts with us as agreed leading to misconception in the construction activities" (PS-1).

In particular, the involvement of more than one consultant on single tasks leads to a misinterpretation and unclear design details (PS-1).

Delays in approving major changes and sample material were also reported as contributing to delays (CM-4, PM-2, and CM-1). In addition, to optimise the communication channels between the consultant and client, this issue could be solved by providing the contractor with the final list of the sample materials during the mobilisation or at earlier stages of the implementation (CM-1). 
Poor supervision of the consultants or their staff was also a determinant of construction delays, according to the documents and interviews associated with the cases. It can be adduced that this problem must have contributed to the problem of unclear design details that can be attributed to the consultant. It can be inferred that without adequate experience and qualifications, it would have been difficult for the consultant to carry out their duties accordingly, creating grounds for the occurrence of delays. Previous research has also found inadequate qualifications of the consultants or their staff to be a predictor of the occurrence of delays in public construction projects (e.g., Assaf and Al-Hejji, 2006) and Al-Kharashi and Skitmore, 2009). To address the problem, Albogamy et al. (2013) stressed the importance of the KSA's government in the recruitment of qualified consultants.

It can be summarised, from the information provided in this section that multiple factors contributed to the delays experienced in the case projects. It is evident that the pre-qualification process was limited in assessing the financial capacity of the contractors to implement the case projects promptly. Moreover, the contractors failed to demonstrate the availability of required experience and technical ability to execute the projects. This is an indication that the prequalification procedure did not take these issues into consideration. Also, decision-making processes were not adequately managed in the case projects, which led to needless time being wasted, causing undesired delays in the project. The problem seemed to have been a lack of effective internal decision-making process within the government office responsible for the execution of the case projects. Additionally, available evidence was suggestive that the project management systems for these case projects lacked a robust project management plan, as well as robust response mechanisms for accommodating the requested change orders without them having negative impacts on the time. While the contractors might have been blamed mostly for the delays experienced, all parties involved in the execution of the projects have contributed in one way or another to the issue.

\subsubsection{Application of PM Tools and Techniques and Delays}

Client, contractor, and consultant-related factors that contributed to the resulted delays in the case projects have been discussed. In addition to these factors, the application of PM principles, tools and techniques in the cases was also studied using the information derived from the projects' documentary sources and interviews. The importance of applying project principles, tools and techniques towards improving construction projects have been noted throughout the literature (e.g., Patanakul et al., 2010; Reiss, 2013; Martinelli and Milosevic, 2016). Consequently, there is a need to determine the use of these PM principles, tools and techniques 
in the case studies. Based on the information gathered from the documentary evidence and interview of the professionals, there was a plan to use some PM principles, tools and techniques in all case projects. However, the effectiveness of the application could not be ascertained. According to Reiss (2013), the use of PM tools and techniques needs to be effective for their benefits for projects to be fully realised. In other words, it is not just enough to utilise these PM principles, tools and techniques, but their effective deployment is paramount. Figure 6.1 displays the main theme of the PM tools and techniques investigated in this study.

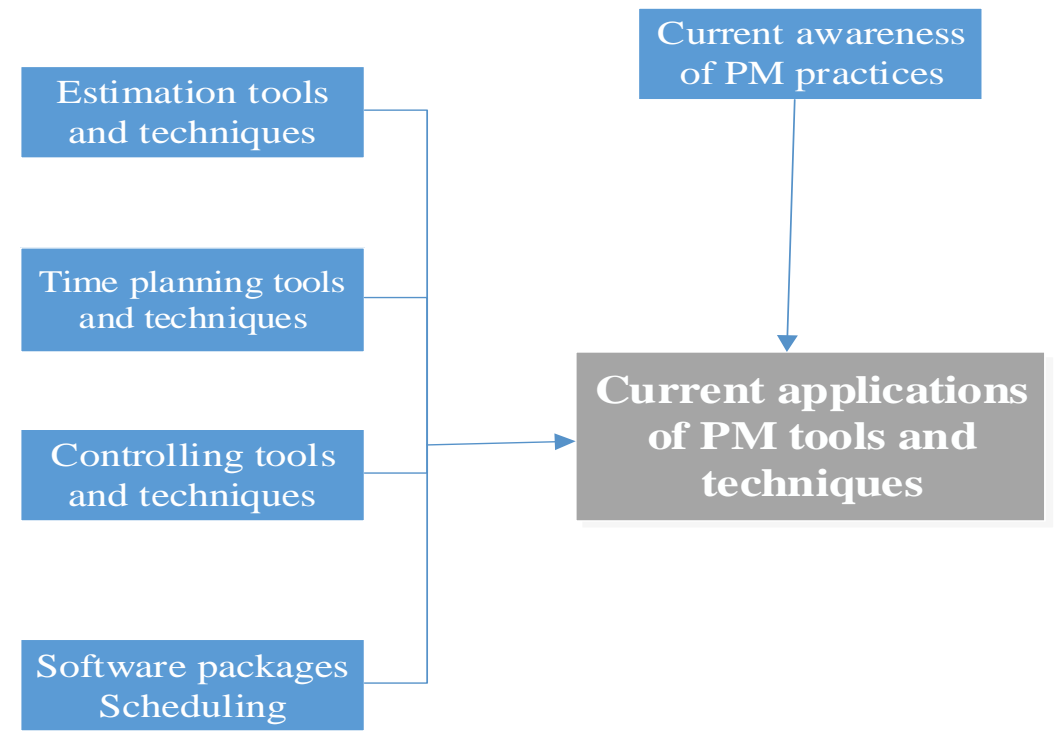

Figure 6.4 PM tools and techniques

All those interviewed mentioned that the importance of using PM principles, tools and techniques, as was emphasised in the case projects. This supports the previous study by AlMahmoud et al. (2012), which suggested that PM concepts have continued to gain rapid acceptance in the KSA. All the interviewees suggested that various PM tools and techniques were recommended and applied in their projects. According to the information gathered from the documentary sources and interviews, all case projects were planned and executed based largely on the Public Works Contracts. There was evidence in all case projects to suggest that in the initiation phase or strategic definition stage, PM methods such as the business case and strategic brief were developed to demonstrate the core objectives and needs for the case projects (SM-2). This is in line with suggestions made in the literature (see for instance, PMI, 2017). 
Also, it was found from the study of relevant documentary evidence (project contracts) and statements obtained from the interviewees (PS1 and SPM-3), that a project charter, outlining their objectives and expected deliverables, was developed for each of the four case projects. The project charter was part of the outputs of the initiation phase, which formed the basis for a further development of the projects' processes. As stated by SPM-3,

"There was a project charter to work with and this informed how the project was planned" (SPM-3).

Although it was possible that a PM plan or something related to it was developed, it was not properly detailed and documented (PSC-4).

\section{Project estimating tools and techniques}

Two projects' estimating tools and techniques found to be used largely in these case projects, according to the professionals interviewed, were expert judgment and data from previous similar projects. Expert judgement and data from previous similar projects have remained popular estimating methods in project management over the years (Hughes, 1996; Bielak, 2000). According to the statement provided by the Planning Manager (PLM-2) who worked on Project-2:

"Estimation of the required materials and resources such as costs for each of the project tasks was undertaken using data available from previous similar projects and where data could not be found, we used our own judgment based on personal experience” (PLM-2).

However, the current project estimates tools were not entirely accurate, and these inaccuracies were the sources of significant delays (PC-1 and PS-1). As a result, there is a need to adopt new estimation tools to offer an accurate estimation of project duration (PC-1). There was no evidence deduced from the documentary sources and interviews to support the notion that other estimating tools such as bottom-up and parametric estimating were applied in determining the schedule for the case projects (PS-4).

\section{Project time management tools and techniques}

Project time management tools and techniques were not used in the case projects based on the documentary sources and information presented by the interviewees. According to the professionals who participated in the interviews, the Gantt Chart and Critical Path Method were used in the management of the case projects. The information gathered from the documentary 
sources did not provide evidence of the tools and techniques that were applied in the time management of the case projects. According to PM-2 and PS-1, a project scheduling software having both Gantt Chart and Critical Path Method functions, was used. According to the Project Manager (PM-2) who worked for a contractor organisation in Project-2:

"[W]e used mostly Gantt Chart and CPM to illustrate the project schedule, as well as monitor and control any changes to it. These functions came with Primavera software that was purchased and used by my organisation in the execution of this particular project." (PM-2).

There was no other evidence provided by the interviewed professionals to suggest that time management techniques such as WBS, PERT, Milestone Technique, Precedence Network Diagram or Line Of Balance were actively explored in managing the time of the case projects. Evidence to this effect was also not found in the documentary sources. CM-4 provided the following statement to demonstrate that no other time management tools and techniques were used widely in the case projects beyond CPM and Gantt Chart:

"I know for sure that Gantt Chart and CPM are used readily to manage schedule in most projects in KSA. Our project was not an exception. I do not think other available methods such as WBS are being given due consideration. One should not forget that the PM principles are relatively new in KSA when compared to countries such as USA or UK." (CM-4).

This finding is supported by a previous report by Mubarak (2015) that Gantt Chart and CPM have gained considerably more acceptance than other techniques in the time management of construction projects.

\section{Project controlling tools and techniques}

Four tools and techniques were identified by the interviewees to have been predominantly used in tracking and controlling the project activities. They are regular progress meeting, performance report, and percentage completion of activities. The regular meetings were held to discuss issues affecting the case projects so as to find relevant solutions for them (PS-4 and CS-3).

Also, the interviewees (PC-1, SM-2, PS-4, and CS-3) reported that the percentage of completion activities, measurement on site and actual project expenditure tracking was undertaken for all the case projects to ensure that the money provided for their execution was being utilised effectively. This was found to be of utmost concern to the client as the 
government had to appropriate funds for several projects in the KSA (PS-1). Moreover, it was indicated that performance reports and percentage completion of activities were used as tools and techniques for controlling the projects (PC-2).

This outcome correlates with what has been suggested by Meredith and Mantel Jr. (2011), that regular progress meetings and performance reports have formed a crucial set of tools for controlling the project results over time.

Outside these four tools and techniques, there was no evidence suggestive that other methods have been used to monitor and control the projects from going off track. Most importantly, the interviewees inferred that neither Earned Value Management nor contractual milestone tracking was used in the execution of the case projects (PMC-4).

\section{Project Planning Software}

The planning of project activities for three of the case projects (Project-1, 2 and 4) were implemented using Primavera P6. The interviewees (PLM-2 and PMC-4) indicated that Primavera was used due to its flexibility and capacity to accommodate thousands of activities and showing them in a manner that is easily understood. According to them, this software also afforded the opportunity for parties to collaborate more effectively on the project and identify any issues with the project progress. The effectiveness of Primavera P6 in project scheduling has also been emphasised by Kastor and Sirakoulis (2009). Furthermore, the affordability of this software was mentioned by some of the respondents as the reason for selecting it. For example, PSC-4 stated the following,

"Primavera was the choice software for planning this project. Initially, we considered Microsoft Project due to its cheaper cost but in the end, we wanted something that would allow more inclusive participation and effective. So, we went for Primavera despite its excessive cost. I believe it was worth it" (PSC-4).

In another instance, a respondent suggested that the scheduling software was chosen based on their conviction that it would give them more realistic value and allow more collaboration on the project than other software (CM-1).

Also, Microsoft Project was used more prominently in one of the case projects (Project-3). According to one of the professionals involved in this project, this software was selected because of its low cost and easy-to-use features (PM-3). These characteristics of Microsoft Project have also been suggested in the study undertaken by Hebert and Deckro (2011). The 
respondents, in addition, indicated that this scheduling software was found to be more engaging due to its ease of learning for the personnel involved in the project (PM-3). However, it was also admitted that it was not best software for the case project.

Other project software such as Project Commander and Asta Power Project were not documented nor mentioned during the interviews to have been applied in these case projects. Majority of the interviewees (e.g., PM-3, PM-1, SM-2, and PSC-4) were of the views that their case projects could have performed better if a wide range of PM tools and techniques was applied effectively.

Effectiveness is defined in terms of implementing the PM tools and techniques towards achieving the desired results on a project, such that no delays resulted during the execution of the project.

\subsubsection{Application of the PM Tools and Techniques in Managing Delays}

The documentary evidence and interviews related to the four cases were examined to determine if ineffective application of the PM tools and techniques contributed to the occurrence of delays in these projects. The information gleaned from both sources showed that while various PM tools and techniques have been applied to identify and manage issues that could contribute to delays supposedly, this application was ineffective to bring about the desired outcomes. This issue was stressed by most of the respondents involved in the case projects. This issue is caused by their incorrect implementation (PM-1). Figure 6.2 displays the main themes that reflect the impact of PM tools and techniques in managing delays.

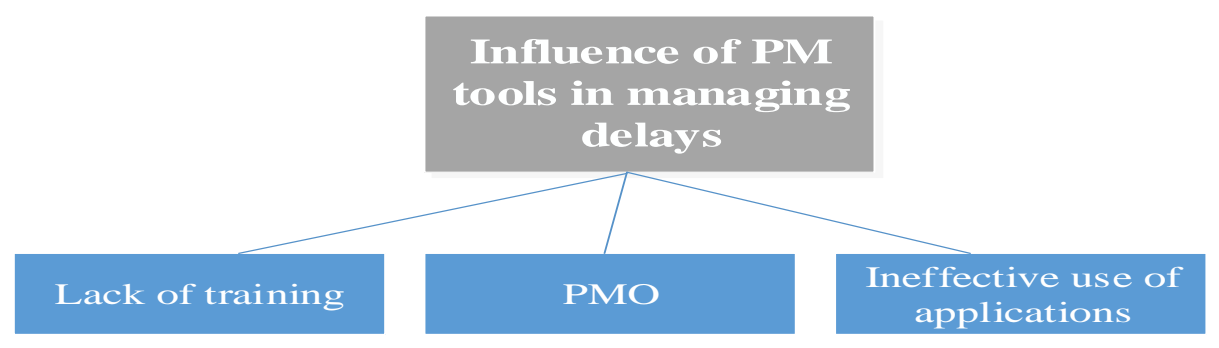

Figure 6.5 PM tools and techniques in managing delays

It can be concluded from the cases studied that the respondents linked this ineffective application of PM tools and techniques to staff inexperience and their lack of adequate qualification to utilise them. A Planning Manager (PLM-2), who was employed to work on 
Project-2 by the project's contractor, was of the opinion that an effective application of PM tools and techniques requires users to be vigorously trained on how to maximise the potentials of such tools and techniques. The respondents (PS-1, CM-1, and PLM-2) suggested that its organisation did not provide them with sufficient training on how to use the features embedded in each of these PM tools and techniques, thereby leading to an underutilisation of them. One of them believed that most of the organisation's staff were not sufficiently knowledgeable about the application of the PM tools and techniques. He stated the following to further support his points,

"We should remember that these tools and techniques cannot apply themselves, they need people to apply them in a right manner to achieve their purpose” (PLM-2).

Those interviewed expressed a belief that incorrect or ineffective applications of these techniques contributed to the delays experienced in the case projects. They believed that many of the workers employed by the organisations involved in the case projects, most especially the contractors, did not have training on the use of those tools and techniques and therefore, could not use them effectively to improve the time and cost performance of the project (PC-2). This is in line with the literature where it is reported that effective use of PM tools can only be realised once appropriate training is provided (East, 2015).

Based on the evidence collected from the interviewees and the available documentary evidence, it was apparent that these PM tools and techniques have not been applied as they should, to prevent or minimise delays significantly in these case projects. The failure of these techniques and tools in curbing delays can be said to have been due to poor application, which could have been avoided by building the capacity of the project team personnel to use them actively. Some of the respondents suggested that this problem could be tied to the absence of Project Management Offices (PMOs) in their project (PC-1, PM-1, and PMC-4). The presence of such PMOs would have supported and enhanced the application of PM tools and techniques, as it would provide the necessary training for the staff to learn how to maximise these tools and techniques towards minimising delays in these case studies (Tjahjana, Dwyer \& Habib, 2009). A PMO is an independent entity from the client and contractor, which handles and manages the progress of the project from start to end (PMI 2013).

Project Management Offices can support a project team in the areas of scheduling, status reporting, application of PM tools, training and mentoring of staff, developing and promulgating methodologies and standards relating to project management, and serving as a 
central source for help in planning and managing efforts (PMI, 2013). The PMO facilitates improvements in project management maturity by serving as the focal point for consistent application of processes and methodologies (Tjahjana et al., 2009). Often, without a PMO, the project management efforts of an organisation are not consistent and are not focused toward a common vision (PMI, 2013). The problem of inconsistencies in the way project standards, policies, and procedures are applied has been identified in the literature (Alghadeer and Mohamed, 2016). However, Latavec (2006) recommends that this problem can be addressed with an establishment of PMOs.

\subsection{Chapter Summary}

This chapter has presented a comprehensive case study analysis of four Saudi Arabian public building projects (identified as Project-1, Project-2, Project-3, and Project-4). Lessons from these case projects have been used to reinforce the understanding of the delay concepts in the Saudi Arabian public construction sector, which have been previously identified in Chapter 5. With the case studies, a contextual understanding to the problems can be achieved. In the chapter, the case projects have been described (including their key features). Also, the delay factors in the case projects have been identified and explained fully. Moreover, an application of PM tools and techniques in these projects have been captured. Lastly, it has been established that the PM tools and techniques have not been applied widely to achieve the desired results, due to a lack of training and the capacity on the part of the employees expected to use them. The available labourers do not have the right knowledge and experience related to PM application. The next chapter offers an exhaustive interpretation and discussion of the research findings presented in Chapters 5 and 6. 


\section{CHAPTER 7}

\section{TRIANGULATION OF FINDINGS AND FRAMEWORK DEVELOPMENT}

\subsection{Introduction}

The two previous chapters have empirically investigated, using both qualitative and quantitative methods, the key issues affecting the occurrence of delays in public construction projects in the KSA. Moreover, the association between the current use of PM knowledge, tools, and techniques and the occurring delays is also identified within those chapters. The research findings obtained from both qualitative and quantitative studies of this thesis, as well as those derived from existing literature, are triangulated in this chapter. The discussion covers the findings on the three main research aspects, which relate to the magnitude of delays and their critical factors, the current use of PM knowledge, tools, and techniques, and the association between their application and the occurrence of delays in public construction projects in the KSA. Also, the recommendations for reducing delays, as provided by the professionals interviewed, are discussed in this section. Based on the triangulation of the research findings from the quantitative analysis, case studies and support of the existing literature, a framework that could be used to minimise the likelihood of delays and support the effective management of delays in public construction projects in the KSA has been developed.

\subsection{Magnitude and Critical Factors of Delays}

The first objective of this study is to identify the critical factors causing delays in construction projects in the KSA. The outcome of the analysis of both the qualitative and quantitative data gathered as part of this research has identified several factors that are critical to the development of delays in public construction projects in the KSA. The results of both quantitative and case studies indicated that delays are prevalent in public construction projects in the KSA. Of the 4357 projects that the survey respondents were involved in, during the last ten years, $57 \%$ of public construction projects experienced significant delays. Also, significant delays occurred in all case projects examined in the qualitative study. The magnitude of delays 
found in this research is lower than those previously reported by Al-Abidien (1983), in which $70 \%$ of KSA's public construction projects were identified as delayed. However, it is higher than $40 \%$ of 2379 Saudi Arabian public construction projects reportedly delayed in the study conducted by Falqi (2004). Also, the magnitude of delays reported in Assaf and Hejji (2006) was between $10 \%$ and $30 \%$, lower than that of this study. This result suggests that the magnitude of delays in the Saudi Arabian public construction projects has not decreased over the last decade, despite efforts by the government to tackle this issue in the recent years.

All stakeholders who typically participated in the execution of public projects in the KSA were found to be impacting the occurrence of delays, as based on the findings gathered from both the qualitative and quantitative studies. The analysis of the quantitative research findings identified construction contractors as the stakeholder with the highest level of influence on delays, followed by the clients, and then the consultants. This outcome supports previous stiudies by Khalil and Al-Ghafly (1999) and Al-Kharashi and Skitmore (2009) in which they reported that stakeholders have a major role to play in the delays occurring in public projects in the KSA. It can therefore be deduced that the collaboration of contractors with all other parties involved in the execution of construction projects, will contribute to minimising this problem.

The five most significant contributors to the occurrence of delays in KSA's public construction project, based on the outcome of the quantitative data, are: slowness in decision-making, assignment of contracts to the lowest bidder system, change orders, ineffective project planning and scheduling, and difficulties in project financing. Three of these factors: slowness in decision-making, change orders, and difficulties in project financing were also identified in the examined cases as being discriminators of delays in the examined projects. Five issues, different from those found in the quantitative study, identified qualitatively to have influenced delays in the studied cases were: poor financial capabilities of the contractors; their lack of required qualifications and inexperience of their manpower; delay in progress payment; unclear and inadequate design details; and poor qualification of the consultants or their staff.

By merging the findings reported in both qualitative and quantitative studies, the factors contributing to the occurrence of delays in the KSA can be generally categorised into: (1) slowness of decision-making; (2) lack of qualifications; (3) lowest bidding system; (4) design issues; (5) financial difficulties; (6) ineffective project planning and scheduling; (7) change orders; and (8) workers' inexperience. Similar to this study's findings, slowness in decision- 
making by the client has also been identified in Al Hammadi (2016) and Assaf and Al-Hejji (2006) as a factor responsible for influencing delays. Also, a lack of qualifications for both contractors and consultants, as well as that of their workers, has also been identified as an important delay issue in the literature (e.g., Al-Ojaimi, 1989; Al-Khalil and Al-Ghafly, 1999; and Al-Kharashi and Skitmore, 2009). In addition, Al-Hammadi and Nawab (2016) and Alofi and Kashiwagi (2017) have identified the lowest bidding system and design issues as influencing delays in construction projects. Research conducted by Al-Kharashi and Skitmore (2009) and Al-Hammadi and Nawab (2016) has shown that financial difficulties can trigger construction delays. Moreover, unclear and inadequate design details identified as contributing to delays in the studied cases can be linked to the poor qualification of the consultants or their staff (Al-Kharashi and Skitmore, 2009). The experience of the workers involved in a particular project was also found to impact the delays in the work (Albogamy et al., 2013).

Also, ineffective project planning and scheduling, identified as a delay factor in the quantitative study, can be attributed to the contractors' lack of required qualifications, and the inexperience of their manpower. The occurrence of delays is also linked to change orders as per the studies undertaken by Albogamy et al. (2013), Mahamid et al. (2015), and Assaf and Al-Hejji (2006). As a result, the delay factors that have been identified in the KSA's construction industry are in agreement with the results reported in the literature. In Table 7.1, an analysis of the supporting literature for each delay factor identified is reported. 
Table 7.1 Summary of mixed analysis of critical delay factors that considered input to the framewor

\begin{tabular}{|c|c|c|c|}
\hline Delay factors & $\begin{array}{l}\text { Quantitative } \\
\text { Findings }\end{array}$ & Qualitative findings & Related Literatures \\
\hline Slowness in decision-making & $\begin{array}{l}\text { Rank (1): } \\
(4.260)\end{array}$ & $\begin{array}{l}\text { PS-4, SPM-3, SDE-1, } \\
\text { PM-1, PS-1, CS-3 and } \\
\text { SM-2 }\end{array}$ & $\begin{array}{l}\text { Long et al., (2004); Assaf and Al-Hejji (2006); Al-Kharashi and Skitmore } \\
\text { (2009); Holoi et al. (2012); and Al Hammadi (2016). }\end{array}$ \\
\hline $\begin{array}{l}\text { Assignment of contracts to the } \\
\text { lowest bidder system }\end{array}$ & $\begin{array}{l}\text { Rank (2): } \\
(4.112)\end{array}$ & $\begin{array}{l}\text { SDE-1, PC-1, PM-2, } \\
\text { PLM-2 and SM-2 }\end{array}$ & $\begin{array}{l}\text { Alkalil and Al-Ghafly (1999); Assaf and Al-Hejji (2006); Al-Kharashi } \\
\text { and Skitmore (2009); Albogamy et al., (2013); Mahamid (2016); and } \\
\text { Alofi and Kashiwagi (2017). }\end{array}$ \\
\hline Change orders & $\begin{array}{l}\text { Rank (3): } \\
(4.114)\end{array}$ & PS-1, PMC-4, PM-3 & $\begin{array}{l}\text { Alkalil and Al-Ghafly (1999); Assaf and Al-Hejji (2006); Al-Kharashi } \\
\text { and Skitmore (2009); Albogamy et al., (2013); and Mahamid et al., } \\
\text { (2015). }\end{array}$ \\
\hline $\begin{array}{l}\text { Project planning and } \\
\text { scheduling }\end{array}$ & $\begin{array}{l}\text { Rank (4): } \\
(4.111)\end{array}$ & PC-1, PMC-4, CM-4 & $\begin{array}{l}\text { Al-Ojaimi (1989); Assaf et al., (1995); Alkalil and Al-Ghafly (1999); } \\
\text { Falqi (2004); Assaf and Al-Hejji (2006); Al-Kharashi and Skitmore } \\
\text { (2009); and Albogamy et al., (2013). }\end{array}$ \\
\hline Difficulties in project financing & $\begin{array}{c}\text { Rank (5): } \\
(4.014)\end{array}$ & PM-2, CM-1, CM-4 & $\begin{array}{l}\text { Assaf and Al-Hejji (2006); Al-Kharashi and Skitmore (2009); and } \\
\text { Albogamy et al., (2013). }\end{array}$ \\
\hline Lack of qualifications & $\begin{array}{l}\text { Rank (6): } \\
(3.981)\end{array}$ & $\begin{array}{l}\text { PC-1, PS-4, PMC- } \\
\text { 4,PSC-4 }\end{array}$ & $\begin{array}{l}\text { Al-Ojaimi (1989); Assaf et al., (1995); Alkalil and Al-Ghafly (1999); } \\
\text { Falqi (2004); Assaf and Al-Hejji (2006); Al-Kharashi and Skitmore } \\
\text { (2009); and Albogamy et al., (2013). }\end{array}$ \\
\hline Design issues & $\begin{array}{l}\text { Rank (7): } \\
(3.943)\end{array}$ & $\begin{array}{l}\text { PM1, PS-1, CM-1, CM- } \\
\text { 4,PSC-4 }\end{array}$ & $\begin{array}{l}\text { Assaf and Al-Hejji (2006); Al-Kharashi and Skitmore (2009); and } \\
\text { Albogamy et al., (2013). }\end{array}$ \\
\hline Workers' inexperience & $\begin{array}{l}\text { Rank (8): } \\
(3.981)\end{array}$ & PM-1, PS-1and PS-4 & $\begin{array}{l}\text { Al-Ojaimi (1989); Alkalil and Al-Ghafly (1999); Falqi (2004); Assaf and } \\
\text { Al-Hejji (2006); Al-Kharashi and Skitmore (2009); and Albogamy et al., } \\
\text { (2013). }\end{array}$ \\
\hline
\end{tabular}




\subsection{Current Use of PM Knowledge, Tools, and Techniques}

The second research objective seeks to determine the current use of PM knowledge, tools and techniques in managing the delays in public construction projects in the KSA. This objective was addressed in both quantitative and case studies (i.e., qualitative). Based on the results gathered from the survey data, the use of PM knowledge was found to be below average, as $35 \%$ of the respondents reflected that they believe that project management philosophy is being used in the public construction sector in the KSA. According to these respondents however, PM concepts have not yet gained adequate acceptance across public construction projects in the KSA. Also, many of the survey respondents suggested that the application of PM tools and techniques was not effective in the KSA's public construction projects. Moreover, most of the participants indicated that the use of project management knowledge was limited in the public construction sector in the KSA, with nearly the majority of them (91\%) recommending a need for an improvement. Most of the respondents suggested that project management knowledge is hardly ever used in the KSA's public construction projects.

Information gathered from the case studies showed that the activities associated with project management concepts such as the development of business case, project charter, and project management plan were undertaken (SPM-3 and PLM-2). According to the professionals, there was a plan to apply project management principles in all of them. Also, the interviewees suggested that the importance of applying PM principles was emphasised in the case projects (PM-1, PMC-4 and PLM-2). However, the interviewees indicated that the PM tools and techniques have not been effectively applied to halt the development of delays in the case studies (SPM-3, PSC-4, CM-4 and PLM-2). The growing awareness of project management principles in construction projects in the KSA has also been identified by Mitra and Tan (2012). Their findings are in line with those of the quantitative research reported in this thesis, where the application of PM concepts in the KSA's construction projects examined, was reported to be ineffective.

Certain PM tools and techniques, found in the quantitative study, were frequently used in the public construction projects in the KSA. The survey respondents identified the Excel sheet, a project planning software as the most widely applied PM tool and techniques. This can be attributed to the wide availability and relatively low prices of a Microsoft subscription. Also, the Excel sheet is easier to learn and use, compared to other software such as Primavera P6 and Microsoft Project. The second most widely used PM tool and technique identified from the 
analysis of the quantitative data is the percentage completion of activities. The percentage of completion for each project activity represents a simple form of determining the extent of completed work in a construction project (Meredith and Mantel $\mathrm{Jr}, 2011$ ). It is simple applicability must have influenced the acceptability of this techniques in the development of KSA's public construction projects. Also, regular progress meetings were identified as the third most popular PM technique used in the KSA. A progress meeting is a common approach used in projects to track emerging issues during a project's execution. This technique has been recommended to ensure an appropriate monitoring of projects by PMI (2013).

Measurement on site and a performance report are the fourth and fifth most importantly used PM tool and technique in the KSA's construction projects, according to the results of the survey study discussed in Chapter 5. This result reinforces the suggestion of Alzara et al. (2016) that a performance report system is important for managing construction delays in the KSA. As these two tools and techniques can be easily developed and used, this must have influenced its wide adoption in the KSA's public construction projects. Their popularity stems from the need to apply an approach that is not costly, considering the fact that most contractors for public projects in the KSA have been identified as lacking sufficient cash flow to execute their contracts adequately.

Similar to the results reported in the quantitative study, expert judgment and previous project data were identified as the two most widely used project estimating tools and techniques in the case studies. This result confirms an earlier study by Jørgensen (2007) that demonstrated the growing acceptance of expert judgment as an important estimating tool and technique in PM. Also, both expert judgment and previous project data have been highly recommended in PMBOK as estimating tools and techniques that can be employed to improve project performance (PMI, 2017). Therefore, this research outcome was not unexpected. However, it was surprising that bottom-up and parametric estimating were not being deployed in the project estimation activities in the KSA's construction projects, despite their prominent application globally. This situation can only be explained by the relatively new adoption of project management concepts in the KSA (Alghadeer and Mohamed, 2016).

Also, most of the project time management planning tools and techniques were reportedly unused in the case studies, with the two mostly applied being Gant Chart and Critical Path Method. This finding is in line with that suggested by Lechler et al. (2005), where the Critical Path Method is reported as a traditional approach to ensure timely delivery of project 
milestones and minimise the chance of delays in several project organisations. Also, the Gantt Chart has been identified as a widely accepted method for managing the schedule or time across many projects over the years (Besner and Hobbs, 2008). This study's finding resonates with that notion. While the Critical Path Method was also found to be the most prevalent time management tool and technique in the quantitative study, Gantt Chart, WBS and PERT were not reported to be equally used as often by the survey respondents. Instead, milestone date techniques were identified as more frequently used when managing time in the KSA's public construction projects.

The results reported in both quantitative and case studies regarding the project controlling tools and techniques agree with one another. The top three tools and techniques identified in both study methods for project monitoring were regular progress meeting, performance report and percentage completion of activities. This outcome correlates with what has been suggested by Meredith and Mantel Jr (2011), that regular progress meeting and performance report have formed a crucial set of tools for controlling the project results over time. Also, measurement on site was noted as another top controlling tool and technique in the quantitative study, unlike actual project expenditure tracking as reported in the case studies. Interestingly, Earned Value Management was not found to be among the most frequently used project controlling tools and techniques in the KSA's public construction projects, despite its dominance in the control of schedule and cost performance of projects in several countries around the world (Fleming and Koppelman, 2016). This result can be attributed to a lack of understanding or appreciation of this technique among important parties involved in the execution of public construction projects in the KSA.

Lastly, the most often applied planning software in the Saudi Arabian public construction projects were found to be the Excel sheet and Primavera P6, according to the outcome of the quantitative study and case studies. This result is not unexpected, considering that the Excel sheet and Primavera P6 have become prominent features in the planning and management of projects over the years. The Excel sheet, in particular, has remained a planning software for daily activities in several organisations since its inception. Primavera P6 is another project planning software that is quickly receiving acceptance across construction project settings. Therefore, its adoption in public construction projects in the KSA is in line with its growing popularity globally. However, Microsoft Project was reported by the majority of participants to be rarely applied within the KSA's public construction projects. Microsoft Project has become the software of choice for planning project activities among several project managers 
globally as it has various essential functions. Microsoft Project is not only good for project planning, but also for monitoring changes that may affect the timely production of key deliverables and achieving main milestones (Ragavi and Uma 2016).

Primavera P6 is identified to have been used in most of the case studies of this research due to its flexibility and capacity to accommodate thousands of activities and showing them in a manner that is easy to understand. Also, this software was suggested by the interviewees involved with the case studies, as providing the opportunity for parties to collaborate more effectively on the project and identify any issues with the project progress (CM-1 and PM-2). The results of this study regarding the planning software agree with the suggestion in Meredith and Mantel Jr (2011) that Primavera P6 and Microsoft Project have both been applied predominantly to plan and track project activities over the recent years. However, it is unknown if the planning software is being used effectively to tackle the problems of delays in the public construction sector in the KSA. It is one thing is to make the planning software available for use in a project; it is another issue whether or not it is applied effectively. For example, the professionals interviewed in the case studies have suggested that the contractor's personnel might not have employed the planning software efficiently due to their limited experience and qualifications. The importance of having appropriate qualification and training for the effective application of project planning and management software has previously been emphasised by Burke (2013).

\subsection{Influence of PM Knowledge, Tools, and Techniques on Delays}

The third research objective in this thesis is to identify the influence of PM knowledge, tools and techniques on the occurrence of delays in public construction projects in the KSA. The findings from the quantitative study revealed that the majority $(85 \%)$ of participants involved in this study expressed confidence that delays in public projects can be potentially mitigated/minimised by applying PM methodologies, tools and techniques. The association between PM knowledge, tools and techniques and delays was addressed in the quantitative study. Using three indicators that included previous project data, bottom-up estimating and parametric estimating, the influence of project estimating tools and techniques on the occurrence of delays in public construction projects in the KSA was determined. The result of 
the SEM-PLS indicated that the application of project estimating tools and techniques was a solution to reduce the occurrence of delays, as reported in Chapter 5. Likewise, the practitioners involved in the case studies did indicate that a more effective use of these tools and techniques would have helped minimise the occurrence of delays in the projects. They also stressed on the need to adopt new estimation tools as most of the participants believed that the current estimation tools used were not accurate (PC-1 and PS-4). While there is no available study that has attempted to specifically identify the link between project estimating tools and techniques and delays in KSA's construction, research focusing on other countries does provide support for the findings in this thesis. For example, research conducted by Kaliba et al., (2009) and Mezher and Tawil (1998) have earlier suggested that poor application of project estimating tools and techniques has led to delays in construction projects executed in Zambia and Lebanon respectively.

Also, the use of project time management planning tools and techniques was shown from the analysis of the quantitative data to be positively related to general management delay factors. This outcome suggests that the lack or inadequate application of project time planning tools and techniques such as Gantt chart, Work Breakdown Structure, Critical Path Method, program evaluation and review technique and milestone date programming are contributing factors to the delays in public construction projects in the KSA. As explained in Chapter 6, this situation can be attributed to the lowest bidder system. The lowest bidder system has been identified as an incentive for contractors to recruit unqualified manpower due to inadequate financial resources to hire more suitable and experienced personnel (Albogamy et al., 2013; Mahamid, 2016). Accordingly, this can contribute to an ineffective application of these tools and techniques, thereby leading to the occurrence of delays. For instance, East (2015) suggests that an adequate knowledge of the effective application of CPM is essential for this technique to positively impact the performance of projects.

A lack of communication between all project parties might have also resulted from the lack of qualified contractors and consultants, another delay factor identified in both quantitative and qualitative findings in this study. Ineffective application of project time management tools and techniques have been indicated in PMI (2013) as likely to impact the flow of communication among the project parties. For instance, an appropriate development of WBS and CPM would ensure that the parties are properly informed about the relationships existing between the project tasks and how these could negatively impede the project progress. Such an understanding can help the parties agree on a more pragmatic approach to prevent or minimise 
the occurrence of delays in their projects. The results obtained in this regard has validated the position of Patanakul et al. (2010), that an effective application of time management tools and techniques is key to preventing problems such as delays.

Furthermore, the findings of the quantitative study pointed to the application of PM control tools and techniques as an important possible contributor to the occurrence of delays in the KSA's public construction projects. According to the study's result, a lack of or inadequate use of the control tools and techniques such as EVM, regular progress meeting, actual project expenditure tracking, performance report and contractual milestone tracking leads to an oversight and thereafter, affects the functions of all project parties towards ensuring satisfactory progress of the public construction projects in the KSA. The significance of using control methods to minimise delay issues has also been emphasised by Martinelli and Milosevic (2016). It is apparent from this study's findings that public construction projects in the KSA have not been benefitting from the application of these important control tools and techniques. Based on the respondents in this thesis, the delays in these projects can be reduced if efforts are intensified towards promoting the use of EVM among other control tools and techniques.

The effect of an inadequate use of the planning software to manage the occurrence of delays in construction projects in the KSA was also identified in the quantitative study in Chapter 5. The study's findings suggest that an inadequate application of the project planning software is a trigger of general management and consultant factors-related delays. Project planning software such as Microsoft Project, Primavera P6, Project Commander, and Asta Power Project have been identified as crucial in the overall management of construction projects all over the world (Burke, 2013). The outcome of this study highlights the underlying issue of effective application of planning software that needs to be addressed, in order to minimise the occurrence of delays in the KSA's public construction projects. Table 7.2 displays a summary of mixed analysis of the findings (regarding the use of PM tools and techniques in managing delays), as reported in both qualitative and quantitative studies of this thesis, alongside the results present in existing literature. 
Table 7.2 Summary of mixed analysis of the PM tools and techniques that considered input to the framework

\begin{tabular}{|c|c|c|c|}
\hline PM tools and techniques & $\begin{array}{l}\text { Quantitative } \\
\text { Findings }\end{array}$ & Qualitative Findings & Related Literatures \\
\hline Gantt chart & SEM-PLS & & PMI (2017) and Besner and Hobbs (2008). \\
\hline WBS & SEM-PLS & & $\begin{array}{l}\text { PMI (2017); PMI (2016); Zecheru and Olaru (2016); and } \\
\text { Memon et al., (2014). }\end{array}$ \\
\hline CPM & SEM-PLS & & $\begin{array}{l}\text { PMI (2013); PMI (2016); East (2015); Alfaifi (2015); } \\
\text { and Şandru and Olaru (2013). }\end{array}$ \\
\hline PERT & SEM-PLS & & $\begin{array}{l}\text { PMI (2017); Alfaifi (2015); and Zhong and Zhang } \\
\text { (2003). }\end{array}$ \\
\hline Bottom-Up Estimation & & PC-1 and PS-1 & PMI (2017) and Kaliba et al., (2009). \\
\hline Primavera 6 & & $\begin{array}{l}\text { CM-1, PM-2, and PSC- } \\
4\end{array}$ & $\begin{array}{l}\text { Kastor and Sirakoulis (2009); Raj saran (2015); and } \\
\text { Subramani } \text { et al., (2014). }\end{array}$ \\
\hline EVM & & PMC-4 & $\begin{array}{l}\text { PMI (2017); Patanakul and Milosevic (2010); Chin-Keng } \\
\text { and Shahan (2015); and Lipke, et al., (2009). }\end{array}$ \\
\hline Parametric Estimation & & PC-1 and PS-1 & PMI (2017) and El Sawalhi (2014). \\
\hline MS project & & PM-3 & Hebert and Deckro (2011) and Raj Saran (2015). \\
\hline
\end{tabular}




\subsection{Minimisation of Delays}

To reduce the incidence of delays in public construction projects in the KSA, it is important that current project management practice is re-considered with a mind of identifying and implementing any necessary strategies or changes to achieve that aim. As already established from the findings of both quantitative and qualitative studies presented in this thesis, PM application in the KSA could contribute significantly to mitigating the incidence of delays. Specifically, all the participants in this study suggested that the delays in the KSA can be minimised if specific strategic actions are taken. According to the majority $(61.5 \%)$ of the survey respondents, delays can be best minimised in the KSA's public construction projects by making appropriate and timely decisions during their construction phase. Also, about $47.7 \%$ and $41.5 \%$ of the participants indicated that the delays can be best reduced during the planning and design phases respectively.

The outcome of this study can be explained by the fact that most of the project activities are normally undertaken during the construction phase (Hardin and McCool, 2015). According to Hardin and McCool (2015), over $60 \%$ of project resources are utilised during the construction phase. This position has also been validated by the case studies' respondents who expressed their belief that delays in the KSA's construction projects can be best mitigated during the construction stage (e.g., PS-1, PC1, SM-2, and PC-2). In addition to the construction phase, a pragmatic prevention of delays in public construction projects in the KSA will require that all other phases such as planning and design, mobilisation and tendering are also managed effectively using appropriate strategies.

\subsection{Strategies for Mitigating Critical Delays in the KSA's Public Construction Projects}

The participants in the study suggested several strategies for reducing delays in public construction projects within KSA. These recommended approaches were considered in the context of relevant PM knowledge principles (knowledge, tools and techniques) for minimising delays in public construction projects within the KSA. This position is also supported by Martinelli and Milosevic (2016). The approaches that have been recommended by the professionals to manage delay factors, so as to consequently minimise the occurrence of delays 
in public construction projection, are expanded upon in this section. In particular, 8 delay factors, which were reported to be the critical factors in public projects in the KSA, are elaborated on, namely: slowness of decision-making; lack of qualifications; lowest bidding system; design issues; financial difficulties; ineffective project planning and scheduling; change orders; and workers' inexperience. PM techniques that can be utilised to address the suggestions for each of the delay factors are also reported. The next section relates the influence of using tools, as determined by both quantitative and qualitative examinations, as conducted in Chapters 5 and 6.

\subsubsection{Slow Decision-making}

It has been established from the results of this study that slow decision-making by the client is a factor contributing to the delays in public construction projects in the KSA. However, it was unveiled in this study that an effective application of PM knowledge, tools and techniques can be used to minimise the problem. According to the study participants, a slow decision from the client (government) can be minimised during the mobilisation phase, if decision requests are prioritised based on their importance and impact level on a project, using information from the PM plan (PS-4 and SM-2). In this instance, decisions that can have more significant negative impacts on a project are given more priority than those with less effects (CS-3). The importance of prioritising decisions towards improving project performance has been emphasised by White and Fortune (2002). A decentralisation of the decision-making process was also suggested as a way to tackle the slow decision-making syndrome in public construction projects in the KSA (PMC-4). This aligns with the suggestion of Marques et al. (2011) that junior managers should also be empowered to make decisions to minimise the disruption to project progress.

The practitioners also reported that slow decision-making can be significantly reduced if there is a team dedicated to assessing decision requests and making recommendations to the persons or body responsible for making the final decision. According to them, such an approach will reduce the time for making decisions as the final decision maker will have adequate information to decide promptly (e.g., SM-2, SPM-3, and PS-4). During the construction phase, the participants suggested that certain actions should be taken to expedite the decision-making time. They expressed their belief that delays motivated by slow decision-making can be minimised by prioritising decisions in accordance to how they can impact the project schedule. For instance, it is suggested that a disruption to the project progress can be halted if decisions relating to activities on a critical path are made quicker (CM-1). Also, the professionals 
suggested that deadlines should be assigned to decisions that are time-sensitive. Moreover, a project management office that can aid in speedy decision-making should be established (PC1 and PMC-4). The PMO may play an essential role through providing a decision-making framework that can facilitate decision-making and effectively communicate with all relevant stockholders (PMI, 2013). More importantly, most of the interviewees believed that rallying the support of all parties during the execution stage would help aid a quick and efficient decision-making process. These actions have also been indicated in the existing literature as being supportive of timely completion of projects (Chapman and Ward, 2002; and Eweje et al. 2012).

In terms of the PM tools that can be applied to manage slow decision-making as a delay factor, the findings of both quantitative and case studies have recommended that the application of PM tools such WBS, CPM, Bottom-up estimation, Gantt Charts and EVM could contribute to manage the delay incidents as well (as discussed in Chapter 3). In particular, WBS would help in outlining the duties that need to be performed for the activities taking place on a construction project. This would, as a result, give a clear indication on the personnel responsible for overseeing the smaller components of the project. The smaller components can then be traced back along the structure to help identify the authority responsible for making decisions for that particular activity. The use of the WBS for improving decision-making has been reported in the study by Zecheru and Olaru (2016). They consider the WBS as a more qualified substantiation of managerial decisions which avoided re-work and delays (Zecheru and Olaru, 2016). The WBS should be used in the planning, mobilisation, and construction phases to best utilise its features for improving the speed at which decisions are made.

CPM and Gantt Charts can be utilised for determining the time that can be spent on making a decision for a particular task. This might depend on a lag or lead that is associated with the activity, which can be utilised to spend time on making a particular decision. Additionally, the scheduling tools will provide the decision maker with an overview of the critical activities located on the critical path. This way, it will be easier to determine which activities require decisions to be made in a short time span so as to avoid project delays. A study by East (2015) reports that the CPM is critical to enhancing the accuracy of the decision-making on construction projects. The use of CPM and Gantt charts is most applicable during the planning and construction phases. Also, EVM can attribute the value of each activity involved, enabling decision makers to understand the value associated with the activity in which they are involved 
in. By helping the managers measure the project performance, it will be easier to identity when decisions need to be made in a short period of time (Chin-Keng and Shahan, 2015).

\subsubsection{Lowest Biding System}

The culture of awarding construction contracts to lowest bidders has been identified in this study as attributing to the delays in the public construction projects in the KSA. To address this problem, the practitioners who participated in this study have made certain recommendations, which can also be supported by previous research findings. The suggestions for addressing this problem during the contractor selection phase of a project include prioritising the financial capacity of the selected contractors and re-examining the advantages of adopting the lowest bidding system. Also, in the mobilisation phase, it is suggested that contractual agreements with contractors should be reconsidered and the financial standing of contractors should be rechecked at this stage, to determine if any interventions are necessary.

According to some of the respondents, the financial capacity of the contractors should form an important criterion during the pre-qualification and tendering exercise (SM-2, PM-3, and PMC-4). The participants suggested that rather than focusing on the lowest bidders, the client should prioritise the financial capability and other criteria that may limit the contractors' capacity to undertake their project functions accordingly, which may thereafter lead to delays. This suggestion is supported by Ibrahin et al., (2016), who indicated that the lowest bidding approach to selecting a contractor can affect a project's performance in terms of cost and time. In addition, the interviewees urged that clients should evaluate the suitability of a lowest bidding system in their projects by considering their features. This is crucial as research has indicated that the lowest bidding system is unsuitable for certain types of projects, especially those that are complex in nature and require a high level of technicality (Lo et al., 2007).

Furthermore, the participants believed that re-visiting the contractual agreements with the contractors during the mobilisation phase of a project will help identify any issues and allow for a re-negotiation with the contractors, so as to ensure a hitch-free project execution. Within the mobilisation phase, it is also recommended that the financial status of the contractors be rechecked to confirm their readiness to undertake project tasks without any financial encumbrance. According to some respondents, such action would enable clients to know if there was, for example, a need to increase the mobilisation payments to be made to the contractors (PC-2 and CM-4). 
Applications of tools such as the bottom-up estimation approach and parametric estimation can lead to the management of issues associated with the lowest bidding system. It has been reported that the bottom-up approach gives a better indication due to the involvement of all project participants. Contractors can be asked to submit their bottom-up estimates to indicate the personnel who will be involved in the project execution, allowing clients to better assess their credibility. In addition, the use of estimation tools by the client to get a better understanding of the underlying relationship that impacts the cost and duration of the activities will provide the client with a better understanding of the requirements of the project. They can then be able to judge the suitability of the contractors, given their better understanding of the project. The results reported from the quantitative analysis conducted using SEM in Chapter 5 indicates a direct correlation between the latter tools discussed and the delays caused due to general management issues in a project, such as the adoption of the lowest bidding system.

\subsubsection{Financial Difficulties}

Project financing problems have been identified in the quantitative study and case projects as being one of the top five significant factors that contribute to delays experienced in the KSA. Specifically, the contractors were found to be deprived of the cash flow required to fulfil their obligations, such as paying their staff members and suppliers when agreed. The professionals interviewed indicated a number of actions that can be taken to address this issue at different phases of a project. In a pre-project phase, it is recommended that the client should consider reliable financing options that will guarantee the availability of financial resources required for the successful implementation of a project. Research has indicated that having a solid arrangement for project financing is essential to prevent disruptions, as a lack of steady cash flow may lead to a situation where important activities cannot be completed on time (Fabozzi and de Nahlik, 2012). This has very much been the case with the public construction projects in the KSA, with numerous cases of contractors not having the access to the required financial resources to support the speedy progress of the projects. Some professionals interviewed cited instances of delayed supply of much needed materials because the suppliers were not paid regularly (e.g., CM-1, SE-2, and PSR-4).

According to the participants in the case studies, public construction projects in the KSA are always solely funded by the governments; therefore, it is likely that the burden is becoming unbearable for them. In view of this problem, they suggested that the KSA governments may have to consider alternative sources or methods. For example, a public private partnership 
model of project funding can be considered (CM-4). Public private partnership (PPP) projects have become widely accepted across several nations as a way of financing their ever-increasing demands for projects (Delmon, 2017). As indicated in PMI (2016), it provides a new source of financial support for the construction and maintenance of public infrastructure with a reduced burden on governments' tight budgets. Despite the growing popularity of PPP, there is still no evidence to suggest that it is being explored by the governments in the KSA. The respondents believed that such an approach could be used to address the shortage of funds needed to execute numerous projects in the Kingdom (CM-4).

In the planning and design phase, the practitioners interviewed in this study suggested the development of a cost management plan using effective estimating tools and techniques (PLM2). Involving all workers responsible in the execution of an activity in the bottom-up estimation approach helps in mapping out all the costs that will be needed during the project execution. Additionally, utilising proper estimating toolsets such bottom-up and parametric estimating, expert judgement, and previous data can provide a deeper understanding of the distribution of the costs throughout the project phases (PMI, 2017).

The interviewees also recommended incorporating effective controlling tools and techniques. As investigated, since EVM has not been used sufficiently in the KSA's public projects, a better use of EVM might be the solution that provides a tracking capability for the performance of project cost objectives. According to PS-4, such actions would help identify possible financial problems that could beset projects from the outset, thereby putting clients on red alert to remedy the issue. This line of thought has also been expressed in Larson and Gray (2013), with the authors canvassing for a sound cost management plan towards reducing tensions in a project's progress. Furthermore, it is advised by the interviewees that financing options and cash flow management plan should be re-evaluated during the planning and design phase.

In the contractor selection stage of a project, the practitioners supported the ideas of considering the financial ability of the prospective contractors during the pre-qualification exercise, as well as developing contractual agreements that encourage the availability of financial resources throughout the execution stage. The practitioners who participated in Singh and Tiong (2006) also highlighted the importance of ensuring that contractors are financially capable before awarding construction contracts to them. Otherwise, projects may be affected negatively. The participants also recommended involving all project parties through constant communication and meetings in the entire construction phase, so as to limit the risk of exposing projects to 
financial problems that could hinder their progress, thus resulting in delays. This is another point that can be covered by the application of the bottom-up technique. The importance of involving all the parties (playing one role or another, including external ones) in a construction project has been demonstrated in the mainstream literature (e.g., Duy et al., 2004; Atkinson, Crawford, and Ward, 2006; and Nibbelink et al., 2017). Stakeholder engagement has been identified as crucial to resolve financial difficulties during construction (Rodriguez-Melo and Mansouri, 2011).

\subsubsection{Lack of Qualifications}

To confront the issues relating to a lack of qualifications of both consultants and contractors, as well as limiting their influence on delays, those interviewed in this study suggested a wide range of actions. According to the participants, a set of required qualifications for contractors and consultants should be set at the initial phase of a project. These qualifications can be in the form of their experience, reputation, and staffing (PM-1). The professionals recommended that these qualifications should guide the recruitment of consultants and choosing of contractors at the planning and design phase and tendering stage respectively. This suggestion is also supported by Mahdi et al. (2002). The practitioners recommended that the best qualified contractor should be selected, rather than the one with the lowest bidding price but without the required technical know-hows and capacity to successfully implement projects within the predetermined schedule. The study by Olaniran (2015) found that the failure to select the best qualified contractors impacts adversely on a construction project. Also, PMI (2016) advises that the experience, reputation, and personnel staffing of contractors can improve a project's performance.

In the mobilisation phase, the participants in the qualitative study of this thesis believe that project management offices should closely and continually monitor the performance of both consultants and contractors, so that appropriate interventions can be applied; as lapses are noted due to their limited qualifications before the full execution of a project begins (PM-1 and PMC4). Furthermore, during the construction stage, the professionals suggested that PMOs should continually monitor the performance of consultants and contractors using effective management tools and information in the master schedule. In addition, they advised that PMOs should support the consultants and contractors with resources, recommending necessary training for them to perform their functions diligently. As such, this can limit the probability of delays occurring (PLM-2 and PC-1). The important roles of PMOs in contributing to the 
successful implementation of projects, thus helping to achieve their schedule and cost objectives, have also been emphasised in Unger et al., (2012).

In terms of the tools that can be adopted to ensure the adequate qualifications of the workers involved, the use of WBS can help establish the requirements in terms of the resources required to complete a certain activity. The CPM can also be used to ensure an effective employment of skilled workers. This can be achieved by constructing the work schedule based on the productivity output of the workers involved. In this case, this can then be used in EVM to contrast the progress of the works with the one determined by the use of estimates-based workers' performance measures. Deviations from the baseline's estimated schedule can indicate a problem with the productivity of the workers, suggesting a need for a further investigation of their skills and qualifications (Anbari, 2003). The WBS needs to be implemented at the pre-project, design and tendering phases of the project, while the CPM and EVM tools need to be applied at all stages of the construction process, to make sure that the project's progress is fully monitored.

\subsubsection{Workers' inexperience}

The lack of adequate experience and capacity on the part of contractors' employees has been identified as a factor leading to the delays in public construction projects in the KSA. According to the findings reported from both quantitative and case studies, there was evidence to demonstrate that the contractors' personnel lacked the required expertise to effectively utilise PM tools and techniques that could have helped in minimising delay experience in these projects. The professionals interviewed admitted that this problem is one of the issues that contributed to delays experienced in the studied case (PC-1, PS-1, and PS-4). Consequently, they recommended actions that could be taken at different phases of a project management cycle in order to curb the problem.

The professionals that were involved in this study indicated that the problem of inexperienced contractors' staff influencing delays can be lessened and managed during both the mobilisation and construction phases of a project. In the mobilisation stage, the participants recommended that the contractors should first identify and clarify the roles and responsibilities important for the execution of their projects (PC-1). This could be achieved via the use of the WBS. Thereafter, they should establish the experience and qualifications considered appropriate for those positions, before recruiting suitably qualified personnel to undertake the project responsibilities. In addition, the participants suggested that the line of reporting and staff 
development plans should be estabished within this phase. These suggestions have also been presented in PMI (2016) as being important towards achieving the project objectives successfully. Furthermore, a similar proposition has been submitted by Huemann (2010), that contractors should employ qualified human resources for projects and support them with necessary training to improve their success chances.

To minimise a personnel's contribution to the delays during a project's construction, the professionals interviewed believe that the individual performance of contractors' staff should be measured against the baseline. Based on the results, further training should continually be made available for low-performing team members (PLM-2). The recommendations for a continuous re-assessment of project team members' performance, and the need to train them as and when deemed essential, have also been advocated by Gällstedt (2003). Moreover, the practitioners advocated that knowledge sharing and learning should be facilitated across the project teams to minimise the likelihood of delays. They believe that contractors should encourage highly skilled members of their staff to mentor inexperienced personnel in their teams to improve their performance, which can stimulate a timely completion of projects. These suggestions are similar to those contained in the study conducted by Ruuska and Vartiainen (2005). The re-assessing of project team members, which should be taking place throughout the construction phase of a project, can be achieved by utilising the EVM tool in order to track the project's progress and performance, both in terms of time and cost. This is supported by a study which examined the importance of EVM in understanding the productivity of construction personnel (Anbari, 2003).

\subsubsection{Design Issues}

Design error and other related issues have been revealed in the analysis of both qualitative and quantitative data as being contributors to the occurrence of delays in the examined projects. While the professionals admitted that it is difficult to avoid delay errors in a typical complex construction involving a high-level of technicality, they believe that the effects of the problem can be minimised by taking certain pro-active measures. In the planning and design phase of a project, the participants advised that the consultants should recruit only competent and experienced design engineers to limit the possibility of errors in this activity. The WBS can be used to highlight the tasks that require an exceptional level of skill through understanding the finer decomposition of the work that is involved (PMI, 2016). Design work that includes complex work can thus be determined through the utilisation of the WBS. This is supported by 
a study conducted by Chang et.al (2010), where the use of the WBS was found to improve the planning design process in projects. EVM was also found to be supported during the implementing of design changes in various phases of the project (Czemplik, 2014). Also, they proposed that collaboration and communication should be advanced between project parties during the design stage as it would help avoid minor details that could trigger unwanted delays in the project during the construction activities. The practitioners, in addition, state that developing a design management plan will ensure that design issues are managed more effectively, thus, restricting the prospects of delays in public construction projects in the KSA. They identified that these aspects have not been adequately addressed in the cases studied. Koskela et al. (2002) demonstrated the importance of experienced design engineers and collaboration among project teams to prevent or minimise the probability of errors that can delay the project progress.

The interviewees (CS-3 and PS-1) suggest the need for collaborative working relationships between all project parties, which could benefit the identification of potential design issues that could be addressed before the construction phase (when they usually have the most damaging impacts on a project's cost and schedule). This aligns with the opinions expressed in PMI (2016). Within this stage, they equally argued for a continuous collaboration between project parties as effective management design issues such as identifying errors and correcting them as quickly as possible helps to reduce their pressure on the schedule. This submission is in line with the one presented in Chapman (2001), which emphasised the importance of managing design issues effectively at the construction phase to inhibit or minimise disruptions to project flow.

\subsubsection{Ineffective Planning and Scheduling}

Ineffective planning and scheduling have been found in this study to contribute to the occurrence of delays. However, those interviewed in this study expressed the belief that delays in the KSA's public construction projects can be effectively minimised, if planning and scheduling activities are managed more effectively at different important phases of a project. They suggested that a project charter should clarify the scope and deliverables in as much details as possible, in order to guide them in making better decisions on planning and scheduling approaches (PC-1, PMC-4and CM-4). The study by Kerzner and Kerzner (2017) indicates that having a project charter that clarifies the project details assists in the effective planning and scheduling of a project. 
The need to adopt new scheduling tools such as WBS, CPM, PERT and Gantt Charts and estimation tools have been stressed upon by the participants. It has been made clear by the participants that the CPM needs to account for the expected performance of workers involved in the activities of the construction works (PS-4). This is to reflect the realistic schedules for the project duration. Combining EVM and CPM was also suggested as a mechanism to better enhance the monitoring of the progress of work. EVM combines the scope, schedule, and resource measurements to assess project progress and performance (PMI, 2013). Changes to EVM, that are a result of deviations caused by delays, could trigger a dynamic scheduling approach, whereby the activities are re-scheduled accordingly. As a result, these tools should be implemented accordingly in the planning and construction phases of the project.

In the planning and design phase, the participants recommended that a realistic project duration and schedule should be set. Mainstream research has indicated that schedules or deadlines set in many projects are unrealistic and often fail to consider inherent uncertainties, related to the constraints and priorities that may impact the project's progress (Hartmann and Briskorn, 2010). Available evidence from the information provided by the professionals showed that adequate uncertainties have not been built into the case projects' schedules, which have contributed to the delays experienced in them. Haquea et al. (2017) stress that the pressure to maximise the scarce financial resources available to organisations have compelled them to demand a faster delivery of projects within a possibly reduced budget. According to Hartmann and Briskorn (2010), the importance of setting unambiguous schedules that are not only realistic, but logical and understood by all project participants cannot be overemphasised. A lack of realistic schedules in the case studies was thought to affect the ability to develop pragmatic objectives, milestones and benchmarks. According to Herroelen and Leus (2005), an application of effective estimating tools and techniques, as well as software, may assist in developing more realistic schedules. This is one area that needs to be improved upon in the planning of public construction projects in the KSA.

In addition to setting realistic schedules during the planning and design phase, the participants recommended that all staff should undergo training in the effective usage of a user-friendly project scheduling software. Moreover, they advocated that a wide range of schedule management tools, such as such as WBS, CPM, and PERT, should be used to develop master schedules. Effective application of these tools and techniques are indispensable to minimise delays in a construction project (Larson and Gray, 2013). For example, along with those interviewed in this study, De Meyer, Loch, and Pich (2002) suggest that an effective application 
of the Gantt chart would help project team members know the project tasks to be performed, their sequence and their duration. This then allows for them to be sensitive to any probable delays. However, this study has found that these tools and techniques are not adequately and effectively used in the execution of public construction projects in the KSA. It is also recommended that collaboration and communication between project parties should be facilitated at this stage (SM-2). Communication has long been identified as one of the most crucial aspects of the PM process (Thomas and Mengel, 2008). The construction industry is critically dependent upon efficient collaboration and communication among its stakeholders (PMI, 2016). Also, a successful implementation of a construction project demands that there is a continuous flow of communication across the project teams and parties (Martinelli and Milosevic, 2016).

In the construction phase, the participants advised that a schedule's performance should be monitored continually using more effective PM tools and techniques. Also, they suggested that there should be a provision of ongoing training to the project teams on managing the schedule and updating status in this phase (PLM-2). This suggestion resonates with the one made by Fleming and Koppelman (2016), which indicates that is a dominant tool for controlling or tracking schedule and cost performance of projects in several countries around the world. However, this study has identified that this technique is not being effectively implemented in public construction projects in the KSA.

\subsubsection{Change Order}

Change orders are mostly inevitable in public construction projects due to many reasons including: variation to project design, unforeseen circumstances such as unexpected site conditions, as well as errors and omissions in the project plans (Keane et al., 2010). The participants in this study identified change orders as a factor contributing to the occurrence of delays in KSA's public construction projects (e.g., PM-1 and PMC-4). They, however, recommended some actions that could be performed to minimise the impacts of this problem on the project's schedule performance at different project phases. This validated the position of Alfaifi (2015) who reported that inadequate strategies for managing changes during the construction project contributes to the incidence of delays.

In the planning and design stage, they advocated that a change management plan should be developed. Also, there should be the establishment of a dedicated team to manage that change process as well. The importance of a change management plan and team to effectively manage 
change orders has been stressed by Ibbs et al. (2001). Also, in the mobilisation phase, they suggested an update to the change management plan and collaboration among project parties regarding the management of change. During the construction phase, the participants advocated for a documentation of change requests and a prioritisation of their treatment. This is in line with recommendations in the PMI (2016). In addition, an evaluation of change requests and a collection of the inputs of concerned project parties on managing change orders is suggested by the professionals. Moreover, they believed that the schedule should be updated based on the implemented changes and more personnel should be brought into work to enforce the requested changes. This is in line with the discussion presented in Chapter 3.

The tools recommended for the implementation of handling the issue of change orders include: EVM, CPM and WBS during the construction stage of the project (PMI, 2013; Virle and Mhaske, 2013; and Czemplik, 2014).

\subsection{Delays' Mitigation Framework}

A framework for managing delays based on the proposed strategies and PM tools discussed in Section 7.5 and their relationship, as displayed through the quantitative and qualitative examinations (as conducted in Chapters 5 and 6), is presented in Figure 7.2. The resulting framework has been developed to illustrate the approaches that can be used to minimise the top 8 delay factors in the KSA's public construction projects, which are: slowness of decisionmaking (CLF3); lowest bidding system (GMEF3); design issues (CSF2); financial difficulties (COF4); ineffective project planning and scheduling (COF1); change orders (CLF2); lack of qualifications and workers' inexperience (COF2). The framework considers the links between the delays and strategies that have been supported by both the interviewees and literature. The tools recommended to deal with each delay, as identified from the quantitative and qualitative assessments undertaken in this thesis, along with the evidence present in the literature, are also shown in the proposed framework. Appropriate strategies associated with each of the most crucial delay factors, identified in the literature, the quantitative and the qualitative studies of this thesis, are presented in the framework (Figure 7.2).

The first part of the framework, as shown in Figure 7.1, captures the findings for both quantitative and case studies conducted in this study and relevant literature. From the triangulation of the research findings (as discussed previously), it resulted in the second part of 
the framework (as seen in Figure 7.2). Also, a coding structure to identify each strategy in Figure 7.2 is displayed in Table 7.3.

In particular, the resulting framework in (Fig 7.2) has been developed to illustrate the approaches that can be used to minimise the top delay factors within the different phases of construction projects in the KSA. For example, it highlights that critical delay factors that are related to clients are best dealt with the implementation of tools such as WBS, Gantt Charts, Parametric Estimation, CPM, and EVM. The phases of implementing these tools are identified as the mobilisation, design and construction phases (Figure 7.2). Strategies that can be implemented include: the use of change management plans; reinforcing design collaborations between project participants; and better documentation of change requests aligned with enhanced schedule updating methods.

In terms of the critical delays associated with the consultants, the most appropriate tools to adopt are again Gantt Charts, Parametric Estimation, CPM and EVM. These should be implemented during the tendering and mobilisation phases of the project. Associated strategies to deal with management-related delay issues include: recruiting experienced engineers; developing design management plans; enhancing collaborative working relationships among the team members; and managing the project.

To address the critical delays factors associated with the contractors, for example, to address ineffective planning and scheduling, it is suggested that PM tools and techniques should be applied effectively. The appropriate PM tools include Gantt Charts, CPM, WBS and EVM. These tools should be adopted at all phases of the project (from the pre-project to the construction phases). Moreover, the strategies that can be adopted to manage the critical delays related to contractors include: ensuring financial viability through efficient cash flow management methods, allocating staff with high experience and qualifications, using support from the PMOs, accurate identification of project scope and deliverables, and use of time management tools to develop a master schedule.

Finally, the critical delays associated with general management can be handled through PM tools such as WBS, CPM, bottom-up estimation and EVM. As can be noticed, these are tools that enhance decision-making through displaying the values associated with the different project activities involved. These tools need to be implemented during the design, construction and mobilisation phases. The suggested strategies to handle management-related delays include: managing costs, contractual agreements, and financial standings of contractors. 
The developed framework may provide the required support to improve management decisions towards reducing the likelihood of delays occurring in public construction projects in the KSA, as well as mitigating against their negative consequences. 
Table 7.3 Summary of key notations adopted in the proposed framework (See Figures 7.1 \& 7.2)

\begin{tabular}{|c|c|c|c|c|}
\hline Stakeholder & Stategies & Phase & Strategy Code & Delay \\
\hline \multirow{15}{*}{ 苞 } & Prioritise decision requests using information in project management plan & \multirow{3}{*}{ Mobilisation } & SCL9 & \multirow{7}{*}{ Slow decision-making } \\
\hline & Decentralise decision-making process (empower junior managers to make certain decisions) & & SCL10 & \\
\hline & Set up a team dedicated to evaluating decision requests and making recommendations & & SCL11 & \\
\hline & Prioritise decision requests considering project master schedule & \multirow{4}{*}{ Construction } & SCL12 & \\
\hline & Assign deadlines to decisions depending on their time-dependence & & SCL13 & \\
\hline & PMO to effectively communicate with stockholders and ensure decisions are made more effectively & & SCL14 & \\
\hline & Rally support of all project parties to make decisions more quickly and efficiently & & SCL15 & \\
\hline & Develop change management plan & \multirow[t]{2}{*}{ Design } & SCL1 & \multirow{8}{*}{ Change orders } \\
\hline & Establish change management team & & SCL2 & \\
\hline & Update change management plan & \multirow[t]{2}{*}{ Mobilisation } & SCL3 & \\
\hline & Reinforce collaboration & & SCL4 & \\
\hline & Document change requests and prioritise their treatment & \multirow{4}{*}{ Construction } & SCL5 & \\
\hline & Evaluate change requests and collect inputs of concerned project parties on managing them & & SCL6 & \\
\hline & Update schedule based on change implementation & & SCL7 & \\
\hline & Recruit more human resources to support timely change implementation & & SCL8 & \\
\hline \multirow{4}{*}{ 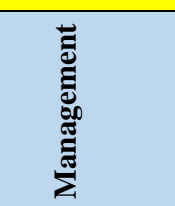 } & Prioritise financial capacity of contractors in tendering exercise & \multirow[t]{2}{*}{ Tendering } & SM1 & \multirow{4}{*}{ Lowest Bidding System } \\
\hline & Consider the merits and consequences of lowest bidding system & & SM2 & \\
\hline & Reconsider the contractual agreements with contractors & \multirow[t]{2}{*}{ Mobilisation } & SM3 & \\
\hline & Reassess the financial standing of contractors and make necessary interventions & & SM4 & \\
\hline \multirow{8}{*}{ 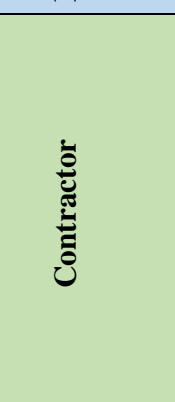 } & Consider reliable financing options & Pre-Project & SCT1 & \multirow{7}{*}{ Financing Difficulties } \\
\hline & Develop cost management plan using effective estimating tools and techniques and including EVM & \multirow[t]{2}{*}{ Design } & SCT2 & \\
\hline & Revisit financing options and cash flow management plan & & SCT3 & \\
\hline & Consider financial soundness of prospective contractors in pre-qualification & \multirow[t]{2}{*}{ Tendering } & SCT4 & \\
\hline & Develop contractual agreements that guarantee project financial provisions & & SCT5 & \\
\hline & Reassess contractual agreements and cash flow management plan & Mobilisation & SCT6 & \\
\hline & Involve all parties to guarantee effective project finance & Construction & SCT7 & \\
\hline & Set required qualifications for contractors and consultants & Pre-Project & SCT8 & Lack of qualifications and experience \\
\hline
\end{tabular}




\begin{tabular}{|c|c|c|c|c|}
\hline & Hire consultants based on pre-determined qualifications & Design & SCT9 & \\
\hline & Pre-qualify contractors based on their qualifications and experience & Tendering & SCT10 & \\
\hline & Select contractor with best qualifications and experience & & SCT11 & \\
\hline & $\begin{array}{l}\text { PMO should monitor the performance of consultants and contractors continuously and provide } \\
\text { support as required }\end{array}$ & Mobilisation & SCT12 & \\
\hline & PMO should support contractors and consultants, recommend training where appropriate & & SCT13 & \\
\hline & $\begin{array}{l}\text { PMO should continually monitor the performance of consultants and contractors using EVM and } \\
\text { information in the schedule }\end{array}$ & Construction & SCT14 & \\
\hline & Identify roles and responsibilities in the project execution & & SCT15 & \\
\hline & Establish experience and qualification requirements for staff recruitment & Mobilisation & SCT16 & \\
\hline & Develop line of reporting and staff training plan & & SCT17 & \\
\hline & Monitor individual worker's actual performance against the expected & & SCT18 & \\
\hline & Recommend appropriate training programs accordingly for low performing staff & Construction & SCT19 & \\
\hline & Facilitate knowledge sharing and learning across project teams & & SCT20 & Lack of qualifications and experience \\
\hline & Encourage highly skilled staff to mentor lowly inexperienced staff & & SCT21 & Lack or quantitedions and experiente \\
\hline & Develop a project charter clarifying project scope and deliverables & Pre-Project & SCT22 & \\
\hline & Set realistic project duration using time management tools such as & Design & SCT23 & \\
\hline & Select project scheduling software that is most user friendly, effective, and train staff on how use it & Design & SCT24 & \\
\hline & Use wide range of time management tools such as WBS, CPM, and PERT to develop master schedule & Design & SCT25 & \\
\hline & Facilitate collaboration and communication between project parties & Design & SCT26 & \\
\hline & Schedule performance should be monitored continually using EVM and regular progress meeting & Construction & SCT27 & Ineffective planning and scheduling \\
\hline & Provide ongoing training to the project teams on managing the schedule and updating status & Construction & SCT28 & \\
\hline & Recruit competent and experienced design engineers & Design & SCD1 & \\
\hline & Facilitate collaboration and communication between project parties during designs & Design & SCD2 & \\
\hline 馬 & Develop design management plan & & SCD3 & \\
\hline 吾 & Establish plan for collaborative working relationships & Mobilisation & SCD4 & \\
\hline $\bar{e}$ & & & SCD5 & \\
\hline & Facilitate continuous collaboration between project parties and teams & Construction & SCD6 & Design Issues \\
\hline & Identify any design issues and required changes and correct any errors & & SCD7 & \\
\hline
\end{tabular}




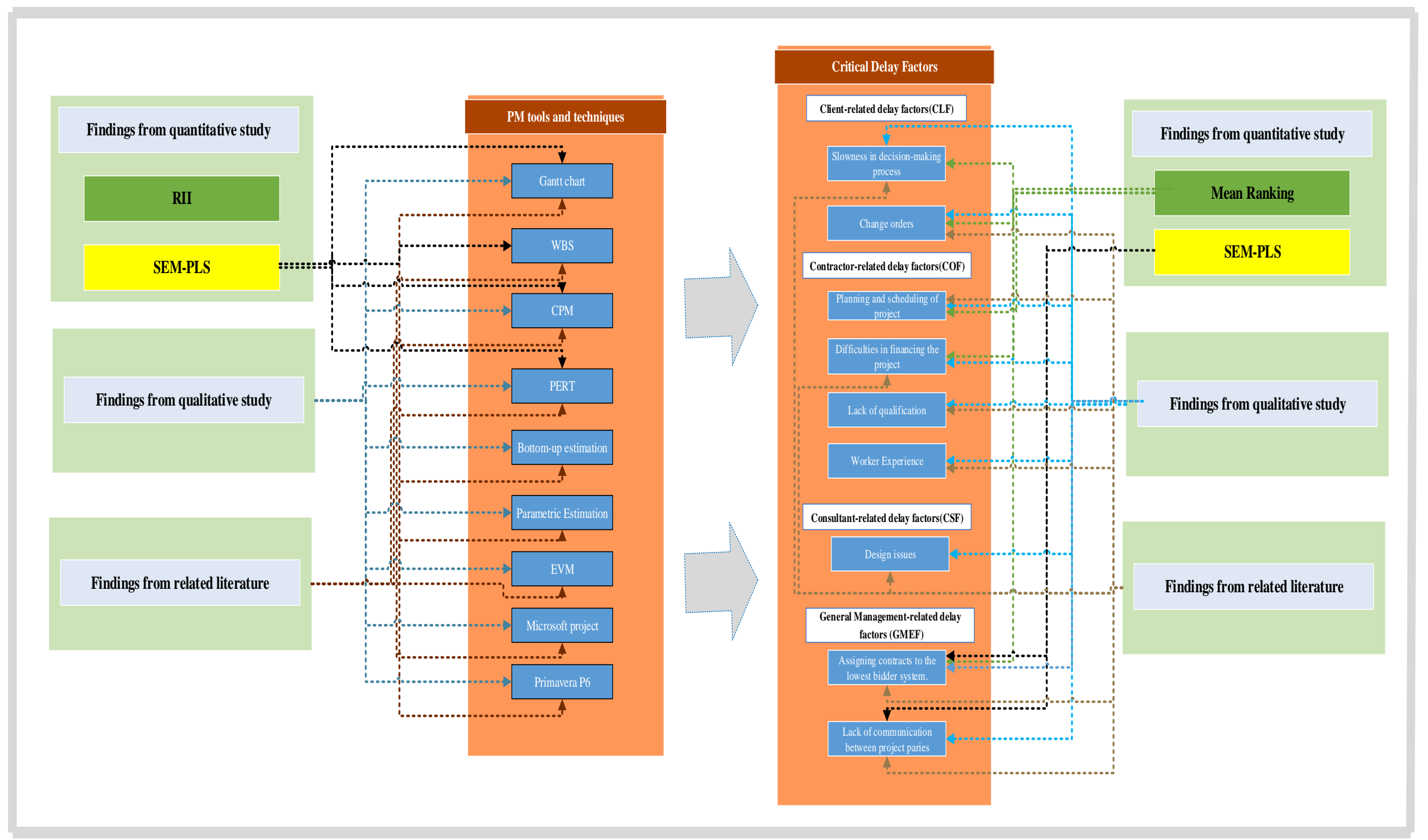

Figure 7.1 Delay Mitigation Framework 


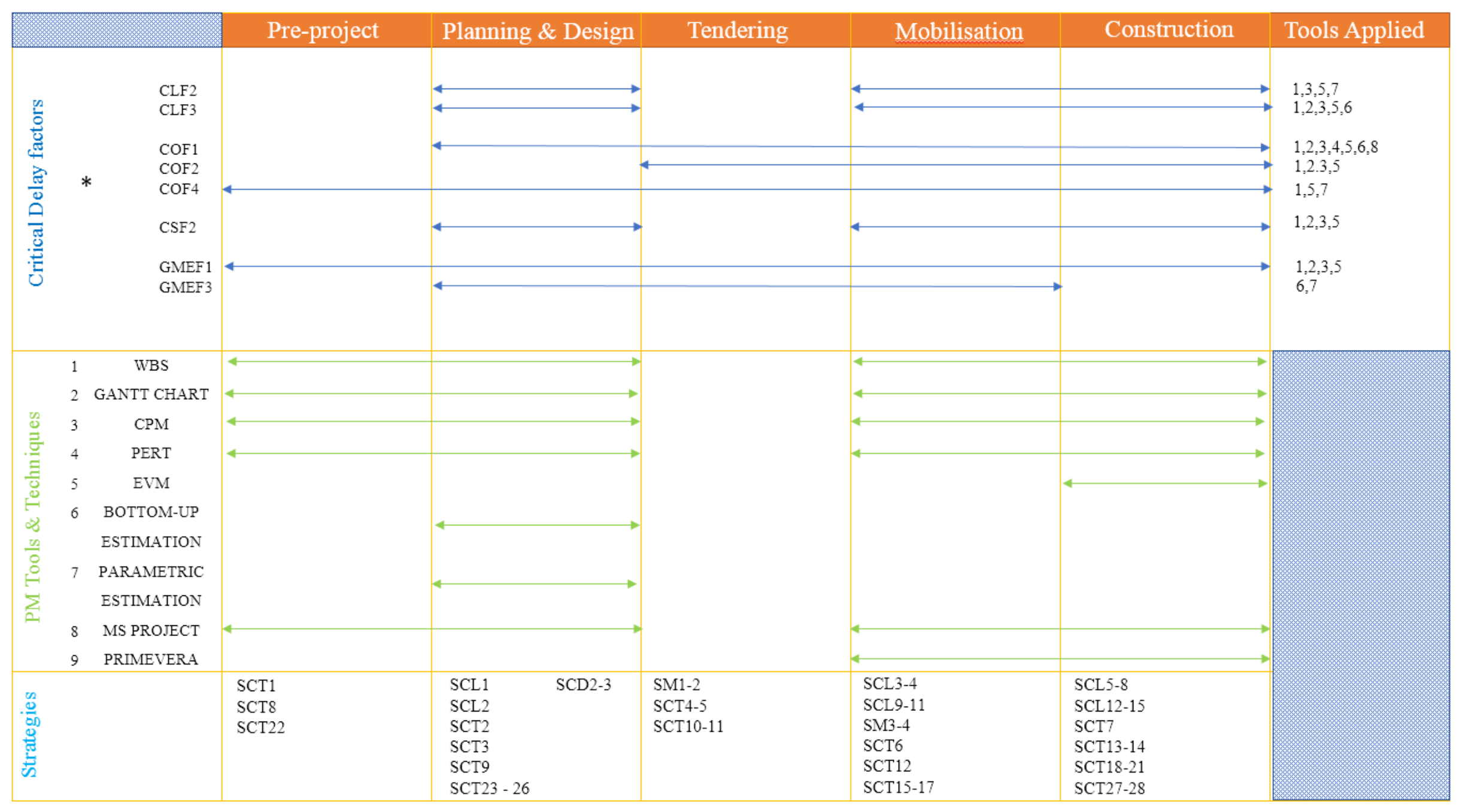

*Refer to Appendix 3 for delay code

Figure 7.2 Delay Mitigation Framework 


\subsection{Chapter Summary}

A comprehensive interpretation and discussion of the research findings presented in Chapters 5 and 6 have been offered in this present chapter. The research results discussed in this chapter have been considered within the context of existing mainstream studies on construction delays. This action has allowed for a comparative analysis of the current study's outcome and those results that have been produced in previous research. Specifically, the discussion has mainly covered the three main research aspects relating to the magnitude of delays and their critical factors, the current use of PM knowledge, tools, and techniques, and the association between their application and the occurrence of delays in public construction projects in the KSA. The robust discussion presented has given due consideration to the information provided by the survey respondents, as well as the statements made by the professionals interviewed in the case studies. Using the findings of the quantitative analysis conducted in Chapter 5, as well as incorporating the recommendations that have been gathered from the professionals involved in the examined case studies and related literature, a framework that could be used to minimise the likelihood of the five most important delays and support the effective management of delays in public construction projects in the KSA was developed. While this framework may not provide a complete antidote to the problems associated with delays in the KSA's construction projects, it can improve the condition significantly if implemented as deemed suitable, based on the peculiar characteristics of the respective projects. The next chapter of this thesis provides the conclusion and recommendations for future study. 


\section{CHAPTER 8}

\section{CONCLUSION AND RECOMMENDATIONS}

\subsection{Introduction}

Construction projects are major catalysts for socio-economic growth of the countries around the world, accounting for a substantial percentage of GDP in the global context. These projects are in many cases complex in nature, requiring collaborative efforts of multiple parties, hundreds of workers, and several activities to be undertaken. Accordingly, the implementation of construction projects is an arduous task, often accompanied by unwanted and damaging delays that affect the realisation of their objectives. This $\mathrm{PhD}$ thesis aims to determine the issues affecting the occurrence of delays in the KSA's public construction projects. Specifically, this thesis seeks to identify the critical factors contributing to the delays and the role of PM tools and techniques in reducing such delays. In proposing practical solutions to the problems, the issues influencing the development of delays in KSA's public construction projects has to be first established.

Various stages were undertaken to address the objectives of this study. First, an in-depth literature review was conducted to develop a conceptual understanding of the delay issues within the global and Saudi Arabian contexts. This desktop review of the phenomenon constituted an exploratory study from which the major themes were identified for further investigation though empirical research. A quantitative survey study was conducted to unveil the delay factors, the current application of PM tools and techniques in the KSA's public construction projects, as well as their impacts on delay occurrence. The results obtained from the quantitative study were used to inform the subsequent phase, a qualitative study involving four selected case studies of public construction projects in the KSA. The outcomes of the literature review, quantitative and qualitative analyses were triangulated to develop a framework that could potentially be used to mitigate against the delays in the KSA's public construction projects. This conclusion chapter presents the overview of the thesis. Additionally, suggestions have been proposed based on the study's findings, as well as contributions of the research to the body of knowledge. Recommended directions for further works are also offered. 


\subsection{Critical Factors Causing Delays and their Relative Importance}

The first objective of this PhD study is to identify the critical factors contributing to the delays in public construction projects in the KSA. This objective was addressed by first undertaking a review of existing literature in order to determine the construction delay factors that have been previously found. Based on the outcome of the literature review, a questionnaire survey was developed and distributed online to construction practitioners in the KSA. Their completed survey data were analysed using the Relative Importance Index (RII) to reveal the factors that the experienced professionals felt were contributing to delays in KSA's public construction projects. These delays were attributed to the clients, contractors, and consultants involved in the planning and execution of projects, as well as general management factors. Based on the analysis of the quantitative data, 20 factors, five linked to each of the four identified categories, were ranked by the survey participants as contributing to delays. Furthermore, the critical delay factors were also investigated in the four cases studied. This was supported by the interviews conducted for the professionals involved in the examined projects. Following the triangulation of both quantitative and case studies, the factors contributing to the delays in public construction projects in the KSA were identified to be: slowness of decision-making; a lack of qualifications; the lowest bidding system; design issues; financial difficulties; ineffective project planning and scheduling; change orders; and workers' inexperience.

\subsection{Current Use of PM Knowledge, Tools, and Techniques}

The second objective of this research is to investigate the current use of PM knowledge, tools and techniques in public construction projects in the KSA. Similar to the process of realising the first objective, this aim was achieved by triangulating both quantitative and qualitative studies. The participants in both studies were asked to determine the current level of awareness and application of PM knowledge, tools, and techniques. The findings showed that a large percentage of the survey respondents perceived the current knowledge about project management concepts in the KSA's public construction projects to be low. Based on the Kruskal-Wallis $\mathrm{H}$ test, there was no difference in the perceptions of the three stakeholder groups, who are usually involved in the execution of construction projects (i.e., clients, contractors, and consultants), regarding the current awareness of PM concepts in the KSA. In addition, most of these participants considered the application of PM tools and techniques to 
be ineffective. Consequently, nearly of them recommended a need for an improvement in the use of PM tools and techniques across the public construction projects in the KSA. Many of the popular PM tools and techniques were identified as not being used. The results from the interviews undertaken in the case studies were found to be similar to those of the quantitative study.

\subsection{Impacts of PM Knowledge, Tools, and Techniques on Delays}

The third objective of this study is to evaluate the relationship between the application of PM knowledge, tools, and techniques and the occurrence of delays in public construction projects in the KSA. This objective was again investigated in both the quantitative and case studies undertaken in this research. SEM was utilised to identify this relationship in the quantitative data, with the results indicating that there was a relationship between four categories of PM tools and techniques and delays. The interpretation of these results showed that the four categories of delay factors (attributed to client, contractor, consultant, as well as general management and external issues) can be minimised by the application of tools and techniques associated with estimating, time, and control aspects of a project, as well as via an effective use of relevant planning and scheduling software. The professionals involved in the case projects also suggested that a more effective application of PM knowledge, tools and techniques could have prevented or reduced the instances of delays in the cases studied.

\subsection{Delay Minimisation Framework}

The fourth and final objective of this study is to develop a framework that could potentially be used to minimise the occurrence of delays in public construction projects in the KSA. This objective was satisfied as per the development of the framework presented in Chapter 7. The framework was designed as a tool to address eight delay factors that have been identified in both quantitative and qualitative parts of this research. They include slowness of decisionmaking; a lack of qualifications; the lowest bidding system; design issues; financial difficulties; ineffective project planning and scheduling; change orders; and workers' inexperience. The recommended actions to managing these delay issues were based on the opinions of the professionals interviewed in this study, supported alongside the information from existing 
literature on the topic. By successfully satisfying all objectives as described above, this research has fully satisfied its aims.

\subsection{Suggestions for Practice}

Based on the summary of findings derived from this study, suggestions to improve the performance of their projects have been formulated for construction project professionals and other important stakeholders including clients, contractors, and consultants, who are involved in the execution of public construction projects not only in the Kingdom of Saudi Arabia, but other countries as well. It is worth noting that these suggestions are based on the perspectives of the researcher of this $\mathrm{PhD}$.

First, professionals and other stakeholders should develop a better understanding of their specific projects and identify appropriate PM tools and techniques that would be most suitable to minimise the different forms of delays that may plague them. Professionals and parties of the projects should apply effective PM tools and techniques throughout the entire project delivery cycle, from the conception to handover stage. Such activities should be undertaken collectively among the project participants, so that everyone's opinions are considered and well-incorporated to yield maximum benefits. There should be a paradigm shift from a rigid approach to managing issues in these projects, to a more flexible one in which opinions are sought from all project participants towards making final decisions, so as to avoid problems such as delays.

Second, project teams should adopt strategies that ensure that the emerging issues around the projects can be closely monitored and pro-active actions are taken to minimise both internal and external changes that could portend major problems for the projects. A more integrative project management approach will ensure that issues are better tracked and identified on time before they lead to uncontrollable delays. Team members, from the client, contractor, and consultant organisations, should be encouraged to offer useful feedback on any events that they may deem as likely to cause unwanted delays, so that they can be escalated to the appropriate authorities for necessary actions to be taken. Getting continuous information about occurrences within and outside the construction projects will help in the quick formation of management options to prevent or minimise delays. 
Third, a project control system should be put in place to check uncertain events that are often associated with the implementation of construction projects. The professionals and parties involved in these projects should be aware that construction projects are unpredictable by nature and not assume that issues can be predicted based on the pre-determined management plans. The project teams and parties should be prepared for other potential issues, that have not been identified in the project management plan, which may ultimately derail the projects. Therefore, they should ensure that their adopted control strategies are effective enough to monitor the interactions of issues around the projects, in order to determine their short and long-term effects.

Fourth, a less strict and more reliable schedule that enhances the optimum performance of not just project team members, but also the parties such as suppliers, should be developed for these construction projects. This schedule will allow the teams to better maximise their future decisions and not consider their plans to be perfect, thereby inhibiting opportunities for further improvements. In addition, the designed schedule should be regarded as a tool to foster effective communication and better organisation of actions and collaboration across the teams and parties within the project environments.

Fifth, the project teams should be fully engaged in weekly or monthly meetings designed to assess decision-making and information-sharing procedures. They should be involved in the development of collective assumptions underlying the decisions taken. Such steps will improve their level of awareness about how actions are to be taken to ensure the smooth performance of the projects. In this instance, every member of the project team is equipped with information to make informed personal decisions to drive better project performance and minimise the chance of delays.

Sixth, there is a need to track and check the developed project plans using systemic reviews and different audit measures and assessment procedures to determine the reliability and practical applications of the respective information. Without a periodic scrutiny of the project plans, it may be difficult to know if they are still relevant, considering the emerging changes in the project settings. As previously unknown changes are unfolding in these projects (projects 1, 2, 3 and 4), it will be crucial that the project plans are altered accordingly to reflect the reality of occurrence in these projects. Such actions will boost an early identification of issues that could potentially cause intractable delays to the projects. 
Seventh, professionals and parties involved in the implementation of construction projects should develop a knowledge sharing base that encourages continuous learning for everyone. Knowledge should be circulated across the project settings so that appropriate actions for project delivery improvement can be identified and implemented promptly. Knowledge sharing will prove crucial for identifying problems that could cause delays in these projects. Knowledge sharing should also be incentivised, where appropriate, so as to promote the full participation of members of the project teams.

Finally, it is recommended that practitioners and parties implementing public construction projects in the KSA and other countries should consider the strategies that have been developed (including the framework in Chapter 7) as they deem fit, as they may be used to help in reducing the likelihood of delays. It is also believed that these strategies may provide a solid foundation for improving upon the project's performance in many other aspects apart from delays.

\subsection{Research's Theoretical Contribution}

The aim of this research is to identify the critical delay factors and consider the role of PM tools and techniques in preventing the delay experience in the KSA's construction projects. This research contributes to the existing body of knowledge in the following ways:

a) It considers the delay factors in public construction projects by linking the occurrence of delays to the application of PM tools and techniques. To the best knowledge of the researcher, this represents a new shift from previous studies which had only considered the delay factors in the construction projects.

b) It extends the existing knowledge by exploring how PM tools and techniques can be of great benefits to addressing the problem of delays not just in the KSA's public construction projects but other construction related projects in other countries. Previous research has neglected this area despite the importance of PM tools and techniques in achieving positive project performance. This gap in the body of knowledge has been addressed in this research.

c) This study has improved on the previous studies on delays in the KSA by developing a mitigation framework for managing delays. This research has not only identified the factors contributing to the delays (as per existing studies), but it has also formulated strategies for minimising the syndrome. 
d) This study has charted a new course towards resolving the problem of delays in the KSA's public construction projects. Findings of this study can help construction management researchers to develop further alternative solutions to the problem of delays not just in construction industry but other sectors such as information technology, defence, and oil and gas.

e) This study's findings offer opportunities for construction management researchers in other countries especially developing nations to relearn issues contributing to their project delays and identify strategies that can be suggested to arrest this endemic problem.

\subsection{Research's Practical Contribution}

In addition to the theoretical contributions of this research outcome, this research contributes to the practice in the following ways:

a) The clients of public construction projects can use the Delay Minimising Framework to guide their contracts' negotiations and agreements with their contractors. Using the perspectives presented in this study, a sound knowledge of the dynamic nature of the construction project environment can assist the governments in the KSA and other nations in making more practical decisions when sanctioning capital expenditure for their projects. With a bird's-eye view of the project settings as provided in this thesis, clients can better evaluate options that will support their project's performance and thus, reduce delays. The project tools and techniques propagated in this study, for example, can be taken into consideration by the project parties in the development of execution plans for their projects, so as to enhance their time performance and minimise delays.

b) The contractors and consultants involved in the execution of these construction projects can also use this framework for negotiating more realistic contract terms with the project's owners. This framework can be employed by the contractors to design and develop processes that enhance the optimum performance of their contracts, in terms of cost and schedule, towards minimising delays. For instance, the framework can assist the contractors in developing monitoring and control systems that attach an importance to every change that occurs in the project environment and provide appropriate mechanisms for troubleshooting these changes, curtailing them before they metamorphose into bigger issues for a project. 
c) The outcome of this research can also benefit project management practice in other sectors such as information technology and oil and gas. The ideas presented in this study can be employed to prevent delays and ensure effective management of projects executed in these sectors.

d) Lastly, the leaders of the project teams, such as project managers and project directors, as well as other core participants in the project execution can utilise the contents of the developed framework to introduce actions that are more efficient or dynamic in addressing the changes that may lead to delays. By integrating the principles of project management, applying appropriate tools and techniques, as well as implementing effective monitoring and controlling strategies for their projects, teams can galvanise ideas that work towards improving not only the quality of their projects' deliverables or components, but also boosting their immunity against delays.

\subsection{Study's Limitations and Suggested Directions for Future Work}

Even though a comprehensive analysis of the applications of PM tools and techniques in the KSA's public sector construction industry, along with the delays that are experienced by the industry, has been conducted in this study, some gaps, that need to be further examined, remain. It should be pointed out that the number of case studies considered was relatively small, when compared to the total number of public construction projects that have been implemented in the booming market of the KSA. As such, a further examination of the ongoing projects can be performed in a separate study to increase the sample data size. In addition, it would be interesting to examine whether the delays analysed and reported in this study will be the same in other sectors of the industry.

Lastly, the Delay Minimising Framework, as presented in Chapter 7 of this study, may not be applicable in private sector projects, as the decision-making processes involved may differ. This can be investigated in the future for a better understanding of the challenges faced by both the private and public sectors in construction, in terms of delays and PM knowledge tools and techniques adopted. It should be decided by the decision-makers if the model is applicable based on the objectives, goals, environments, complexity, and other factors that may define the affected project. Nonetheless, the framework provides the practitioners and parties involved in 
the execution of public construction projects in the KSA with a decision-support tool that can be applied to prevent or reduce the chance of delays occurring.

Further research is required to improve on the understanding of delay issues in public construction projects addressed in this thesis. Consequently, the following suggestions are presented in this section for future work on this research area:

a) Prior to this study, there was no publicly available study that had collected data to determine the role of PM tools and techniques in the occurrence of delays. Accordingly, more databased research studies are necessary to consolidate the understanding of this problem and propose other effective management practices to confront this challenge. In this regard, different research designs and methods from those used in this current study can be employed to further improve the understanding of the issue of delays in construction.

b) More studies can focus on examining further project management strategies to prevent delays in construction projects. For example, such investigations can examine more appropriate PM tools and techniques to address different forms of delays that are inherent in public construction projects. The results obtained from these proposed research studies can enhance better decision-making for the affected projects.

c) Future studies can assist in conceptualising and developing broad-based processes that are effective in monitoring and detecting all issues that can lead to a potential damage of the progress of construction projects and reduce the occurrence of delays in them. These processes can rely on advances in analytical approaches such as the use of machine learning and artificial intelligence to detect delay.

d) Lastly, the research principles used in this current study regarding the concept of delays can be extended to examine other project settings. For example, a study could be carried out to show the delay factors associated with privately-owned construction projects or information technology projects, and assess their similarity with the delays identified in this thesis, bearing in mind that such projects are executed under different conditions as compared to public construction projects.

\subsection{Summary}

The summary of the findings associated with each of the chapters contained in this thesis has been presented in this concluding chapter. Several suggestions have been made for current practitioners, based on the research findings that were identified in this study. In addition, 
theoretical contributions and the practical significance of the research are presented as well. Lastly, the suggested directions for future work and current limitations of this study are presented in this chapter.

\section{References:}

Abbasi, G. Y., \& Al-Mharmah, H. (2000). Project management practice by the public sector in a developing country. International Journal of Project Management, 18(2), 105-109.

Abdelnaser O., Peter J.N., Mahmood A., Hussin A., and A H. Aziz (2005). Causes of construction delays: case studies in Langkawi Island, Malaysia, Paper presented at International Conference on built environmental in Kuala Lumpur, Malaysia, organized by University of Malaya.

Ackermann, E. C., \& Hartman, K. (2000). The Information Searcher's Guide to Searching + Researching on the Internet + W3: Franklin, Beedle II\&amp; Associates Inc.

Adams, J. (1997). The principles of project management. Project Management Institute.

Adedeji, A. N., Sidique, S. F., Rahman, A. A., \& Law, S. H. (2016). The role of local content policy in local value creation in Nigeria's oil industry: A structural equation modeling (SEM) approach. Resources Policy, 49, 61-73.

Altarawneh, J. Y., Thiruchelvam, V., \& Samadi, B. (2018). Analysis of Critical Success Factors Influence on Critical Delays for Water Infrastructure Construction Projects in the Abu Dhabi emirate Using PLS-SEM Method. International Business Research, 11(2), 16.

Aibinu, A. A., \& Jagboro, G. O. (2002). The effects of construction delays on project delivery in Nigerian construction industry. International journal of project management, 20(8), 593-599.

Aibinu, \& Jagboro, G. O. (2002). The effects of construction delays on project delivery in Nigerian construction industry. International Journal of Project Management, 20(8), 593-599. doi:http://dx.doi.org/10.1016/S0263-7863(02)00028-5

Aibinu, \& Odeyinka, H. (2006). Construction Delays and Their Causative Factors in Nigeria. Journal of Construction Engineering and Management, 132(7), 667-677. doi:doi:10.1061/(ASCE)0733-9364(2006)132:7(667)

Alzara, M., Kashiwagi, J., Kashiwagi, D., and Al-Tassan, A. (2016). Using PIPS to minimise causes of delay in Saudi Arabian construction projects: university case study. Procedia Engineering, 145, 932-939.

Atkinson, R., Crawford, L., and Ward, S. (2006). Fundamental uncertainties in projects and the scope of project management. International journal of project management, 24(8), 687-698.

Al-Khalil, M. I., \& Al-Ghafly, M. A. (1999). Delay in public utility projects in Saudi Arabia. International Journal of Project Management, 17(2), 101-106. doi:http://dx.doi.org/10.1016/S0263-7863(98)00020-9. 
Al-Kharashi, A., \& Skitmore, M. (2009). Causes of delays in Saudi Arabian public sector construction projects. Construction Management and Economics, 27(1), 3-23.

Albogamy, A., Scott, D., Dawood, N., \& Bekr, G. (2013). Addressing crucial risk factors in the middle east construction industries: a comparative study of Saudi Arabia and Jordan. Paper presented at the Sustainable Building Conference Coventry University, West Midlands, UK.

Aliaga, M., \& Gunderson, B. (2003). Interactive Statistics: Prentice Hall.

Alofi, A., \& Kashiwagi, J. (2017). Professionals' Impressions Regarding the Saudi Arabian Procurement and Contracts System. Performance Information and Value, 41.

Alotaibi, N. O., Sutrisna, M., \& Chong, H.-Y. (2016). Guidelines of Using Project Management Tools and Techniques to Mitigate Factors Causing Delays in Public Construction Projects in Kingdom of Saudi Arabia. Journal of Engineering, Project, and Production Management, 6(2), 90.

Alturki, F. (2013). Saudi Arabia's 2014 budget. Riyadh .

Assaf, \& Al-Hejji, S. (2006). Causes of delay in large construction projects. International Journal of Project Management, 24(4), 349-357. doi:http://dx.doi.org/10.1016/j.ijproman.2005.11.010

APM. (2006). APM Body of Knowledge (5th ed.): Association for Project Management.

APM Body of Knowledge. (2006). High Wycombe, Buckinghamshire, UK: Association for Project Management (APM).

Anbari, F. T. (2003). Earned value project management method and extensions. Project management journal, 34(4), 12-23.

Auerbach, C., \& Silverstein, L. B. (2003). Qualitative data: An introduction to coding and analysis. NYU press.

APM (2012). Association of Project Management Body of Knowledge (PMBOK guide), sixth edition.

ALTHYNIAN, F. 2010. An economic study reveals the reasons for the delay in the implementation of $82 \%$ of infrastructure projects in the Kingdom. Alriyadh Newspaper, Issue 15295

ANTI-CORRUPTION COMMISSION. 2013. 820 billion SR put 3000 limping projects under the Focus. Alriyadh Newspaper, p.16264.

Al-Khalil, M. I., \& Al-Ghafly, M. A. (1999). Important causes of delay in public utility projects in Saudi Arabia. Construction Management \& Economics, 17(5), 647-655.

Arnaboldi, M., Azzone, G., \& Savoldelli, A. (2004). Managing a public sector project: the case of the Italian Treasury Ministry. International Journal of Project Management, 22(3), 213-223.

Allen, I. E., \& Seaman, C. A. (2007). Likert scales and data analyses. Quality progress, 40(7), 64.

Al Saudi, I. S. (2011). The impediments to the adoption of the design and build project procurement strategy in the Saudi construction industry (Doctoral dissertation, HeriotWatt University).

Agyakwa-Baah, A., Chileshe, N., \& Stephenson, P. (2010). A risk assessment and management framework to support project delivery (Doctoral dissertation, National Technical University of Athens).

Al-Medlej, H. I. (1997). Decision making process in higher education institutions: the case of Saudi Arabia (Doctoral dissertation, Middlesex University).

Alghadeer, A., \& Mohamed, S. (2016). Diffusion of Organisational Innovation in Saudi Arabia: The Case of the Project Management Office (PMO). International Journal of Innovation and Technology Management, 13(04), 1650019. 
Axelrod, R., \& Tesfatsion, L. (2006). Appendix AA guide for newcomers to agent-based modeling in the social sciences. Handbook of computational economics, 2, 1647-1659.

Babbie, E. (2012). The Practice of Social Research: Cengage Learning.

Baiden, B. K., Price, A. D., \& Dainty, A. R. (2006). The extent of team integration within construction projects. International Journal of Project Management, 24(1), 13-23.

Barrie, D. S., \& Paulson, B. C. (1992). Professional construction management: including CM, design-construct, and general contracting. McGraw-Hill Science/Engineering/Math.

Besner, C., and Hobbs, B. (2008). Project management practice, generic or contextual: A reality check. Project Management Journal, 39(1), 16-33.

Bendat, J. S., \& Piersol, A. G. (2011). Random data: analysis and measurement procedures (Vol. 729): John Wiley \& Sons.

Bennett, F. L. (2003). The management of construction: a project life cycle approach. Routledge.

Bendat, J. S., \& Piersol, A. G. (2011). Random data: analysis and measurement procedures (Vol. 729). John Wiley \& Sons.

Berggren, C., Söderlund, S., \& Andersson, C. (2001). Clients, contractors, and consultants. Project Management Journal, September, 32, 3.

Blackburn, S. (2008). The Oxford dictionary of philosophy (2nd ed.). New York: Oxford University Press.

Blaikie, N. (2007). Approaches to social enquiry: Advancing knowledge (2nd ed.). Cambridge, UK: Polity Press.

Bogdan, R. C., \& Biklen, S. K. (1998). Qualitative research in education. An introduction to theory and methods: ERIC.

Boyd, D., \& Chinyio, E. (2008). Understanding the construction client. John Wiley \& Sons.

Bourn, J. (2001). Modernising Construction. UK: National Audit Office.

Bourn, J. (2003). PFI : Construction Performance. UK: National Audit Office.

Bryman, A. (2012). Social research methods: Oxford university press.

Bryman, A. (2015). Social research methods. Oxford university press.

Bubshait, A., \& Al-Musaid, A. (1992). Owner Involvement in Construction Projects in Saudi Arabia. Journal of Management in Engineering, 8(2), 176-185. doi:10.1061/(asce)9742$597 x(1992) 8: 2(176)$

Burgess, R. G. (2005). The ethics of educational research: Routledge.

Burke, R. (2013). Project management: planning and control techniques.

Butler, C. W., \& Richardson, G. L. (2011). A Variable Time Project Planning and Control Model. Journal of Management Policy and Practice, 12(6), 11.

Burke, R. (2013). Project management: planning and control techniques. New Jersey, USA.

Burr, A. (Ed.). (2016). Delay and disruption in construction contracts. CRC Press.

Callahan, M. T. (2010). Construction delay claims. Aspen publishers.

Carr, R. I. (2000). Construction Congestion Cost (CO3) basic model. Journal of Construction Engineering and Management-Asce, 126(2), 105-113. doi:10.1061/(asce)07339364(2000)126:2(105)

Carson, C., Oakander, P., \& Relyea, C. (2014). CPM Scheduling for Construction: Best Practices and Guidelines: Project Management Institute (PMI).

Carstens, D. S., Richardson, G. L., \& Smith, R. B. (2016). Project management tools and techniques: A practical guide. CRC Press.

Chidambaram, R., Narayanan, S. P., \& Idrus, A. B. (2012). Construction delays causing risks on time and cost-A critical review. Australasian Journal of Construction Economics and Building, The, 12(1), 37.

Clough, R. H., Sears, G. A., \& Sears, S. K. (2000). Construction project management. John Wiley \& Sons. 
Chang, A. (2002). Reasons for Cost and Schedule Increase for Engineering Design Projects. Journal of Management in Engineering, 18(1), 29-36. doi:10.1061/(asce)0742$597 x(2002) 18: 1(29)$

Christensen, L., \& Johnson, B. (2004). Educational research: Quantitative, qualitative, and mixed approaches. In: Boston: Pearson.

Cocchiarella, N. B. (2007). Formal ontology and conceptual realism: Springer.

Cook, T. D., \& Campbell, D. T. (1979). Quasi-experimentation: design \& analysis issues for field settings: Rand McNally College.

Creswell, J. W. (2013). Research design: Qualitative, quantitative, and mixed methods approaches: Sage publications.

Crawford, L. (2009). World PM Trends and the Position of P2M in the Global Community. In S. Ohara and T. Asada, Japanese Project Management KPM - Innovation, Development and Improvement (pp. 381-402). Modern Institute of Management: Japanese Management and International Studies.

Cronbach, L. J. (1946). Response sets and test validity. Educational and psychological measurement, 6(4), 475-494.

Czemplik, A. (2014). Application of earned value method to progress control of construction projects. Procedia Engineering, 91, 424-428.

Chapman, C., \& Ward, S. (2002). Managing project risk and uncertainty: A constructively simple approach to decision making. John Wiley \& Sons.

Connolly, J. J., Kavanagh, E. J., \& Viswesvaran, C. (2007). The convergent validity between self and observer ratings of personality: A meta-analytic review. International Journal of Selection and Assessment, 15(1), 110-117.

Chang, A. S., Shen, F. Y., \& Ibbs, W. (2010). Design and construction coordination problems and planning for design-build project new users. Canadian journal of civil engineering, 37(12), 1525-1534.

Creswell, J. W. (2013). Steps in conducting a scholarly mixed methods study.

Dai, C. X., \& Wells, W. G. (2004). An exploration of project management office features and their relationship to project performance. International Journal of Project Management, 22(7), 523-532.

Dainty, A., Moore, D., and Murray, M. (2007). Communication in construction: Theory and practice. Routledge.Dai, C. X., \& Wells, W. G. (2004). An exploration of project management office features and their relationship to project performance. International journal of project management, 22(7), 523-532.

De Vos, A. S., Delport, C., Fouché, C. B., \& Strydom, H. (2011). Research at grass roots: A primer for the social science and human professions: Van Schaik Publishers.

Deloitte. (2017). Construction 2017: A Positive Market Outlook?. Retrieved from https://www2.deloitte.com/content/dam/Deloitte/xe/Documents/About-

Deloitte/mepovdocuments/mepovissue22/construction_mepov22.pdfDenzin, N. K. (2009). The elephant in the living room: or extending the conversation about the politics of evidence. Qualitative Research, 9(2), 139-160. doi:10.1177/1468794108098034

Denzin, N. K., \& Lincoln, Y. S. (2000). The discipline and practice of qualitative research. Handbook of qualitative research, 2, 1-28. Deacon, H., \& Van der Lingen, E. (2015). The use of the critical path and critical chain methods in the South African construction industry. Acta Structilia: Journal for the Physical and Development Sciences, 22(1), 7397.

De Meyer, A., Loch, C. H., and Pich, M. T. (2002). Managing project uncertainty: from variation to chaos. MIT Sloan Management Review, 43(2), 60.

Delmon, J. (2017). Public-private partnership projects in infrastructure: an essential guide for policy makers. Cambridge University Press. 
Doloi, H., Sawhney, A., Iyer, K. C., \& Rentala, S. (2012). Analysing factors affecting delays in Indian construction projects. International Journal of Project Management, 30(4), 479-489.

Dillman, D. A. (2011). Mail and Internet surveys: The tailored design method--2007 Update with new Internet, visual, and mixed-mode guide: John Wiley \& Sons.

Ding, C.-S., Hsieh, C.-T., Wu, Q., \& Pedram, M. (1996). Stratified random sampling for power estimation. Paper presented at the Proceedings of the 1996 IEEE/ACM international conference on Computer-aided design, San Jose, California, USA.

Drost, E. A. (2011). Validity and reliability in social science research. Education Research and Perspectives, 38(1), 105.

Duy Nguyen, L., Ogunlana, S. O., \& Thi Xuan Lan, D. (2004). A study on project success factors in large construction projects in Vietnam. Engineering, Construction and Architectural Management, 11(6), 404-413.

Duy Nguyen, L., Ogunlana, S. O., \& Thi Xuan Lan, D. (2004). A study on project success factors in large construction projects in Vietnam. Engineering, Construction and Architectural Management, 11(6), 404-413.

East, W. (2015). Critical Path Method (CPM) Tutor for Construction Planning and Scheduling: McGraw Hill Professional.

Easterby-Smith, M., Thorpe, R., \& Jackson, P. (2012). Management research: Sage Publications.

Enshassi, A., Mohamed, S., \& Abushaban, S. (2009). Factors affecting the performance of construction projects in the Gaza strip. Journal of civil engineering and management, 15(3), 269-280.

Erdogan, B., Anumba, C., Bouchlaghem, D., \& Nielsen, Y. (2005). Change management in construction: the current context. Paper presented at the 21st Annual ARCOM Conference, London.

Eriksson, P., \& Kovalainen, A. (2008). Qualitative Methods in Business Research: SAGE Publications.

Eriksson, P. E., \& Westerberg, M. (2011). Effects of cooperative procurement procedures on construction project performance: A conceptual framework. International Journal of Project Management, 29(2), 197-208.

Eweje, J., Turner, R., \& Müller, R. (2012). Maximizing strategic value from megaprojects: The influence of information-feed on decision-making by the project manager. International Journal of Project Management, 30(6), 639-651.

Erdogan, B., Anumba, C., Bouchlaghem, D., \& Nielsen, Y. (2005, September). Change management in construction: the current context. In 21st Annual ARCOM Conference (pp. 1085-1095).

Fabozzi, F. J., \& de Nahlik, C. (2012). Project financing 8th edition. Euromoney.

Faridi, A. S., \& El-Sayegh, S. M. (2006). Significant factors causing delay in the UAE construction industry. Construction Management \& Economics, 24(11), 1167-1176. doi:10.1080/01446190600827033

Fleming, Q. W., \& Koppelman, J. M. (2016). Earned value project management. PA, US: Project Management Institute.

Fleming, Q. W., \& Koppelman, J. M. (1998). Earned Value Project Management: A Powerful Tool for Software Projects. CROSSTALK The Journal of Defense Software Engineering, 19-23.

Flick, U. (2011). Introducing research methodology: A beginner's guide to doing a research project: Sage.

Fosnot, C. T. (2013). Constructivism: Theory, perspectives, and practice: Teachers College Press. 
Frame, J. D. (2002). The new project management: tools for an age of rapid change, complexity, and other business realities: John Wiley \& Sons.

Frimpong, Y., Oluwoye, J., \& Crawford, L. (2003). Causes of delay and cost overruns in construction of groundwater projects in a developing countries; Ghana as a case study. International Journal of Project Management, 21(5), 321-326. doi:http://dx.doi.org/10.1016/S0263-7863(02)00055-8

Fewings, P. (2013). Construction project management: An integrated approach.

Routledge.Frame, J. D. (2002). The new project management: tools for an age of rapid change, complexity, and other business realities. John Wiley \& Sons.

Falqi, I. (2004). Delays in Project Completion: A comparative study of construction delay factors in Saudi Arabia and the United Kingdom. (MSc), Heriot Watt University, UK.

Hoyle, R. H. (Ed.). (2012). Handbook of structural equation modeling. Guilford Press.

Fornell, C., \& Bookstein, F. L. (1982). Two structural equation models: LISREL and PLS applied to consumer exit-voice theory. Journal of Marketing research, 440-452.

Fraj, E., Martinez, E. \& Montaner, T. (2006). Explaining ecological products purchase using consumers' psychographic characteristics. In Moutinho, L., Hutcheson, G. and Ritra, P. (Eds), Advances in Doctoral Research in Management, World Scientific, London, UK, 47-76.

Gao, H., \& Zhang, X. (2013). A Markov-Based Road Maintenance Optimisation Model Considering User Costs. Computer-Aided Civil and Infrastructure Engineering, 28(6), 451-464. doi:10.1111/mice.12009

Gällstedt, M. (2003). Working conditions in projects: perceptions of stress and motivation among project team members and project managers. International Journal of Project Management, 21(6), 449-455.

Gill, P., Stewart, K., Treasure, E., \& Chadwick, B. (2008). Methods of data collection in qualitative research: interviews and focus groups. Br Dent J, 204(6), 291-295.

Glaser, B. G., \& Strauss, A. L. (2009). The Discovery of Grounded Theory: Strategies for Qualitative Research: Aldine Transaction.

González, P., González, V., Molenaar, K., \& Orozco, F. (2013). Analysis of causes of delay and time performance in construction projects. Journal of Construction Engineering and Management, 140(1), 04013027.

Golafshani, N. (2003). Understanding reliability and validity in qualitative research. The qualitative report, 8(4), 597-607.

Gomm, R. (2004). Social research methodology: Palgrave Macmillan New York.

González, P., González, V., Molenaar, K., \& Orozco, F. (2014). Analysis of Causes of Delay and Time Performance in Construction Projects. Journal of Construction Engineering and Management, 140(1), 04013027. doi:doi:10.1061/(ASCE)CO.1943-7862.0000721

Guba, E. G., \& Lincoln, Y. S. (1994). Competing paradigms in qualitative research. In N. K. Denzin \& Y. S. Lincoln (Eds.), Handbook of qualitative research (pp. 105-117). Thousand Oaks: Sage.

Guillemin, M., \& Gillam, L. (2004). Ethics, reflexivity, and "ethically important moments" in research. Qualitative Inquiry, 10(2), 261-280.

Global Construction Perspectives and Oxford Economics (2015). Global Construction 2030: A global forecast for the construction industry to 2030. UK: Global Construction Perspectives and Oxford Economics.

Golafshani, N. (2003). Understanding reliability and validity in qualitative research. The qualitative report, 8(4), 597-606.

George, D., \& Mallery, P. (2003). SPSS for Windows step by step: A simple guide and reference, Allyn \& Bacon, Boston. 
Golini, R., Kalchschmidt, M., \& Landoni, P. (2015). Adoption of project management practices: The impact on international development projects of non-governmental organisations. International Journal of Project Management, 33(3), 650-663.

Haquea, F., Tabassumb, R., \& Islamc, M. M. (2017). Project Scheduling Problem, Quality Loss and Time-Cost Tradeoff. World Review of Business Research, 7(2), 68-87.

Hardin, B., \& McCool, D. (2015). BIM and construction management: proven tools, methods, and workflows. John Wiley \& Sons.

Hartmann, S., \& Briskorn, D. (2010). A survey of variants and extensions of the resourceconstrained project scheduling problem. European Journal of operational research, 207(1), 1-14.

Hanson, J. L., Balmer, D. F., \& Giardino, A. P. (2011). Qualitative research methods for medical educators. Academic pediatrics, 11(5), 375-386.

Harrison, F. L., \& Lock, D. (2004). Advanced project management: a structured approach. Gower Publishing, Ltd.

Hale, D. R., Shrestha, P. P., Gibson Jr, G. E., \& Migliaccio, G. C. (2009). Empirical comparison of design/build and design/bid/build project delivery methods. Journal of Construction Engineering and Management, 135(7), 579-587.

Hair Jr, J. F., Hult, G. T. M., Ringle, C., \& Sarstedt, M. (2016). A primer on partial least squares structural equation modeling (PLS-SEM). Sage Publications

Herroelen, W. (2005). Project scheduling - Theory and practice. Production and operations management, 14(4), 413-432.

Herroelen, W., \& Leus, R. (2005). Project scheduling under uncertainty: Survey and research potentials. European journal of operational research, 165(2), 289-306.

Healy, P. L. (1997). Project Management: Getting the Job Done on Time and in Budget: Butterworth-Heinemann.

Hendrickson, C., \& Au, T. (2000). Project Management for Construction: Fundamental Concepts for Owners. Engineers, Architects and Builders, Prentice Hall, Pittsburgh.

Hansson, S. O. (2006). Falsificationism falsified. Foundations of Science, 11(3), 275-286.

Hatch, M. J., \& Cunliffe, A. (2006). Organisational Theory: Modern, Symbolic, and Postmodern Perspectives. New York: Oxford University Press Inc.

Haugan, G. T. (2002). Effective work breakdown structures: Management Concepts Inc.

Horner, C. (2000). Thinking through philosophy: An introduction. Cambridge, UK: Cambridge University Press.

Husein, A. T. (2013). Construction and Projects in Saudi Arabia: Overview. Retrieved from

Hulland, J. (1999). Use of partial least squares (PLS) in strategic management research: A review of four recent studies. Strategic management journal, 195-204.

Henseler, J., Ringle, C. M., \& Sinkovics, R. R. (2009). The use of partial least squares path modeling in international marketing. In New challenges to international marketing (pp. 277-319). Emerald Group Publishing Limited.

Hebert, J. E., \& Deckro, R. F. (2011). Combining contemporary and traditional project management tools to resolve a project scheduling problem. Computers \& Operations Research, 38(1), 21-32.

Ilieş, L., Crişan, E., \& Mureşan, I. N. (2010). Best practices in project management. Review of International Comparative Management, 11(1), 43-51.

Industries at a Glance: Heavy and Civil Engineering Construction: NAICS 237. (2017). United States Department of Labor - Bureau of Labor Statistic. Retrieved from https://www.bls.gov/iag/tgs/iag237.htm.

Iromuanya, C., Hargiss, K. M., \& Howard, C. (2013). Critical Risk Path Method: A Risk and Contingency-Driven Model for Construction Procurement in Complex and Dynamic 
Projects. International Journal of Strategic Information Technology and Applications (IJSITA), 4(2), 61-73.

Ikediashi, D. I., Ogunlana, S. O., \& Alotaibi, A. (2014). Analysis of project failure factors for infrastructure projects in Saudi Arabia: A multivariate approach. Journal of Construction in Developing Countries, 19(1), 35.

Jergeas, G. (2008). Analysis of the front-end loading of Alberta mega oil sands projects. Project Management Journal, 39(4), 95-104.

Jick, T. D. (1979). Mixing qualitative and quantitative methods: Triangulation in action. Administrative science quarterly, 602-611.

Johnson, R., \& Gray, R. (2010). A history of philosophical and theoretical issues for mixed methods research. Sage handbook of mixed methods in social and behavioral research, 69-94.

Jung, Y., \& Woo, S. (2004). Flexible work breakdown structure for integrated cost and schedule control. Journal of construction engineering and management, 130(5), 616625.

Jorgensen, M., \& Shepperd, M. (2007). A systematic review of software development cost estimation studies. IEEE Transactions on software engineering, 33(1).

Jørgensen, M. (2007). Forecasting of software development work effort: Evidence on expert judgement and formal models. International Journal of Forecasting, 23(3), 449-462.

Kaliba, C., Muya, M., \& Mumba, K. (2009). Cost escalation and schedule delays in road construction projects in Zambia. International Journal of Project Management, 27(5), $522-531$.

Kaliba, C., Muya, M., \& Mumba, K. (2009). Cost escalation and schedule delays in road construction projects in Zambia. International Journal of Project Management, 27(5), $522-531$.

Kaliba, C., Muya, M., \& Mumba, K. (2009). Cost escalation and schedule delays in road construction projects in Zambia. International journal of project management, 27(5), 522-531.

Kaming, P. F., Olomolaiye, P. O., Holt, G. D., \& Harris, F. C. (1997). Factors influencing construction time and cost overruns on high-rise projects in Indonesia. Construction Management \& Economics, 15(1), 83-94. doi:10.1080/014461997373132

Kaplan, D. (2004). The Sage handbook of quantitative methodology for the social sciences: sage Publications.

Kazaz, A., Ulubeyli, S., \& Tuncbilekli, N. A. (2012). Causes of Delays in Construction Projects in Turkey. Journal of Civil Engineering and Management, 18(3), 426-435. doi:10.3846/13923730.2012.698913

Kelley Jr., J. E., \& Walker, M. R. (1959). Critical-path planning and scheduling. Paper presented at the Proceeding of the Eastern Joint IRE-AIEE-ACM Computer Conference, Boston, Massachusetts.

Kadefors, A. (2004). Trust in project relationships-inside the black box. International Journal of project management, 22(3), 175-182.

Keane, P., Sertyesilisik, B., \& Ross, A. D. (2010). Variations and change orders on construction projects. Journal of legal affairs and dispute resolution in engineering and construction, 2(2), 89-96.

Kerzner, H. (2013). Project management: a systems approach to planning, scheduling, and controlling. John Wiley \& Sons.

Kaliba, C., Muya, M., \& Mumba, K. (2009). Cost escalation and schedule delays in road construction projects in Zambia. International Journal of Project Management, 27(5), $522-531$. 
Kastor, A., \& Sirakoulis, K. (2009). The effectiveness of resource levelling tools for resource constraint project scheduling problem. International Journal of Project Management, 27(5), 493-500.

Kerzner, H., \& Kerzner, H. R. (2017). Project management: a systems approach to planning, scheduling, and controlling. John Wiley \& Sons.

Keane, P. J., \& Caletka, A. F. (2015). Delay analysis in construction contracts. John Wiley \& Sons.

Kimmel, A. J. (2007). Ethical Issues in Behavioral Research: Basic and Applied Perspectives: Wiley.

Kothari, C. R. (2004). Research methodology: methods and techniques: New Age International.

Koushki, P. A., Al-Rashid, K., \& Kartam, N. (2005). Delays and cost increases in the construction of private residential projects in Kuwait. Construction Management \& Economics, 23(3), 285-294. doi:10.1080/0144619042000326710

Kumar, R. (2010). Research Methodology: A Step-by-Step Guide for Beginners: SAGE Publications.

Koushki, P. A., Al-Rashid, K., \& Kartam, N. (2005). Delays and cost increases in the construction of private residential projects in Kuwait. Construction Management and Economics, 23(3), 285-294.

Kim, E., Wells, W. G., \& Duffey, M. R. (2003). A model for effective implementation of Earned Value Management methodology. International Journal of Project Management, 21(5), 375-382.

Koskela, L. J., \& Howell, G. (2002). The underlying theory of project management is obsolete. In Proceedings of the PMI Research Conference (pp. 293-302). PMI.

Koushki, P. A., Al-Rashid, K., \& Kartam, N. (2005). Delays and cost increases in the construction of private residential projects in Kuwait. Construction Management and Economics, 23(3), 285-294.

Krahe, L. M., McColl, A. R., Pallant, J. F., Cunningham, C. E., \& DeWitt, D. E. (2010). A multi-university study of which factors medical students consider when deciding to attend a rural clinical school in Australia. Rural and Remote Health, 10(3), 1477.

Larson, E. W., \& Gray, C. (2013). Project Management: The Managerial Process with MS Project. McGraw-Hill.

Lechler, T. G., Ronen, B., \& Stohr, E. A. (2005). Critical chain: A new project management paradigm or old wine in new bottles?. Engineering Management Journal, 17(4), 45-58.

Lavold, G. D. (1988). Developing and using the work breakdown structure. Project Management Handbook, Second Edition, 302-323.

Le-Hoai, L., Lee, Y., \& Lee, J. (2008). Delay and cost overruns in Vietnam large construction projects: A comparison with other selected countries. KSCE Journal of Civil Engineering, 12(6), 367-377. doi:10.1007/s12205-008-0367-7

LeCompte, M. D., \& Goetz, J. P. (1982). Problems of reliability and validity in ethnographic research. Review of educational research, 52(1), 31-60.

Lo, T., Fung, I., \& Tung, K. (2006). Construction Delays in Hong Kong Civil Engineering Projects. Journal of Construction Engineering and Management, 132(6), 636-649. doi:doi:10.1061/(ASCE)0733-9364(2006)132:6(636)

Lipke, W., Zwikael, O., Henderson, K., \& Anbari, F. (2009). Prediction of project outcome: The application of statistical methods to earned value management and earned schedule performance indexes. International journal of project management, 27(4), 400-407.

Lewis Reynolds, P., \& Lancaster, G. (2007). Predictive strategic marketing management decisions in small firms: A possible Bayesian solution. Management decision, 45(6), 1038-1057. 
Lu, M., \& Li, H. (2003). Resource-activity critical-path method for construction planning. Journal of construction engineering and management, 129(4), 412-420.

Losch, A. (2009). On the origins of critical realism. Theology and Science, 7(1), 85-106.

O'Brien, P., \& Abidi, S. R. (2006). Modeling intelligent ontology evolution using biological evolutionary processes. In Engineering of Intelligent Systems, 2006 IEEE International Conference on (pp. 1-6). IEEE.

Lewis-Beck, M., Bryman, A. E., \& Liao, T. F. (2003). The Sage encyclopedia of social science research methods. Sage Publications.

Lee, K. Y., Huang, H. L., \& Hsu, Y. C. (2007). Trust, satisfaction and commitment: on loyalty to international retail service brands. Asia Pacific Management Review, 12, 161-169.

Luck, L., Jackson, D., \& Usher, K. (2006). Case study: a bridge across the paradigms. Nursing inquiry, 13(2), 103-109.

Martinelli, R. J., \& Milosevic, D. Z. (2016). Project management toolbox: tools and techniques for the practicing project manager. John Wiley \& Sons.

Mahamid, I., Al-Ghonamy, A., \& Aichouni, M. (2015). Risk matrix for delay causes in construction projects in Saudi Arabia. Research Journal of Applied Sciences, Engineering and Technology, 9(8), 665-670.

Mahamid, I., Bruland, A., \& Dmaidi, N. (2011). Causes of Delay in Road Construction Projects. Journal of Management in Engineering, 28(3), 300-310.

Mahamid, I. (2013). Contractors perspective toward factors affecting labor productivity in building construction. Engineering, Construction and Architectural Management, 20(5), 446-460.

Mahdi, I. M., Riley, M. J., Fereig, S. M., \& Alex, A. P. (2002). A multi-criteria approach to contractor selection. Engineering Construction and Architectural Management, 9(1), 29-37.

Markie, P. (2013). Rationalism vs. Empiricism. In E. N. Zalta (Ed.), The Stanford Encyclopedia of Philosophy (Summer 2013 Edition ed.).

Mason, J. (2002). Qualitative Researching: SAGE Publications.

Maykut, P. S., \& Morehouse, R. E. (1994). Beginning Qualitative Research: A Philosophic and Practical Guide: Falmer Press.

Malterud, K., Siersma, V. D., \& Guassora, A. D. (2016). Sample size in qualitative interview studies: guided by information power. Qualitative health research, 26(13), 1753-1760.

Memon, A. H., \& Rahman, I. A. (2014). SEM-PLS analysis of inhibiting factors of cost performance for large construction projects in Malaysia: perspective of clients and consultants. The Scientific World Journal, 2014.

Meredith, J. R., \& Mantel Jr, S. J. (2011). Project management: a managerial approach. John Wiley \& Sons.

Mercier, A. G., \& Nunnally, R. S. (1965). The Critical Path Method: The Fundamentals. Retrieved from Monteray, California:

Mertens, D. M. (2014). Research methods in education and psychology: Integrating diversity with quantitative, qualitative and mixed approaches (Fourth ed. Vol. Thousand Oaks): SAGE Publications, Inc.

Mezher, T. M., \& Tawil, W. (1998). Causes of delays in the construction industry in Lebanon. Engineering Construction \& Architectural Management (Wiley-Blackwell), 5(3), 252260.

Mitra, S., \& Wee Kwan Tan, A. (2012). Lessons learned from large construction project in Saudi Arabia. Benchmarking: An International Journal, 19(3), 308-324.

Miles, M. B., Huberman, A. M., \& Saldana, J. (2013). Qualitative data analysis. New York, USA: Sage. 
Ministry of Finance (2018). Budget Statement: Fiscal Year 2018. Ministry of Finance, Riyadh KSA. Retrieved from https://www.mof.gov.sa/en/budget/Documents/171228\%20\%20budget\%20Statement $\% 20$ eng\%20Single.pdf.

Milosevic, D. Z. (2003). Project management toolbox: tools and techniques for the practicing project manager: J. Wiley \& Sons.

Morgan, D. L. (2007). Paradigms lost and pragmatism regained methodological implications of combining qualitative and quantitative methods. Journal of mixed methods research, $1(1), 48-76$.

Morse, J. M., Barrett, M., Mayan, M., Olson, K., \& Spiers, J. (2008). Verification strategies for establishing reliability and validity in qualitative research. International journal of qualitative methods, 1(2), 13-22.

Murphy, A., \& Ledwith, A. (2007). Project management tools and techniques in hightechnology SMEs. Management Research News, 30(2), 153-166.

Myers, M. D. (2009). Qualitative Research in Business \& Management: SAGE Publications.

Medrano, M., Brouwer, J., McDonell, V., Mauzey, J., \& Samuelsen, S. (2008). Integration of distributed generation systems into generic types of commercial buildings in California. Energy and Buildings, 40(4), 537-548.

Meredith, J., \& Mantel, S. J. (2009). Project Management: A Managerial Approach, 6Th Ed (W/Cd): Wiley India Pvt. Limited.

Miller, J. B., Garvin, M. J., Ibbs, C. W., \& Mahoney, S. E. (2000). Toward a new paradigm: Simultaneous use of multiple project delivery methods. Journal of Management in Engineering, 16(3), 58-67.

Molenaar, K. R., Sobin, N., \& Antillón, E. I. (2010). A synthesis of best-value procurement practices for sustainable design-build projects in the public sector. Journal of Green Building, 5(4), 148-157.

Memon, A. H., Abdul Rahman, I., Ismail, I., \& Zainun, N. Y. (2014). Time management practices in large construction projects.

Minnameier, G. (2010). The logicality of abduction, deduction, and induction. In Ideas in action: Proceedings of the applying peirce conference (pp. 239-251). Helsinki: Nordic Pragmatism Network.

Mitra, S., \& Wee Kwan Tan, A. (2012). Lessons learned from large construction project in Saudi Arabia. Benchmarking: An International Journal, 19(3), 308-324.

Mir, F. A., \& Pinnington, A. H. (2014). Exploring the value of project management: linking project management performance and project success. International journal of project management, 32(2), 202-217.

Mezher, T. M., \& Tawil, W. (1998). Causes of delays in the construction industry in Lebanon. Engineering, Construction and Architectural Management, 5(3), 252-260.

Mubarak, S. A. 2005. Construction project scheduling and control, Prentice-Hall, Upper Saddle River, N.J

Milosevic, D. Z. (2003). Project management toolbox: tools and techniques for the practicing project manager. John Wiley \& Sons.

Neuman, W. L. (2006). Social research methods: Qualitative and quantitative approaches.

Neuman, W. L., \& Robson, K. (2004). Basics of social research: Pearson.

Nkado, R. N. (1995). Construction time influencing factors: The contractor's perspective. Construction Management and Economics, 13(1), 81-89.

Norton, A.-L. (1997). The Hutchinson dictionary of ideas. Oxford: Helicon.

NSECHR. (2007). National Statement on Ethical Conduct in Human Research 2007 (Updated March 2014). In Canberra.: The National Health and Medical Research Council, the Australian Research Council and 
NcNair, D (2016). Concurrent Delays. PricewaterhouseCoopers Report. Retrieved from http://www.pwc.com.au/legal/assets/investing-in-infrastructure/iif-24-concurrentdelay-feb16-3.pdf

Nibbelink, J. G., Sutrisna, M., \& Zaman, A. U. (2017). Unlocking the potential of early contractor involvement in reducing design risks in commercial building refurbishment projects-a Western Australian perspective. Architectural Engineering and Design Management, 13(6), 439-456.

Oertig, M., \& Buergi, T. (2006). The challenges of managing cross-cultural virtual project teams. Team Performance Management: An International Journal, 12(1/2), 23-30.

O'Brien, D. (2006). An Introduction to the Theory of Knowledge. Cambridge, UK: Polity Press.

Odeh, A. M., \& Battaineh, H. T. (2002). Causes of construction delay: traditional contracts. International Journal of Project Management, 20(1), 67-73. doi:http://dx.doi.org/10.1016/S0263-7863(00)00037-5

Odeyinka, H. A., \& Yusuf, A. (1997). The causes and effects of construction delays on completion cost of housing project in Nigeria. Journal of Financial Management of Property and Construction, 14(1), 31-44.

Ohara, S. (2004). A Guidebook for Project and Program Management for Enterprise Innovation (P2M) (Vol. II): Project Management Professionals Certification Center (PMCC).

Ohara, S. (2005). A Guidebook for Project and Program Management for Enterprise Innovation (P2M) (Vol. I): Project Management association of Japan (PMAJ).

Onwuegbuzie, A. J., \& Collins, K. M. (2007). A typology of mixed methods sampling designs in social science research. Qualitative Report, 12(2), 281-316.

Onwuegbuzie, A. J., \& Johnson, R. B. (2006). The validity issue in mixed research. Research in the Schools, 13(1), 48-63.

Odeh, A. M., \& Battaineh, H. T. (2002). Causes of construction delay: traditional contracts. International journal of project management, 20(1), 67-73.

Olander, S., \& Landin, A. (2005). Evaluation of stakeholder influence in the implementation of construction projects. International journal of project management, 23(4), 321-328.

Olaniran, O. J. (2015). The effects of cost-based contractor selection on construction project performance. Journal of Financial Management of Property and Construction, 20(3), 235-251.

Olsen, B. E., Haugland, S. A., Karlsen, E., \& Husøy, G. J. (2005). Governance of complex procurements in the oil and gas industry. Journal of Purchasing and Supply management, 11(1), 1-13.

OGC (2011). PRINCE 2 Background. Retrieved from http://webarchive.nationalarchives.gov.uk/20110822131357/http://www.ogc.gov.uk/m ethods_prince_2_background.asp.

Ohara, S. and Asada, T. (2009). Japanese Project Management KPM - Innovation, Development and Improvement. World Scientific, Singapore.

Omini, A. A., Nnamdi, O. E., Edwin, N., \& Gladys, N. (2017). Project Cost Overrun Management in Universities Using Partial Least Squares-Structural Equation Modelling. American Journal of Applied Mathematics, 5(4), 108-113.

Patanakul, P., Iewwongcharoen, B., \& Milosevic, D. (2010). An empirical study on the use of project management tools and techniques across project life-cycle and their impact on project success. Journal of General Management, 35(3), 41-66.

Park, M., \& Peña-Mora, F. (2003). Dynamic change management for construction: introducing the change cycle into model-based project management. System Dynamics Review, 19(3), 213-242. 
Pallant, J. (2010). SPSS survival manual: A step by step guide to data analysis using SPSS: McGraw-Hill International.

Patanakul, P., Iewwongcharoen, B., \& Milosevic, D. (2010). An Empirical Study on the use of Project Management Tools and Techniques across Project Life-Cycle and their Impact on Project Success. Journal of General Management, 35(3), 41-66. doi: $10.1177 / 030630701003500304$

Peters, T. F. (2003). Dissecting the doctrine of concurrent delay. AACE International Transactions, CD11.

PMI. (2013). A guide to the Project Management Body of Knowledge (PMBOK guide), fifth edition.

PMI. (2017). A guide to the Project Management Body of Knowledge (PMBOK guide), sixth edition.

PMI. (2016). Construction Extension to the PMBOK® Guide. Pennsylvania: Project Management Institute, Inc.

Polit, D. F., \& Beck, C. T. (2010). Generalization in quantitative and qualitative research: Myths and strategies. International journal of nursing studies, 47(11), 1451-1458.

Popkewitz, T. S., Tabachnick, B. R., \& Zeichner, K. M. (1979). Dulling the senses: Research in teacher education. Journal of Teacher Education, 30(5), 52-60.

Practice Standard for Work Breakdown Structures. (2006). Project Management Institute (PMI).

Projects \& Operations: Local Urban Infrastructure Development Project. (2014). The World Bank. Retrieved from http://projects.worldbank.org/P095949/local-urbaninfrastructure-development-project?lang=en\&tab=overview

Punch, K. F. (2013). Introduction to social research: Quantitative and qualitative approaches: Sage.

Puri, Y. (2016, October 14). Points to Remember - PMBOK 5th Edition - Part 8 - Procurement Management. Project Management.com.

Ponce de Leon, G. (1987). Theories of concurrent delays. AACE Transactions, 6, 1-5.

PMAJ (2016). A Guidebook of Project and Program Management for Enterprise Innovation, third edition.

PMI (2015). Capturing the Value of Project Management. PMI's Pulse of the Profession. Retrieved from http://www.pmi.org//media/pmi/documents/public/pdf/learning/thought-leadership/pulse/pulse-of-theprofession-2015.pdf

PRINCE2 (2016). PRINCE 2 Processes. Retrieved from https://www.prince2.com/aus/prince2-processes.

PMI. (2013). A guide to the Project Management Body of Knowledge (PMBOK guide), fifth edition.

PMI. (2016). Construction Extension to the PMBOK® Guide. Pennsylvania: Project Management Institute,

Pinto, J. K. (2015). Project management: achieving competitive advantage. Prentice Hall.

Pentland, B. T., \& Feldman, M. S. (2005). Organisational routines as a unit of analysis. Industrial and corporate change, 14(5), 793-815.

QSR. (2014). What is Qualitative Research? Retrieved from http://www.qsrinternational.com/what-is-qualitative-research.aspx

Ramey, H. \& Grubb, S. (2009). Modernism, Postmodernism and (Evidence-Based) Practice. Contemporary Family Therapy, 31(2), 75-86.

Rahman, I. A., Al-Emad, N., \& Nagapan, S. (2016). Projects delay factors of Saudi Arabia construction industry using PLS-SEM path modelling approach. In MATEC Web of Conferences (Vol. 81, p. 07001). EDP Sciences. 
Rahman, I. A., Memon, A. H., Abdullah, N. H., \& Azis, A. A. A. (2013). Application of PLSSEM to Assess the Influence of Construction Resources on Cost Overrun. In Applied Mechanics and Materials (Vol. 284, pp. 3649-3656). Trans Tech Publications.

Ramanathan, C., Narayanan, S. P., \& Idrus, A. B. (2012). Construction delays causing risks on time and cost-a critical review. Construction Economics and Building, 12(1), 37-57.

Raskin, J. D. (2008). The evolution of constructivism. Journal of constructivist psychology, 21(1), 1-24.

Richter, N. F., Sinkovics, R. R., Ringle, C. M., \& Schlaegel, C. (2016). A critical look at the use of SEM in international business research. International Marketing Review, 33(3), 376-404.

Rodriguez-Melo, A., \& Mansouri, S. A. (2011). Stakeholder engagement: Defining strategic advantage for sustainable construction. Business Strategy and the Environment, 20(8), 539-552.

Ruuska, I., \& Vartiainen, M. (2005). Characteristics of knowledge sharing communities in project organisations. International journal of project management, 23(5), 374-379.

Ruqaishi, M., \& Bashir, H. A. (2014). Causes of delay in construction projects in the oil and gas industry in the gulf cooperation council countries: a case study. Journal of Management in Engineering, 31(3), 05014017.

Robson, C. (2011). Real world research: a resource for users of social research methods in applied settings: Wiley Chichester.

Roseke, B. (2017, February 21). Project Procurement Management According to the PMBOK. Project Engineer.

Sambasivan, M., \& Soon, Y. W. (2007a). Causes and effects of delays in Malaysian construction industry. International Journal of Project Management, 25(5), 517-526.

Sambasivan, M., \& Soon, Y. W. (2007b). Causes and effects of delays in Malaysian construction industry. International Journal of Project Management, 25(5), 517-526. doi:http://dx.doi.org/10.1016/j.ijproman.2006.11.007

Sanders, D., \& Eagles, W. D. (2001). Delay, Disruption and Acceleration Claims. Retrieved from

Sawalhi, N., \& Enshassi, A. (2012). Application of Project Time Management Tools and Techniques to the Construction Industry in the Gaza Strip. Construction Economics and Building, 5(1), 1-8.

Şandru, M., \& Olaru, M. (2013, January). Critical path method applied to the multi project management environment. In ECMLG2013-Proceedings For the 9th European Conference on Management Leadership and Governance: ECMLG 2013 (p. 440). Academic Conferences Limited.

San Cristóbal, J. R. (2011). Contractor selection using multicriteria decision-making methods. Journal of Construction Engineering and Management, 138(6), 751-758.

Sijtsma, K. (2009). On the use, the misuse, and the very limited usefulness of Cronbach's alpha. Psychometrika, 74(1), 107.

Saadé, R. G., Dong, H., \& Wan, J. (2015). Factors of project manager success. Interdisciplinary Journal of Information, Knowledge, and Management, 10, 63-80.Santiago, J., \& Magallon, D. (2009). Critical Path Method. CEE320, Winter 2013.

Sears, S. K., Sears, G. A., Clough, R. H., Rounds, J. L., \& Segner, R. O. (2015). Construction project management. John Wiley \& Sons.

Sueyoshi, T., \& Aoki, S. (2001). A use of a nonparametric statistic for DEA frontier shift: the Kruskal and Wallis rank test. Omega, 29(1), 1-18.

Sayer, A. (2000). Realism and Social Science: SAGE Publications.

Schwandt, T. A. (1994). Constructivist, interpretivist approaches to human inquiry. 
Schwandt, T. A. (2007). The Sage dictionary of qualitative inquiry: Sage.

Scott, D. (2005). Critical realism and empirical research methods in education. Journal of Philosophy of Education, 39(4), 633-646.

SE Goldmine. (2017). MIL-STD-881. Retrieved from http://segoldmine.ppiint.com/documents/mil-std-881

Seale, C. (1999). Quality in Qualitative Research. Qualitative Inquiry, 5(4), 465-478. doi:10.1177/107780049900500402

Shabbab Al Hammadi, M. Project Time Overruns in Saudi Arabian Con-struction Industry.

Sofaer, S. (2002). Qualitative research methods. International Journal for Quality in Health Care, 14(4), 329-336.

Standard Practice: Work Breakdown Structures for Defense Materiel Items. (2011). Retrieved from

Stumpf, G. F. (2000). Schedule Delay Analysis. Cost Engineering, 42(7), 32.

Söderholm, A. (2008). Project management of unexpected events. International Journal of Project Management, 26(1), 80-86.

Smith, N. J., Merna, T., \& Jobling, P. (2009). Managing risk: in construction projects. John Wiley \& Sons.

Shenhar, A. J., \& Dvir, D. (2007). Reinventing project management: the diamond approach to successful growth and innovation. Harvard Business Review Press.

Sweis, G., Sweis, R., Hammad, A. A., \& Shboul, A. (2008). Delays in construction projects: The case of Jordan. International Journal of Project Management, 26(6), 665-674.

Sosik, J. J., Kahai, S. S., \& Piovoso, M. J. (2009). Silver bullet or voodoo statistics? A primer for using the partial least squares data analytic technique in group and organisation research. Group \& Organisation Management, 34(1), 5-36.

Siegal, S. (1956). Nonparametric statistics for the behavioral sciences. McGraw-hill.

Shabbab Al Hammadi, M. Study of Delay Factors in Construction Projects.2016.

Subramani, T., Sarkunam, A., \& Jayalakshmi, J. (2014). Planning and Scheduling of High Rise Building Using Primavera. International Journal of Engineering Research and Applications, 4(6), 134-144.

Singh, D., \& Tiong, R. L. (2006). Contractor selection criteria: investigation of opinions of Singapore construction practitioners. Journal of construction engineering and management, 132(9), 998-1008.

Silverman, D. (2015). Interpreting qualitative data. New York, USA: Sage. Auerbach, C., \& Silverstein, L. B. (2003). Qualitative data: An introduction to coding and analysis. NYU press. Miles, M. B., Huberman, A. M., \& Saldana, J. (2013). Qualitative data analysis. New York, USA: Sage.

Taylor, M. D. (2003). How to Develop Work Breakdown Structures. In: 連結.

Teddlie, C., \& Tashakkori, A. (2010). Overview of contemporary issues in mixed methods research. Sage handbook of mixed methods in social and behavioral research, 2, 1-44.

Thomas, J., \& Mengel, T. (2008). Preparing project managers to deal with complexityAdvanced project management education. International journal of project management, 26(3), 304-315.

Tjahjana, L., PMP, P. D., \& Habib, M. (2009). The program management office advantage: A Powerful and Centralized Way for Organisations to Manage Projects. AMACOM Div American Mgmt Assn.

Trauner, T. J., Manginelli, W. A., Lowe, J. S., Nagata, M. F., \& Furniss, B. J. (2009). Construction Delays: Understanding Them Clearly. Analyzing Them Correctly, 1-23.

Turner, R. J., Huemann, M., Anbari, F. T., \& Bredillet, C. N. (2010). Perspectives on projects. Routledge. 
The Middle East and Africa (MEA) region's construction industry will grow by $6.9 \%$ annually in 2016-20. (2015). Ventures Onsite.the Australian Vice-Chancellors' Committee. Commonwealth of Australia.

Toor, S.-U.-R., \& Ogunlana, S. O. (2008). Problems causing delays in major construction projects in Thailand. Construction Management \& Economics, 26(4), 395-408. doi:10.1080/01446190801905406

The Society of Construction Law (2002). The Society of Construction Law Delay and Disruption Protocol. Retrieved from https://www.scl.org.uk/sites/default/files/SCL\%20Delay\%20and\%20Disruption\%20Pr otocol\%20-\%20subject\%20to\%20Rider\%201.pdf.

Unger, B. N., Gemünden, H. G., \& Aubry, M. (2012). The three roles of a project portfolio management office: Their impact on portfolio management execution and success. International Journal of Project Management, 30(5), 608-620.

Vanhoucke, M. (2013). Earned Value Management. In Project Management with Dynamic Scheduling (pp. 217-240). Springer Berlin Heidelberg.

Van Thuyet, N., Ogunlana, S. O., \& Dey, P. K. (2007). Risk management in oil and gas construction projects in Vietnam. International journal of energy sector management, 1(2), 175-194.

Vennström, A., \& Erik Eriksson, P. (2010). Client perceived barriers to change of the construction process. Construction innovation, 10(2), 126-137.

Virle, R., \& Mhaske, S. (2013). Application of Earned Value and Earned Schedule to Construction Project. International Journal of Scientific Engineering and Research (IJSER), 1(1)

Walliman, N. (2006). Social research methods: Sage.

Watt, D. J., Kayis, B., \& Willey, K. (2010). The relative importance of tender evaluation and contractor selection criteria. International Journal of Project Management, 28(1), 51-60.

Walker, A. (2015). Project management in construction. John Wiley \& Sons.

Weigao, Q., \& Bo, S. (2011, 24-26 June 2011). Current situation analysis and safety countermeasure study on road traffic accidents in China. Paper presented at the Remote Sensing, Environment and Transportation Engineering (RSETE), 2011 International Conference on.

Welman, C., Kruger, F., \& Mitchell, B. (2005). Research methodology: Oxford University Press.

Winter, G. (2000). A comparative discussion of the notion of validity in qualitative and quantitative research. The qualitative report, 4(3), 4.

Wolf, F. M. (1986). Meta-analysis: Quantitative methods for research synthesis (Vol. 59): Sage.

Wong, K., \& Vimonsatit, V. ( 2012). A study of the factors affecting construction time in Western Australia. Scientific Research and Essays, 7(40), 3390-3398.

Wilson, J. M. (2003). Gantt charts: A centenary appreciation. European Journal of Operational Research, 149(2), 430-437.

Winch, G. M. (2010). Managing construction projects. John Wiley \& Sons

Wysocki, R. K. (2011). Effective project management: traditional, agile, extreme. John Wiley $\&$ Sons.

Goodman, A. S., \& Hastak, M. (2006, August). Infrastructure planning handbook: planning, engineering, and economics. ASCE.

White, D., \& Fortune, J. (2002). Current practice in project management-An empirical study. International journal of project management, 20(1), 1-11. 
Whittington, R., Pettigrew, A., Peck, S., Fenton, E., \& Conyon, M. (1999). Change and complementarities in the new competitive landscape: a European panel study, 19921996. Organisation Science, 10(5), 583-600.

Wilson, W. J. (2012). The truly disadvantaged: The inner city, the underclass, and public policy. University of Chicago Press.

Wong, K. K. K. (2013). Partial least squares structural equation modeling (PLS-SEM) techniques using SmartPLS. Marketing Bulletin, 24(1), 1-32.

Yamin, R. A., \& Harmelink, D. J. (2001). Comparison of linear scheduling model (LSM) and critical path method (CPM). Journal of Construction Engineering and Management, 127(5), 374-381.

Yana, A. G. A., Rusdhi, H. A., \& Wibowo, M. A. (2015). Analysis of factors affecting design changes in construction project with Partial Least Square (PLS). Procedia Engineering, 125, 40-45.

Yin, Y., Zhang, X., Peng, D., \& Li, X. (2009). Model validation and case study on internally cooled/heated dehumidifier/regenerator of liquid desiccant systems. International journal of thermal sciences, 48(8), 1664-1671.

Zain Al-Abidien, H. M. (1983, 14-19 May). About the effect of delay penalty on the construction of projects and modification proposal. Paper presented at the Engineering Conference, King Abdulaziz University, Jeddah.

Zavadskas, E. K., Vilutienè, T., Turskis, Z., \& Šaparauskas, J. (2014). Multi-criteria analysis of Projects' performance in construction. Archives of Civil and Mechanical Engineering, 14(1), 114-121.

Zikmund, W. G., Babin, B. J., Carr, J. C., \& Griffin, M. (2013). Business research methods. Cengage Learning.

Zecheru, V., \& Olaru, B. G. (2016). Work Breakdown Structure (WBS) in Project Management. Revista de Management Comparat International, 17(1), 61.

Zikmund, W. G., Babin, B. J., Carr, J. C., \& Griffin, M. (2013). Business research methods. Cengage Learning.

Zimmermann, H. (2007). Realist power Europe? The EU in the negotiations about China's and Russia's WTO accession. JCMS: Journal of Common Market Studies, 45(4), 813832.

Zhong, D. H., \& Zhang, J. S. (2003). New method for calculating path float in program evaluation and review technique (PERT). Journal of construction engineering and management, 129(5), 501-506.

Every reasonable effort has been made to acknowledge the owners of copyright material. I would be pleased to hear from any copyright owner who has been omitted or incorrectly acknowledged. 


\section{Appendix 1 The survey questionnaire}

Information Statement

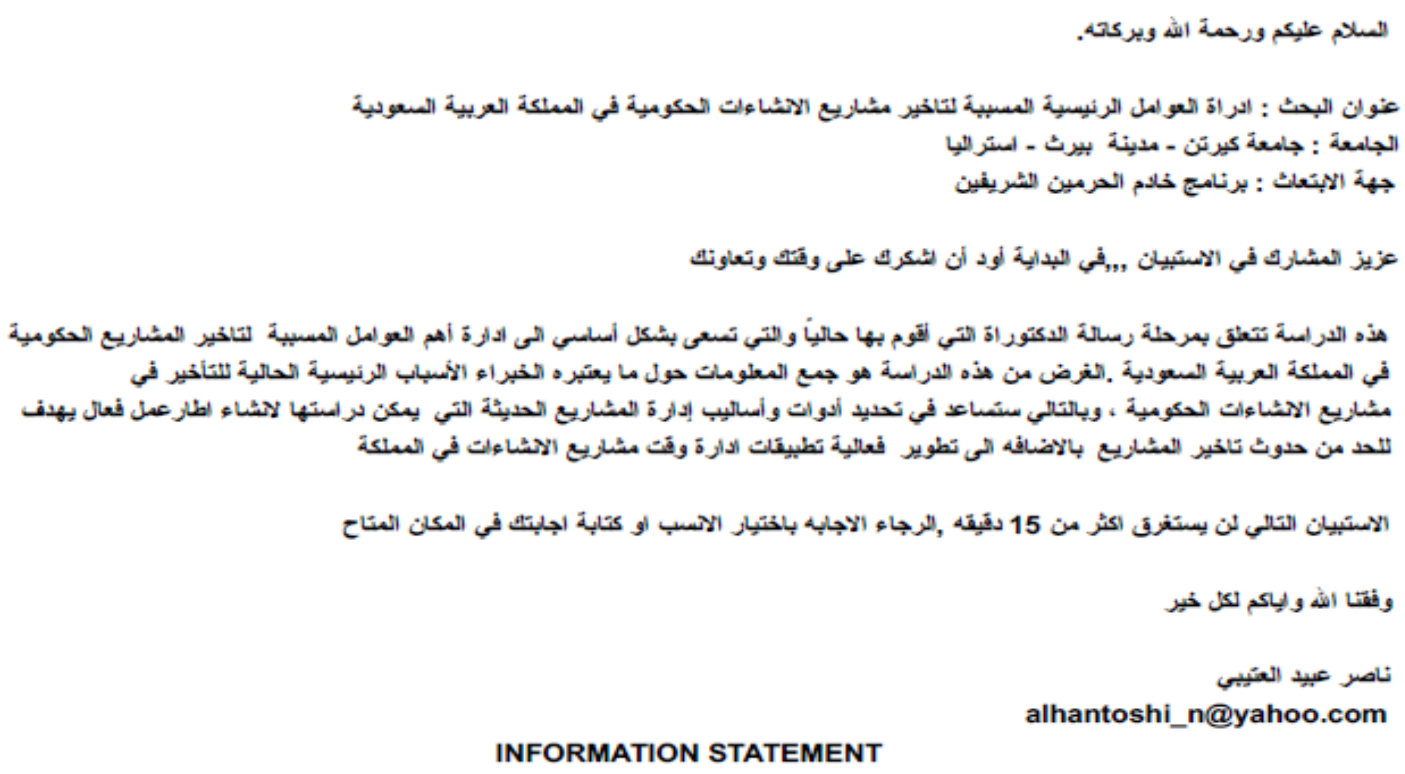

Project Title: MANAGING CRITICAL FACTORS CAUSING DELAYS IN PUBLIC CONSTRUCTION PROJECTS IN KINGDOM OF SAUDI ARABIA.

Institution: Curtin University. Investigator: Alotaibi, Nasser.

Funded by: Ministry of Education, KINGDOM OF SAUDI ARABI

The primary purpose of this survey is to obtain initial opinions of construction experts in KSA about the most prevalent causes of delays in construction projects in the KSA, in order to develop framework that applying project management knowledge, tools, techniques and methodologies to minimize delays as well as support the effective time management practices across the construction industry in KSA public sector. The negative effects of construction delays are not desirable and sustainable for the improvement of construction industry in KSA. The planned research will be seeking solutions for construction delays in KSA. This study is an important step towards achieving the research objectives. The following questions have been developed after an exhaustive review of literature worldwide on the topic and the questions put are a direct result of that review.

The questionnaire will take about 15 minutes to complete.

\section{CONSENT FORM}

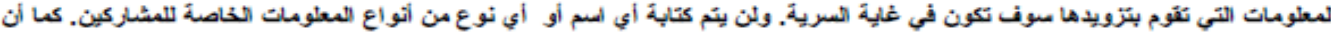

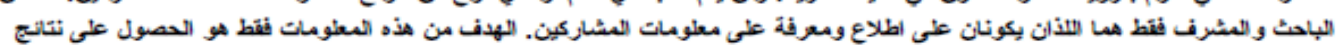




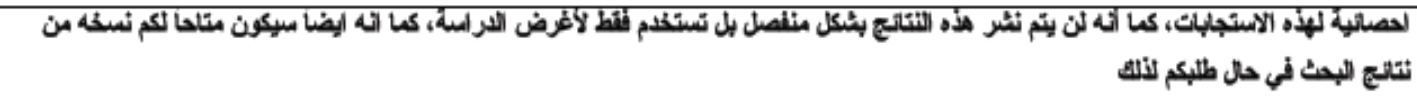

The information provided for this survey will be kept in strictest confidentiality. At no stage will any name or identification be made during the course of the research and on any form of documentation. The researcher and research supervisor will be the only personnel aware of the participants for the research project. The purpose of the information provided during the survey will not be published separately but will be used in the main study, copy which will be made available to you upon request.

* 1. Please be informed that by submitting the survey, you are giving consent that your response should be used for the purpose of developing a research study:

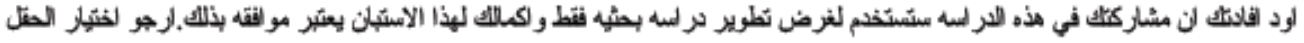

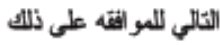

I have been read the information statement and understand the purposes of the study,I understand I can withdraw at any time without prejudice;Any information which might potentially identify me will not be used in published material;Any information which might potentially identify me will not be used in published material.

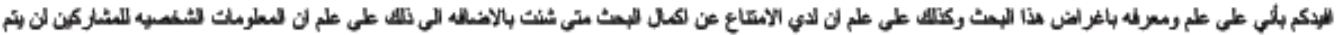
ستيدالها 
Q معلومات عامه عن المشاركين. Questions related to the respondent'sexperience

2. What is your organisational type?(Please tick the appropriate Box) ماهي صفة الجهة التي تعل ليها

مالك للشاري Client /owner

متارل Contractor

لمترلري Consultant

Other (please specify)

3. What is your role in the organization ? ماهو نورك في الجهة التي تعل لايها ؟

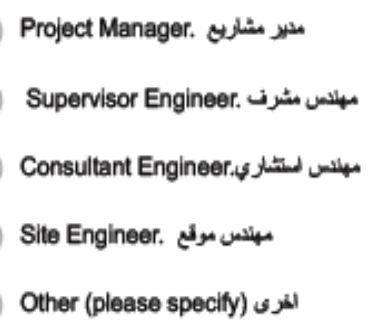

(please specify)

4. How many years of experience within public construction projects do you have? (Please tick the appropriate Box)

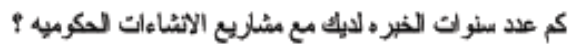

$0-5$ years

$6-10$ years

$11-15$ years

$16-20$ years

More than 20 years 
5. What is your level of education ? ? ماهو مو مالك التطليمي

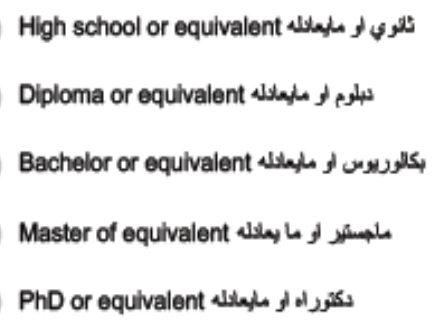

6. What type of public projects you have usually involved ? ماهي طبيعة المشاريع للثي شاركت بها غالبأ ؟

مullding.

Infrastructure.

Roads. طرن

Other (please specify) المزرى 
Questions related to the performance of project/s you have been involved in. معلومات عن لداءوالمثاريع

7. How many public contraction projects have you involved in the last 10 years?

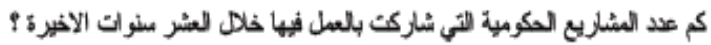

Number projects عد لمثلري

8. How frequent have you experienced delays within public construction projects out of projects you have involved in the last 10 years?

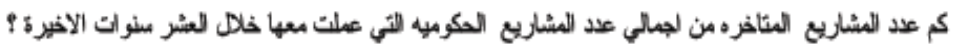

\# Project Delayed Out of \# projects you involved

عدا الشثرب السأري:

9. Can you please provide a specific example of the worst delay you have experienced?

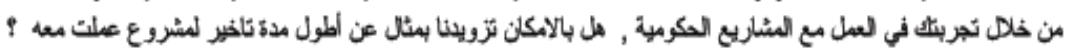

Planned project duration(Months)

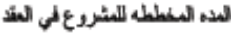

Final/actual project duration(Months)

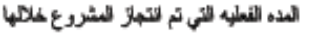

Project Duration in

(Months)

مدة المثروع بالاشير

10. From your experience in public projects, have you completed project earlier than planned ? if yes, Please provide example for the shortest duration.Otherwise, please choose "No"

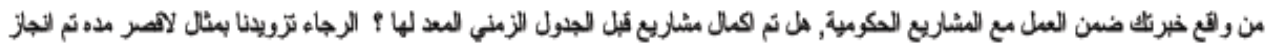

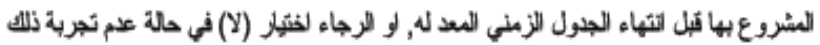

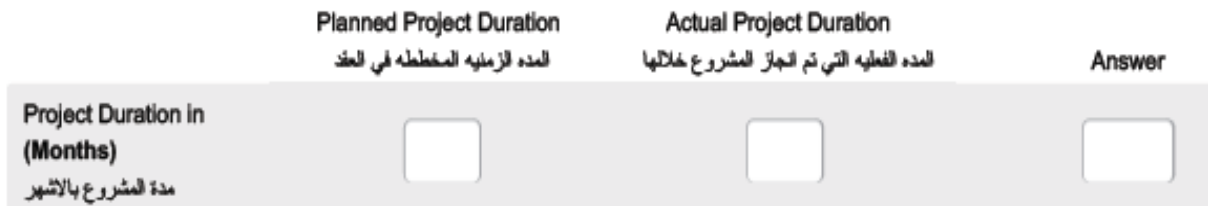


11. From your experience which stakeholder is likely the major source of delays in construction project in

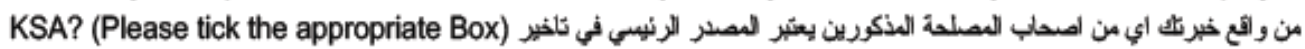
المُّربي

Client

Contractor لمقالرل

Consultant الاستشاري

Other (please specify) الفزى

12. In which of the following project processes do you think delay can be BEST minimized?(More than one

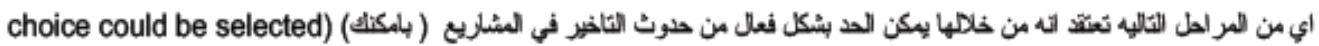
لختيّل اكثر من اخثيّر

Planning Phase. مرطد التكبل

Designing Phase. مرحة قلمسبم

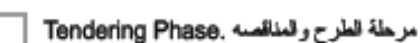

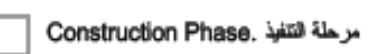

Other (please specify) للف 
Critical Factors Causing Delays عو امل تاخير المشاريع الحكومية

19. How much do you agree that delays are majorly caused by the following factors?(Please tick the appropriate Box)

Contractor related:

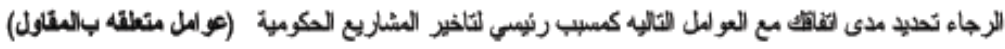

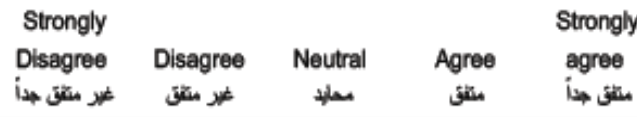

Ineffective planning and scheduling of project.

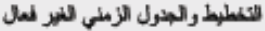

Poor qualification, skills and experience of the staff.

عم كلقة وخيرة طمى لفئال

Poor site management and supervision.

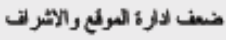

Difficulties in financing the project.

معريك المقارل الهالي

Delay in sub-contractors' work

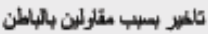

Other (please specify)ses

20. How much do you agree that delays are majorly caused by the following factors? (Please tick the appropriate Box)

Client Related:

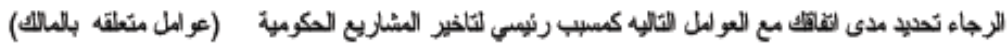

\begin{tabular}{|c|c|c|c|c|c|}
\hline & 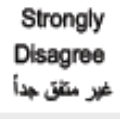 & 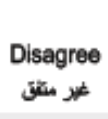 & $\begin{array}{c}\text { Neutral } \\
\text { معزئ }\end{array}$ & $\begin{array}{c}\text { Agree } \\
\text { مقأى }\end{array}$ & $\begin{array}{c}\text { Strongly } \\
\text { agree } \\
\text { مuتى }\end{array}$ \\
\hline 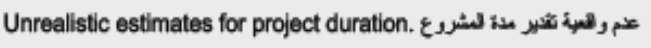 & & & & & \\
\hline Change orders. تلير لطليكت & & & & & \\
\hline Slowness in decision-making process. بطد في تكلاد الثزارت & & & & & \\
\hline 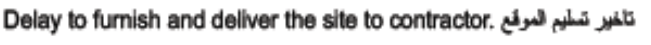 & & & & & \\
\hline تلفير الافعتك الساليه Delay in progress payment & & & & & \\
\hline
\end{tabular}

Other (please specify) عوليل المزر 


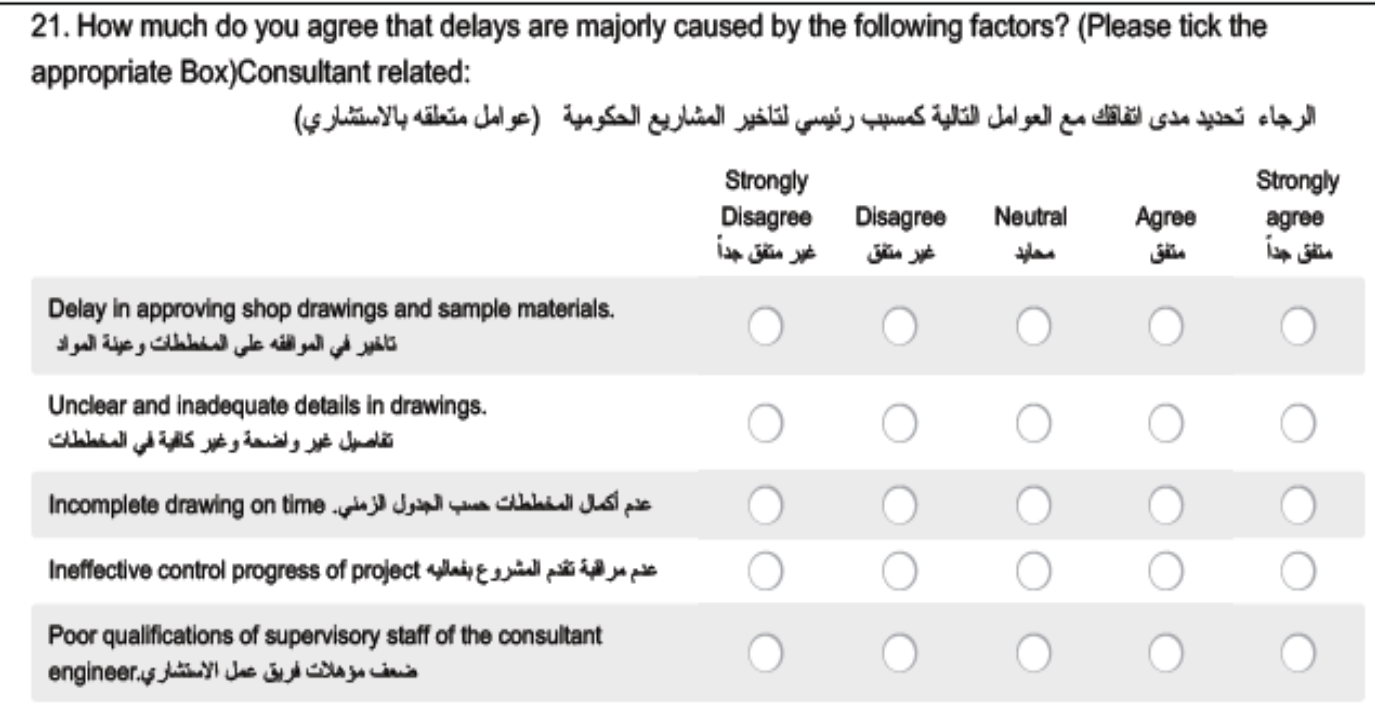

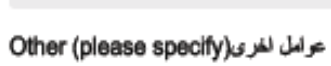

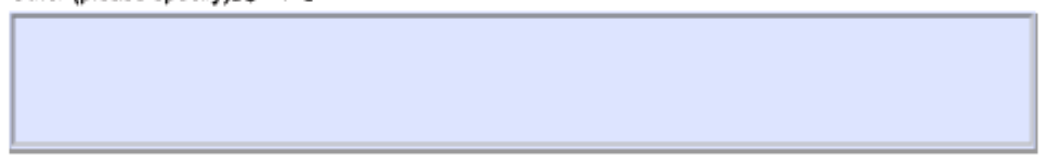

22. How much do you agree that delays are majorly caused by the following factors? (Please tick the appropriate Box) General management and external related:

\begin{tabular}{|c|c|c|c|c|c|}
\hline & 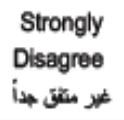 & 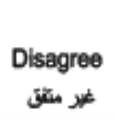 & $\begin{array}{c}\text { Neutral } \\
\text { مer }\end{array}$ & $\begin{array}{l}\text { Agree } \\
\text { مقنى }\end{array}$ & 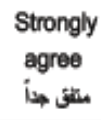 \\
\hline 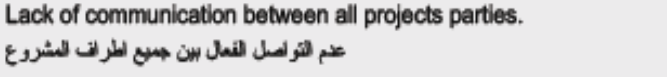 & & & & & \\
\hline 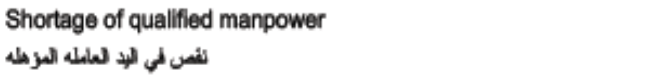 & & & & & \\
\hline 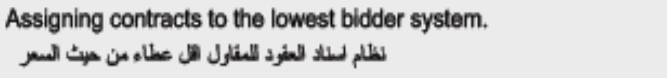 & & & & & \\
\hline 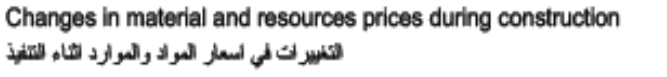 & & & & & \\
\hline 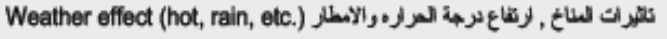 & & & & & \\
\hline
\end{tabular}

Other (please specify) الشرى 
Project Management in Public Construction Projects in KSA.

13. From your experience, what do you think about the following statement "delays in public projects can be potentially mitigated/minimized by applying project management methodologies,tools and techniques"? (Please tick the appropriate Box)

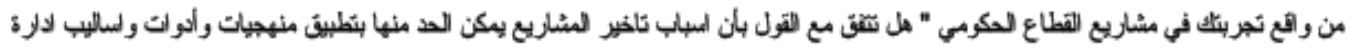

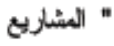

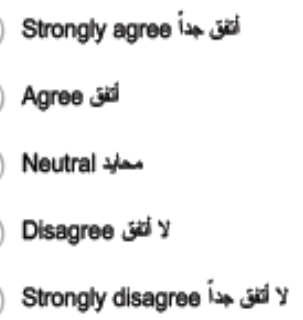

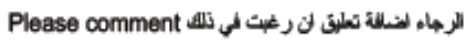

14. Project Management in Public Construction projects in KSA.Please tick your choice (strongly agree, Agree, Neutral, Disagree, or Strongly disagree )

الرجاء تصديل مدى الغفاك مع النظريات التالية

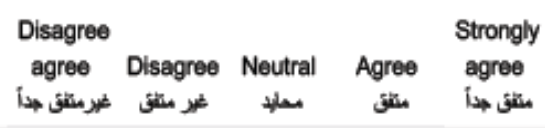

Project management concepts are not novelties and already widely accepted

in the construction industry in KSA.

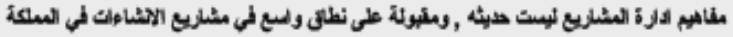

Project management tools/techniques are not widely recognized or implemented in KSA.

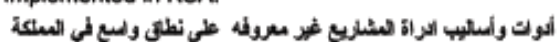

Project management tools/techniques are accepted and understood but generally has not been used effectively in KSA.

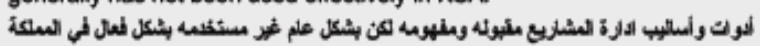

Project management tools/techniques are only popular or used in certain construction sectors in KSA.

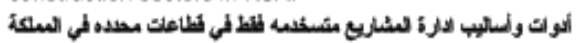

There is a need for further use and application of the project management tools/techniques in public construction in KSA.

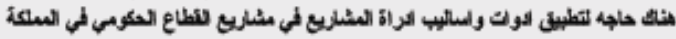


Applications of Project Managment (Planning,Tools and Techniques) in Construction Projects in KSA

15. Construction projects planning in KSA.

Please tick your choice (Always - Frequently, Sometimes, Rarely, Never)

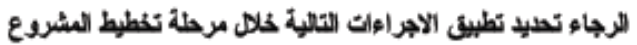

Never Rarely Sometimes Frequently Always

دانتأ

The estimation of the project duration is typically conducted based on each individual activity (at the lowest level in WBS/schedule).

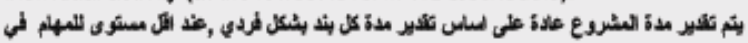

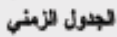

The estimation of activity duration involves an estimation of all resource allocated for that activity.

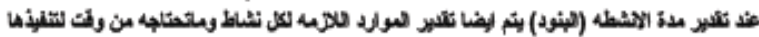

Upon a successful tender, a new/different detailed project management plan is normally prepared before construction phase.

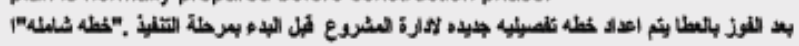

Upon a successful tender, a new/different schedule baseline is normally prepared before construction phase.

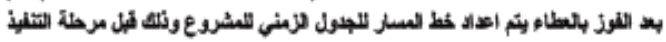

The (new) project management plan is normally approved by the project stockholders.

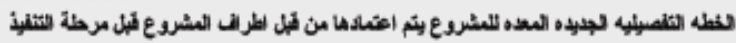

16. How often do you use following project management tools and techniques in estimating duration

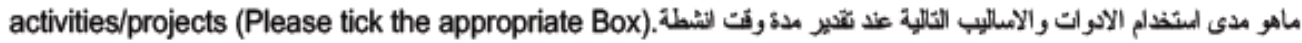
المثروع

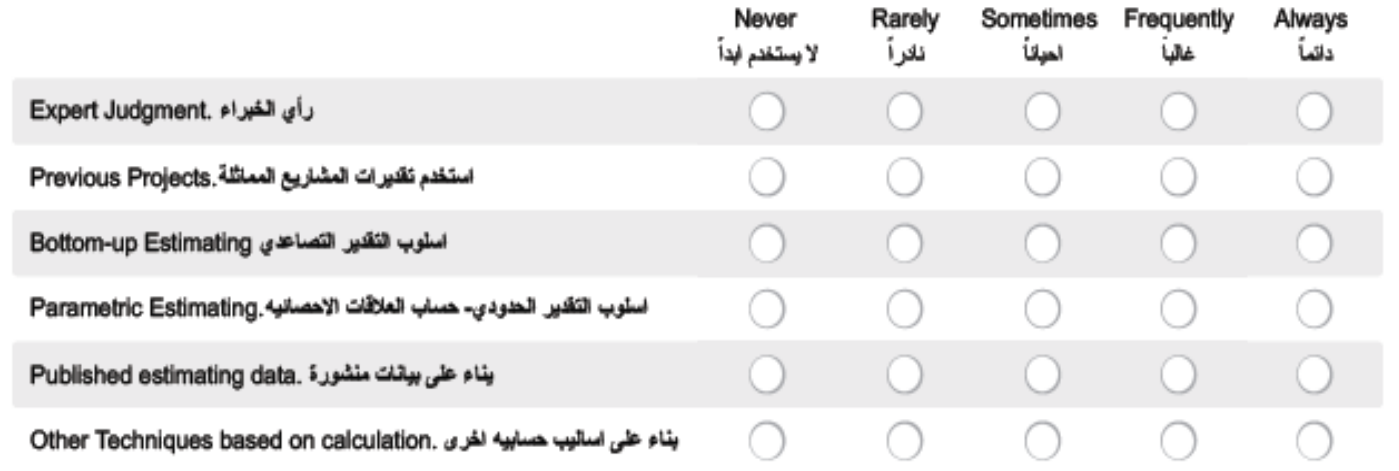

Other PM tools (please specify) ترجاء اتعند 
17. How often do you use the following project management tools and techniques in planning your project

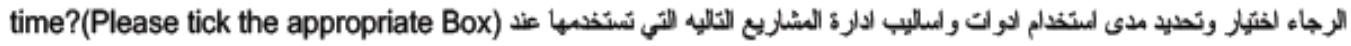
التخطيط لوثت الممُروع

\begin{tabular}{|c|c|c|c|c|c|}
\hline & 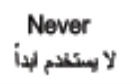 & $\begin{array}{c}\text { Rarely } \\
\text { ندراً }\end{array}$ & $\begin{array}{c}\text { Sometimes } \\
\text { احهنأ }\end{array}$ & $\begin{array}{l}\text { Frequently } \\
\text { illk }\end{array}$ & $\begin{array}{c}\text { Always } \\
\text { sis }\end{array}$ \\
\hline \multicolumn{6}{|l|}{ Gantt Bar Chart. مغطط جلت } \\
\hline \multicolumn{6}{|l|}{ 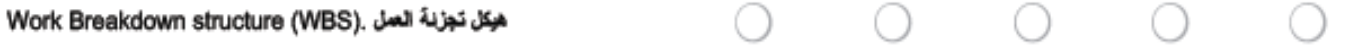 } \\
\hline \multicolumn{6}{|l|}{ Critical Path Networks/Method(CPM). سئوب العسرل لحرع } \\
\hline \multicolumn{6}{|l|}{$\begin{array}{l}\text { Program Evaluation and Review Techniques (PERT). } \\
\text { سلوب تكيبم ومراجعة ثيرنيج }\end{array}$} \\
\hline \multicolumn{6}{|l|}{ 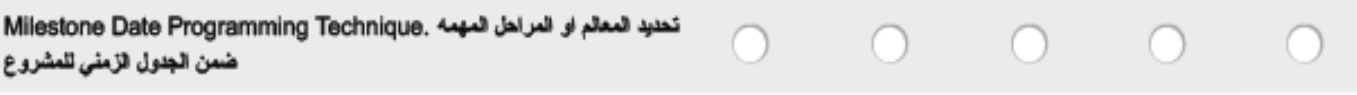 } \\
\hline \multicolumn{6}{|l|}{ 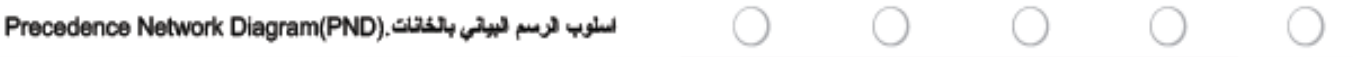 } \\
\hline 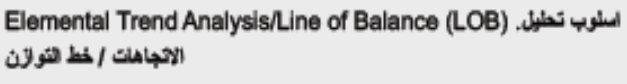 & & & & & \\
\hline
\end{tabular}

Other PM tools (please specify) المرى ,الرجاه التعيخ

18. How often do you use the following project monitoring and controlling tools in your project?(Please tick

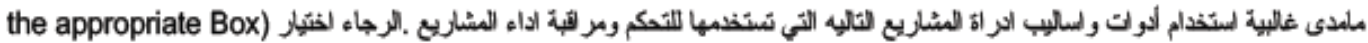
الاجالية المثليش

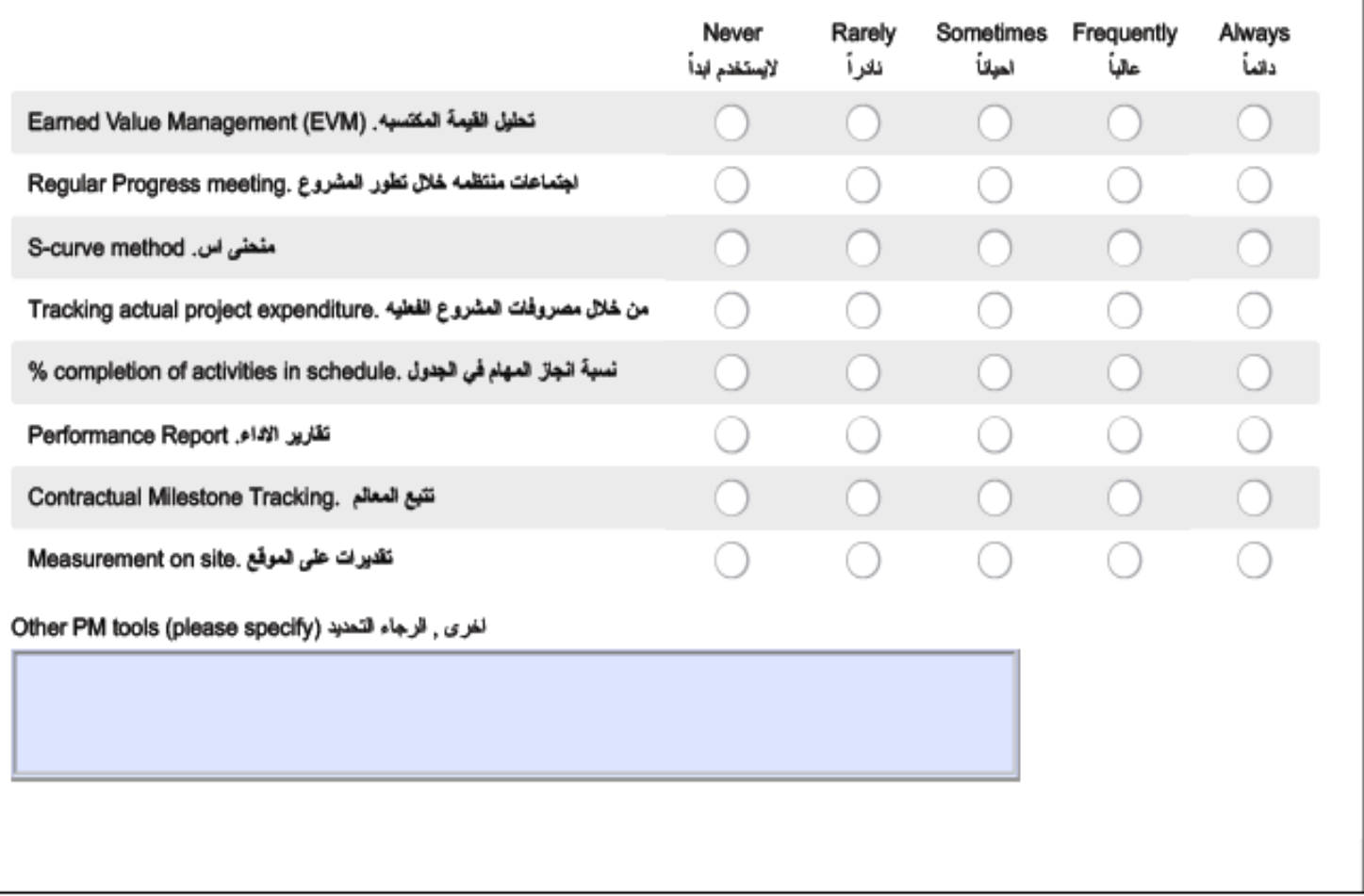


Sن Software Packages البرامج المستخفه

23. Which software Packages do you apply for planning and scheduling control your project? (Please tick the appropriate Box)

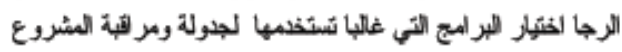

Excel sheet
Microsoft project
Primavera P6
Project Commander
Asta Power Project

Other (please specify) امرى 


\section{Appendix 2 Consent Form and Guideline Questions for Interview}

\section{Participant Consent Form}

\section{Curtin University}

Project Title: MANAGING CRITICAL FACTORS CAUSING DELAYS IN PUBLIC CONSTRUCTION PROJECTS IN KINGDOM OF SAUDI ARABIA

Institution: Curtin University

Research Student Supervisor: A/Prof. Monty Sutrisna

Funded by: Ministry of Education, Kingdom of Saudi Arabia

Investigator: Alotaibi, Nasser

You have been selected as an expert in the area and your input to this survey will be invaluable in gaining a better understanding of the issues pertaining to construction delays in kingdom of Saudi Arabia. Please be aware that interviews and focus group discussions will be audio recorded for later transcription. You are free to refuse to answer any question and to withdraw your participation at any time without needing to provide any explanation for your decision. In this event, the researcher will destroy all data gathered from any withdrawing participant.

\section{Confidentiality:}

The information provided for this survey will be kept in strictest confidentiality. At no stage will any name or identification be made during the course of the research and on any form of documentation. The researcher and research supervisor will be the only personnel aware of the participants for the research project. The purpose of the information provided during the survey will be to produce a statistical analysis of the responses, and the results of the analysis will not be published separately but will be used in the main study, copy which will be made available to you upon request.

\section{Voluntary participation:}

Participation in this survey completely voluntary; participants are at liberty to withdraw at any time without prejudice or negative consequences.

\section{Consent statement}

Please be informed that by submitting the survey questionnaire or attending the interview/focus group discussions, you are giving consent for your response to be audio recorded and analysed for the purposes of this research study.

\section{Curtin Ethics Statement}

Curtin University Human Research Ethics Committee (HREC) has approved this study (HREC number XX/XXXX). Should you wish to discuss the study with someone not directly involved, in particular, any matters 
concerning the conduct of the study or your rights as a participant, or you wish to make a confidential complaint, you may contact the Ethics Officer on (08) 92669223 or the Manager, Research Integrity on (08) 92667093 or email hrec@curtin.edu.au.

Participant Signature

Date

Researcher Signature

Date
Print Name

Print Name

\section{Guideline Questions for Interview (for the use of the interviewer only)}

Name of respondent:

Position in the organisation:

Nature of the organisation:

Business address:

Contact details: o Tel: o e-mail:

Years of experience: year(s) Signature: Date: ___ 
about this particular projects

○ In summary, how was the project managed?

1. Sources of delays

- In this project, which stakeholder could be considered the major source of delays? Why?

- In this project, what project processes could best be employed to minimise delays? Why?

\section{Project Management Methods/techniques/tools}

○ Were there any project management tools/techniques/methods implemented? Which ones?

○ How did that/those tools/techniques perform in your opinion?

○ Why did you think the project management tools/techniques/methods perform this way?

○ Do you think these project tools/techniques/methods could have been applied better? If so, why?

○ Do you think how the tools and techniques are being and have been applied could have contributed to the delays experienced?

- From your experience with this project, do you think application of project management tools/techniques/methods is worth the stress? Why?

- From your experience with this project, are there any specific barriers to the application of project management tools/techniques/methods?

\section{Project planning}

○ Thinking back to this project, what kind of procedures were applied for planning?

-Were there detailed project management plan prepared before construction?

- How were project activities estimated?

○o you think this technique was accurate/effective? Why?

$\circ$ Anything (else) you think should have been applied in that project? Why? 
1. منهجيات وادوات واساليب ادارة المشاريع. دعنا نتحدث عن هذا المشروع

س / باختصار، كيف كاتت الية ادارة هذا المشروع ؟ س /هل كاتت هنأك أي منهجيات او أدوات واساليب لإدارة المشاريع تم استخدامها و تنفيذها ؟ الرجاء التحديد؟ س /كيف كان اداء تلك الأدوات / التقتيات في رأيك ؟ س /لماذا تعتقد أن اداء هذه الادوات والاساليب كان بهذا الشكل ؟ س /هل تعتقد أن هذه الأدوات المشروع / تقتيات / طرق يمكن ان تطبق بشكل أفضل؟ إذا كان الأمر كذلك، لماذا؟ س /أي شيء (آخر) تعتق أن انه كان من المفترض تطبيقه في هذا المشروع؟ لماذا؟ س /من تجربتك مع هذا المشروع، هل تعتقد أن تبني تطبيق ادوات وتقتيات إدارة المشاريع يستحق الاهميه ؟ لماذا؟ س /من تجربتك مع هذا المشروع، هل هناك أي عوائق تحد من تطبيق اساليب وادوات إدارة المشاريع ؟ 2. التخطيط والمتابعة للمشروع

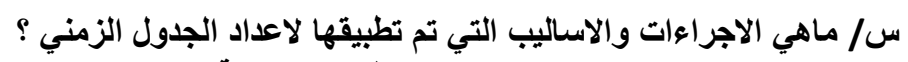

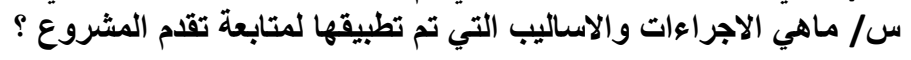
س /هل كاتت هناتك خطة تفصيليه لإدارة المشروع أعدت قبل مرحلة التنفيذ؟ س /كيف قدرت أنشطة المشروع ؟ س/ هل تعتقد أن هذه التقتية دقيقة / فعالية؟ لماذا؟ 3. مصادر التأخير 
س/ في هذا المشروع، اي من اطراف المشروع يمكن اعتباره المصدر الرئيسي للتأخير؟ لماذا؟ س /في هذا المشروع ، اي من مراحل المشروع يتبر المصدر الرئيسي للتاخير ؟ لماذا؟

\section{Appendix 3 Description and coding for latent variables}

\begin{tabular}{|c|c|c|}
\hline Constructs & Items & Code \\
\hline & & PETT \\
\hline \multirow{7}{*}{$\begin{array}{l}\text { Project Estimation Tools and } \\
\text { Techniques }\end{array}$} & Expert Judgment. & PETT1 \\
\hline & Previous Projects. & PETT2 \\
\hline & Bottom-up Estimating. & PETT3 \\
\hline & Parametric Estimating. & PETT4 \\
\hline & Published estimating data. & PETT5 \\
\hline & Other Techniques based on calculation. & PETT6 \\
\hline & & TMTT \\
\hline \multirow{8}{*}{$\begin{array}{l}\text { Project Time Planning Tools and } \\
\text { Techniques }\end{array}$} & Gantt Bar Chart. & TMTT1 \\
\hline & Work Breakdown structure (WBS). & TMTT2 \\
\hline & Critical Path Networks/Method(CPM). & TMTT3 \\
\hline & Program Evaluation and Review Techniques (PERT). & TMTT4 \\
\hline & Milestone Techniques. & TMTT5 \\
\hline & Precedence Network Diagram(PND). & TMTT6 \\
\hline & Elemental Trend Analysis/Line of Balance (LOB). & TMTT7 \\
\hline & & TCTT \\
\hline \multirow{9}{*}{$\begin{array}{l}\text { Project Controlee Tools and } \\
\text { Techniques }\end{array}$} & Earned Value Management (EVM). & PCTT1 \\
\hline & Regular Progress meeting. & PCTT2 \\
\hline & S-curve method. & PCTT3 \\
\hline & Tracking actual project expenditure. & PCTT4 \\
\hline & $\%$ completion of activities in schedule. & PCTT5 \\
\hline & Performance Report. & PCTT6 \\
\hline & Contractual Milestone Tracking. & PCTT7 \\
\hline & Measurement on site. & PCTT8 \\
\hline & & PPS \\
\hline \multirow{5}{*}{ Project Software Package } & Excel sheet & PPS1 \\
\hline & Microsoft project & PPS2 \\
\hline & Primavera P6 & PPS3 \\
\hline & Project Commander & PPS4 \\
\hline & Asta Power Project & PPS5 \\
\hline \multicolumn{3}{|l|}{ Delay Factors } \\
\hline & & $\mathrm{COF}$ \\
\hline \multirow{3}{*}{ Contractor related factors } & Planning and Scheduling of project. & COF1 \\
\hline & Poor qualification, skills and experience of the staff. & COF2 \\
\hline & Poor site management and supervision. & COF3 \\
\hline
\end{tabular}




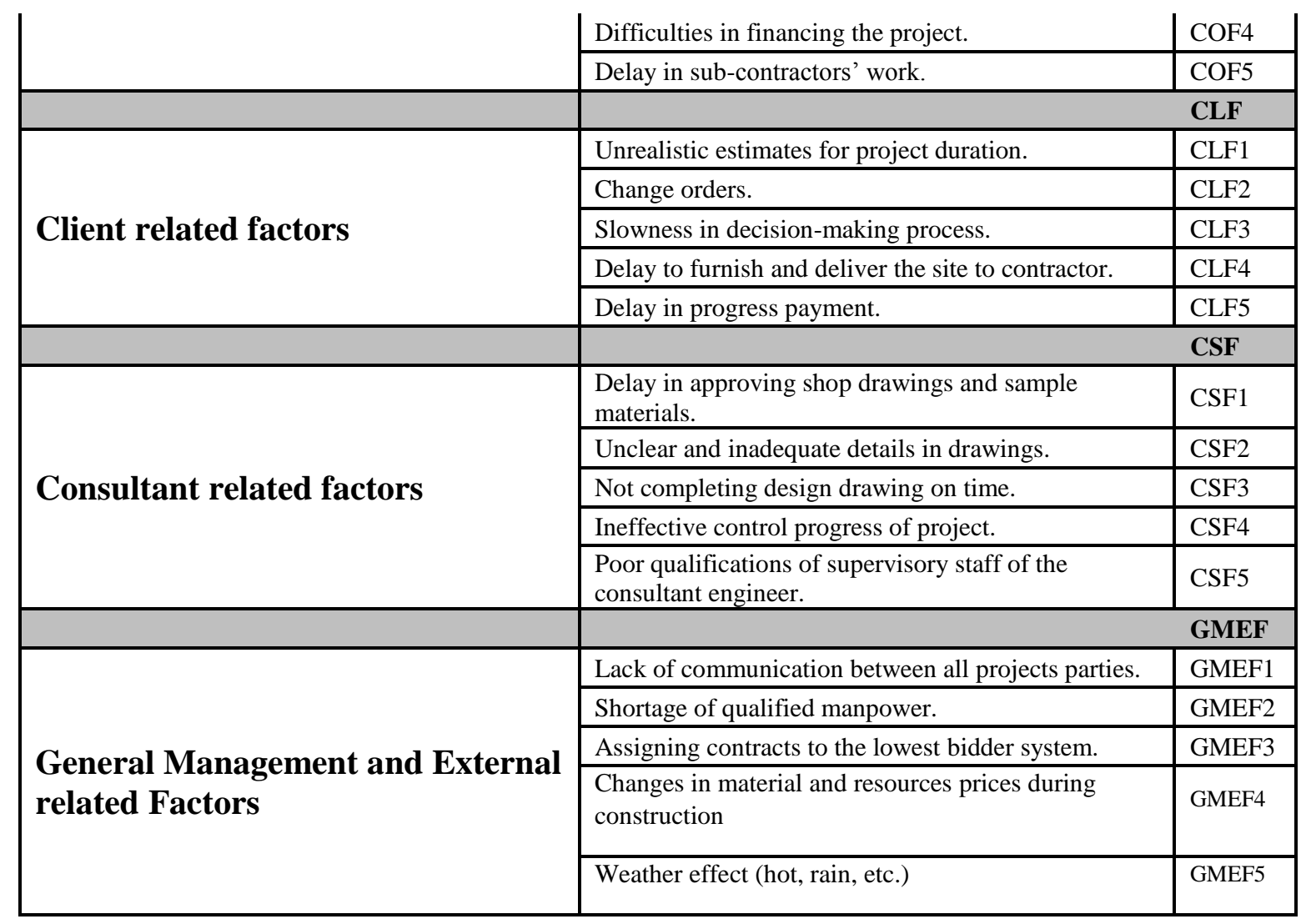




\section{Appendix 4 Ethics approval}

\section{MEMORANDUH}

\section{Curtin University}

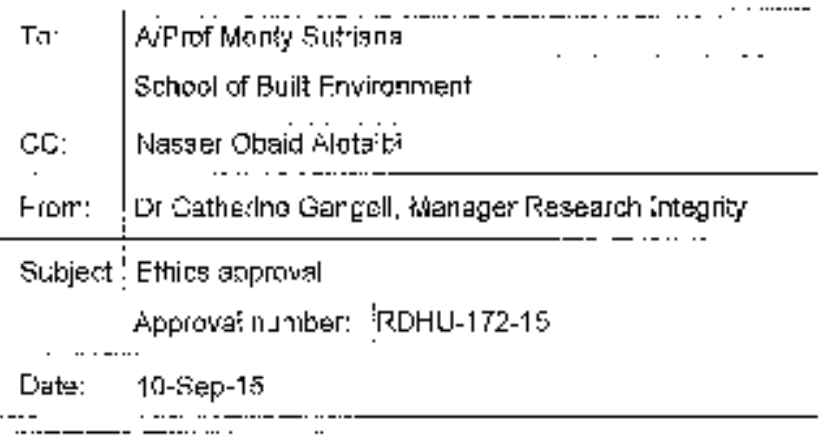

Ofice a: Reseerch and I]eveleriment ruma!! Resears! Enics Othico

Fhank you for your asplication submitted to the Hitman Research Ëthics Office fa tho projoct: . . 5326

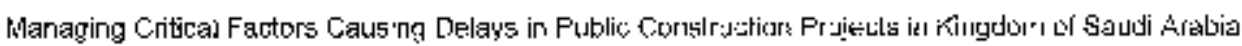

Your application has bex approved through tre low risk ethics apprasals präess al Cus:itu Liniversity.

Гlease note the following contiitians ct appraval:

1. Ápproval is granted tar a feriod of teur years fiort $\quad$ to-Sop-16 to $\quad$ 10-Sep-19

2. Researcl must to condicted as stated in the apprcved protocol.

3. Any amendrents to the approved praiocsl musl ve approved by the Ethics offics.

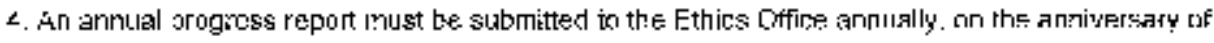

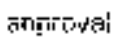

5. All adverse everils musal be neporked to the Eth:cs Office.

6. A compietion report mast be subrr itted to the Ethics Orfice on ormplelin? ur it:e puojecl.

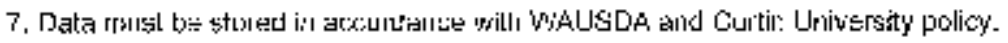

8. The Ethics Dffice may conclect a lanjo nly ióentified audit of a popotior of research projecis approved by the HFF.C.

Shotild you have any querios abou: the considaration of your projest please contact the E.thicis Suppor

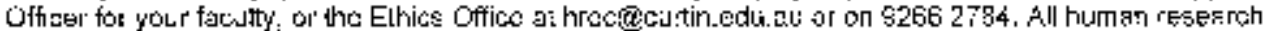
ethics forms and guidelines are aveitable on the sthics wabsits.

Yours exincersly.

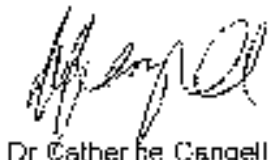

M'ianager, Resecrsh Integrity 


\section{Appendix 5 The reliability statistics results}

$\underline{\text { Reliability Statistics }}$

\begin{tabular}{lcc}
\hline & Cronbach's Alpha & N of Items \\
\hline PETT & .722 & 6 \\
\hline TMTT & .711 & 7 \\
\hline PCTT & .827 & 8 \\
\hline PPS & .751 & 5 \\
\hline COF & .707 & 5 \\
\hline CLF & .683 & 5 \\
\hline CSF & .793 & 5 \\
\hline GMEF & .760 & 5 \\
\hline
\end{tabular}

\section{Appendix 6 The inter-item correlation matrix}

Item-Total Statistics

\begin{tabular}{|c|c|c|c|c|c|}
\hline & $\begin{array}{c}\text { Scale Mean if } \\
\text { Item Deleted }\end{array}$ & $\begin{array}{c}\text { Scale } \\
\text { Variance if } \\
\text { Item Deleted }\end{array}$ & $\begin{array}{c}\text { Corrected } \\
\text { Item-Total } \\
\text { Correlation } \\
\end{array}$ & \begin{tabular}{|c} 
Squared \\
Multipl \\
$\mathrm{e}$ \\
Correlat \\
ion
\end{tabular} & $\begin{array}{c}\text { Cronbac } \\
\text { h's } \\
\text { Alpha if } \\
\text { Item } \\
\text { Deleted }\end{array}$ \\
\hline $\begin{array}{l}\text { Planning Phase delay } \\
\text { can be the BEST } \\
\text { minimised } \\
\text { Designing Phase delay } \\
\text { can be the BEST } \\
\text { minimised }\end{array}$ & $\begin{array}{l}189.5637 \\
189.6260\end{array}$ & $\begin{array}{l}502.361 \\
502.229\end{array}$ & $\begin{array}{l}-.024 \\
-.018\end{array}$ & & $\begin{array}{l}.885 \\
.885\end{array}$ \\
\hline
\end{tabular}




\begin{tabular}{|l|} 
Tendering Phase delay \\
can be the BEST \\
minimised \\
Construction Phase \\
delay can be the BEST \\
minimised \\
delays in public \\
projects can be \\
potentially \\
mitigated/minimised by \\
applying project \\
management \\
methodologies, tools \\
and techniques \\
Project management \\
concepts are not \\
novelties and already \\
widely \\
Project management \\
tools/techniques are not \\
widely recognized or \\
implemented in KSA \\
Project management \\
tools/techniques are \\
accepted and \\
understood but \\
generally has not been \\
used effectively in \\
KSA. \\
Project management \\
tools/techniques are \\
only popular or used in \\
certain construction \\
sectors in KSA. \\
There is a need for \\
further use and \\
application of the \\
kroject management
\end{tabular}

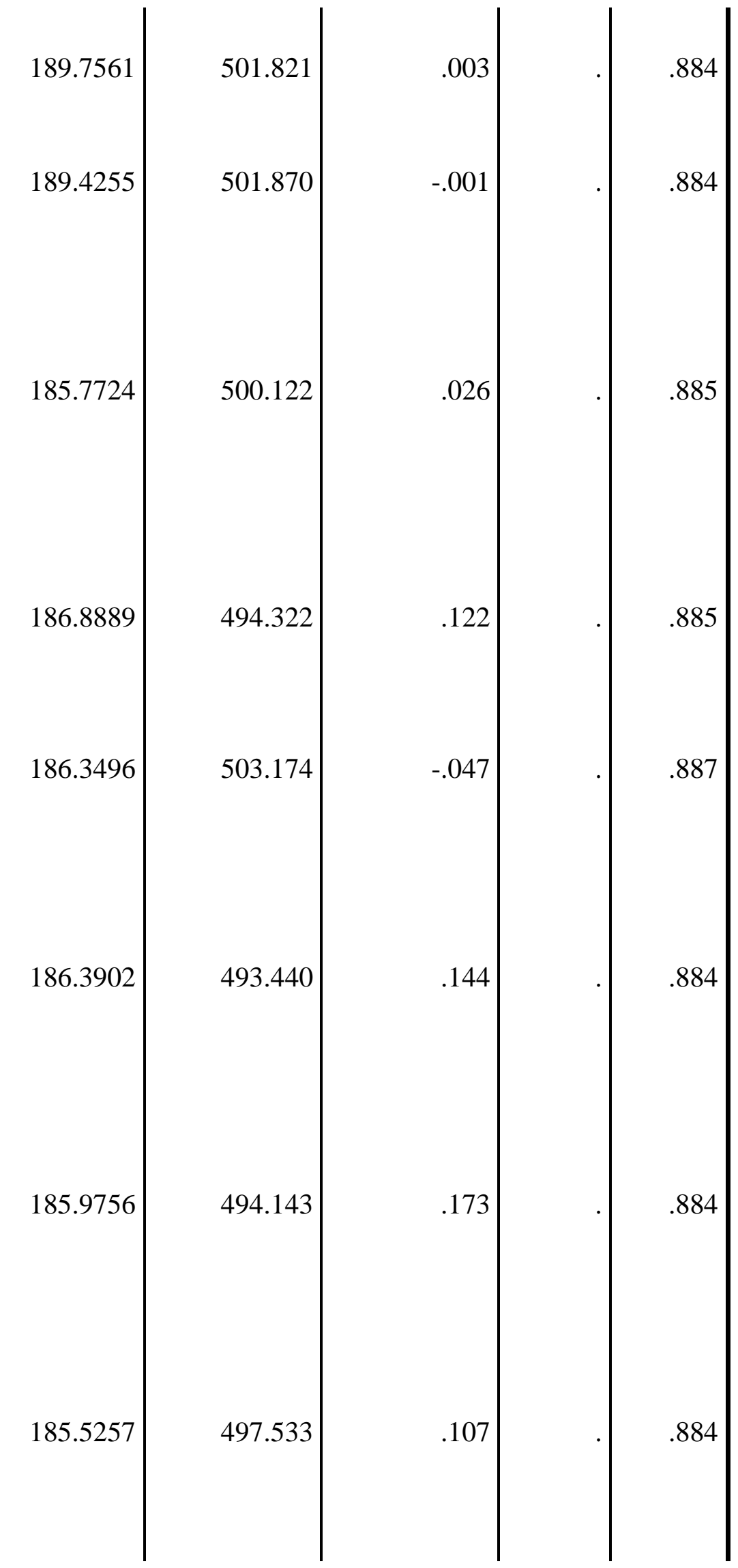




\begin{tabular}{|l|} 
The estimation of the \\
project duration is \\
typically conducted \\
based on each \\
individual activity (at \\
the lowest level in \\
WBS/schedule). \\
The estimation of \\
activity duration \\
involves an estimation \\
of all resource allocated \\
for that activity. \\
Upon a successful \\
tender, a new/different \\
detailed project \\
management plan is \\
normally prepared \\
before construction \\
phase \\
Upon a successful \\
tender, a new/different \\
schedule baseline is \\
normally prepared \\
before construction \\
phase. \\
The (new) project \\
management plan is \\
normally approved by \\
the project \\
stockholders. \\
Expert Judgment \\
Previous Projects. \\
Bottom-up Estimating. \\
Parametric Estimating. \\
Published estimating \\
data \\
other Techniques \\
Gantt Bar Chart. \\
(WBS)
\end{tabular}




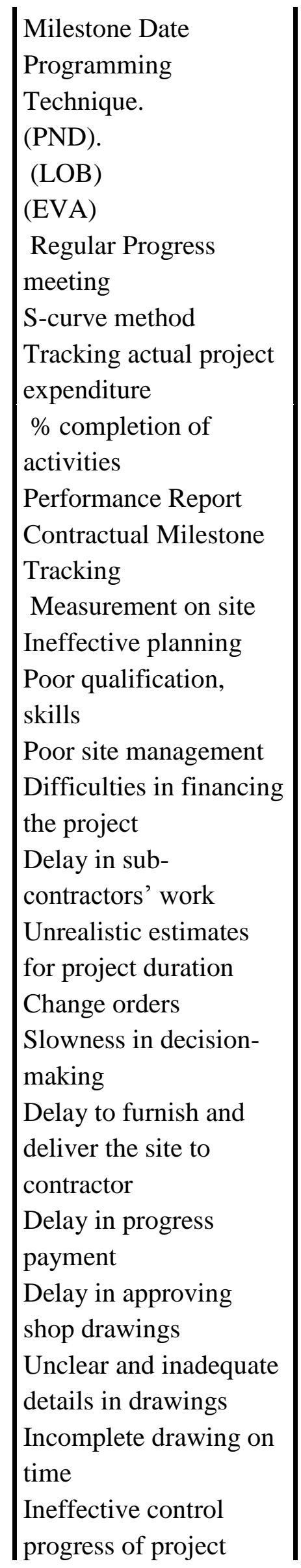

\begin{tabular}{|c|c|c|c|}
\hline 186.8564 & 470.743 & .559 & .878 \\
\hline 187.5989 & 479.638 & .429 & .881 \\
\hline 188.0108 & 476.141 & .549 & .879 \\
\hline 187.7263 & 475.661 & .568 & .879 \\
\hline 186.3957 & 478.397 & .511 & .880 \\
\hline 187.5989 & 474.094 & .525 & .879 \\
\hline 186.5691 & 478.648 & .450 & .880 \\
\hline 186.2304 & 482.602 & .446 & .881 \\
\hline 186.5176 & 477.348 & .522 & .879 \\
\hline 186.9458 & 474.269 & .520 & .879 \\
\hline 186.4065 & 479.035 & .491 & .880 \\
\hline 185.9295 & 494.984 & .150 & .884 \\
\hline 186.0596 & 494.529 & .162 & .884 \\
\hline 186.2764 & 495.059 & .147 & .884 \\
\hline 186.0271 & 488.314 & .265 & .883 \\
\hline 186.1653 & 484.633 & .331 & .882 \\
\hline 186.0894 & 491.245 & .212 & .883 \\
\hline 185.8130 & 492.625 & .227 & .883 \\
\hline 185.7805 & 491.248 & .276 & .883 \\
\hline 186.7751 & 486.849 & .277 & .883 \\
\hline 186.3631 & 486.444 & .281 & .883 \\
\hline 186.3279 & 491.509 & .177 & .884 \\
\hline 186.0976 & 494.202 & .157 & .884 \\
\hline 186.2873 & 490.232 & .227 & .883 \\
\hline 186.4255 & 488.213 & .242 & .883 \\
\hline
\end{tabular}




\begin{tabular}{|c|c|c|c|c|}
\hline $\begin{array}{l}\text { Poor qualifications of } \\
\text { supervisory staff }\end{array}$ & 186.2060 & 495.474 & .122 & .884 \\
\hline Lack of communication & 186.1545 & 491.158 & .256 & .883 \\
\hline $\begin{array}{l}\text { Shortage of qualified } \\
\text { manpower }\end{array}$ & 186.1355 & 486.569 & .339 & .882 \\
\hline $\begin{array}{l}\text { Assigning contracts to } \\
\text { the lowest }\end{array}$ & 185.9160 & 489.773 & .305 & .882 \\
\hline Changes in material & 187.0434 & 484.971 & .370 & .881 \\
\hline $\begin{array}{l}\text { Weather effect (hot, } \\
\text { rain, etc.) }\end{array}$ & 187.2900 & 486.054 & .333 & .882 \\
\hline $\begin{array}{l}\text { Frequency of using the } \\
\text { Excel sheet }\end{array}$ & 186.3117 & 493.536 & .183 & .884 \\
\hline $\begin{array}{l}\text { Frequency of using the } \\
\text { Microsoft project }\end{array}$ & 187.1355 & 480.536 & .396 & .881 \\
\hline $\begin{array}{l}\text { Frequency of using the } \\
\text { Primavera P6 }\end{array}$ & 186.7236 & 477.494 & .411 & .881 \\
\hline $\begin{array}{l}\text { Frequency of using the } \\
\text { Project Commander }\end{array}$ & 188.2602 & 486.025 & .352 & .882 \\
\hline $\begin{array}{l}\text { Frequency of using the } \\
\text { Asta Power Project }\end{array}$ & 188.3740 & 487.990 & .330 & .882 \\
\hline
\end{tabular}


Appendix 7 Work Breakdown Structure for Construction Estimation

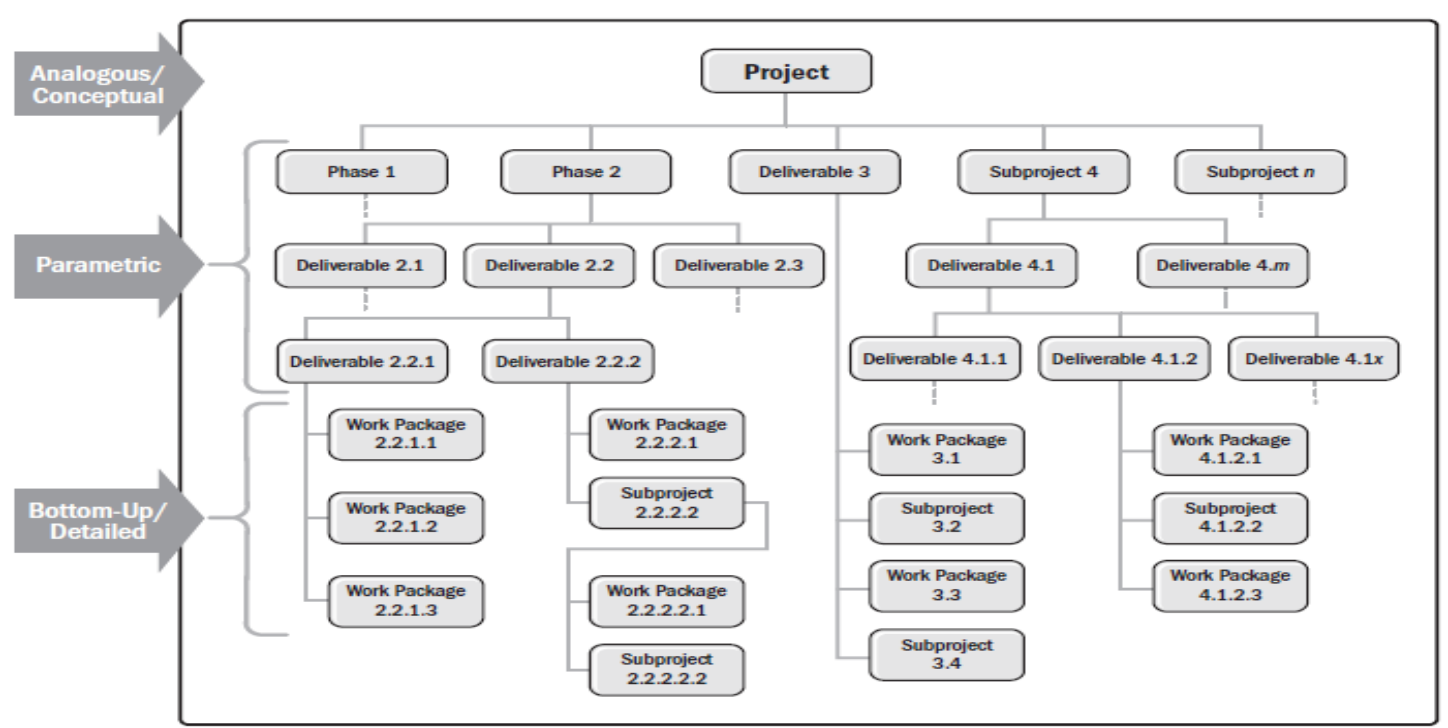

